\title{
FRAMEWORK OF A COMPARATIVE LIFE CYCLE ANALYSIS FOR RAIL AND ROAD FREIGHT TRANSPORT
}

by

\section{Hasan Tayyeb}

A thesis submitted to the Faculty of Graduate and Postdoctoral Affairs in partial fulfillment of the requirements for the degree of

\author{
Doctor of Philosophy \\ in
}

Civil and Environmental Engineering

Carleton University

Ottawa, Ontario

The Doctor of Philosophy in Civil and Environmental Engineering is a joint program with the University of Ottawa, administrated by the Ottawa Carleton Institute for Civil Engineering

C 2018, Hasan Tayyeb 


\begin{abstract}
Transport plays a central role in the development of economies and people around the world, by adding value to goods and developing industries, among other economic benefits. Selection of transportation modes are of significant interest to shippers, government actors and the general public due to both costs and impacts. The main objectives of this thesis are two-fold. First, is to develop a framework of economic life-cycle analysis focusing on rail and trucking systems to identify the most viable and reliable land transportation mode for moving goods based on hauling distances and freight loads. The second objective is to build a comprehensive model to estimate the shipping life cycle cost for design strategies using statistical procedures and GIS software applications.
\end{abstract}

Contributions of this thesis include: (1) Development of a Life Cycle Cost Analysis (LCCA) model that includes all of the direct costs, indirect costs and pollution produced by using rail and trucking freight transportation systems; (2) Determination of effect of issue of border delays, which is one of the main constraints when border inspection stations are factored into shipment processes; (3) Planning a future rail network that passes through different countries using ArcGIS; (4) Application of the reliability and sensitivity analysis using the implemented model; (5) Development of logistics applications using different scenarios that help to evaluate intermodal yard locations, alternative route selection, risk and warehouse facility locations; and (6) Establishment of guidelines for environmentally sustainable and reliable freight transportation systems to aid transportation engineers and policy makers. Data from different countries, municipalities and companies within the Gulf Cooperation Council region were used to build the model and conduct the analysis. 


\section{Acknowledgements}

All thanks and praise is due to God, first and foremost, for blessing me with all the abilities and skills to complete this thesis. It is difficult to sufficiently express my gratitude to my supervisors, Professors Abd El Halim Omar Abd El Halim and Said Easa for their guidance, advice and support. With their enthusiasm, inspiration and great efforts to explain things clearly and simply, they helped make this a success. Throughout my graduate studies, they provided encouragement, sound advice, excellent teaching, excellent company and many brilliant ideas. Professor Abd El Halim's support was instrumental in the execution and completion of this thesis.

This thesis could not have been completed without the collaboration and cooperation of the people who provided data, especially H.E. Dr. Abdullah Al-Katheeri, the Executive Director of Land Transport Sector at the UAE Federal Transport Authority, and Professor Bassam Ghulman, the Director of the Harriman High Speed Rail Project, KSA. Mr. Abdulghader Sanyour, Head of Technical Department at Jeddah Islamic port, KSA. The author would also like to thank Mr. Carlos El-Hashem, the Deputy Chairman for the Arab Union of Land Transport, Dr. Murad Hashim, the Deputy Vice President for Climatology and Research Applications at the Presidency of Meteorology and Environment in Saudi Arabia for their help and cooperation in providing the data used in this thesis. I would like also to thank the Saudi Arabian Government, Carleton University, and NSERC for the financial support to complete this mission.

I wish to thank my brother, Mohammad and my sisters, Fadia and Jawaher for providing a loving environment for me while I completed this research. Special thanks go to my wonderful wife Sahar, my daughters, Diala and Kenzie and my son, Saif for their patience during the long nights and early mornings spent completing this thesis. 
Lastly, and most importantly, I wish to thank my parents, Mr. Yousef Tayyeb and Ms. Asmaa Jawdat. They bore me, raised me, supported me, taught me and loved me. To them I dedicate this thesis. 


\section{Table of Contents}

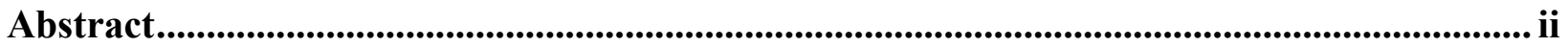

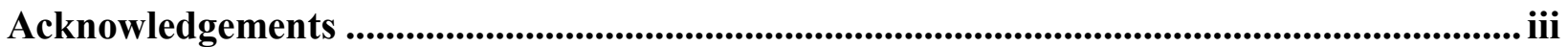

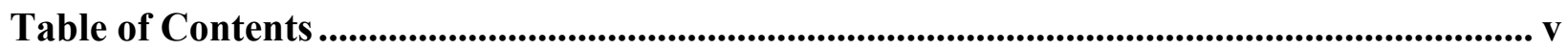

List of Tables ......................................................................................................................... viii

List of Figures............................................................................................................................................. $\mathrm{xi}$

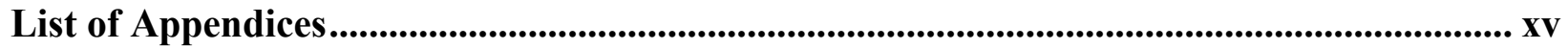

1 Chapter: Introduction ................................................................................................................... 16

$1.1 \quad$ Economic Importance of Freight Transportation …............................................................. 16

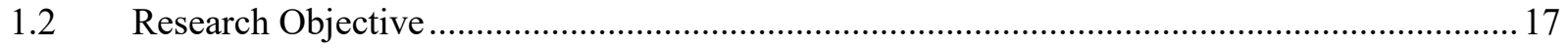

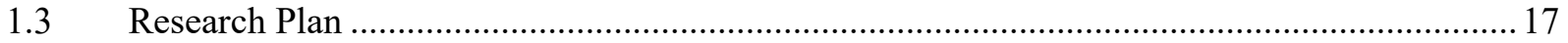

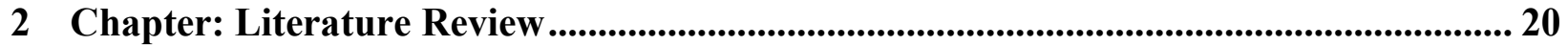

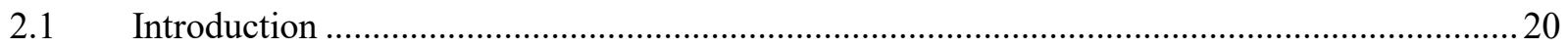

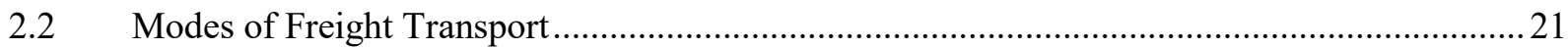

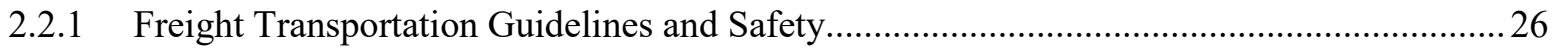

2.2.2 Freight Transportation Impact on Environmental and Social Life.....................................28

2.2.3 Freight Data Challenges and Cost Calculation.................................................................. 31

2.2.4 Reliability and Efficiency of Freight Transportation ..................................................... 35

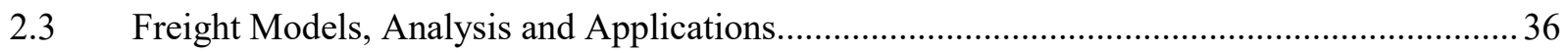

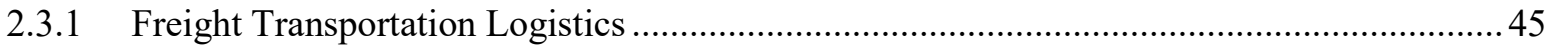

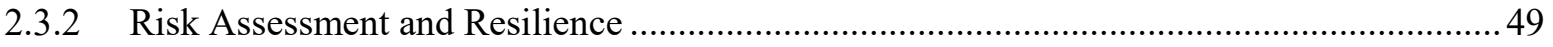

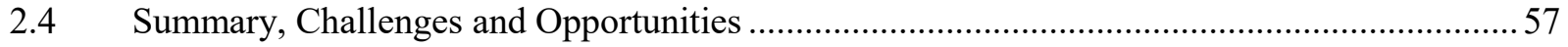

3 Chapter: Development of Life-Cycle Analysis Framework.............................................. 60

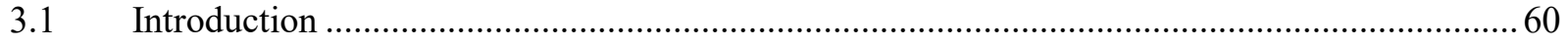

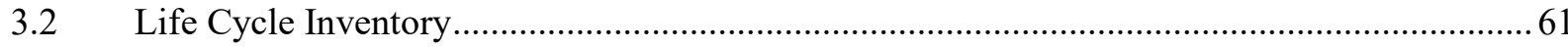




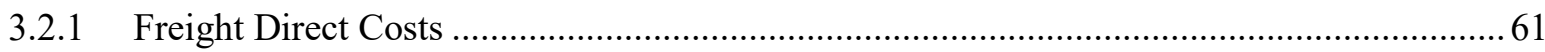

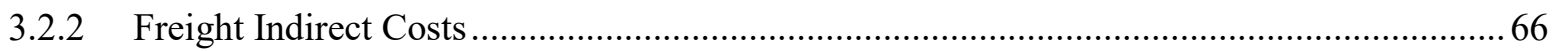

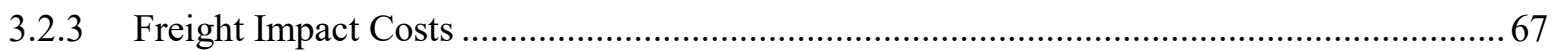

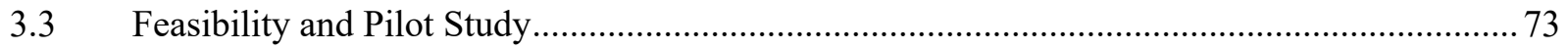

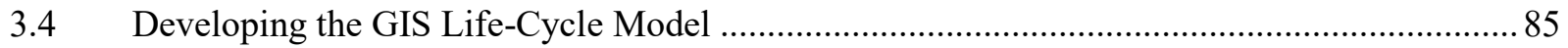

4 Chapter: Life-Cycle Framework Analysis and Results................................................... 95

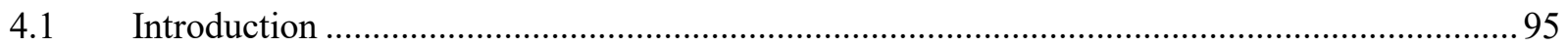

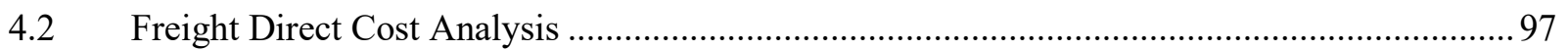

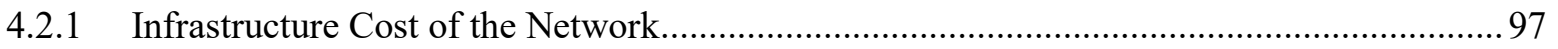

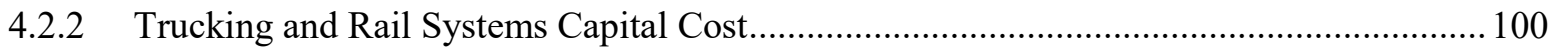

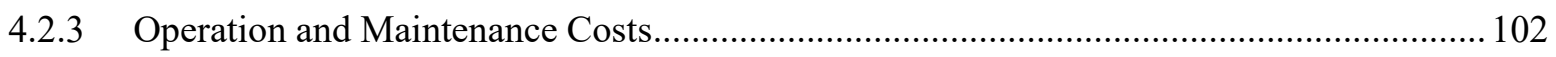

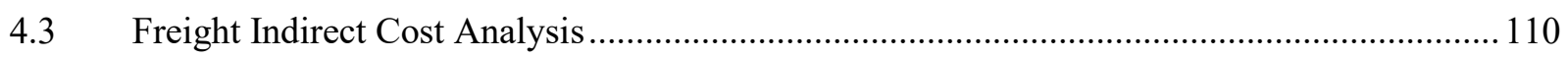

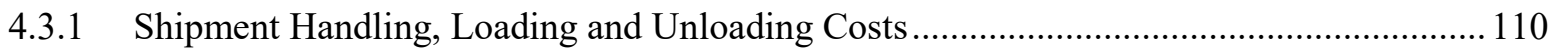

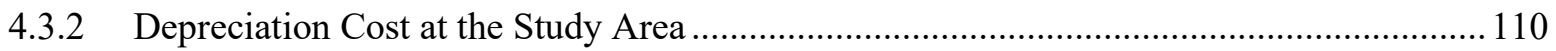

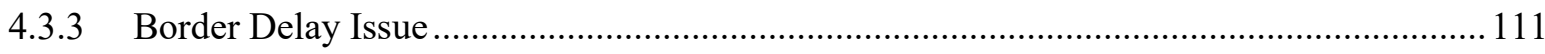

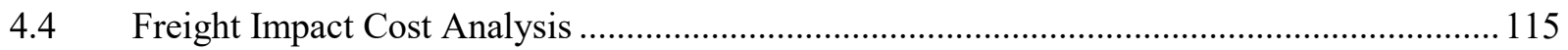

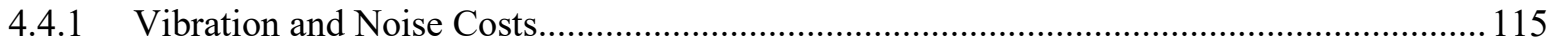

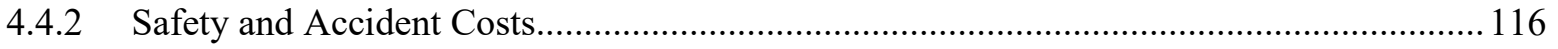

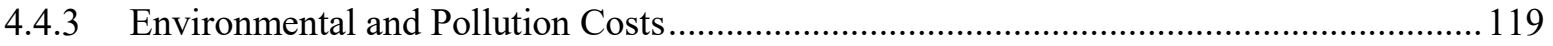

4.5 GIS Model Analysis and Reliability Assessment .............................................................. 119

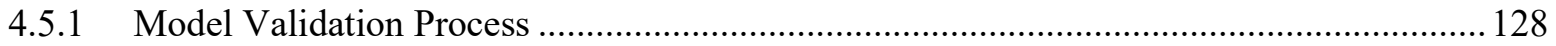

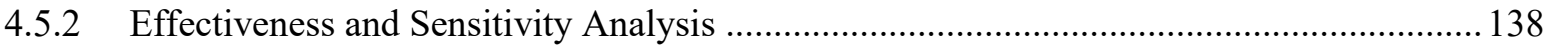

5 Chapter: Logistic Application of Proposed Framework..................................................... 149

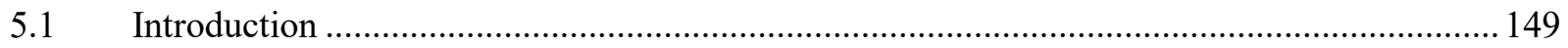

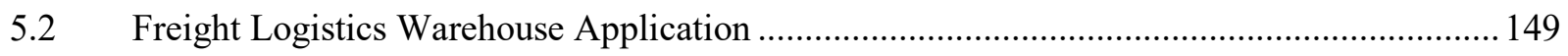

5.3 Intermodal Yard Location Application......................................................................... 153 


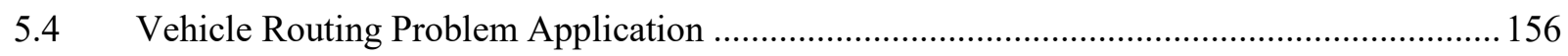

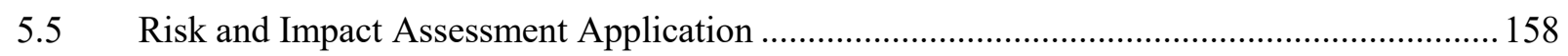

6 Chapter: Discussion, Conclusions and Recommendations ....................................... 165

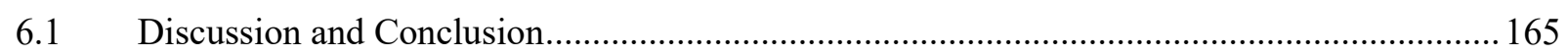

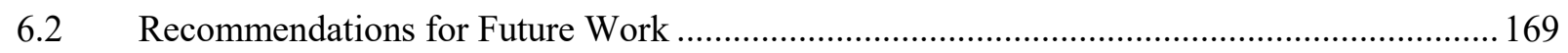

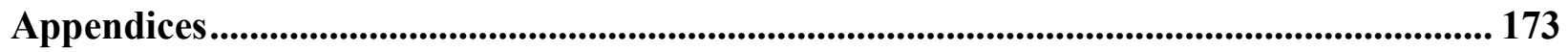

Appendix A ModelBuilder Road Life-Cycle Analysis model...................................................... 173

Appendix B ModelBuilder Intermodal Life-Cycle Analysis model............................................ 174

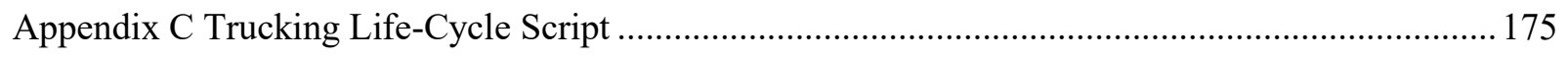

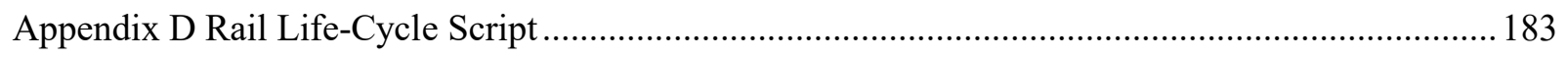

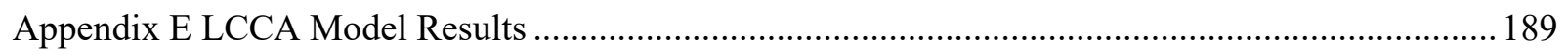

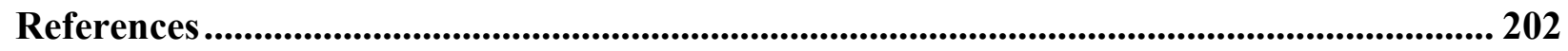




\section{List of Tables}

Table 1 Average efficiency (minutes/unit) of loading and unloading for rail and truck shipping

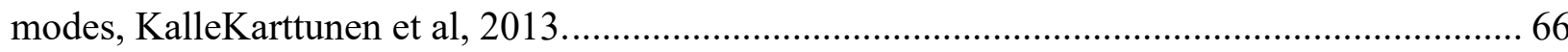

Table 2 Unit pollutant emission for freight trains and trucking freight systems, Transport

Research Laboratory, 2001.

Table 3 Greenhouse Gas Emission local and global Impacts, Environment and Climate Change

Canada, 2017 71

Table 4 Forecast GDP and Population of the GCC countries, Abu Dhabi Municipality, 2012. .. 75

Table 5 Import/Export tonnage between the GCC Countries (x000) tons, Abu Dhabi

Municipality, 2006. 77

Table 6 Comparison of the Key Characteristics of Leading Countries Compared to UAE and

Saudi Arabia, Etihad Rail, 2014. 78

Table 7 European Union driver regulations, Abu Dhabi Municipality, 2014. 83

Table 8 Road infrastructure construction and maintenance cost, Etihad Rail - Abu Dhabi

Municipality, 2017 97

Table 9 Rail infrastructure construction and maintenance cost, Abu Dhabi Municipality, 2014. 99

Table 10 Rail rolling stock capital cost, Abu Dhabi Municipality, 2014. 101

Table 11 Fuel price at the GCC countries US\$/ Liter, Global Petrol Price index, 2016. 103

Table 12 Operation and maintenance cost of freight service, Abu Dhabi Municipality, 2014 . 105

Table 13 GCC Railway segment lengths, Abu Dhabi Municipality, 2014. 109

Table 14 Truck and Rolling Stock Depreciation Cost US\$/km, Saudi National Transportation

Plan, 2008. 
Table 15 Manipulated Cost-of-accident per 1,000 ton-km for the GCC countries in US\$, Abu

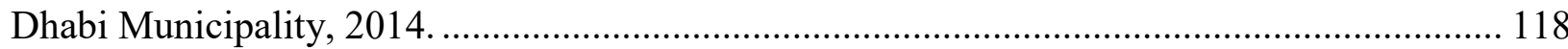

Table 16 Summary of external factor cost items breakdown in US\$ per 1,000 ton-km, (Abu

Dhabi Municipality, 2014), (Saudi Railway Organization, 2003), and (European Commission, 2002).

Table 17 Trucking Life-Cycle Cost Analysis results in US\$. ........................................... 122

Table 18 Railway Life-Cycle Cost Analysis results in US\$ ............................................ 123

Table 19 Intermodal Life-Cycle Cost Analysis results in US\$........................................... 124

Table 20 Trucking real cost vs. the developed model cost............................................... 130

Table 21 Railway real cost vs. the developed model cost. ................................................ 132

Table 22. Sample of the comparison cost results between the statistical equations and GIS model

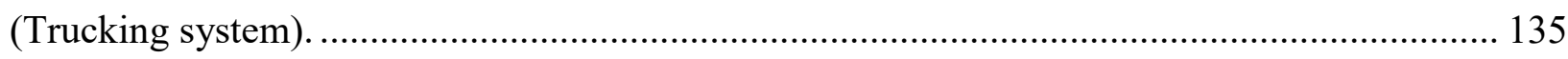

Table 23. Sample of the comparison cost results between the statistical equations and GIS model (railway system -23 ton). 137

Table 24 Shipping distances and the impact cost between the origins and destination............. 141

Table $25 \mathrm{CO} 2$ amount produced by using trucking systems on the original routes................. 143

Table $26 \mathrm{CO} 2$ amount produced by trucking systems using the alternative routes.................. 144

Table 27 Total shipping cost for original and alternative shipping routes. .......................... 145

Table 28 Warehouse location scenarios cost analysis. ................................................. 151

Table 29 Warehouse scenario distribution analysis..................................................... 152

Table 30 Intermodal yard location impact on shipping cost and mode selection.................... 155

Table 31 Total shipping cost of delivering shipments between different origins and destinations using different routes and different transportation modes. ........................................... 157 


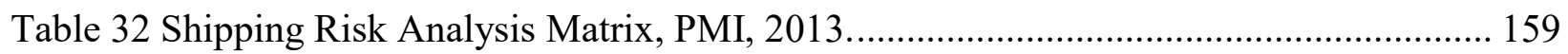
Table 33 Shipping cost in normal conditions using different modes between origins and

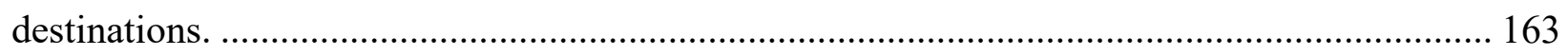
Table 34 Shipping cost during hazardous conditions using different modes between origins and

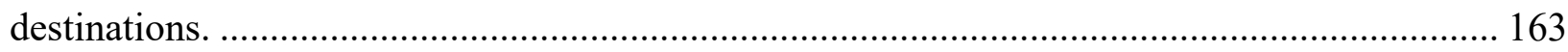




\section{List of Figures}

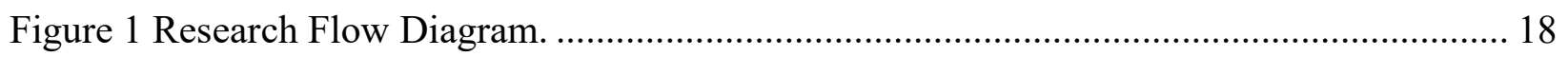

Figure 2 General Risk Management Process adapted from Jenkins et al., 2010, and Rao and

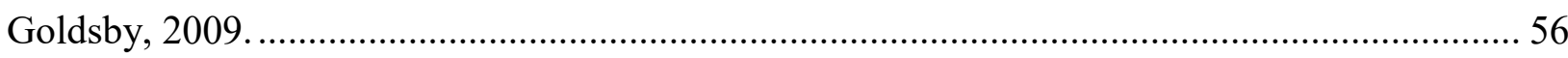

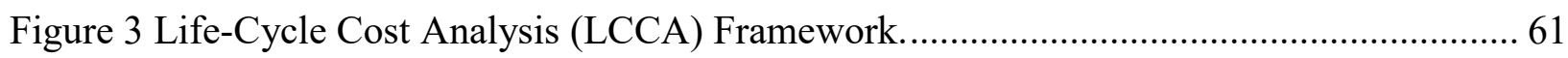

Figure 4 Surveillance systems for rail tracks in Saudi Arabia.................................................. 62

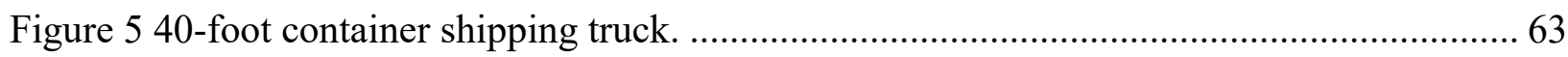

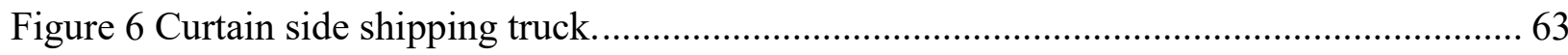

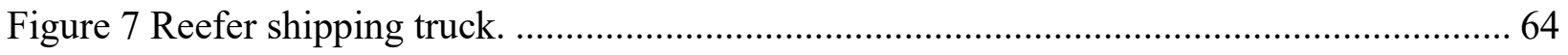

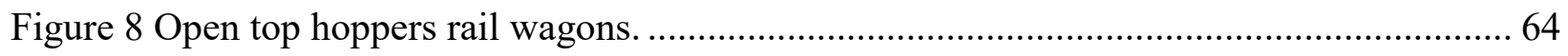

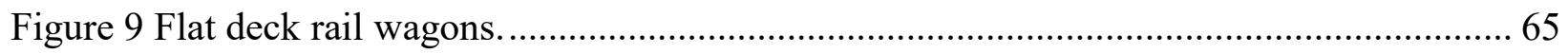

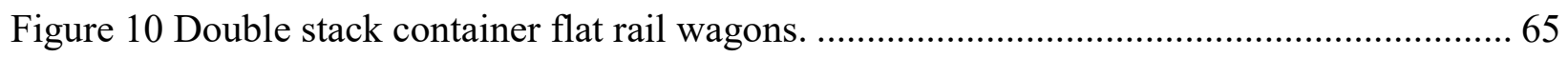

Figure 11 Noise source path receiver frameworks Abu Dhabi Municipality, 2012.................... 68

Figure 12 Effects of prolonged exposure for different noise level, Occupational Safety and

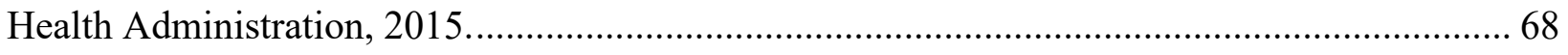

Figure 13 U.S. greenhouse gas emission, Environmental Protection Agency, 2013.................... 70

Figure 14 CO2 time series 1990-2014 per capita for world region/country, Emissions Database

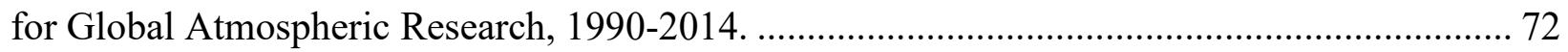

Figure 15 Existing road connections between the GCC countries, 2017 .................................... 76

Figure 16 Current and future rail freight lines and land bridges at the GCC region, modified from

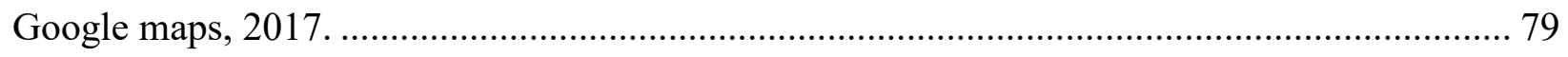

Figure 17 Part of the current freight rail line in Saudi Arabia, 2017......................................... 80 
Figure 18 Truck overloading in Saudi Arabia.

Figure 19 Road damage caused by overloaded trucks in UAE, Abu Dhabi Municipality, 2012. 82

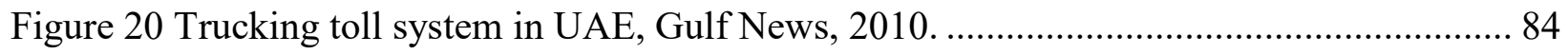

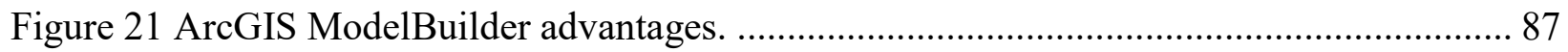

Figure 22 ArcGIS ModelBuilder considerations. ........................................................... 88

Figure 23 GCC map using Lambert Conformal Conic projection, Esri-2017......................... 89

Figure 24 Future GCC rail project raster map, Abu Dhabi Municipality, 2014...................... 90

Figure 25 Geo-referencing GCC rail raster map process using ArcGIS. ............................... 91

Figure 26 Current and future Saudi rail project's raster map, Saudi Railways Organization, 2018.

Figure 27 Geo-referencing the Saudi rail raster map process using ArcGIS............................ 92

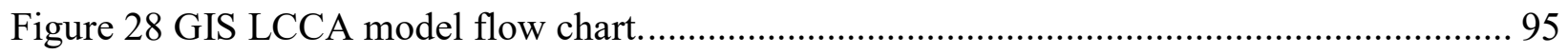

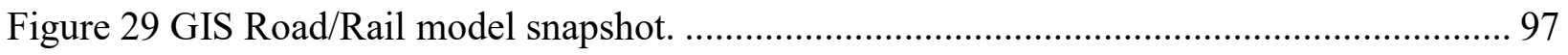

Figure 30 GCC rail connecting segments, Abu Dhabi Municipality, 2014........................... 108

Figure 31 Al-Ghuwaifat border between the UAE and Saudi Arabia, Modified from Google map, 2017.

Figure 32 Border delay issues at the border between the UAE and Saudi Arabia, Modified from

Google maps, 2017. 112

Figure 33 Border delay hours estimate, Al-Joaan General Transport, 2016. 113

Figure 34 Trucks queue crossing the Saudi Arabian and Bahraini border. 114

Figure 35 A recent Saudi Arabian Customs safety standard, Saudi Customs, 2016. 117

Figure 36. GIS ModelBuilder Road selected results snapshot. 120

Figure 37 GIS ModelBuilder Rail selected results snapshot. 121 
Figure 38 Total shipping cost of various shipment weights from Riyadh to Kuwait using trucking, railway and intermodal systems.

Figure 39 Trucking cost tree diagram

Figure 40 Railway cost tree diagram.

Figure 41 Total life-cycle cost percentages.

Figure 42 Freight Shipping cost breakdown equations of the GCC region.

Figure 43 Oil basket price in variation in USD, OPEC, 2016. 139

Figure 44 Impact of fuel price fluctuations on the total shipping cost. 140

Figure 45 Example of rail and trucking shipping route between Kuwait City and Jubail. 142

Figure 46 Example of original and alternative shipping routes between Jubail and Dammam city.

Figure 47 Original and alternative routes $\mathrm{CO} 2$ impact produced.

Figure 48 Minimum temperature around the GCC Region, Presidency of Meteorology and

Environment, 2016. 146

Figure 49 Maximum temperature around the GCC Region, Presidency of Meteorology and

Environment, 2016. 146

Figure 50 The effect of hail and snow on the shipment delivery, Presidency of Meteorology and

Environment, 2016. 147

Figure 51 Snapshot of the warehouse location scenario and the model LCCA. 150

Figure 52 Intermodal yard location effect on mode selection within the GCC network. 154

Figure 53 Snapshot of a selected shipment route using different transportation modes. 157

Figure 54 Snapshot of flood scenario when shipping a container using trucking transportation system. 161 
Figure 55 Snapshot of flood scenario when shipping a container using an intermodal transportation system. 


\section{List of Appendices}

Appendix A: ModelBuilder Road Life-Cycle Analysis model ........................... 173

Appendix B: ModelBuilder Intermodal Life-Cycle Analysis model...................... 174

Appendix C: Trucking Life-Cycle Script............................................ 175

Appendix D: Rail Life-Cycle Script............................................183

Appendix E: LCCA Model Results................................................. 189 


\section{Chapter: Introduction}

\subsection{Economic Importance of Freight Transportation}

Transportation plays a central role in the economic development and social growth of societies and nations. It contributes to the wealth of a nation through several functions. Firstly, transportation serves in moving people and goods within and between various geographical spaces. Secondly, it is a function that can add value. More specifically, value is added to raw materials by transporting them from their natural sites to industrial factories, which transfers the materials into various products for the consumer market. Thirdly, transportation can also contribute to security and any given nation's defense forces. Finally, it can be said with confidence that transportation is the backbone of world trade.

Within the last twenty years, shipping transport has emerged as one of the leading sets of technologies by utilizing fuel efficient engines that with less weight, and subsequent reduced emissions aim to assist the functioning of world trade, and to also meet the challenges of a world with highly varied and frequently changing requirements. Shipping transport can be considered a fundamental part of economics, and a potential multiplication of a country's wealth. Advancement in all modes of transport has emerged with the development of highways, rail tracks and air routes. Due to the availability of different types of shipping modes, customers for global merchandise transport are able to make selections from multiple options, according to the weight of transported material, costs, timeframes as well as safety measures. Freight movements are defined by technological changes, trade agreements, as well as government policies and regulations. Because of the widespread impact of freight movement and how such movement is governed, it is 
imperative to consider the potential impact of freight movement on roads, traffic, safety and the environment of surrounding communities.

\subsection{Research Objective}

The main purpose of this thesis is two-fold. Firstly, the thesis shows the development of a framework of an economic life-cycle analysis to identify the most viable and more reliable transportation mode in terms of cost, emissions produced, delay times for moving goods based on hauling distances, and freight loads. Secondly, the thesis introduces the development of a valuable tool for design strategies using statistical procedures and software applications, where the objective is to investigate the effects of rules and regulations of governments, intricate security and safety matters, borders and several other unforeseen issues that influence cost estimations between rail and trucking systems. The thesis is also situated in a location-specific context, and the geographic focus of the study will be on the Gulf Cooperation Council (GCC) countries, which is an intergovernmental, political and economic alliance consisting of several countries, including Saudi Arabia, Kuwait, the United Arab Emirates, Bahrain and Oman, and Qatar.

\subsection{Research Plan}

A detailed research plan has been developed to achieve the objectives of this thesis, and Figure 1 illustrates the different components of this plan. 


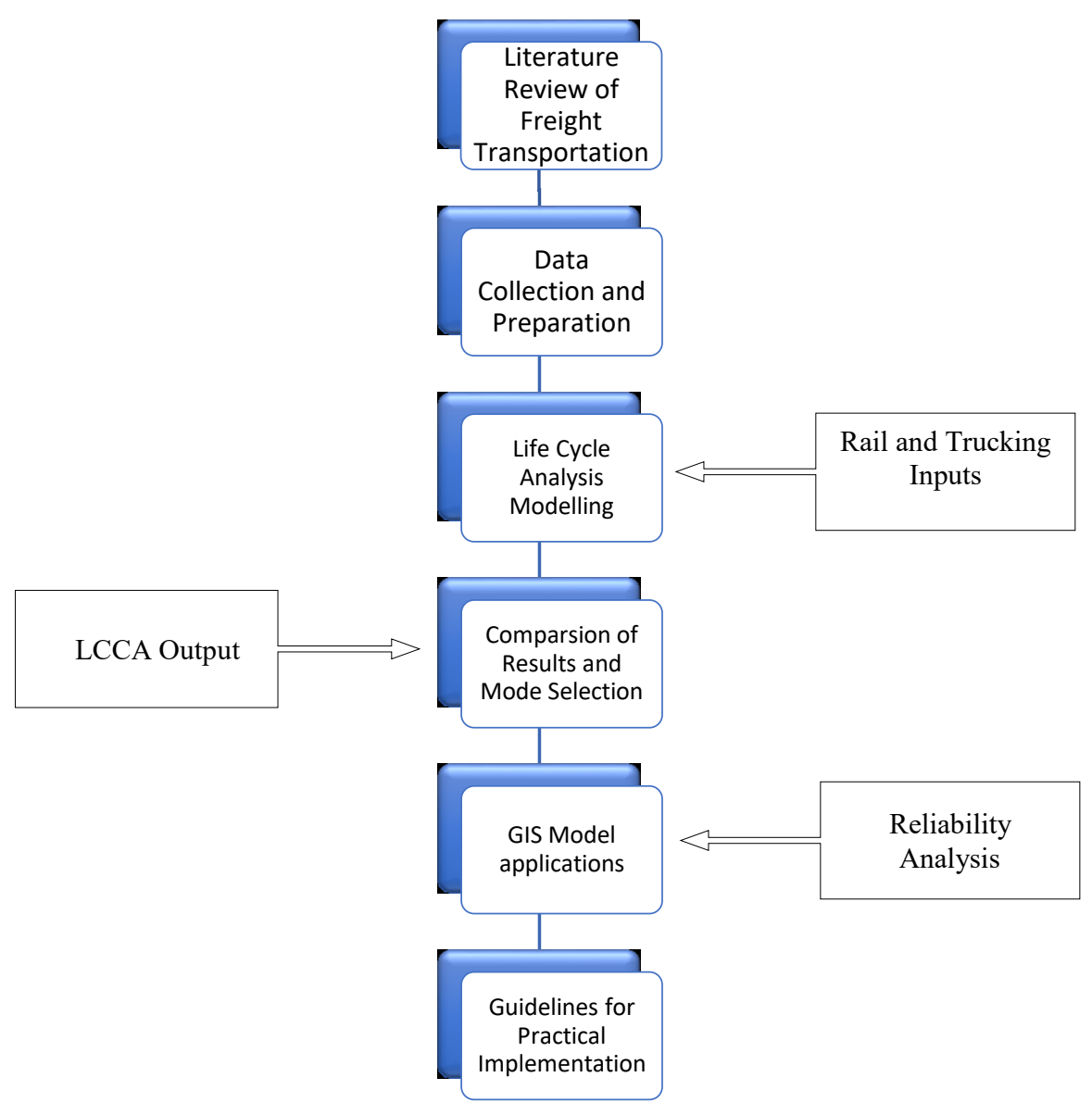

Figure 1 Research Flow Diagram.

Various deficiencies were found after conducting a comprehensive literature review to study the life-cycle cost analysis for goods movement. These deficiencies included: the limitation of cost factors included; lack of a super-network that conglomerates both road and rail systems; lack of having one model that can facilitate decision-making processes and support logistics management; and lastly, there is no current study that has been conducted for researching specific GCC conditions and issues related to the borders between the GCC nations. Taking these limitations into account with the objective to assess the viability of using both railway and trucking 
systems, data and information were then collected to develop an economic framework for the subsequent creation of a valuable tool for future development of freight transport design strategies.

As a part of the research components, data were collected from different sources that influence the life-cycle cost and mode selection analysis. In addition to the data collection, various factors were explored that may affect mode selection results that require consideration when studying the effectiveness of using the proposed mode of shipping. Such factors include weather and environmental conditions, safety, as well as rules and regulations. The economic analysis involved collecting data relevant to capital cost, operational cost, depreciation cost and other external costs to discover the practical freight cost. Some of these cost types were already present, while others required calculation based on the available database. Further to this, impact analysis was also assessed using cost benefit analysis to determine the net benefit of using one mode over the other. A Geographic Information System (GIS) version 10.4.1 was then used to discuss the intermodal options and other shipping scenarios. Assessing costs, impact analysis and the use of GIS are key in serving one of the primary objectives of this thesis, which is to ultimately aid policy makers' decisions, where the most economically appropriate and reliable freight mode can be more readily apparent as well as provide guidance in evaluating the outcomes of creating and revising rules and regulations. 


\section{Chapter: Literature Review}

\subsection{Introduction}

Shipping and transport industries endure continuous changes and transformations in response to technological developments and changes in world trade (such as self-driving vehicles and more fuel-efficient engines, for instance), including supply and demand. Vast amounts of documentation, research papers as well as technical and economic reports are available in literature on this area. This information and data are valuable assets in providing a basic understanding and knowledge base of the different types and methods of shipping options, as well as constraints among transportation modes for different types of shipping. Additionally, it is important to identify variables that govern the freight industry including geographical aspects, economic impacts of regional and international boundaries, different approaches related to cost analysis and evaluation, as well as other concerns in the shipping transport industry, such as border delay issues. This section will also provide key context regarding the modes, logistics and risks associated with shipping.

Two types of shipping modes are used by the transportation industry: single-modal and intermodal. Both assist in the moving of freight from one place to the other as per the commodity and the geography of the area(s) where shipping is taking place. Mahoney (1985) found that freight transport modes can be categorized as truck and rail, total truck, total rail and others, which may include water, air, pipeline and several other modes that are mechanisms for transport. The scrutiny of modal choices stands to be one of the most fascinating areas of study in transportation planning. 
The ongoing increase and demand of population requirements around the world demand the efficiency of two leading modes outside of sea transport, which are truck and rail, which happen to be the focal points within this thesis. These two land modes stand out to be the very foundations of freight transport, and hence have attracted the attention of the research community. From data and descriptions found in the literature, one can say that for the vast majority of commodities, truck and rail symbolize the prevailing share of freight circulation in Canada and all over the world.

Various studies within this body of literature are solution driven to find the most reliable mode for shipping, to focus on minimizing costs of freight transport while maximizing public benefits, as well as presenting methods for ensuring that goods are moved in the most effective ways possible. Environmental and safety matters prove to be more vital when decisions are made to utilize any mode available by policy makers, rather than incorporating operational cost issues. These matters create a necessity to consider total cost analysis, a process where overall factors are considered, which includes making a cost estimation and includes decision-making about the mode choice. Users must understand the full costs of different modes of transportation in order to make appropriate and well-informed comparisons. The following sections are intended to review the conclusions found in the literature regarding the issues that affect freight mode selection, models and tools for analyzing freight transportation costs.

\subsection{Modes of Freight Transport}

Freight transport can take place by various means (including trains, roads, aircrafts, ships, pipelines and so forth). Here only two modes are discussed in the interest of the present work and the research carried out for this thesis. Rail transport is commonly referred to as train transport, which are steel wheeled vehicles running on rail track is known as a rail route or railroad. 
Rail is used for travelers and product movements from one point of origin to the other point of destination. Trains are fueled by steam, diesel or by electric power supplied to it by trackside frameworks. In urban areas, municipalities and administrations face specific issues with intercity trains. Another unit, known as cargo, generally utilizes rail freight cars that require emptying of payloads and manual stacking. Since the 1960s, compartment trains have turned into the overwhelming answer for general cargo shipments. Expansive amounts of goods and commodities are transported by rail.

Road is a line of communication (travelled way) open for public traffic (Javanovic et al, 2004). These roads are the means that support area sections by foot or by any type of vehicles running on them, subsequently forming a system of transport. There are always various vehicles on the road and the most widely recognized street vehicle that has been created by human is the car. Data shows that in 2015, there were 1,309 million vehicles on the road around the world (Statista, 2017). There are different types of vehicles and movements that make use of roads, including motorcars, motorcycles, trucks, bikes and people on foot. There are always arrangements that are to be made for each of these road users. For instance, the utilization of transport paths provides the need for open transport whereas cycle paths give unique zones of streets to bikes. Motorcars offer high adaptability, yet are regarded with high vitality and regional utilization, and they are the primary wellspring of commotion and air contamination in urban communities. Street transport by truck is regularly the underlying and last phase of cargo transport.

After researching growing transport requirements and the challenges associated with logistics management, the European Commission published a paper in 2011 discussing the challenge of the changes that were required to improve infrastructure in a way so that competitive rail systems can be established, which could subsequently move freight over distances that have 
as much variation when road freight movement is used. Without any arguments on the mode, trucks were accepted to transport the freight if the distance was less than $300 \mathrm{~km}$. For longer distances it was found that an intermodal system with improved efficiency is a better option. This research also demonstrated that overall, there is a lack of progress in intermodal infrastructures, which can provide optimal solutions in terms of energy use, emissions and minimizing of environmental issues.

Road is chosen as the first choice by most shippers for short distances, but environmental impacts and congestion due to an increased load on roads demonstrate the need for alternative rail systems to be implemented. A new definition is being set for intermodal freight systems as a method of transport where maximum distance is traveled by rail, air or via sea and only a very short distance is traversed by road at the beginning and end of the journey. It involves the use of cargo-protecting units specially designed for intermodal transport so that the switching between modes can be easily performed and the freight is transported in faster, economical and environmentally safe conditions. There are many advantages with this method, including that it does not require any separate arrangements to transport via different modes and additionally, no extra effort is needed to load or reload individual items.

The intermodal terminals are the places where the transfer of goods from one mode to other is carried out and they are designed to provide facilities for transferring the freight from one mode of transfer to the other mode with different properties. Intermodal methods capitalize on the ability of different systems to operate together with minimal cost, necessary safety measures and successful delivery of the freight. These particular outcomes greatly contribute to growth in intermodal business. Any given country's geography, national and international policies and type of freights to be transported largely contribute in deciding how an intermodal system is to be 
developed in order to achieve an optimal solution. In the next sections, examples of prior studies and research will delve into decision-making and cost considerations between single mode and intermodal systems in various contexts.

To begin, there are four main factors that contribute to a shipper's decision with regards to the route and the mode of transport to be selected (Manners, 2017). The first factor is the cost of the goods to be transported, which represents the total cost involved in sending the shipment by rail or road. The second factor is time sensitivity, such as when certain goods are in high demand, or if goods need to be transported quickly if the goods are key contributors to other product(s) in demand. The third factor is the weight of the goods to be shipped, and generally heavy goods in large quantity that require more space are transported via rail for longer distances. The last factors are the attributes of the freight, whether the products are safe to transport using any mode, or if the goods need to be transported with special care. In such cases, road is often the best mode option.

In a 2001 study performed by the Center for Urban Transportation Research (CUTR), conclusions were drawn on key differences between truck and rail modes. More specifically, it was determined that trucking completes the majority of short-trip distances and is primarily responsible for the most expensive goods, while rail completes more extensive trip distances and generally transports inexpensive goods that are bulk in quantity and heavier in weight. The CUTR analyzed the movement of products through road or rail in order to obtain answers about which mode results in maximum revenues for taxpayers' earnings. It should be noted that taxpayers are not responsible for paying tax to perform road maintenance due to impacts from the shipping companies' traffic. As a way to cover such costs, policy makers should give more consideration to implement toll systems for truck users in order to compensate for maintenance, noise, emissions and congestion related to the operation of shippers' trucks on roads. This study by the CUTR was 
complex to analyze, given that each transport mode has its very own cost framework, fundamental needs and requisites.

A later study by Cenek (2012) was carried out in New Zealand on three different transportation modes, which were coastal shipping, rail and road. These modes were employed to pull 20-foot-long shipping containers that were designed to permit real-time observation of movement and impact forces along the route. Cenek's study did not cover the infrastructure capital cost of using the shipping modes, but it was demonstrated that the ratio of cost in transporting a 20 -foot container for a $1500 \mathrm{~km}$ trip was 1 (sea) to 1.7 (rail) to 2.8 (road). The rail mode had to carry approximately 25 containers per train, and the maritime mode had to carry at least 297 containers per vessel to achieve balance with hauling a container using the road mode in relation to fuel economy and CO2 discharges per kilometer (Cenek, 2012).

Mahmudi and Flvnn (2006) analyzed the economics of trans-shipping biomass from truck to train in a North American setting and presented the following major findings. Transshipment was preferable only when the price per unit distance of the second mode was less than the initial mode. Trans-shipment to rail was also found to be cost-effective if rail lines were passing through significant localities, as road systems often permit more flexibility when it comes to certain locations due to the spread of road networks versus rail lines. Mahmudi and Flvnn concluded that unit trains have improved timing capabilities in moving goods between origins and destinations because they can transport twice the tonnage in one day rather than shipping the same tonnage using a stream of trucks.

A study was implemented by the Oregon Department of Transportation in 2006 to investigate the viability of diverting truck cargo to rail in the Columbia River corridor, one of the most dynamic and multimodal corridors in the U.S. for freight transportation. The study found that 
most of the freight moved in the Portland region is accomplished through the utilization of trucks. It was reported that $67 \%$ of all cargo in the area traveled by truck and was estimated to rise to $73 \%$ by 2030. If a transporter or consumer was not situated on a train spur or at a train station, they were forced to use trucks for either the whole consignment or a portion of it. Finally, this study concluded that cargo which travels long distances and does not require special or protective handling can potentially be diverted from truck to train (and subsequently reduce fuel costs) if the quantity is large in size and particularly when the cargo is of lower value.

\subsubsection{Freight Transportation Guidelines and Safety}

All individual modes play a significant role in the freight distribution scheme and safety guidelines that apply to all modes of transportation, such as design speed, the maximum weight so as to not damage the roads and the number of hours undertaken by drivers for transit. It is always required to identify and express perilous subjects influencing freight transport safety, security and competency. Consequently, for cultivating planning, scheming and processing of freight transportation, extremely comprehensive guidelines and regulations concerning the automobile, the credentials of the driver and essential apparatus are established. Guidelines and regulations are available on both the federal (between the Gulf countries) and state levels (between cities). These may fall into two classes: taxation, such as having tolls and police powers which could factor in rules such as the size and weight of automobiles, and secondly, limiting the shipping quantity per truck or wagon so as to ensure other safety necessities when shipping dangerous goods. Railroads, on the other hand, are slightly more influenced by state legislative bodies, whereas trucks use public highways, and therefore are considerably more affected by these guidelines (Norton, 1971). 
When trucks are considered, congested roads and motorway systems have to cater to the needs of rising freight demands. This in return escalates the threat of fatal accidents, particularly if trucks are operated in chief monetary and metropolitan hubs. Generally, the chief threat measures in relation to steering of freight by rail or truck include an analysis of the influence that fragile or hazardous materials can have on the population and the atmosphere. Additionally, the length of routes, paths, weather conditions (fog, snow or ice, for instance) on the roads and highways, as well as casualty rates for individual modes have to be taken into consideration for safer freight delivery. Furthermore, the matter affecting the transportation of huge amounts of chemicals listed as "toxic by inhalation" through main metropolises always leads to a question of whether truck or rail should be the mode of transport. Several matters and challenges affecting the movement of dangerous commodity supplies from truck to rail have been reported by Spraggins (2010).

Discussion on freight transport security was also included in a study by Miller (1991) and Forkenbrock (2001). Forkenbrock compared the external costs of rail and truck freight transport, with consideration to total cost pricing. However, this total cost pricing was inclusive of emanations (air pollution and greenhouse gases) and noise influences as the factual costs to society. It was stated that external costs were inclusive of safety issues, and that the well-being of society should be completely acknowledged and readily apparent when transportation strategies are designed. Earlier work from Forkenbrock (1999) showed the assessment of the external cost of freight shipment by truck, including all calamities such as mortalities, damages, property impairment and unrecovered costs linked with the provision, operation and maintenance of public roads and bridges.

In another paper by Morton et al. (2006), safety costs were estimated with the inclusion of costs associated with policing (bank trucks requiring security guards, for instance), accidents 
and regulations regarding the various modes of freight transport. There are numerous other studies and documents that have specifically focused on the serious matter of safety issues and their impact on total cost. There continues to be much debate about the extent to which security methods are taken into consideration by government strategies that focus on rail and truck transportation systems.

\subsubsection{Freight Transportation Impact on Environmental and Social Life}

Environmental effects can be largely categorized under the headings of emissions and noise pollution. Emissions include lead compounds, various nitrogen oxide compounds, carbon monoxide, hydrocarbons, smoke and odors. Exhaust smoke, mainly from diesel automobiles, comprises carcinogenic compounds that can lead to cancer. Previous research and records have shown that road vehicles produce by far the most NOx and $\mathrm{CO} 2$ per ton-kilometer as compared to other modes of freight transportation. Congestion, ambient air and noise pollution, greenhouse gas emissions and issues influencing societal life, primarily due to trucks, contribute to significant apprehensions over freight transport modes across the globe. Petrol-driven automobiles lead to the higher proportion of all emissions, with the exception of smoke and odor that are produced mainly by diesel-driven automobiles. For entire societal costs to be reduced, policy makers must comprehend the full social charges of diverse modes of transport.

Noise is one of the key issues in environmental pollution, influencing not only main cities but also rural regions with fewer houses and less development. Ubeda (2006) included noise along with other factors for environmental cost estimates to evaluate the environmental charges in road freight transportation in Spain. It was discovered that 17 to $22 \%$ of the European population is open to traffic noise of over $65 \mathrm{~dB}$ and in this context; noise was the chief environmental cost of 
road transportation. As a method to reduce environmental pollution, it was suggested to increase the usage of rail in combination with road transport. Upton (2008) undertook a study to determine ideal operating procedures in freight transportation maneuvers for New Zealand to maximize returns. For example, when purchasing a truck, the type of fuel used and fuel consumption needs to be taken into account otherwise other alternative modes may need to be considered. To accomplish this, Upton used what he defined as best practices in his research to include solutions that complement most value (and not most price). He considered the social, political, economic and environmental agendas in which trading work were considered as the parameters and anticipations for these best practices. For example, if the matter of concern is associated with the transport mode availability, then the best practice is to emphasize on the local plan of the city in question to determine what the most sensible selection is based on the layout of that city while also considering how particular layouts best accommodate certain modes.

According to a study performed by Piecyk (2007), the external costs of road freight transportation in the U.K. were found to be absorbed by duties and taxes paid by truck users such as road tolls and vehicle excise duty. It was emphasized that road freight transportation systems play a critical role in the development of the British economy and preservation of social wellbeing. Piecyk's report provided efficient estimates of the whole external charges of road freight transportation in the U.K. by taking into consideration three types of costs. These were the environmental charges (comprising climate change, air pollution, noise and accidents), congestion costs (related to delays, driver and fuel costs), and groundwork charges that cover infrastructure costs. Many of these charges were found to be abided by the public at large rather than the companies operating freight automobiles. It was anticipated that if the government were to deliver extra road space and use additional modes to discharge traffic congestion, congestion charges 
would be reduced and the level of internalization can be enhanced, so that taxes are minimized through the reduction of external costs.

An evaluation of $\mathrm{CO} 2$ releases for truck-only and rail-based intermodal freight schemes in Europe by Kim (2009) found that rail-based intermodal freight transportation systems were more environmentally friendly than truck-only freight schemes, particularly for long-distance delivery and in terms of $\mathrm{CO} 2$ emissions. Kim assessed the input and output of emissions for three different kinds of freight transportation modes: trucks, diesel trains and electric trains (that produce emissions from power plants involved in manufacturing), using mathematical equations for each case. The assessment offered some input for short or medium-term policies for regulating $\mathrm{CO} 2$ emissions in the European Union. An example of these policies is encouraging support toward mode shifts and implementing regional plans that are inclusive of intermodal schemes for city networks.

Recently, a study by the Victoria Transport Policy Institute (2013) defined emission rates from a diverse range of automobiles. This report acknowledged that larger and older diesel automobiles with ineffectual emission controls have greater emission costs. Additionally, emissions rates tend to be greater for short trips due to exposure and stoppages during peak hours. It was established that urban driving executes higher levels of air pollution costs than rural driving. On the other hand, climatic variation, ozone depletion and acid rain emanations have significant costs irrespective of where driving occurs, as these environmental effects are not limited to the locale in which driving takes place. Normally, climatic change cost estimations tend to upsurge with the passing of time and rest on how the emissions scenarios being taken into consideration play out in reality. 
European rail industries (CER-UIC-UNIFE, 2014) carried out a survey on mega trucks against rail freight and prepared a document to highlight the results of road congestion on environmental and safety matters. The survey inquired about public opinion in the acknowledgment of the necessity to diminish environmental pollution and external costs of transportation. This survey led the European Commission to reach a conclusion for the requirement to modify freight transportation from road to more justifiable transportation modes that take environmental impacts into consideration.

Komor (1995) conducted a review on freight modes and energy use, which included analyzing the U.S.'s current freight system. The study discussed the technologies and strategies for decreasing energy usage in freight transportation systems, such as aerodynamic performance and fuel-efficient engines for railway and trucking systems. It was noted that issues on worldwide climate change and city air quality led to a variety of transport policy variations. This and similar evaluations offer significant support in developing and revising transport strategies to be more effective, economically viable and environmentally sound.

\subsubsection{Freight Data Challenges and Cost Calculation}

Freight cost data are tremendously significant and valuable, but obtaining such data is often challenging and sometimes even impossible for public-sector agencies. For most freight transport modes, there are no uniform data standards or set data collection frequencies. Ibeasa (2012) is one of many authors who have investigated various methods that are employed for gathering data, and his study examined the matter of data collection for urban freight transportation analysis. The results confirmed the difficulties related to costs in urban freight analysis as well as the fact that sufficient data are often unavailable. 
Holguín-Veras (2013) identified the detailed kind of direct freight transport cost data fundamentals that are mandatory for public speculation, policy and supervising decision-making. He discussed and outlined techniques to address the gaps in freight cost data such as interviews, random surveys and web searches. This study also labeled and evaluated diverse plans like logistics plans and financial plans needed to identify and obtain these cost data elements. HolguínVeras concluded that the fact that most data sources are either national in scope or collected for rather specific uses makes it difficult for potential users to determine how applicable the data are for local and regional analyses.

Further, in the same context of data availability, The University of Florida's Bureau of Economic and Business Research (BEBR, 2001) performed data collection to examine the flexibility and extent of subsidies and taxes coupled with social well-being, efficiency costs and benefits that might be attained through strategic interferences to attain mode transfer in Florida. The research pool was comprised of thirty-two companies who possessed six types of commodities. After a call for data through telephone calls and letters, a database was built in the form of review questions and questionnaires that were used for gathering data for formulating the research. Only 10 out of these 32 likely subjects were able to provide fruitful data. This lack of adequate data and validity proved to be a hindrance in collecting the relevant material. However, the research process was still beneficial in that it helped in highlighting key issues in data collection and availability. Alternative reflections from previous studies and research have revealed an absence of data in many cases. This has generated a necessity to look for advanced methods of GIS and statistical analysis for filling the gaps and enhancing the databank for using the available models in the literature or any other restructured model (Southworth, 2003) (Beuthe, 2001). 
Southworth (2003) argued for the necessity of better data, modern methods and models for tracking, analyzing and forecasting the potential emerging influences on freight activity, which could be financial in nature, such as demand and cost data. Data-driven decision-making was found to be indispensable to the future accomplishment of supply chain activities and processes. Beuthe (2002) studied the external costs only and analyzed that the external effects of interurban freight transportation provide an approximation of the chief social costs they inflict on the population. To estimate the whole financial and social costs of transport by the whole foremost modes, it is often compulsory to calculate costs per vehicle-kilometer. Beuthe also intended to make comparisons among alternative modes of transportation by presenting the resources consumed and other environmental and social influences such as delays, congestion, time and road damage.

Builders (2005) scrutinized shifts in trucking costs in Canada. Builders' report compared door-to-door truck transport services to rail intermodal Container on Flat Car (COFC) and Trailer on Flat Car (TOFC) services for short distance and long-distance transportation. Logistics costs were calculated based on the average value of shipping in the study's region of interest in Canada, which is about $\$ 75,000$. A shipment that cost $\$ 75,000$ was taken as a sample and therefore the time values of shipping, inventory, delays and the annual interest rate were calculated to find the total logistics cost. For the short-length distance, which was Toronto to Montreal, it was reported that all costs were lesser for direct trucking. On the intermediary distance length, which was Toronto to Winnipeg, transport costs for rail intermodal were lesser. However, logistics costs including facilitation for supplementary inventory requirements and time value cost for money favoured trucking door-to-door services if the trailer/container load was valued at $\$ 75,000$. The distance length, from Winnipeg to Toronto, therefore favoured trucking because of transportation costs and the time value. The longer the distance, like Toronto to Vancouver for instance, considerably 
favoured rail intermodal services for transportation costs and overall logistics costs. Builders also classified some of the primary reasons for altered trucking industry charges from 2003 to 2005, which included aspects such as driver shortages, a fuel cost boom and foreign currency adjustments between Canada and the United States.

Other topics of interest in freight transport are statistical and mathematical tools that have a significant role in freight transportation research based on the tools' ability to estimate price and their influence on important parameters, which for instance, could be finding the best price while considering environmental impacts. Another concern is that freight transport has to constantly face and acclimatize quickly to shifting political, social and economic circumstances. This demands a precise and effectual approach to contribute to planning and decision-making processes. Crainic and Laporte (1997) acknowledged some of these chief concerns in freight transport planning and presented suitable operations research models, approaches and computerbased planning tools like GIS and Neural Network as methods to address such concerns.

In a 2014 study by Kulpa, there was an establishment of freight truck trip generation equations at a regional level using the commodity base model based on the commodity type. The author employed several data sources, including secondary survey data and sought indirect approaches such as Neural Network to find the relationship between direct and indirect variables. Later, these developed data sets were used to get an estimation of trip generation equations, applying linear and nonlinear regression as well as artificial neural networks (ANN). It was shown that empirical values of trip generations for modeling purposes could be achieved without questionnaires and surveys in transport corporations for overall summaries on truck use. However, examining small sample data does not necessarily represent the full picture. These statistical 
methods may provide models or can be employed for studying freight transportation if suitable equations are formulated taking all factors and cost variables into account (Kulpa, 2014).

\subsubsection{Reliability and Efficiency of Freight Transportation}

A main aspect of freight transportation that occupies major concern for consumers is reliability, which can be defined in terms of the variability of travel time. Large variability in travel time can introduce numerous economic impacts that can be significant, and time is one of the most important elements to freight system users. In order to measure reliability, models usually estimate cumulative incident related delays like access to port, terminal and sorting yards as a function of volume-to-capacity ratios (Systematics, 2006). In a recent study by Deflorio (2013), there was a focus on a set of indicators for assessing the quality of a freight distribution service with time windows in terms of freight availability and prediction of delivery time. These service functions on a given road network aim to fulfill a number of requests, and reliability significantly affects the service charge and final shipping cost. The researchers uncovered the capability of the designated indicators to forecast with good approximation the transport costs and consequently, the upkeep of the service quality planning decisions.

Another report by Significance (2012) analyzed the certified values of time in freight transportation in the Netherlands by using a cost-benefit analysis that provided the first values of reliability on an empirical basis. For the conversion of transportation time savings, certified values of time accessibility on the basis of surveys among shippers were carried out between 2003 and 2004. To attain entire money values of time and reliability from the models, supplementary data on the transportation costs per hour for factor costs were evaluated. In conclusion, reliability was 
framed as a measure that is meaningful to both public and private sectors, and the willingness of freight shippers to pay for faster and more reliable service is dependent on several considerations.

\subsection{Freight Models, Analysis and Applications}

Transport models and analysis tools are required at various steps while conducting research for freight transport and decision-making with regards to modal transfers. The development of suitable models and tools for the analysis, operation and planning of transport systems, and subsequent policy making decisions leads to successful and more reliable results. Freight transport is complex, and several aspects have to be covered when evaluating the influence of transportation strategies and infrastructural processes. In order to support decision-making in public forums, it is very common to use progressive freight transportation analysis models starting with analysis and following with optimization.

Ham (2005) presented the preparation and formulation of multi-modal systems algorithms and solutions to solve the optimization problem using interregional commodity shipment data from the United States. Ham discussed the approximation of key parameters such as distance and shipping cost, and presented an assessment of the performance by calculating the t-value and correlation coefficient of the combined model of interregional, multimodal commodity shipments as well as a transportation network flows model with practical data. In order to represent comprehensive transport costs well, transit time and distance are necessary parameters to be inclusive of in the transport network representation.

Similarly, Easa (1996) performed research on intercity cement transportation. Easa discussed the disaggregate mode choice approach and its application in freight transportation and explained why consumers make particular choices. One of the main tasks of this research was to 
examine logit and probit models using a linear and nonlinear utility function. The researchers initially developed and calibrated these models. Later, these models were statistically validated and compared. Data used in these models were from annual transported tonnage, origin-destination (O-D) of the shipment, total cost, travel time, losses and waiting time. It was assumed that human choice is nonlinear, and for example, when shipping a 20 -ton container, there is a $50 \%$ probability that a trucking system will be selected, but if the weight increases to 40 tons, there is a $70 \%$ chance that the shipper will favour using the rail system. It was observed through examination and data analysis that the probit model was more valid than the logit model in terms of goodness to fit, likelihood values and chi-square values. From the results of this research, it was concluded that cost is a significant variable in all models.

Crainic (1986) explained a summarized literature appraisal on intermodal models and analyzed a general modeling framework for the service system that was designed for multi-mode and multi-commodity freight transport. The observations from the behavior and performance of the algorithm were found to be helpful to improve the planning process for freight transportation. Another recent research study by Wang (2013), used discrete models (more specifically, disaggregate model, probit model and logit model) to analyze how and to what extent freight characteristics such as commodity type, fuel cost, and road/rail networks influence freight mode choice. This was done by testing the differences in mode choice among three zones in Maryland. The probit model considers the normal distribution for the error term, while the logit model undertakes the logistics distribution for the error terms in the utility function. The discrete model used the mode choice between truck and rail as the dependent variable and the characteristics of the commodity, shipment, network and fuel cost as the explanatory variables (independent variable). Biogeme software was used to estimate both binary probit and logit models by finding 
the maximum likelihood estimation of a parametric model. Variables such as some commodity types, a low value of time, shipment weight, value and distance were found to be insignificant, while fuel cost was found to be significant. The results from Wang's study provided a clear picture for policy makers to make actions to reduce truck-related highway congestion and air pollution.

There are various studies that show the use of GIS to handle large amounts of freight transport data. Ellis et al. (1996) presented methodologies that use GIS and a classical least cost transportation optimization model to perform freight transport analysis. The primary advantage of the use of GIS in this research is its ability to examine the data and flows graphically. A simulation model, with the use of GIS for urban freight transport, was developed by Visser (1996), which generated truck trips based on statistical data and then simulated the route choice to evaluate the effectiveness of different measures on freight transportation.

Another study presented by Standifer (2000) showed the usage of GIS for analyzing the intermodal freight network relevant to shippers for the state of Texas. Standifer developed a GIS network for transport to analyze the impacts of factors such as price, time, location and policies on shipper routing. Standifer found that ArcGIS is very suitable for routing investigations, as it possesses all of the necessary tools to perform such analysis.

In Virginia, Brogan et al. (2001) and Falzarano (2007) used GIS techniques to develop a planning methodology for the purposes of generating the spatial model focused on improving statewide intermodal freight transportation infrastructure. The methodology involved procuring country level commodity flow data and choosing key commodities for Virginia to form a system inventory. Traditional trip models were discussed and routes and environmental impacts were analyzed for future flows of a single commodity between the existing origin-destination pairs, and finally, the mode choice analysis was performed. 
Winebrake et al. (2012) used ArcGIS network analysis to develop a geospatial intermodal freight transport model for analyzing cost, energy and environmental impacts as well as time tradeoffs associated with intermodal freight transport along the U.S. eastern seaboard. Each route in this GIS model included attributes such as average speed, distance and emissions that were needed to calculate the required analysis between the two nodes in the network. By incorporating a network optimization model, least cost, optimum delivery time and emissions options were calculated for the more economically suitable freight transport selection.

Recently, Grossardt et al. (2015) developed a GIS-based model of the three primary surface modes, including intermodal connections using data on freight movements in the Kentucky portion of the Ohio River Valley. This Integrated Freight Network Model (IFNM) was able to solve questions related to congestion, safety, maintenance and other impacts. The model was also able to perform analysis for a single mode on the specific O-D route with any other modal substitution in order to obtain the best results for choosing the most reliable mode and to inform decision-making processes. The report concludes that the IFNM model can be of immense value in determining the changes to multimodal freight network dynamics with any internal or external constraints (Grossardt, 2015).

Numerous elements of economic analysis strategies are often accessible for use in highway planning and performing the mode selection such as Life-Cycle Cost Analysis (LCCA) and Cost-Benefit Analysis (CBA) (Economic Analysis Primer, 2003). Freight transportation models and various analysis tools are present in this body of literature and can be helpful in estimating the cost benefits and total cost assessment along with reliability of freight transportation. This literature review reveals two types of models that are presented comprehensively, which are: Cost-Benefit Models and Life-Cycle Cost Analysis Models. 
Cost-Benefit Analysis (CBA) can be defined as a method to measure and evaluate all relative direct economic impacts of public investment projects. For rail and trucking systems, freight transportation benefits are the direct benefits associated with freight investments, including travel time savings, operating cost savings and emission rate changes. Allen's (1999) discussion of the California Life-Cycle Benefit/Cost Evaluation Model presents concrete ways of formulating economic assessments to handle several transit modes and transit enhancement projects within California. Allen discussed peak period effects, value of time, automobile operating costs, accident costs, network effects, environmental costs, discount rates, passing lanes and high occupancy lanes. All of these sections offer pivotal information and cost evaluation for studying benefits analysis, economic assumptions and values in freight transportation.

A study on rail systems by Wilson et al, (2011) assessed the viability of the South Orient Railroad for a TIGER III Discretionary Grant within the United States. The team analyzed the impacts to society that would occur if existing rail service ceased, and their analysis provides an existing "base case" of benefits from current operations on the line. Several public benefits have been measured that resulted from comparing shipping by railway to shipping by truck. The benefits analysis included the highway maintenance cost savings, the reduction in air pollution, highway overcrowding relief benefits, safety benefits, noise benefits and fuel savings. According to Belella (2005), there are seven freight measure categories that need to be considered when estimating benefit analysis, which include: reliability (to provide estimation of delivery performance); responsiveness (to provide a measure of origin to destination speed); flexibility (a measure of the agility of a system to respond to market changes that maintain or improve competitive advantages); costs (for calculating the cost of moving freight); asset management (an organization's effectiveness in managing assets and meeting the demand for satisfaction); safety (an estimate of 
safe conditions through danger, risk and injury reduction); and lastly, security (an estimate of an ability to mitigate security risks and threats).

Another report on transportation cost and benefit analysis by the Victoria Transport Policy Institute (2013) provided an estimation of benefit analysis by considering emission charges of numerous aspects of automobiles that influence emission rates and charges of automobile air pollution such as fuel-efficient engines, electric trucks and trucks that are lighter in weight. Mechanical automobile pollution discharges and their influences were discussed, and it was highlighted that automobile air contamination charges differ depending on the automobile, whether it is truck, car, or rail fuel, as well as travelling circumstances. Research by Sage et al. (2013) focused on intermodal systems, and submitted work on the development of freight benefit and cost methodology. The work presented an improved method to analyze freight benefits associated with proposed highway and truck intermodal systems in terms of cost reduction, improved logistics and increases in regional employment in Washington State. In general, cost and benefit models are powerful tools for decision-making in planning and the evaluation of project alternatives. Schematic

Life-cycle cost analysis (LCCA) refers to all charges linked with a system from the perspectives of producers and consumers. LCCA in freight transportation considers all phases: including design and development, construction or production, exploitation, operational sustenance, phase-out and disposal. The ability to arrive at correct decisions depends jointly on a sound conceptual understanding and the capability to handle the quantitative features of the analysis required in life-cycle costing studies (Fabrycky, 1991). The life-cycle cost evaluation takes into consideration all of the operator and agency charges related to future activities, inclusive of future periodic maintenance and rehabilitation. One of the main purposes of lifecycle studies is 
to assess overall energy and environmental inferences of diverse tactical substitutes so that society can meet its demand for various services with minimal impact. A number of cost classifications have come into existence to serve as a base for life-cycle cost and economics. Some of these classifications include: investment cost; operations and maintenance cost; fixed costs that cannot be changed due to distance or quantity change; variable cost that can be changed due to distance and quantity change; incremental or marginal cost; direct cost related to the system itself; indirect cost that can occur due to border delays; total and unit cost; recurring cost that can be repeated as the same amount on each shipment; non-recurring costs that occur one time; and sunk or past cost which was paid and unreturned.

Significant factors that can alter cost estimates are geographical borders. Trucking is the primary way through which merchandise is transported across borders, and subsequently, trucking plays an important role in the integration of national economies. Anderson (2012) examined trucking across borders and discussed in detail the cost of cross border and domestic trucking. Higher fixed costs per shipment, especially exports, and higher line-haul prices led to higher trucking costs for international businesses due to the effect of the distance and its interactions that includes inspection processes and delays.

Another study by Penner (1978) calculated the operation factors only including fuel, labor influences and economic costs of several kinds of truck transport. Penner provided an improved understanding of the evolution in a transport system that employs a reduced amount of energy and yet contributes to the requirements of the state. Penner also identified a technique for calculating the economic cost, energy and labor impacts for different types of trucks. Overall economic costs per ton-mile were calculated. From the analysis, it appeared that owner-operator truck transport functions at a cost and level of effectiveness competitive with the average railroad. 
In contrast, other modes of motor freight are more expensive than rail in every way. According to Penner, any dimension must address the question of appreciating the benefits of highways to consumers and non-consumers, calculating the lifetime of the system and accounting for ongoing new construction and depreciation.

Gaines (1998) and Wang (1996) examined the life-cycle energy usage and emissions for heavy-duty trucks only, and the potential for reductions in energy use while taking into consideration all phases of the products' lifecycles, from material extraction to final disposing of the product. An example of this could be using different material and selecting lightweight trucks that have less low rolling resistance to reduce energy use. Ma (1997) proposed a condition-based maintenance $(\mathrm{CBM})$ model that supports replacements upon failure policy for freight car components in order to obtain the greatest benefits from system maintenance. For example, if there are 100 parts in the system where only $95 \%$ of them were defective, and about $5 \%$ of them are good, the common practice is to fix all of them, but Ma suggests a replacement upon failure policy only. In order to capture all of the consequences of a given maintenance policy on a systemic level, life-cycle cost was taken into consideration. It was calculated as the sum of preliminary cost, operational cost, inspection cost and replacement and failure charges divided by the life of the component. Further, an economic model was developed in order to compare the impacts on lifecycle cost. It was found that even though premium trucks were more expensive than standard trucks, they had better performance, longer lives and could save $5 \%$ of the life-cycle cost compared to standard trucks if replacement upon failure and CBM are implemented.

Crainic (2004) studied advanced freight transport systems such as fleet management, communication and intelligent transportation systems for over-crowded metropolitan zones. The purpose of this study was to introduce an organizational and technological framework for the 
management of metropolitan cargo transport and to classify a number of significantly linked planning and operational matters with the corresponding operations research models. Due to an increase in freight traffic that caused many inhabitants to move out of these urban areas, Crainic suggested performing LCCA to aid policy makers in reducing the impact of freight traffic to society, and to encourage consideration of cause and effect. Morton (2006) introduced a framework study using a universal schemes method, which included the total cost for two chief modes (rail and road) of cargo transportation in an area in South Africa. The analysis identified several major activities including LCCA for the area specifically in South Africa, initial infrastructure cost and maintenance cost, freight product study and operational cost, environmental and safety issues, user pays principal as well as the customer service quality in terms of delays. It was observed that LCCA still needs to be carried out for rail and road modes involving all affected parties for reviewing external and internal costs, border delays (if any) and evaluation of the current conditions.

A report by Hall (2010) examined the economic influences on truck owners in the 20202030 timeframe for future savings. An LCCA approach to estimate costs and fuel savings was taken into consideration. The analysis results depicted that investment in fuel efficient technologies will harvest net economic benefits over a typical truck ownership period. The life-cycle model included operations and maintenance costs, capital costs and remaining worth of the automobile over the period of ownership. Conversely, a simple payback calculation considered initial capital costs and fuel savings accrued over a two-year timeframe. It was reported that a transition toward increased utilization of life-cycle analysis in the industry would increase the proficiency of a state's trucking fleet while saving capital for truck owners. 


\subsubsection{Freight Transportation Logistics}

The term 'logistics' comes from a French word known as 'loger', which means art of war related to the movement and supply of armies. Throughout history, there are many such instances where those who had efficient strategic logistics plans ended up having competitive advantages. Leon the Wise and Alexander the Great used logistics plans and described them as methods that can be helpful in acquiring the nourishment, clothing and ammunition for their armed forces in the most efficient ways possible (Ghiani et al, 2013). World War II also serves as an example of where the importance of logistics came to the fore and contributed significantly to the Allied victory. Logistics, in this case, demonstrated great possibility in terms of organization and structure when contrasted with countries and other forces that were not employing these same principles. Though the context has since shifted, logistics provide societal benefits and can also provide seamless experiences with shipping, receiving and transport processes. Since then and more rapidly from the start of the mid 1960s, numerous components have expanded the notion of logistics. In today's framework of logistics, there is inclusion and discussions on topics such as deregulation, focused weights, data innovation, globalization, benefit influence and many other important aspects.

Logistics systems depend on several variables and a successful prediction of these can be of great help to meet the time lag between supply and demand. Arranging and controlling logistics frameworks requires forecasts at the level of future economic activities. Logistics requirements need predictions in the form of customer demand, to incorporate client requests, crude material expenses, labor charges, fixed and variable costs, travel times, lead times and so forth. 
Forecasting is done by making assumptions on a given hypothesis that is formulated after observing the data from the past. If the data profile shows some regularity in its features then futuristic trends can be predicted and values can be forecasted with ease. These forecasts can refer to time horizons and can be classified into three categories: long, medium and short-term forecasts (Ghiani. et.al, 2013).

Long-term forecasts are made for a time period of one to five years only, as any variables can change completely in the face of political and technological changes. Medium forecasts are made for a period of a few months to one year to control tactical logistical decisions. Medium forecasts are used to deal with inventory management, annual production of commodities and warehouse allocations. Short-term forecast includes a few days to several weeks and is required to use resources so that production and distribution targets can be achieved. Forecasts for a shorter time interval like a few hours or a day are not as prevalent and only occur in highly dynamic situations.

In order to make a forecast, a methodology has to be developed. In general, two types of methods are used that can be described as qualitative or quantitative (Wood et.al, 2010). Qualitative methods are used when there is a lack of enough data for any prediction. In this method, judgment from an expert is used as subjective analysis. Simple mathematical tools are used to combine different variables with their weights on the basis of decisions from an expert in the field. The qualitative method is very useful for long-term or medium-term predictions when there is a chance of political changes or advancement in technology.

In a logistics system for forecasting or predicting any variable, quantitative methods can be applied if enough data is available for analysis. The techniques that are used for prediction depend on the type of variable to be predicted as well as the quality and quantity of available data. 
Normally time series data is taken for a particular variable and the density index method is applied to classify its graphical representation. The use of graphical representation is always preferred to interpret any series data as it supports many complex methods and visual analysis (Ghiani et al, 2013).

The connection between logistics and intermodal transport systems is a significant one. With the growing velocity in supply chains, intermodal freight transport has occupied a critical position in shipping operations. The ability of road and rail services in delivering freight at port and disseminating the load from port to the respective consumer markets play an important role in the growth of shipping businesses. This requirement has led to the development of high-level rail infrastructures in areas where high congestion on roads could block efficient transportation. New roads are also in construction so that busy traffic areas can be diverted on different routes with few differences in the traveled distance. Thus, intermodal freight transport occupies a solid place for complete logistics flow in sea, air, and road or on rail. There are more opportunities for shipping lines in terms of repositioning containers when they work together with road and rail infrastructures and utilize intermodal freight transport facilities for cheaper estimates.

Facilities that organize and implement logistics deal with managing the number, position, hardware and size of new spaces for operation and storage. In addition, facilities also manage the divestment, relocation or cutting back of existing operational or storage spaces. In business logistics, the location is planned in such a way that the design of facilities should be able to support the commodity flow easily from suppliers to demand points. For public sectors, it comprises the arrangement of offices from which clients are serviced. The problem of facility locations and other relevant issues become more important when a logistics system is being started from scratch. Facility location decisions are also needed when there is a variation in demand 
patterns, modifications of materials, energy, labor cost or any change that can affect spatial distribution. Facility location decisions are strategic, depending on many issues and are often made when a new product or service is launched.

Activities in the interest of freight transport play a crucial role in logistics frameworks and planning. They contribute significantly toward logistics costs and service levels rendered to customers. For effective and inexpensive freight transport, the facilities for logistics systems needs to be set up at locations that can support dual objectives: shorter distance trips and low cost. Thus, methods of transport vary concerning these two central parameters: cost and travel time. These parameters are utilized by organizations when selecting transport administrations, either when they go about as private bearers or when they are bought outside. Freight traffic assignment problems (TAPs) are taken by administrative bodies to find the least cost routing of freight through the existing facilities in the network to allow the best transport flow from the origin (supplier or manufacturing unit) to the destination (retailer or warehouse). TAPs are of mainly two types: static or dynamic. Static models describe the situations that are not affected with time, in contrast to dynamic models where time dimensions are explicitly taken into account.

The vehicle routing problem (VRP) is a most challenging combinatorial motion or advancement and integer number programming task. VRP is a process that can help to determine an ideal set of paths for vehicles while still maintaining the objectives of location demands and the desires of clientele. Thus, VRP serves the objective of transporting commodities to sets of customers with known demands with minimum vehicle routes from origin to destination depot. Frequently, the connection is that of conveying merchandise situated at a focal stop to clients who have set requests for such products. The first work in this direction as described in the literature is that from Dantzing and Ramser in 1959, who came up with an algorithmic approach for 
petroleum deliveries. Later on in 1964, Clarke and Wright used a modified approach by applying a savings algorithm or the funds calculation approach. After these two initial practices, many papers have been reported with different algorithms and commercial packages which are now available that can help to solve real world VRP.

Though VRP is complex in nature, it is very important as it finds numerous applications in any industry. Transportation is mostly required for small objectives to any big target of a given company or organization. By using advanced computers and applying optimization methods, the VRP can generate significant savings for a company, as cost is the direct parameter when it comes to using any transport systems. The percentage of savings becomes even larger if the company is dealing with a business where transportation is an essential unit.

There can be many variables in VRP and optimization methods are applied to come up with the solution that may be the shortest path with minimum cost along with the set of defined constraints on the variables. Extra information of any type (including windows of time, loading and unloading time and the home origin) are sometimes added to the VRPs to check any shortcomings of the methods and suitable approaches are accepted to get optimized solutions. Mainly the common objective of VRPs is to minimize the global transportation cost or to minimize the number of vehicles. The precise relevancy of VRP will be discussed when applying logistics management applications in this thesis.

\subsubsection{Risk Assessment and Resilience}

Risk can be defined as the expected value of consequences to society if an event occurs. Thus, risk R can be calculated by multiplying the probability $\mathrm{P}$ of the undesired event with the value $\mathrm{V}$ of the consequence that it can create to the public and can be expressed as $\mathrm{R}=\mathrm{PV}$. 
Resilience can be measured in terms of two properties of a system, which are functionality and recovery in the event of damage. The key questions then become: if damage occurs, how well is the system going to function? And secondly, how fast can it recover and return to its original state? Risk can also be framed as an uncertainty of a situation or event that can antagonistically impact the performance of an association or organization. Even if a particular risk has lower probabilities, it can still have an impact on short or long-term performance of an organization or structure. (Tang and Musa, 2011).

Transportation meets a variety of needs, and this spectrum can range from essential commodities to disposal of toxic waste that can be hazardous to public health. With a variety of needs also comes a variety of potential risks. With the advancement of technology, it is possible to make freight carriages physically strong to ensure the security of its cargo to a significant extent. In addition to this, set automated devices linked to a network are arranged and used to provide live updates on the route. This provides better monitoring of the integrity of the cargo and the freight carriers in many cases (Saat \& Barkan, 2005; Zhu et al., 2012). Yet, it is exceedingly difficult and challenging to monitor all aspects of this infrastructure. One of the reasons can be long geographical distances, especially when these stretch across cities, provinces and countries. It is even more difficult to ensure integrity from a safety and security perspective to maintain a strong and resilient security posture that can withstand, detect, oppose and recover from emerging threats, risks and any kind of vulnerabilities imposed upon that system. The aim is for systems to be resilient at all times and through varied weather conditions. Therefore, it is crucial that there is the facilitation for mitigation strategies based on security engineering design to increase the rate of resiliency for any fragile and interdependent systems, with the overall aim of minimizing losses should a failure to transport take place. 
Risk to freight transport systems can be described under four general classifications, which are planned, unplanned, natural and deteriorative (Radvanovsky and Brodsky, 2016). Planned risks can accrue due to individuals inflicting damage to freight rail frameworks with the expectation of causing huge postponements, harm, or cataclysmic disruptions. Unplanned risks are inadvertent, where there might be a driver's error resulting in an accident, or errors made by rail and shipyard workers, which might result in mechanical failure without the objective of creating a delay or catastrophic failure. Natural risks are sudden demonstrations of nature unfavorably impacting the system, and these can include flooding, wind, fire, tornadoes, snow squalls, ice storms and excessive warmth (Plant and Krepp, 2013). Deteriorative risk includes the neglect of asset integrity management leading to failure.

Overall, global supply chains can be affected not just from a few but several inside or outside risk areas. Reliability, timeliness, quality and design, information sharing, shared labor skills, levels of visibility, management control and possibility of external risks should be discussed early in order to strategically mitigate these issues. Sources of risk can be many, but by and large can be categorized into two groups (Goh et. al. 2007). The first type of risk that can arise is due to internal instability and the second can be explained as being due to the external environment. Risk can also be described as a probability of occurrence of a damage that is resulted from a loss in operations (Jenkins et al. 2010).

Freight transportation is comprised of complex systems that include immense street and rail organizational interfacing between nations. This complexity creates vulnerabilities and risk to railways extending crosswise over endless territories of land spanning across multiple jurisdictions that are often overlooked (Major Vulnerabilities to Railway Security, 2015). 
In times when freight transport was less diverse and less complex, the main objective was to have a supply chain so that a product could be delivered in the most effective way to optimize the business providing said product. These supply chains were simpler than today's complex supply chains, which are a consequence of globalization. To maintain a sustainable supply chain, there are several risk factors including the traditional challenges of lowering costs, just-intime delivery, reducing transportation time and meeting pressures from consumers.

Supply chains at global levels demand the interaction between people, and this brings many ethical issues at several stages of transport. In the present world of competition, cost and profit has been the single driving force that is behind the unethical behaviors of certain organizations and corporations.

Threats to supply chains over the last decade have caught the attention of manufacturers and decision makers to a large extent. Both in global and domestic markets, supply chains are meeting challenges of heavy natural disasters, extreme economic swings and geopolitical changes. These challenges are increasing with time, and dangers of external risks and internal risks have encouraged stakeholders to develop risk mitigation strategies and tactics. Risk cannot be avoided completely, as there is always some element of risk involved in almost all areas, including quality and safety, legal issues, security problems, environmental fluctuations, natural disaster issues, terrorism and so forth. With global supply chains, there are additional challenges that can arise due to many factors, including:

- Longer lead times that decrease productivity and streamlined operations

- Global customs processes leading to supply disruptions

- Foreign regulations affecting product supply 
- Increased congestion at ports with increased demand markets

- Political and economic instability, such as increased or decreased exchange rates

- Insurance market increases due to security concerns related to transportation facilities and safe movement of goods

While risk can be substantial in terms of the forms it can take and variety of outcomes, it is possible to reduce its effects by identifying the risk prone areas as well as evaluating and measuring the impact in advance. An effective risk management plan can be developed to face unforeseen risk factors and reduce the losses that can impact businesses, workers, consumers and bystanders. Political issues, economic instability and natural disasters are not new phenomena, but the drastic changes that can result from such occurrences brings about new challenges. One of the main factors that have contributed to rebalancing risks connected to various parts of the supply chain are the emerging supply chain strategies of global manufacturers that have changed over the past decade.

There are worldwide-published documents, reports, books and papers that describe how logistics service providers are dealing with risk management and administration when safe transport and cargos of different types are required. Pujawan and Geraldin (2009) found that the risk to the manufacturer is often influenced by their own business partners. The risk can arise from internal instability such as suppliers, customers or even logistics agents that are part of the chain in the business. Research by Kusmantini et. al. (2015) in Yogyakarta presented a risk map showing 23 sources of risk and the 43 risks that can arise to negatively affect the process of a supply chain of furniture and handicraft products. For risk mapping, they used an analytical technique by using the framework of the House of Risk (HOR), which generally contains procedures and foundations for the identification, analysis and estimation of risks. It works to design risk mitigation strategies 
that could be implemented for a company and risk management as an overall process. Shipments of fuel are also good examples of the need for proper handling during transportation due to the risks involved in transporting these items.

Many efforts are being made to introduce hydrogen into transportation systems as fuel. This is mainly due to the emission of carbon dioxide in the environment and scarcity of petroleum imports. Like any other fuel or energy carrier, hydrogen can increase risks if it is not properly handled or controlled. Caputo et al. (2011) have shown the impact of an accident risk on road transportation if the hydrogen payload is used in the vehicle. There can be several failure scenarios in the event of a large hydrogen release, where there may be a leak within normal operations, or at the time of a collision.

Supply chain risk management (SCRM) has become popular in attempts to control and manage risk over the last decade. Frankly speaking, there is no specific definition for SCRM that can be found in literature. It has emerged in different applications in various studies. Tummala and Schoenherr (2011) have used this technique to display how supply chain risk management processes (SCRMP) can be utilized to assess and regulate risk in a specific area. Harland et al. (2002) have discussed risks in supply chain networks by describing disasters, consequences, losses and probability of occurrences in freight transport processes.

Brenchley (2000) has presented risk involved in cargo transportation in terms of an event, the outcomes, impairments and exclusively the size of loss that can occur as a result of an event. Chopra and Sodhi (2004) investigated risk management in supply chains with the objective to have their analysis help to avoid any network structure breakdowns. They presented many risk categories such as delays, forecast, inventory, capacity, receivables and procurement. Risk 
management, risk strategies, risk categories and other driven factors were discussed and it was found managing supply chain risk is quite complex.

Gaudenzi and Borghesi (2006) presented use of the Analytic Hierarchy Process to evaluate the supply network risk. To provide an estimate or to understand the volume of risk, they considered explicitly the customer requirements such as time, delivery, completion of order, order correctness and damage free detection. Schroeder and Gomes (2014) investigated risk that can occur when international trade is practiced so that it can be helpful to business owners in managing their risks involved with freight transport on that scale. In any case, there is not enough research on risk administration to contribute toward a good understanding in a quantitative manner. Only few formal studies have been made that can shed some light onto decision-making within logistics companies in terms of probability of risk in occurrence, severity and in informing their transport strategies.

Jenkins et al., (2010) and Rao and Goldsby (2009) presented general risk management processes that can be seen in Figure 2. The process initially starts with providing context that includes both internal and external factors. Then the risk assessment is performed in four steps: risk identification, risk analysis, risk evaluation and risk mitigation. This process is monitored, reviewed, communicated and consulted continuously. It is expected that the implementation of risk treatment, that is mitigated, shared and retained will result in better performance in future.

According to a report from Abnamro (2015) on the Logistic Service Provider (LSP) industry, more than 90 percent of the LSPs and transport companies claim to be aware of their principal operational and strategic risks. However, only 61 percent of those have an alternative plan if there is a major breakdown in their operations. 


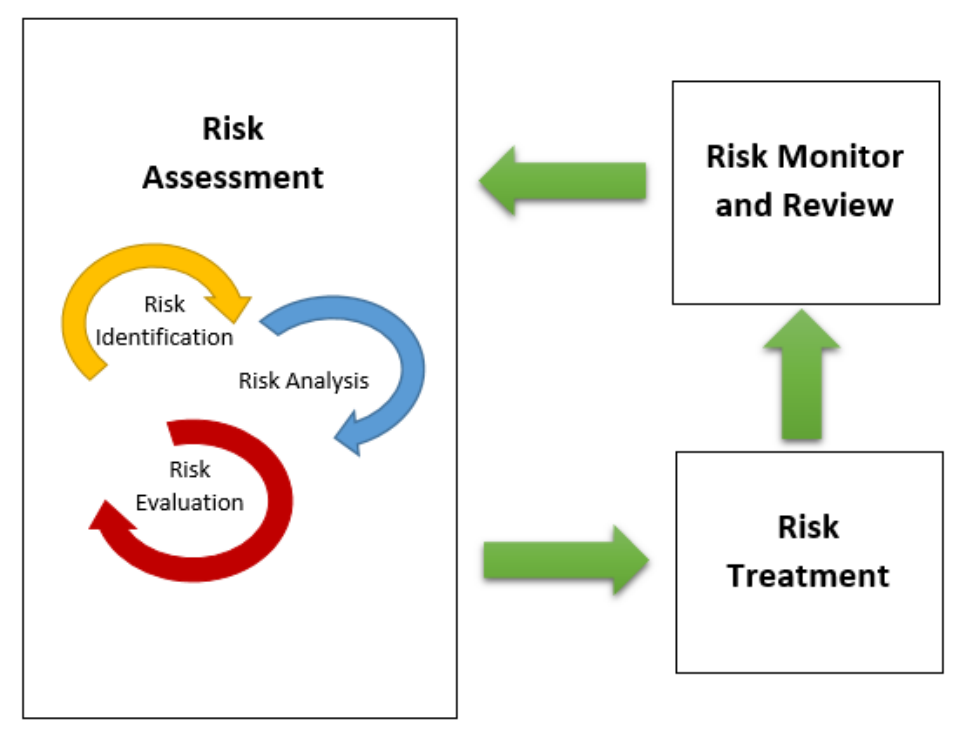

Figure 2 General Risk Management Process adapted from Jenkins et al., 2010, and Rao and Goldsby, 2009.

Performance measurement has become an interesting issue over the past 20 years. There is a well-known adage of performance measurement by Hamel and Prahalad (1994), which states "if you can't measure it, you can't manage it". The definition of performance measurement can be explained by understanding the action in each activity in order to lead organizations to reach target objectives. Chan and Chan (2004) explained the definition of performance measurement in terms of how to meet goals by focusing on output efficiency. To know the level of the risk impact on supply chains, appropriate key performance indicators (KPIs) should be developed. Pedersen and Gray (1998) defined key factors of transportation selection criteria as time, cost and service quality corresponding with expert opinions.

Identifying hazards requires making decisions and measurements on how harm might take place. This process can be aided when it is consultative and includes assessments from multiple parties within the supply chain, and risk can therefore be more easily controlled. Having identified the hazards, it is also necessary to know what the likelihood is of the risk occurring, the 
level of risk and what measures can be taken to reduce harm and future occurrences. It is not possible to eliminate all risk, even with all of this knowledge in place. It is only expected that all main risks are carefully noticed and taken into consideration with steps to manage them in the most responsible and reasonable ways possible. This means balancing the level of risk against the measures needed to control the real risk in terms of cost, time or effort. It also means that action is not necessary if the action required would be grossly disproportionate to the level of risk.

\subsection{Summary, Challenges and Opportunities}

Various studies have been conducted on freight transportation costs. In making decisions on mode selection, users should take into consideration all environmental, security, cost, weather, rules and regulatory matters of freight transportation. In general, studies on freight have one common limitation, which is data that are not large enough to encompass the topics efficiently. Based on the literature, lack of costs data such as accident cost, environmental impact cost, noise cost, capital cost and depreciation data might lead to potential bias analysis (see Crainic [1986]; Abu-Taleb [1996]; Forkenbrock [1999]; Wilson et al [2011]; Fender [2012], and Anderson [2012]).

As per Mahmudi and Flvnn (2006), selection of the modes of freight transportation depends on the type of commodity to be delivered, along with the availability of proper data. A lacking of the political, social and environmental factors that are involved in influencing the viability of averting some truck commodities to train is disruptive to a whole picture of the abilities and limitations of freight modes (Bryan, 2008). Moreover, less attention has been given to 
opportunities for modal shifting of commodities, and limiting studies to one city or to a smaller amount of data might also affect the results.

Further to this, when it comes to single equation estimation of mode selection or shipment volume, there is a presence of potential biases in assessed parameters of that particular model (Abdelwahab, 1998). Another limitation that was found in the literature is that studies generally lack a super-network that conglomerates both the road and rail systems in a given area, for unequivocally considering the multi-modal transport scheme in a given area (Rwakarehe, 2014). As a result, a lack of information results in policy makers making decisions which are not as informed as they could be (Tavasszy, 1998). Studies also lack the addition of more factors associated with shipment size, warehouse, intermodal yard location and network future expansion options [see Wang, (2013); Allen (1999)]. A study from Brogan et al. (2001) has some limitations with the use of GIS, wherein GIS analysis could be used to determine where to locate intermodal facilities to get the maximum benefit of the current freight flow. Combining different attributes, such as minimum time and minimum impact can improve decision-making and lead to more economically viable solutions. Grossardt et al. (2015) developed a GIS-based model using data on freight movements. This model can test the networks by trying to improve freight movement along corridors. However, basic average unit price for shipments using rail and road networks were not analyzed.

In order to address some of the limitations discussed above, a comprehensive Life-Cycle Cost Analysis (LCCA) model and framework for this thesis has been conducted on freight transportation in the Arabian Gulf area. The uniqueness of this area is that the countries' boundaries are closed for most of the daytime periods, which will affect decision-making on transport processes in specific ways. Moreover, unlike other studies, total life-cycle cost will be 
included in this thesis for both trucking and railway systems. Frameworks will be developed and analyzed using GIS, which will prove to be an efficient tool for optimization and design system strategies in future. 


\section{Chapter: Development of Life-Cycle Analysis Framework}

\subsection{Introduction}

In order to achieve this thesis' core objectives of identifying the most viable and reliable form of land transportation as well as creating a tool for design and strategies, a Life-Cycle Cost Analysis (LCCA) framework has been developed. LCCA can aid in informing decision-making and as well as shape the implementation of policies and regulations promoting sustainable development and service delivery. Several different factors were included in a LCCA framework in this body of work to evaluate the results. The framework parameters for each mode of freight transport has been considered, and for this thesis, not only direct and indirect costs will be included, but also environmental effects and border delays, which can have a significant impact on the final decision of mode selection. ModelBuilder as a visual programming language has also been used to run multiple geo-processing tools along with their various parameters to develop a LCCA GIS model. Moreover, Python scripts were also used to help in finding the model errors, which can be run from outside of ArcGIS. Figure 3 shows the LCCA framework that has been implemented and to be considered for LCCA model analysis and calculations. The following sections will discuss the framework and its parameters in detail. 

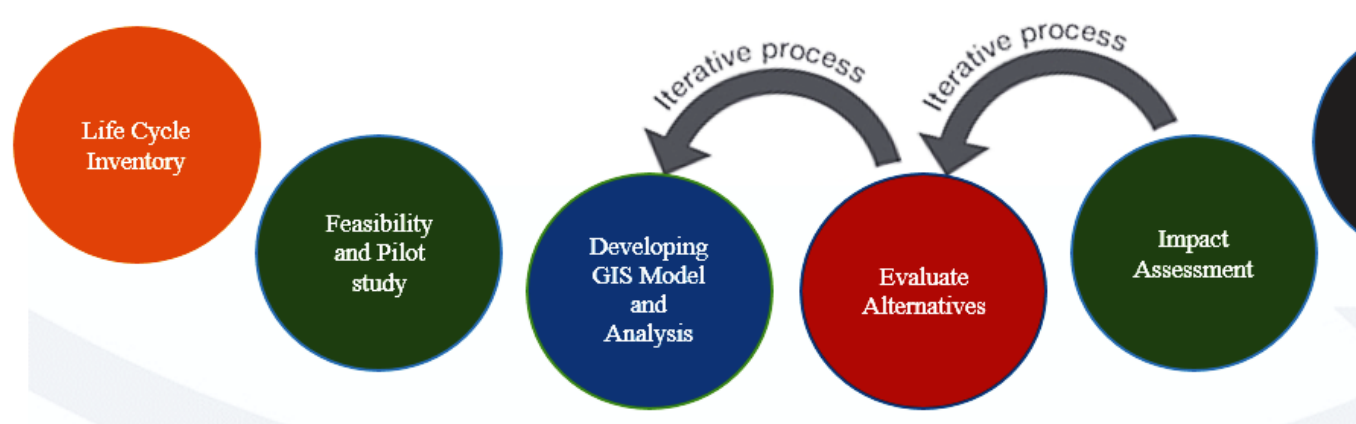

Figure 3 Life-Cycle Cost Analysis (LCCA) Framework.

\subsection{Life Cycle Inventory}

As significant contributors of economic development and trade, rail and road have their own differing needs and costs attached to them as mode choices. These costs and needs vary depending on several factors such as distance of transportation, bulkiness of commodities and the final destination of the goods. Side effects should also be considered since each mode has some side effects to society and potential greater effects to the world at large. For example, noise pollution is more common with rail and air congestion is more common with road transport. Pollution collectively affects the world at large through increasing occurrences of natural disasters as a consequence of global warming. These factors are collectively termed as impact costs. In general, when it comes to comparing road and rail as two modes of transportation, each has its own successes and drawbacks. This section of this thesis presents the inputs to the framework considered for each mode of transport.

\subsubsection{Freight Direct Costs}

The first type of direct cost is the infrastructure costs, which cover capital and maintenance 
expenses that are related to constructing and maintaining road and rail track networks. It should be mentioned that infrastructure maintenance cost for railway systems includes the costs of periodic surveillance of the tracks and line, inspection and verification of the railway system components, as well as corrections and repairs to the railway systems. Figure 4 shows an example of the surveillance system that is in use by the Saudi Railways Organization (SRO) that can monitor rail track conditions 24/7. While there are other components that contribute to the efficiency of a transport organization such as SRO, their specific surveillance strategy not only contributes to a broader understanding of maintenance costs, but this strategy also deals with assessing risk, security and safety issues that were touched on earlier.

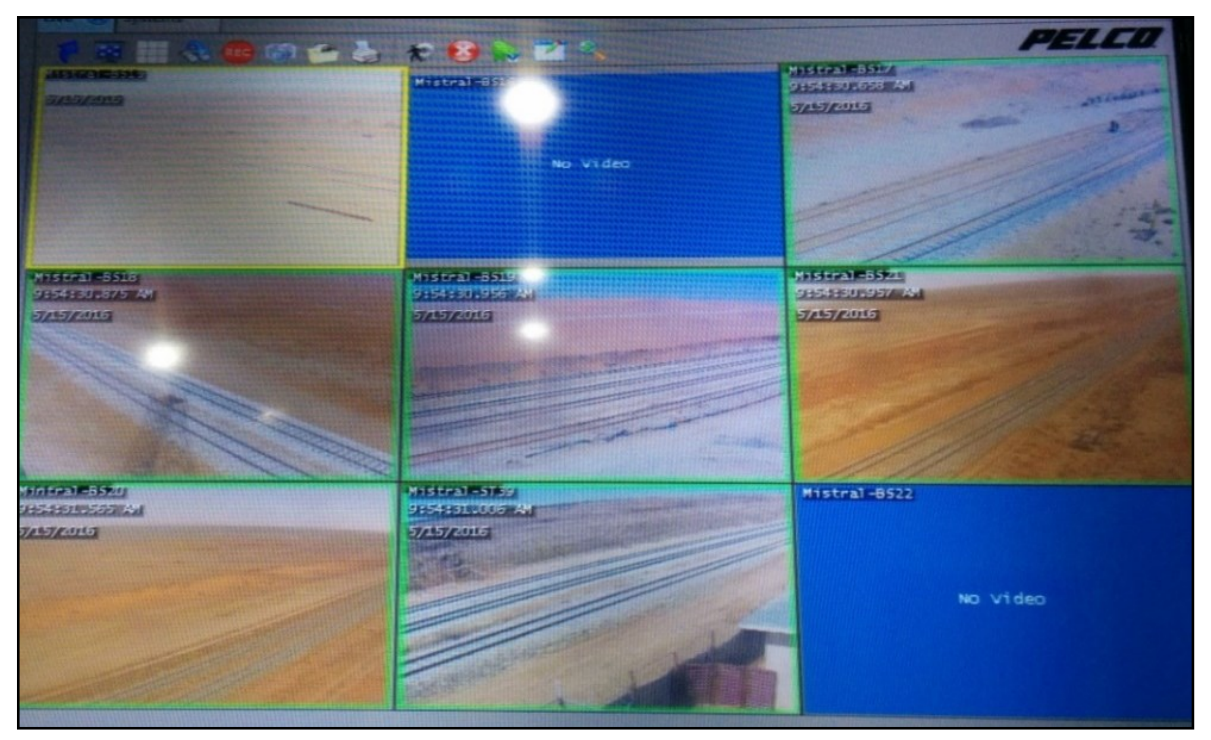

Figure 4 Surveillance systems for rail tracks in Saudi Arabia. Taken by Author.

The second direct cost is the freight systems' capital costs that include trucks, road infrastructure, rail tracks, rolling stock and locomotive costs. There are different types of trucks and wagons that can be used based on the type of commodities being transported. As in the case with trucks, rail wagons also vary based on the types of shipment weights and type of commodity. There are strong shipping weight restrictions for road transport for security and safety reasons. 
Unlike trucking systems, railways are free to go up to 80 tons of payload per wagon.

Figures 5, 6 and 7 show examples of the common types of trucks used for shipping worldwide (Taken by Author). For example, a normal container and curtain side trucks can be used for all types of dry and general cargo, while reefer trucks are used when the temperature needs to be controlled. Each one has different specifications and payload value.

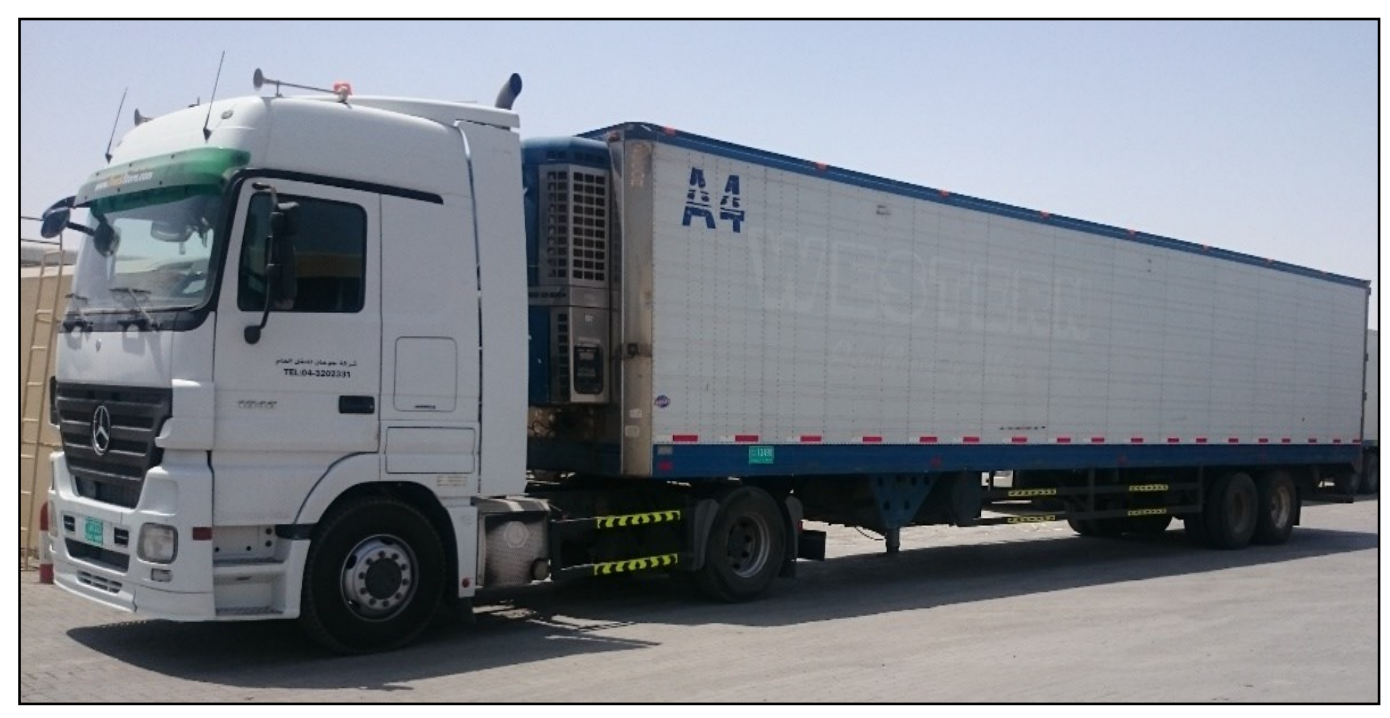

Figure 5 40-foot container shipping truck.

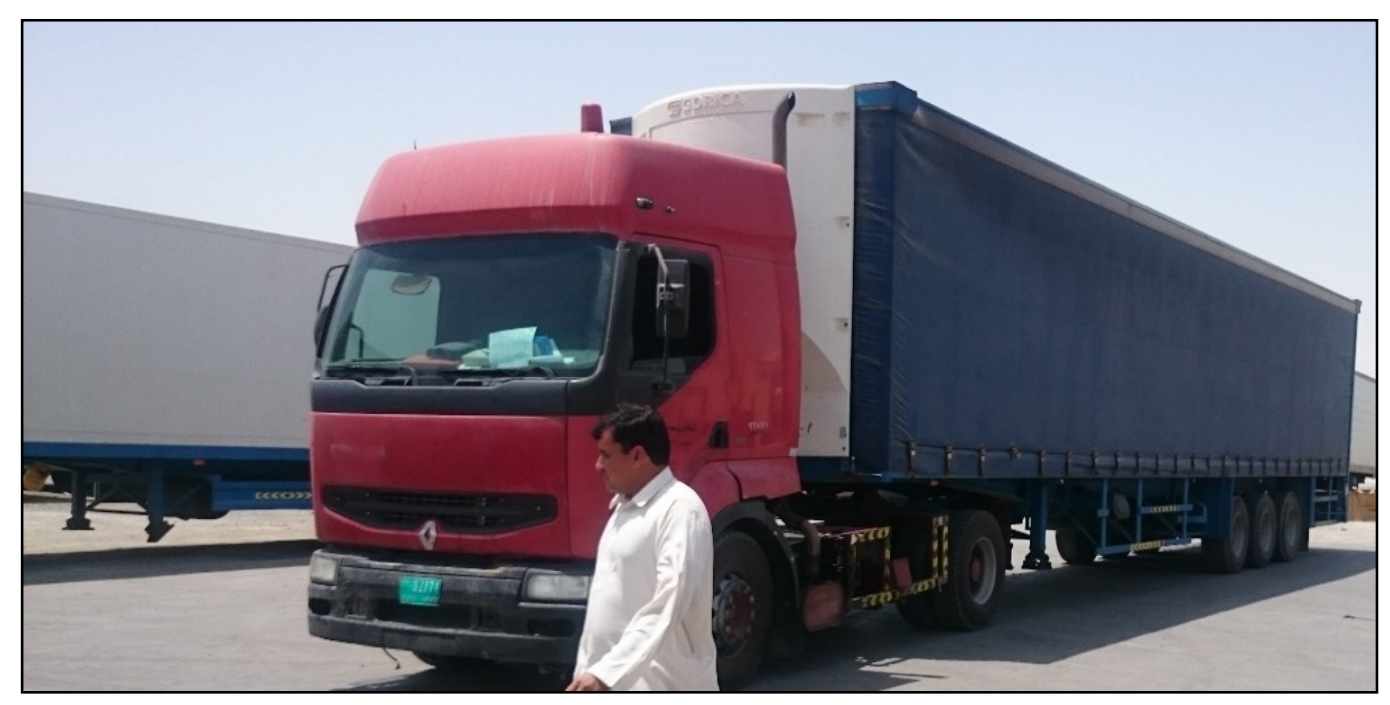

Figure 6 Curtain side shipping truck. 


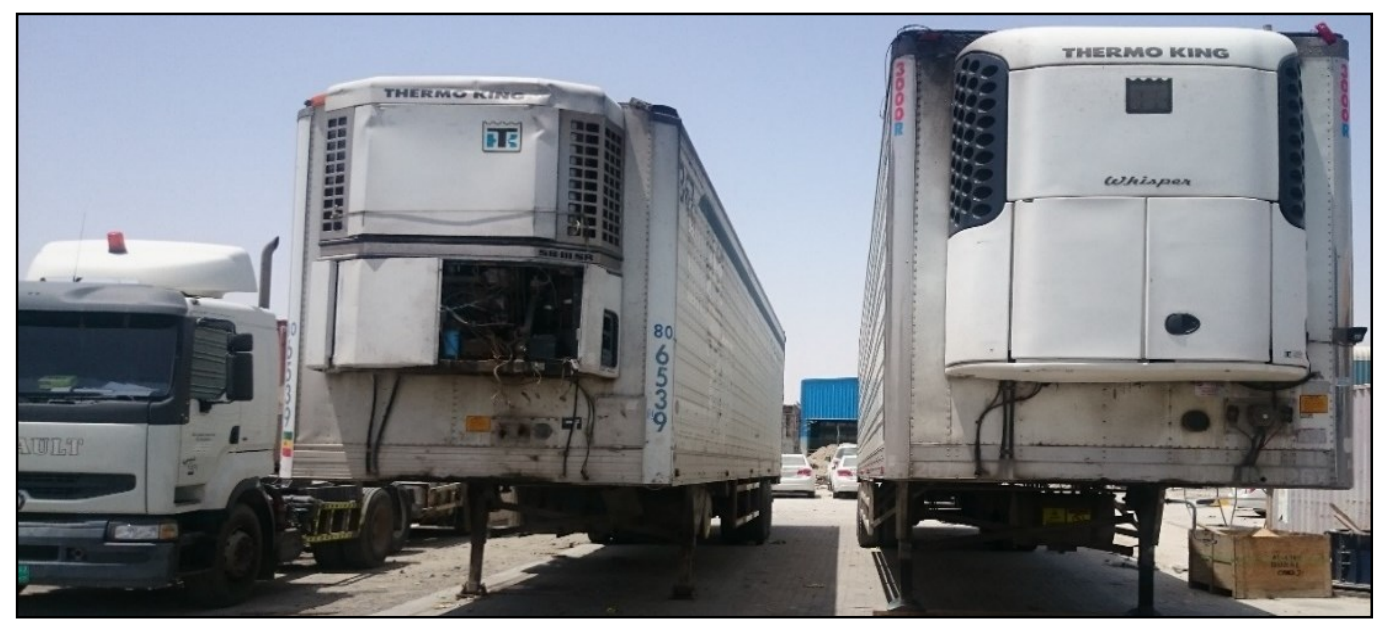

Figure 7 Reefer shipping truck.

Figures 8, 9 and 10 show the different types of rail wagons that are typically used worldwide (Taken by Author).

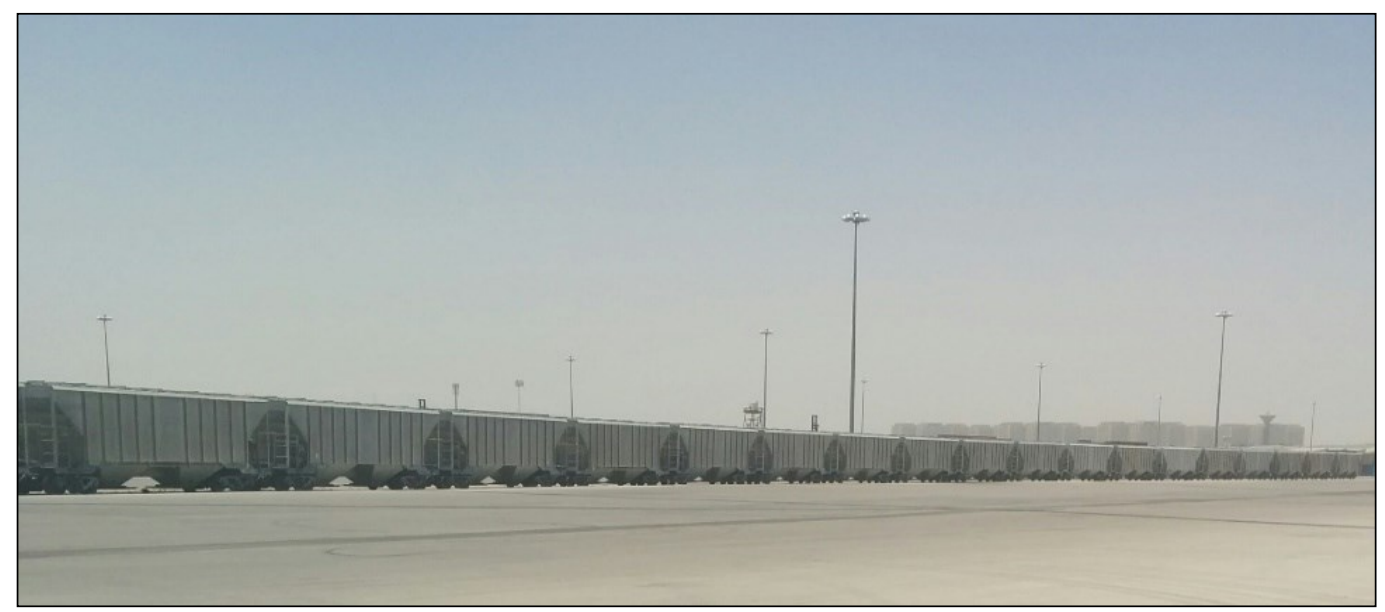

Figure 8 Open top hoppers rail wagons. 


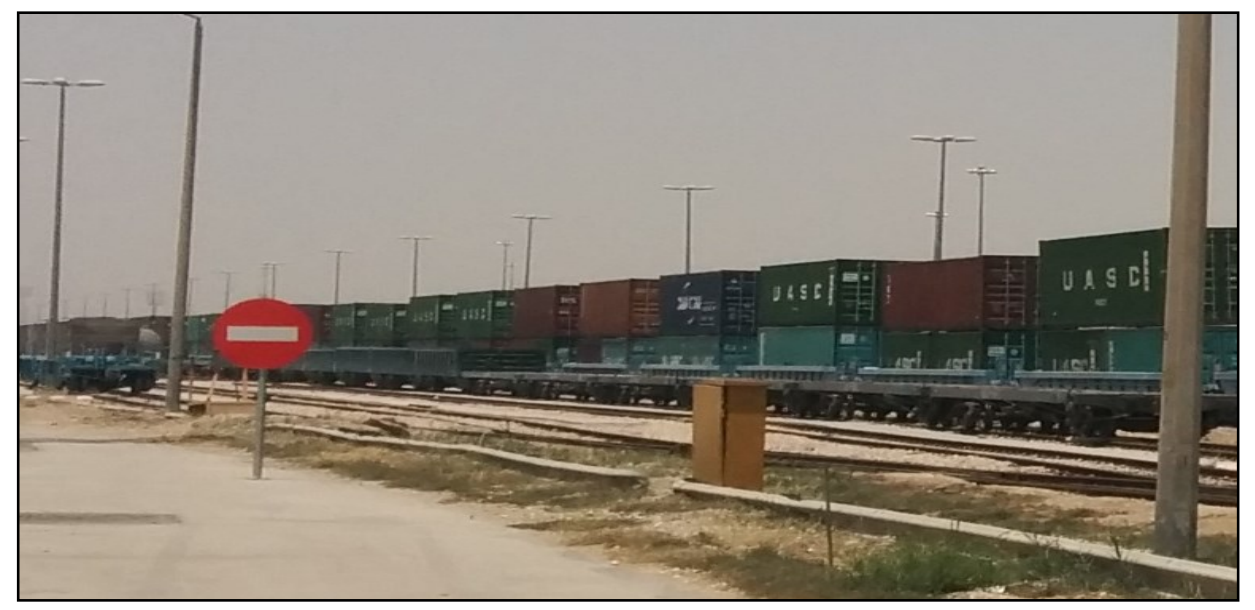

Figure 9 Flat deck rail wagons.

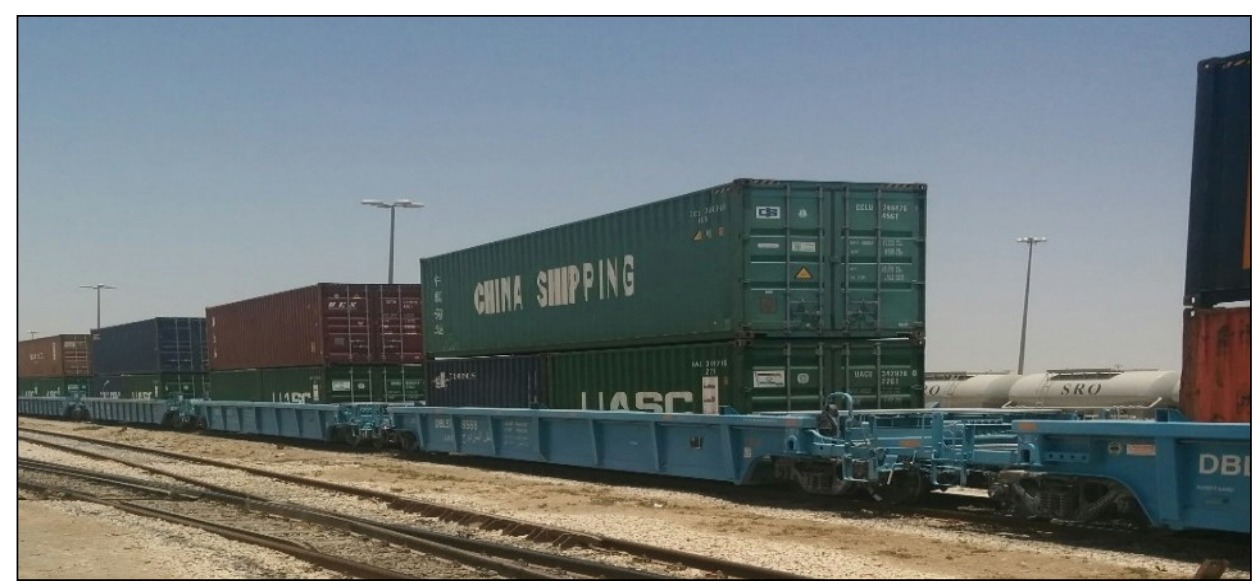

Figure 10 Double stack container flat rail wagons.

As for rail, locomotive and wagon prices need to be considered when estimating shipping cost, and the price of locomotives also varies based on efficiency and horsepower. Finally, when selecting between various transportation modes, consideration of operational and maintenance costs is essential. This part of costs includes fuel, labor, truck/rolling stock maintenance and repair costs. Operation usually depends on the fuel price in each country and average wages as well. All that said, operational and maintenance costs are subject to variability in terms of origins and destinations. 


\subsubsection{Freight Indirect Costs}

Moving commodities by elevating cargo containers onto a rail wagon or a shipping truck and moving it to its destination require specific handling processes, which play a role in loading and unloading shipments. Costs of loading and unloading vary based on the weight and the type of commodity being shipped. Shipping mode, warehouse locations and the equipment used are central components when it comes to loading and unloading processes for goods. Table 1 below lays out the use of a diesel forklift for loading and unloading with the average efficiency (minutes/unit).

Table 1 Average efficiency (minutes/unit) of loading and unloading for rail and truck shipping modes, KalleKarttunen et al, 2013.

\begin{tabular}{|c|c|c|}
\hline \multirow{2}{*}{ Transportation option } & \multicolumn{2}{c|}{ Efficiency, minutes/unit } \\
\cline { 2 - 3 } & Loading (min-max) & Unloading (min-max) \\
\hline \multicolumn{3}{|c|}{ Truck Transport } \\
\hline Container truck \\
\multicolumn{2}{|c|}{$50-80 /$ truck } & $25-35 /$ truck \\
\hline Intermodal Container & Railway Transport & $5-7 /$ container \\
\hline
\end{tabular}

Another indirect cost considered in moving cargo is depreciation. Depreciation is a term used in economics when an asset loses its value over time. The depreciation of assets must also be considered while evaluating the life-cycle cost of transportation. Improving maintenance (thereby reducing depreciation rates) can extend the useful life of an asset, but the cost of maintaining an asset subsequently increases over time (Railway Reform, 2011). As per Storchmann (2004), the 
depreciation rate usually depends on the automobile age, usage and the relative price of a new asset to the cost of repairs. Several studies and different models have been conducted on estimating the depreciation cost of automobiles and railway systems in the last two decades. In conclusion, depreciation must be evaluated regularly to know the true value of assets, to ensure that shipping business ventures are worthwhile continuing and that all expenses can be recovered.

In addition to depreciation, handling, loading and unloading cost, the LCCA needs to consider border delays as an indirect cost, which is a major issue that can differ based on shipment routes. Some regions are restricted by lessened flexibility of border crossings, which happens to be the case in several of the GCC countries, and this will be elaborated on further in this chapter.

\subsubsection{Freight Impact Costs}

Noise, vibration, and emissions are three of the main environmental impacts of freight transport. The effect of noise and vibration depends on how close road and railway systems are to adjacent populated areas, and also the population distribution around roads and highways. As per Le Maitre (2015), the level of noise is a function of traffic volume, distance to the noise, percentage of trucks, road and track conditions and noise barrier effectiveness. These issues can negatively impact health, which can include symptoms such as: headaches, sleep disturbance, hearing impairment and stresses that can arise from damage to personal property. Noise can be generated from wheel interfacing, horns and bells. Several factors can affect noise and vibration intensity such as the traffic volume, the distance from the noise source, the type of locomotive and horns, number of trains per day and the length of the train.

In general, sound levels between 30-50 dBA in calm environments are considered normal, while those above $70 \mathrm{dBA}$ can be disruptive. It has been estimated that train traffic generates about 
$82 \mathrm{dBA}$ at a $15 \mathrm{~m}$ distance from the centerline of the track (Abu Dhabi Municipality, 2012). Figure 11 shows the noise source path receiver frameworks, while Figure 12 shows the effects of prolonged exposure for different noise levels as per the Occupational Safety and Health Administration (OSHA).

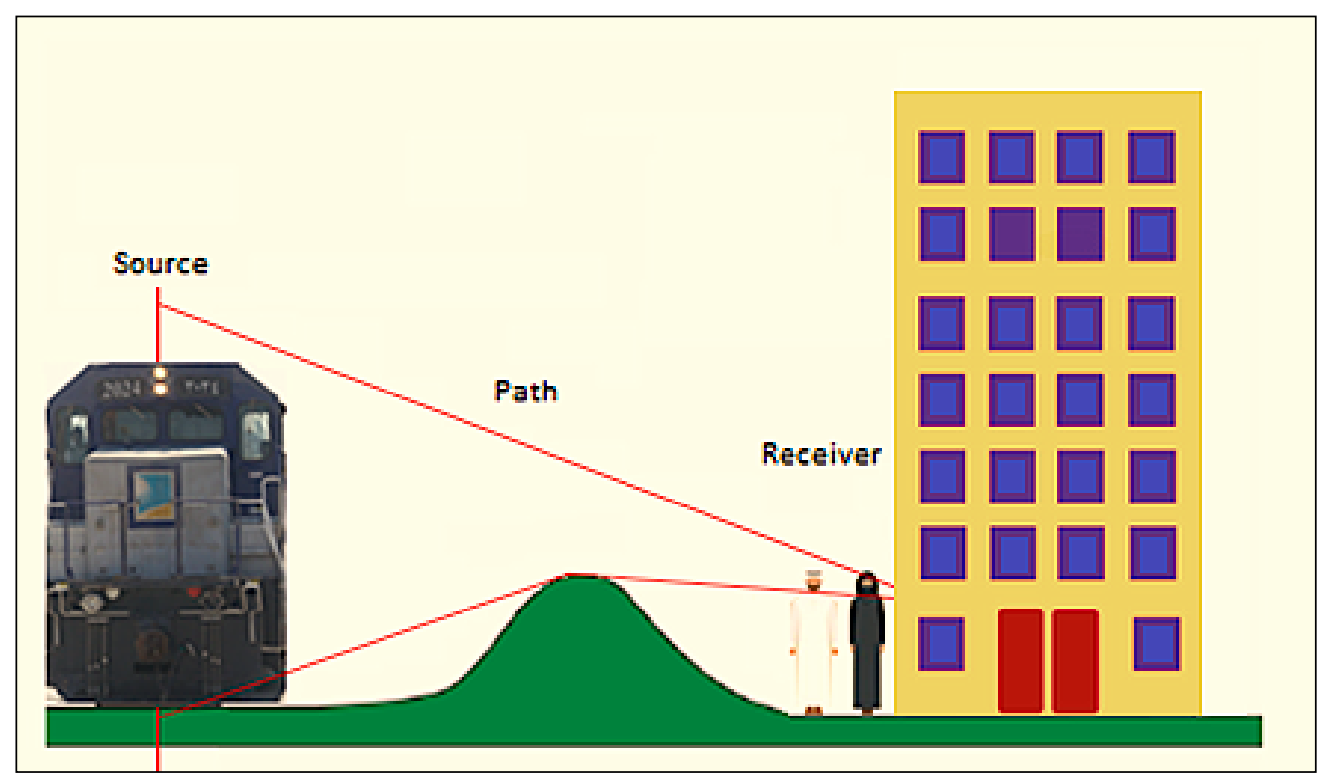

Figure 11 Noise source path receiver frameworks Abu Dhabi Municipality, 2012.

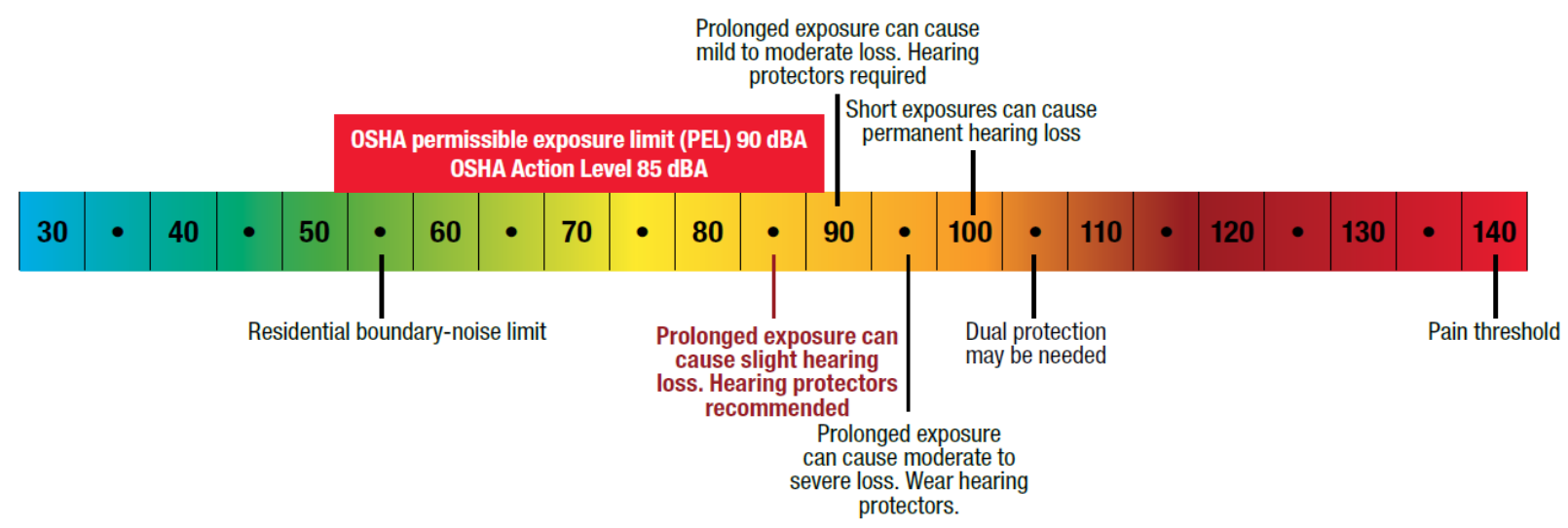

Figure 12 Effects of prolonged exposure for different noise level, Occupational Safety and Health

Administration, 2015. 
Vibration can also regenerate noise when a train travels along a railway creating an energy that can propagate through the intervening soil and into buildings in the adjacent vicinity. Vibrations need to be considered before finalizing the corridor routes and alignment because there is significant variance from site to site. In relation to cost, it has been reported that it is difficult to quantify the marginal cost of noise and vibration. As per the Committee for Study of Public Policy for Surface Freight Transportation (within the U.S. National Research Council), noise cost can be assumed to be zero in rural areas. As a result, urban distances have only been considered in calculating noise factors.

As a third factor, emissions have increased proportionally with the growth of freight transportation usage. Table 2 shows the emission percentages produced of using both trucking and railway systems.

Table 2 Unit pollutant emission for freight trains and trucking freight systems, Transport Research Laboratory, 2001.

\begin{tabular}{|c|c|c|}
\hline \multirow{2}{*}{ Pollutants } & Freight Train & Freight Truck \\
\cline { 2 - 3 } & \multicolumn{2}{|c|}{ g/ton.km } \\
\hline $\mathrm{CO}_{2}$ & 38.296 & 72 \\
\hline NOx & 0.834 & 1.1 \\
\hline $\mathrm{CO}$ & 0.148 & 1.5 \\
\hline $\mathrm{PM} 10$ & 0.018 & 0.1 \\
\hline $\mathrm{HC}$ & 0.039 & 0.15 \\
\hline
\end{tabular}

It is clear from the above table that pollution emitted by truck is higher than a rail system, which can cause significant environmental damages. About $27 \%$ of greenhouse gas emissions are 
a result of transportation systems as shown in Figure 13 (Environmental Protection Agency-EPA, 2013). There are various components of greenhouse gas emissions resulting from road and railway shipping transport, including the major direct greenhouse gas emission, which is $\mathrm{CO}_{2}$. Emissions of $\mathrm{CO}_{2}$ are directly related to the amount of fuel used to operate vehicles or locomotives. Emissions of other gases have a small contribution to the total emissions of greenhouse gases.

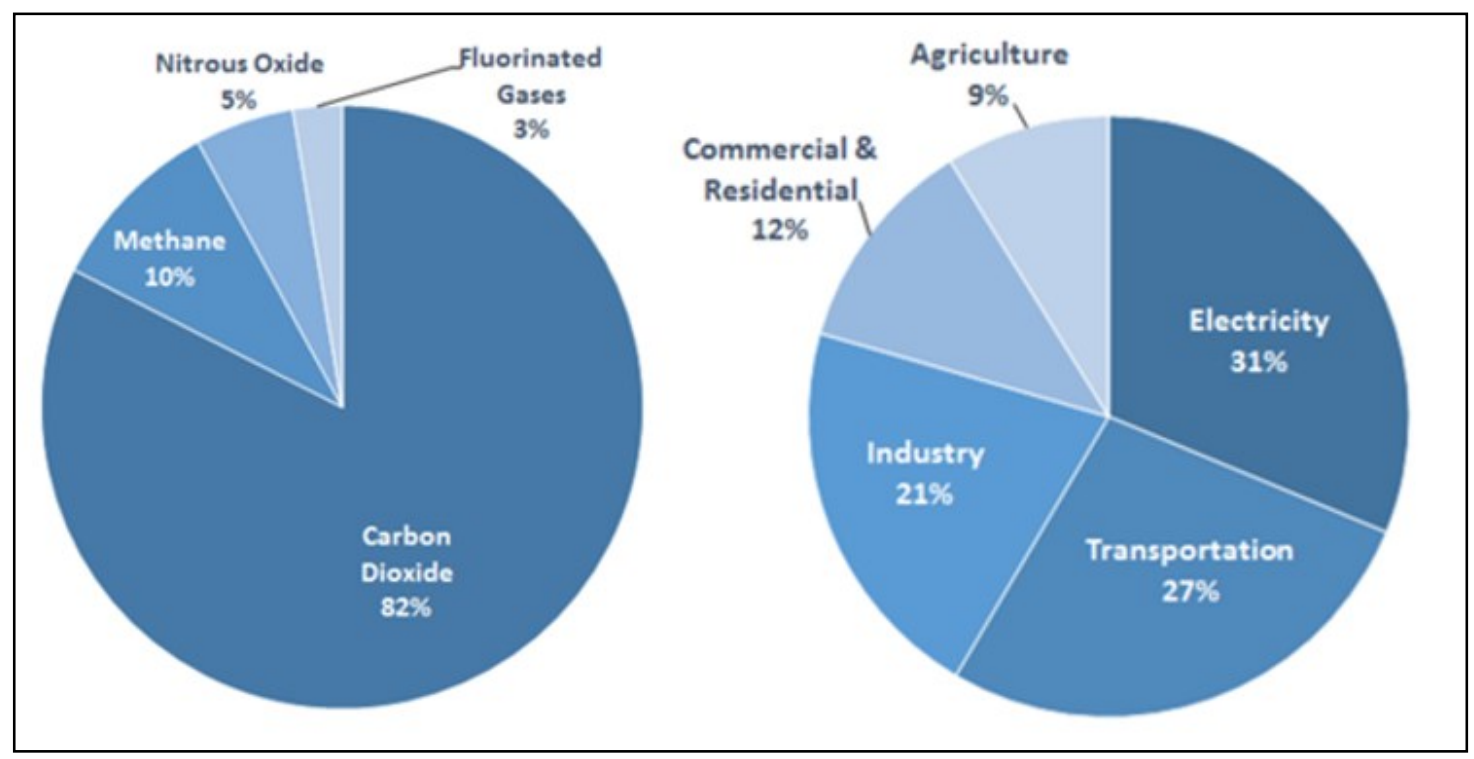

Figure 13 U.S. greenhouse gas emission, Environmental Protection Agency, 2013.

Emissions have two distinct impacts at local and global levels. At the local level, they are a source of air pollution, thereby reducing air quality. While at the global level, they can contribute to climate change. Both local and global level air pollution can result in the deterioration in human health, damage to property, declines in crops and agricultural production as well as other economic impacts as shown in Table 3. 
Table 3 Greenhouse Gas Emission local and global Impacts, Environment and Climate Change Canada, 2017.

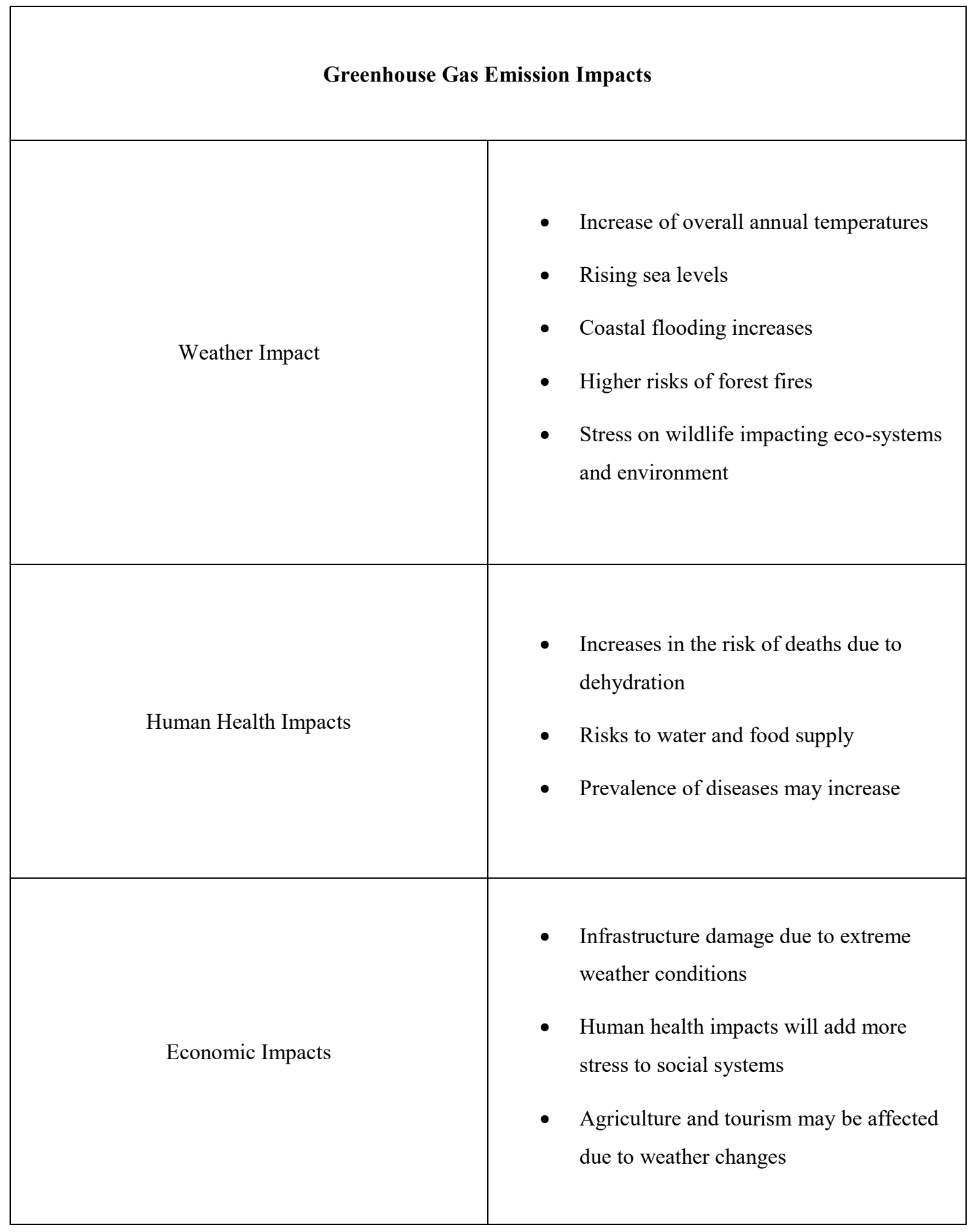


Figure 14 shows the percentage of $\mathrm{CO}_{2}$ per capita in 2014 for all regions in the world. Countries that have a very high percentage of $\mathrm{CO}_{2}$ per capita are required to consider this as a major issue requiring as much resolution as possible and to plan for reductions when implementing future transportation plans and mode selection.

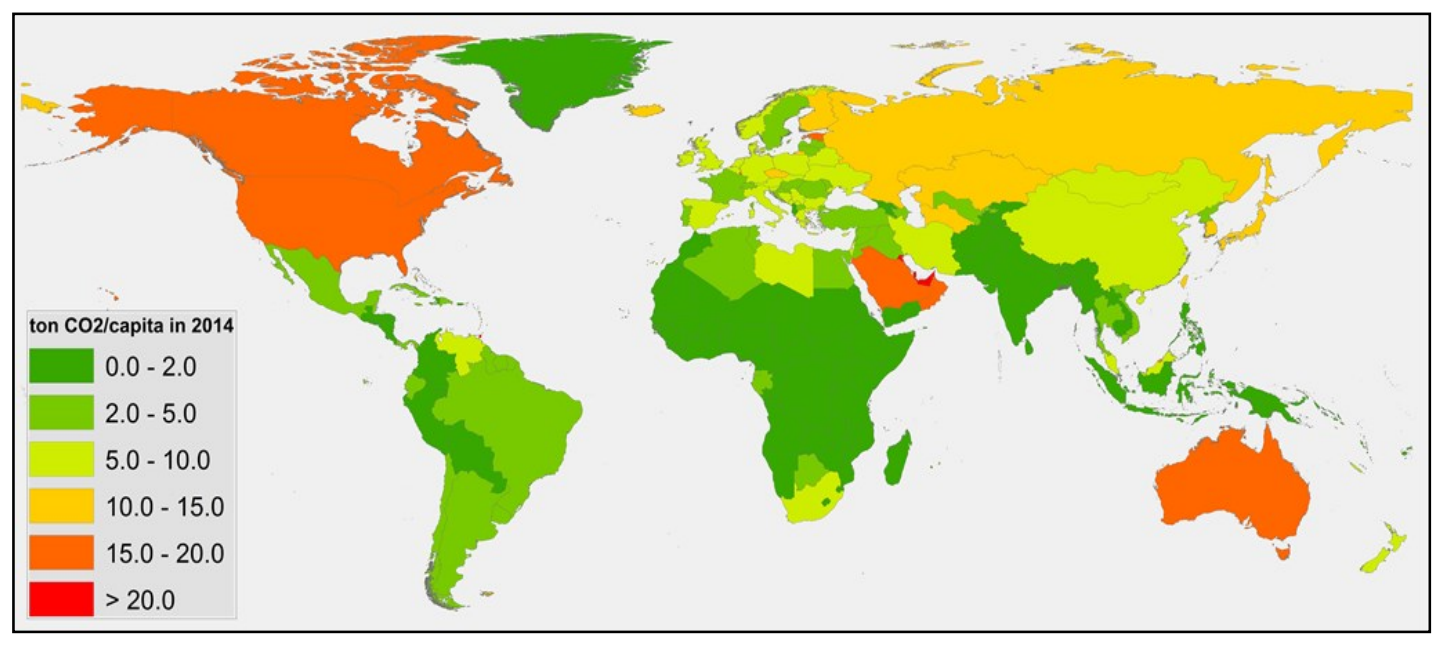

Figure 14 CO2 time series 1990-2014 per capita for world region/country, Emissions Database for Global Atmospheric Research, 1990-2014.

In comparing the two modes, trucks producing a higher amount of greenhouse gas emissions can carry serious issues, particularly in urbanized communities. Unlike trucks, rail has low emission rates, and encouraging modal shifts from truck to rail are encouraged because the environmental impacts can be reduced with such changes. That said, pollution as a concept is applicable to broad categories of outcomes, and costs can be estimated based on the amount of exposure to transport modes, regardless if the mode is truck, rail or otherwise (Victoria Transport Policy Institute, 2015). 
Another impact that needs to be considered in freight transport is accident costs. As per Osterhaudt (2002), accident costs can be quantified based on the number of injuries and fatalities of using that mode per year. Hazardous materials such as combustible liquids and flammable materials can cause further potential damage in the event of accidents, which can affect people and the spaces they inhabit. As a result, mitigation measures against risk need to include the application of stringent safety regulations in addition to sufficiently sealed and protected containers used to transport these materials.

\subsection{Feasibility and Pilot Study}

Since 1908, when the Ottoman Empire (Turkish Empire) decided to build the Hejaz Railway, it was expected that the economies of the Arabian Peninsula will continue to grow based on annual pilgrimages and other economic diversification. The decision of building the rail system was made to facilitate the transportation of people and military forces, and to improve the economic and political integration of the Arabian countries. In 1916, after the world war-I the rail line that ran from Damascus to Medina was destroyed and all plans to restore the line in the 1960s were not fulfilled.

Currently, due to the oil and petrochemical market in the region, tourism and other economic purposes, the GCC countries (Bahrain, Kuwait, Oman, Qatar, Saudi Arabia and the United Arab Emirates) in the Arabian region are likely to continue developing both within the countries themselves as well as with surrounding areas and the broader global community. The GCC area is therefore an ideal case study for examining transportation development. The sections below will describe some of the characteristics of the GCC area as well as considerations that should be taken into account with mode selection, mode shifts and overall development of 
transportation in the area. In order to offer further perspective on development in these countries, Table 4 shows the forecasted Gross Domestic Product (GDP) and populations of the GCC countries from 2001 up until 2015. 
Table 4 Forecast GDP and Population of the GCC countries, Abu Dhabi Municipality, 2012.

\begin{tabular}{|c|c|c|c|c|c|c|c|c|c|c|}
\hline Years & \multicolumn{2}{|c|}{2001} & \multicolumn{2}{|c|}{2002} & \multicolumn{2}{|c|}{2003} & \multicolumn{2}{|c|}{2004} & \multicolumn{2}{|c|}{2005} \\
\hline Country & $\begin{array}{l}\text { GDP } \\
\text { (US\$) }\end{array}$ & $\begin{array}{c}\text { Pop. } \\
\text { (Million) }\end{array}$ & $\begin{array}{l}\text { GDP } \\
\text { (US\$) }\end{array}$ & $\begin{array}{c}\text { Pop. } \\
\text { (Million) }\end{array}$ & $\begin{array}{l}\text { GDP } \\
\text { (US\$) }\end{array}$ & $\begin{array}{c}\text { Pop. } \\
\text { (Million) }\end{array}$ & $\begin{array}{l}\text { GDP } \\
\text { (US\$) }\end{array}$ & Pop. (Million) & $\begin{array}{l}\text { GDP } \\
\text { (US\$) }\end{array}$ & $\begin{array}{c}\text { Pop. } \\
\text { (Million) }\end{array}$ \\
\hline Bahrain & 13,807 & 0,910 & 14,529 & 0,934 & 15,569 & 0,958 & 16,436 & 0,983 & 17,722 & 1,007 \\
\hline Kuwait & 45,508 & 2,182 & 46861 & 2,261 & 53,293 & 2,325 & 57,147 & 2,390 & 61,148 & 2,457 \\
\hline Oman & 43,147 & 2,478 & 46384 & 2,538 & 47,577 & 2,341 & 48,532 & 2,416 & 51,140 & 2,509 \\
\hline Saudi Arabia & 391,073 & 20,887 & 395,049 & 21,386 & 402,391 & 21,887 & 407,387 & 22,390 & 416,535 & 22,896 \\
\hline UAE & 106,991 & 3,167 & 109,825 & 3,349 & 122,878 & 3,551 & 134,786 & 3,761 & 145,829 & 4,106 \\
\hline Qatar & 19,411 & 0,648 & 20,795 & 0,682 & 21,521 & 0,717 & 26,004 & 0,756 & 27,585 & 0,796 \\
\hline Years & \multicolumn{2}{|c|}{2006} & \multicolumn{2}{|c|}{2010} & \multicolumn{2}{|c|}{2015} & \multicolumn{2}{|c|}{2020} & \multicolumn{2}{|c|}{2025} \\
\hline Country & $\begin{array}{l}\text { GDP } \\
\text { (US\$) }\end{array}$ & $\begin{array}{c}\text { Pop. } \\
\text { (Million) }\end{array}$ & $\begin{array}{l}\text { GDP } \\
\text { (US\$) }\end{array}$ & $\begin{array}{c}\text { Pop. } \\
\text { (Million) }\end{array}$ & $\begin{array}{l}\text { GDP } \\
\text { (US\$) }\end{array}$ & $\begin{array}{c}\text { Pop. } \\
\text { (Million) }\end{array}$ & $\begin{array}{l}\text { GDP } \\
\text { (US\$) }\end{array}$ & Pop. (Million) & $\begin{array}{l}\text { GDP } \\
\text { (US\$) }\end{array}$ & $\begin{array}{c}\text { Pop. } \\
\text { (Million) }\end{array}$ \\
\hline Bahrain & 19,000 & 1,033 & 23,941 & 1,089 & 30,121 & 1,161 & 37,716 & 1,233 & 44,363 & 1,298 \\
\hline Kuwait & 65,000 & 2,754 & 80,056 & 3,047 & 106,876 & 3,404 & 140,900 & 3,711 & 170125 & 3,958 \\
\hline Oman & 53,000 & 2,577 & 60,233 & 2,928 & 70,235 & 3,415 & 80,909 & 3,934 & 92123 & 4,479 \\
\hline Saudi Arabia & 431,000 & 23,185 & 530,386 & 25,294 & 688,606 & 27,927 & 878,855 & 30,683 & $1,043,804$ & 33,710 \\
\hline UAE & 158,000 & 4,229 & 216,943 & 4,481 & 302,570 & 4,735 & 420,419 & 4,930 & 521,417 & 5,082 \\
\hline Qatar & 29,500 & 0,838 & 42351 & 1,144 & 56,245 & 1,545 & 70,765 & 1,945 & 86512 & 2,377 \\
\hline
\end{tabular}


Currently, the six GCC countries are connected with a road network as shown in Figure 15 (GIS-Snapshot by Author).

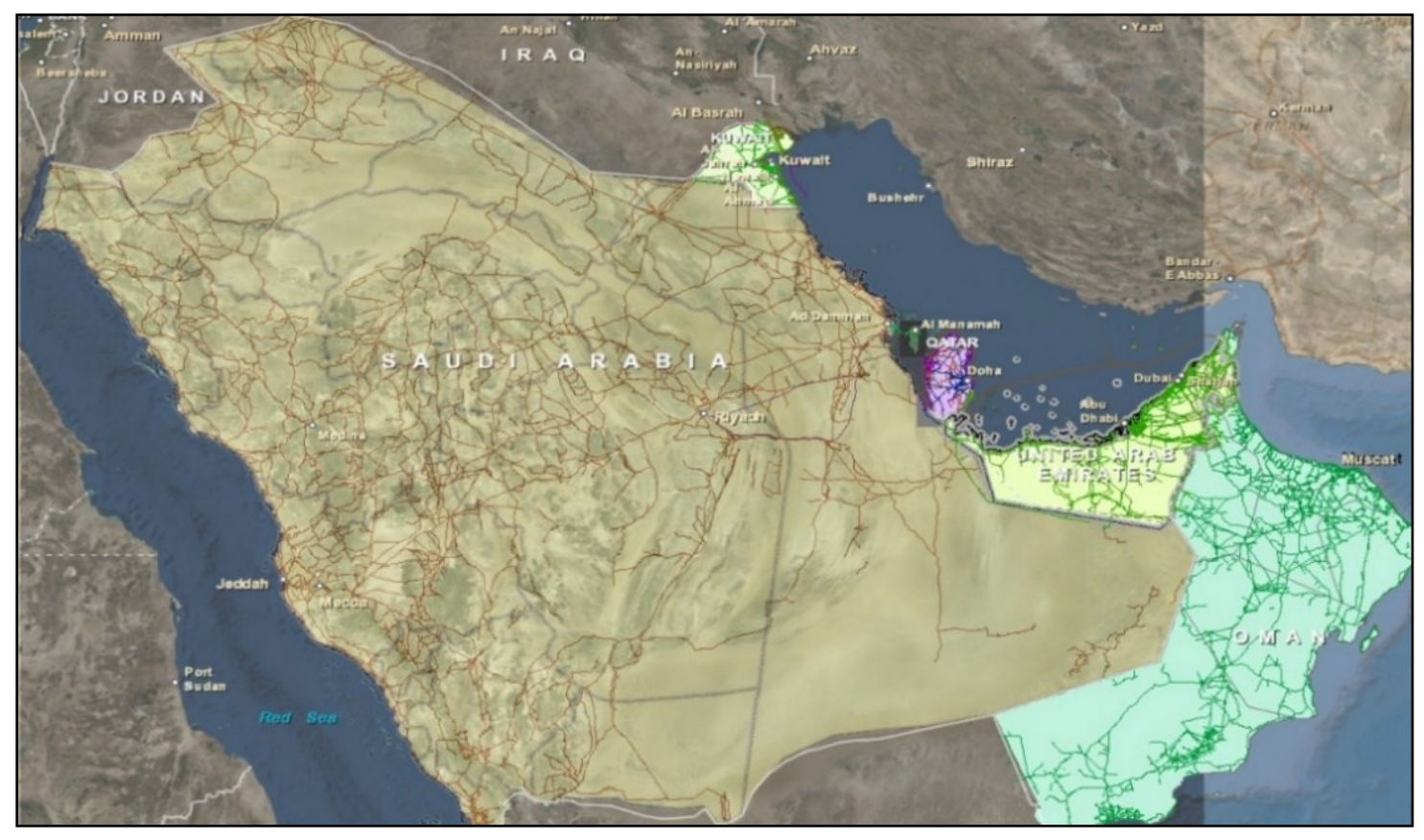

Figure 15 Existing road connections between the GCC countries, 2017.

There are well-developed highway transportation systems connecting the region's countries, but in terms of railway systems, the establishment of further efforts can have positive outcomes for users, consumers, the environment, safety and overall costs.

It was found that in 2006, around 50 million tons of commodities were transported in and out of the GCC area. This consisted of petroleum products transported by pipelines, including items such as mineral oils, cement, lime, raw materials (such as iron ores, gravel, stone, steel, and aluminum), foodstuffs and other consumer products that can be transported by land or sea. Table 5 shows the annual amount of import and export tonnage within the GCC countries in 2006. 
Table 5 Import/Export tonnage between the GCC Countries (x000) tons, Abu Dhabi Municipality, 2006.

\begin{tabular}{|c|c|c|c|c|c|c|c|}
\hline Qrom & Qatar & Kuwait & Bahrain & UAE & KSA & Oman & TOTAL \\
\hline Kuwait & 20 & - & 32 & 22,777 & 1,696 & 52 & 24,577 \\
\hline Bahrain & 55 & 160 & - & 3,391 & 1,060 & 3 & 4,669 \\
\hline UAE & 436 & 233 & 461 & - & 3,212 & 515 & 4,857 \\
\hline KSA & 436 & 460 & 2,147 & 1,729 & - & 244 & 5,016 \\
\hline Oman & 25 & 81 & 232 & 940 & 367 & - & 1,645 \\
\hline TOTAL & 972 & 977 & 2,990 & 39,849 & 7,214 & 964 & 52,964 \\
\hline
\end{tabular}

The numbers in the table above demonstrate a necessity to have other freight alternative modes such as railway lines to meet future challenges and to develop a complete transportation system because current modes are struggling to satisfy current needs and meet future demands. Alternative modes should be taken into consideration, where: rail routes are connected with port terminals and intermodal yards that have an easy access point, there is acknowledgement of geographical and geological characteristics, and where environmental impacts, rules and regulations in the Gulf area are incorporated. Table 6 summarizes an overview of the key characteristics of ground transportation of leading countries compared with UAE and Saudi Arabia, where high variation in these characteristics can be observed. 
Table 6 Comparison of the Key Characteristics of Leading Countries Compared to UAE and Saudi Arabia, Etihad Rail, 2014.

\begin{tabular}{|c|c|c|c|c|c|c|}
\hline & Australia & Sweden & Switzerland & $\begin{array}{c}\text { United } \\
\text { Kingdom }\end{array}$ & UAE & $\begin{array}{c}\text { Saudi } \\
\text { Arabia }\end{array}$ \\
\hline $\begin{array}{c}\text { Population } \\
\text { (Million) }\end{array}$ & 22.3 & 9.1 & 8.0 & 63.4 & 5.5 & 26.9 \\
\hline $\begin{array}{c}\text { Area } \\
\text { (Sq.-km) }\end{array}$ & $7,700,000$ & 450,000 & 41,000 & 240,000 & 84,000 & $2,100,000$ \\
\hline $\begin{array}{c}\text { Roadway length } \\
\text { (km) }\end{array}$ & 360,000 & 570,000 & 71,000 & 390,000 & 4,000 & 48,000 \\
\hline $\begin{array}{c}\text { Expressway } \\
\text { length (km) }\end{array}$ & 20,000 & 1,900 & 1,800 & 3,500 & 3,500 & 3,900 \\
\hline $\begin{array}{c}\text { Rail route } \\
\text { length (km) }\end{array}$ & 38,000 & 13,000 & 5,000 & 16,000 & 220 \\
\hline
\end{tabular}

Although trucking is most widely used, conditions of some highways between GCC countries are poor, and this is compounded by other impacts, therefore requiring a shift in the load of traffic to GCC railways. Figure 16 provides a visual depiction of what this shift to rail would look like, which includes current and future freight railway systems connecting these countries. 


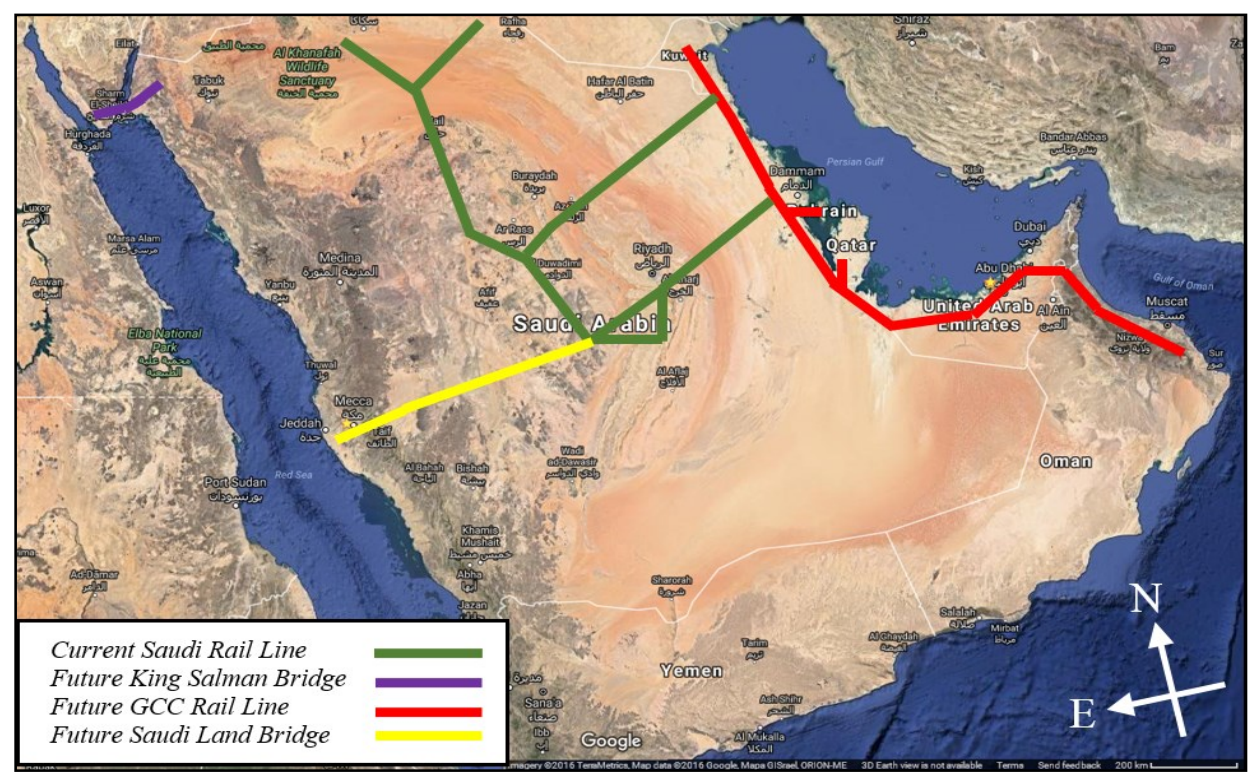

Figure 16 Current and future rail freight lines and land bridges at the GCC region, modified from Google maps, 2017.

In addition to existing connections between GCC countries via express highways and the current Saudi rail line, various studies have been proposed to connect all six GCC countries and as well as connecting Asia and Africa using a rail system across Saudi Arabia's Tiran and Sanafir Islands as shown in Figure 16. The green line belongs to the Saudi Railways Organization (SRO), and the yellow line represents the future land bridge connecting the eastern and western areas of the country. The red line represents the future GCC corridor that is planned to be connected with the Saudi Freight rail lines as a means to improve the total economy of the Gulf area. Figure 17 also shows part of the current rail line in Saudi Arabia for visual context. Beyond simply connecting the rail network and building rail infrastructure, freight yards that can be used for storing, loading and unloading also need to be considered as a part of the network for future freight and logistics needs. In increasing the use of freight yards, it is imperative for safety 
measures to be considered when handling dangerous material to avoid accidents such as fires and explosions.

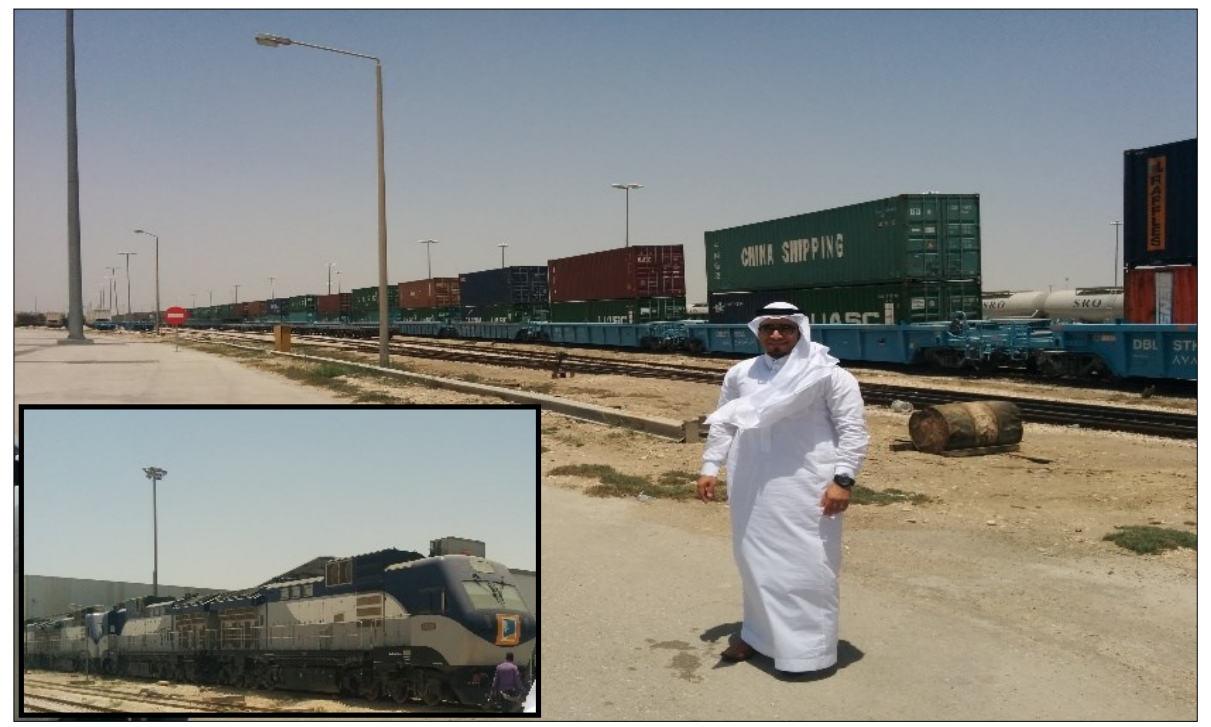

Figure 17 Part of the current freight rail line in Saudi Arabia, 2017. Taken by Author.

Saudi Arabia is the largest country within the GCC area, and in addition to the road network that is connected to all GCC counties, it has a rail freight network for goods movement connecting the central region of the country with the Arabian Gulf coast, beside the recent North-South lines that are known as the phosphate lines. The current market is not well-managed due to the absence of a life-cycle cost analysis used as a basis for shipping. Although local government agencies sometimes support local freight transport, foreign truck companies still offer lower prices for shipping goods. There is the potential for many violations to be incurred by local carriers such as overloading and long driving hours, which will affect local shipping businesses.

Truck overloading is a major issue when it comes to road shipping, and this is particularly observable in the GCC area. Although truck weight limits are enforced by police services, some shippers still do not follow the appropriate rules and regulations. This type of decision-making can 
impact roads, causing damages and creating potential for serious accidents as shown in Figure 18.

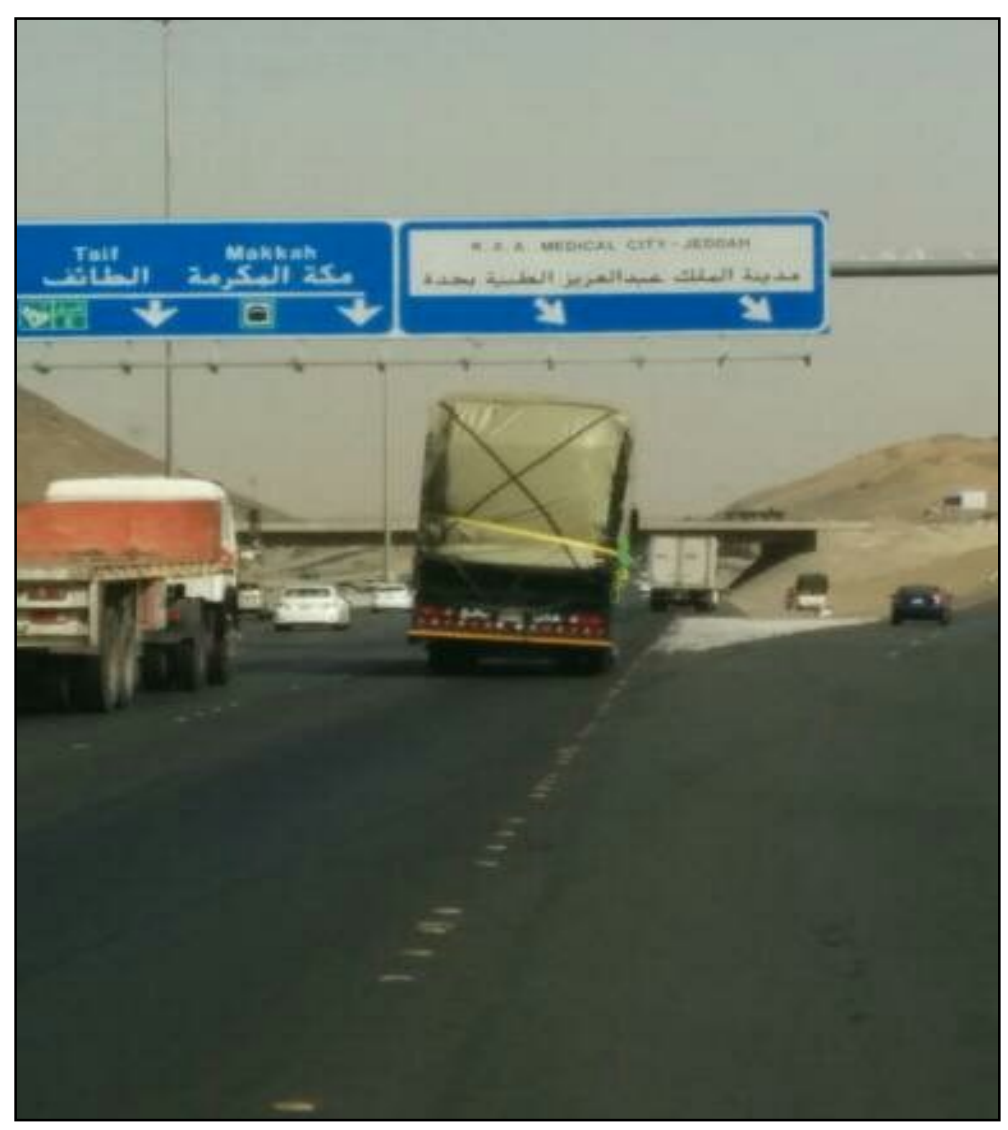

Figure 18 Truck overloading in Saudi Arabia. Taken by Author.

A report by Abu Dhabi municipalities shows that approximately $80 \%$ of 6-axle trucks in the UAE exceed a potential Gross Vehicle Weight (GVW) limit of 23 tons. Violations of this regulation can cause severe road damage as shown in Figure 19, and such damage demonstrates the increased risk of damage when road is selected over a railway system. 


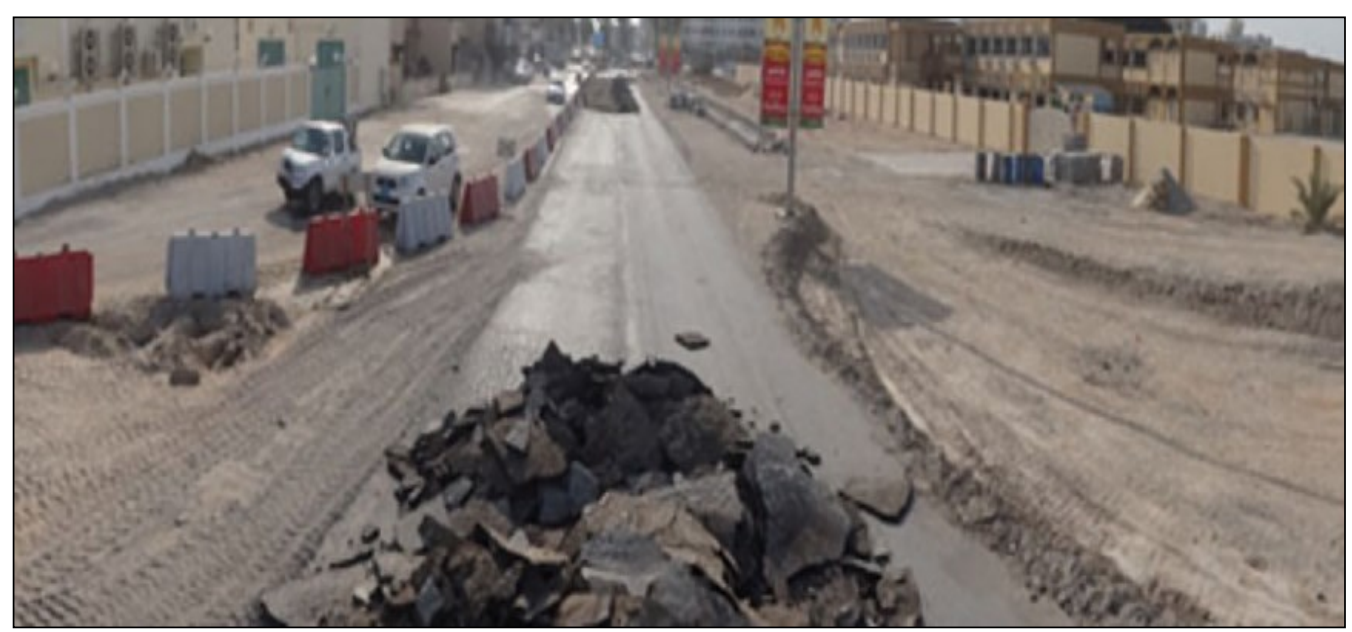

Figure 19 Road damage caused by overloaded trucks in UAE, Abu Dhabi Municipality, 2012.

In Saudi Arabia, weight restrictions have been in place for quite some time, so all trucks crossing the border to and from any of the GCC countries need to adhere to Saudi weight restrictions regardless of the weight they can carry within their own region. Weighbridges on highways and between cities are useful in monitoring truck weights as a means to minimize the impacts of trucking systems on roads. From the shippers' perspective, overloading can reduce a truck's mileage because more trucks are subsequently required to carry the same volume. The cost of following regulations by adding new trucks needs be considered in the mode selection analysis in order to shift from road to rail.

Long driving hours are also a key concern that can affect road safety in Saudi Arabia and GCC countries. As with most modern countries in the world, European Union countries have some restrictions when it comes to drivers' hours for truck users. Table 7 illustrates the period of rest that is required between daily and weekly driving limits in EU countries. However, in the GCC countries, drivers are paid based on the number of trips or volume they can deliver. So, the lack of appropriate driving monitoring systems on each truck allows drivers in GCC counties to drive 
beyond recommended levels in order to increase their income.

Table 7 European Union driver regulations, Abu Dhabi Municipality, 2014.

\begin{tabular}{|c|c|}
\hline Breaks from driving & $\begin{array}{l}\text { A break of at least } 45 \text { minutes must be taken after more than } 4.5 \\
\text { hours of driving }\end{array}$ \\
\hline Daily driving & $\begin{array}{l}\text { A maximum of } 9 \text { hours, extendable to } 10 \text { hours no more than } \\
\text { twice a week }\end{array}$ \\
\hline Weekly driving & Maximum of 56 hours \\
\hline Bi-weekly driving & Maximum of 90 hours in any two-week period \\
\hline Daily rest & $\begin{array}{l}\text { Minimum of } 11 \text { hours, which can be reduced to minimum of } 9 \\
\text { hours no more than three times between weekly rest }\end{array}$ \\
\hline Weekly rest & $\begin{array}{l}\text { A regular weekly rest of at least } 45 \text { hours, to be started no later } \\
\text { than the end of six consecutive } 24 \text {-hour periods from the end of } \\
\text { the last weekly rest }\end{array}$ \\
\hline
\end{tabular}

In Saudi Arabia, the government is responsible for the payment of costs associated with the construction of roads as well as required operation and maintenance. There are no taxes or funds to be collected from shippers that are related to usage of their trucks and the subsequent impact to roads. The UAE started imposing road tolls for road users as shown in Figure 20 in order to collect funds. Such a system is considered a good method of addressing some externalities of road transport as well as generating revenues to cover infrastructure and maintenance 
requirements. Imposing a differentiated toll on cars and trucks across major roads will also likely be beneficial to create more sustainable transport systems in the GCC area.

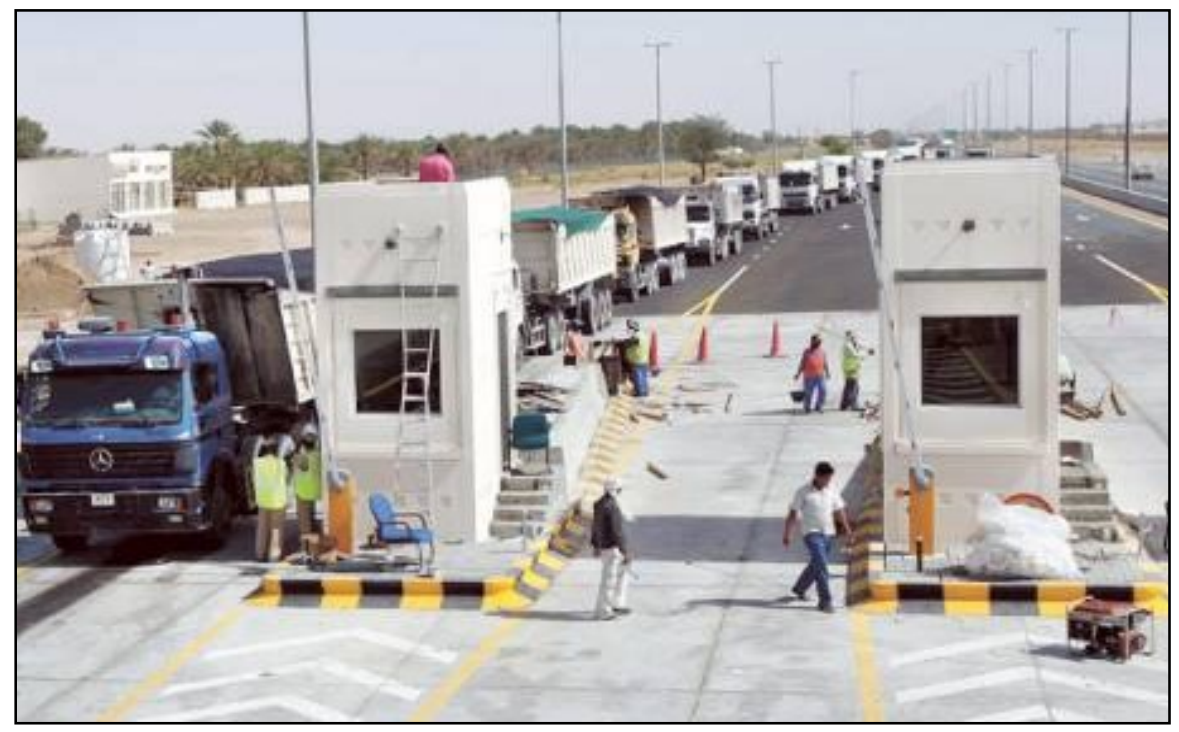

Figure 20 Trucking toll system in UAE, Gulf News, 2010.

Transport organizations are responsible for developing strategies, planning, coordination and improving rules and regulations to address main challenges facing the freight transportation sector, which can be overloading, drivers' hours, strict regulations with the entry of commodities which may cause border delays, as well as a lack of a taxation system for road use. GCC borders (and Saudi Arabian borders in particular) have very strict regulations when it comes to alcohol and pork products. In addition to the operational restricted hours at borders, a further layer to the flow of commodities in this area is that all vehicles must be inspected for these products at the border even if Saudi Arabia is not the shipment destination. Saudi Arabia and the GCC countries are, however, working towards creating an investment program for freight and passenger services to increase revenue and to improve logistics in an effort to smooth over some of these restrictionrelated issues. In order to improve logistics and increase revenue, transport organizations should 
engage in an assessment of the transport market, develop cost models and introduce new policies and regulations that better align with these objectives.

The highlights above on specific issues that arise in the GCC area as well as some discussion of the area's basic characteristics and future plans, the GCC area as a case study sets the tone for why different transportation mode types need to be investigated and why there are certain pros and cons for both. The above section provided examples of what is and is not working in order to inform what future transportation development can be. In order to review this in greater depth, based on the available data, a life-cycle model will be developed and analyzed in order to find the most reliable method for shipping, whether that is by using rail or trucking systems.

\subsection{Developing the GIS Life-Cycle Model}

A network is a system of interconnected parts or elements that show source features to their respective destinations. This type of network flow is best suited for representing the transportation network for a city or a region of interest. The elements of a network from the source features are depicted as lines, points and turns that are combined to represent possible routes from one location to another. For instance, roads and rail tracks in a city or province from one location to another provide an important network used for the transporting of people, resources and goods, which are processes that play a vital role in modern life.

There are many techniques in place that are in operation for building network graphs as well as the analysis of these graphs for any particular objective of a potential user. Out of many approaches, GIS is being used very extensively in this direction because of its various functionalities and modeling techniques. By use of a GIS network analysis, shortest paths, cost analysis and other variables are calculated in the presence of few constraints. This information 
from network analysis is very crucial and is needed to run organizations more efficiently with improved strategic decision-making. In the next sections, the components of network analysis and graphics will be described in more detail.

The GIS network analysis consists of two major parts. First, the physical network, which comprises all of the data layers, is needed to prepare the network in order to layer in ArcGIS. Second is the logical network that consists of preparing the tables that models network connectivity and references network element relationships. The main final components of network analysis are: network dataset, network elements and connectivity. A network dataset is first created to model the real-world networks to facilitate the routing analysis. This network dataset contains the data of locations and attributes of streets, highways and railways along with the other important relational connectivity of these features. All network elements have their attributes that help to control navigation over the network. These attributes hold details and properties of each element in the network dataset and are vital to the network analysis.

The term model that is often used in GIS can convey different meanings depending on the applications and extensions as well as the objective of the user. The most general definition of a model can be thought of as an abstraction of reality from the real world. It is used to represent an object, a process or an event from practical application and solving real world challenges. In the context of geo-processing in ArcGIS, a model can be defined as a process or a sequence of connected processes that are created using the ModelBuilder, a graphical tool for automated GIS processes.

The facilities in ModelBuilder are kind of a visual programming language that enables one to create a program without relying much on the actual programming codes. One can create this program by adding data and using direct tool elements from the ModelBuilder for a specific model 
and then connect them to form a workflow to achieve the target. ModelBuilder is a built-in application in ArcGIS that is specially designed for this purpose and facilitates creating reusable and sharable geo-processing workflows. Figure 21 presents some of the numerous advantages that are provided in ModelBuilder for developing any model.

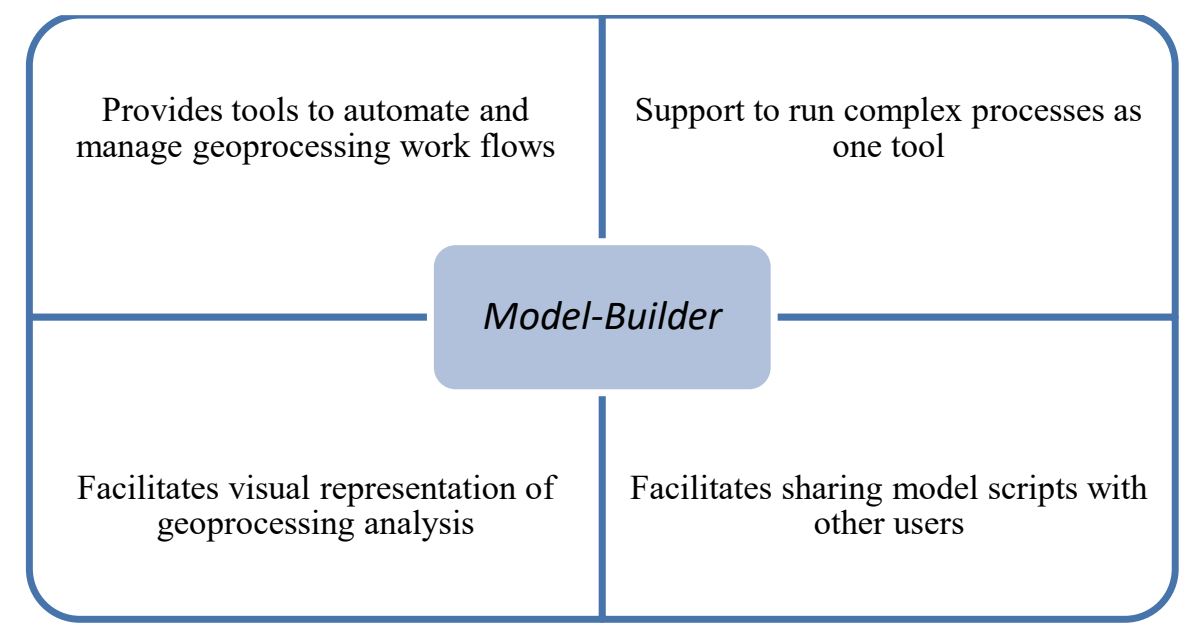

Figure 21 ArcGIS ModelBuilder advantages.

In ModelBuilder, one can add data and elements to the model and connect them in a processing workflow. The three basic types of elements that can be added to the models are: 1) variables that are being used by the user, 2) tools required for geo-processing, and 3) the connectors themselves. Variables are either data type or value variables generated by using some tools. A data variable can be an input or an output to other geo-processing steps. Geo-processing can be carried out using many tools, including-common system tools, script tools, model tools or custom tools that can be added to perform any specific customized functionality, whereas connectors can be in the form of a simple data connector, an environmental setting, a precondition or a feedback.

If ModelBuilder will be utilized when performing some types of GIS analysis or completing a data management project, users must consider the following questions before placing 
a single element into the model. Figure 22 shows the important points to be considered before building a model.

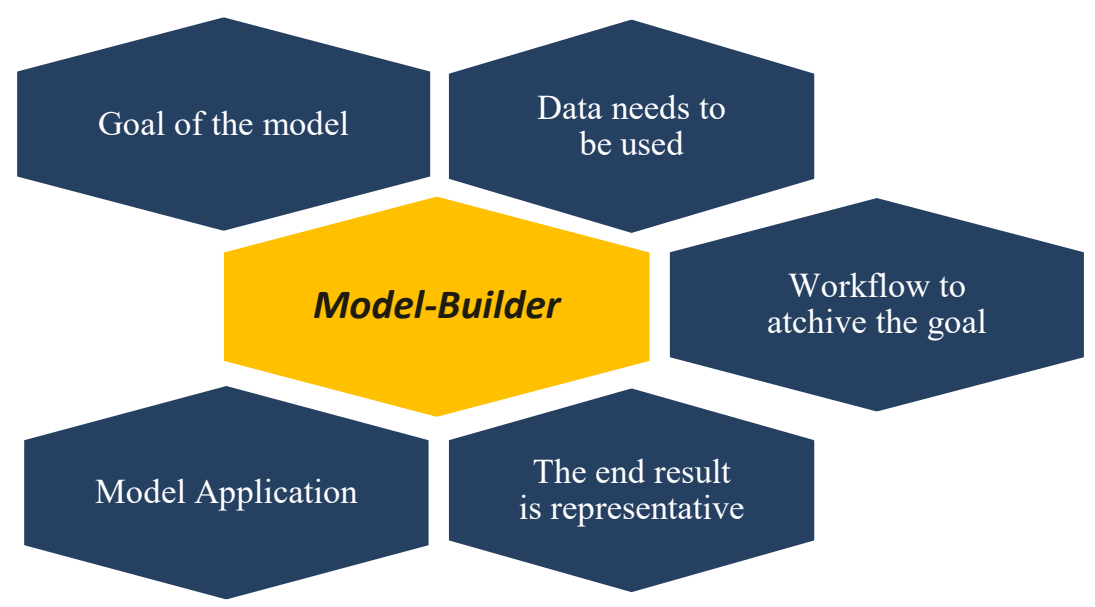

Figure 22 ArcGIS ModelBuilder considerations.

Whenever it is required to build a model or a plan to develop any kind of objective, one has to make some set of guidelines on the basis of the above questions. This helps to perform model analysis with a full understanding of the data and tools as well as gather all necessary knowledge before starting to build it.

Setting a map coordinate system is essential when modeling using GIS networks. In order to perform a map analysis, accurate geographical location of each element included in those maps should be identified. As per the Environmental Systems Research Institute (Esri), a coordinate system is a reference system used to represent the actual locations of any geographic features, which can be helpful when assigning shipment routes using Global Positioning System (GPS). As per the General Directorate of Military Survey, the Geographic Coordinate System used for the GCC area is GCS_WGS_1984. However, in considering the earth as a two-dimensional surface for visualization purposes, a projected coordinate system to transform from a three-dimensional surface to a flat surface needed to be identified. As per the General Commission for Survey in 
Saudi Arabia, the projected coordinate system that is currently used is the Lambert Conformal Conic projection. Figure 23 aids in visualizing how the GCC data maps are situated within the world map using the above coordinate and projection systems.

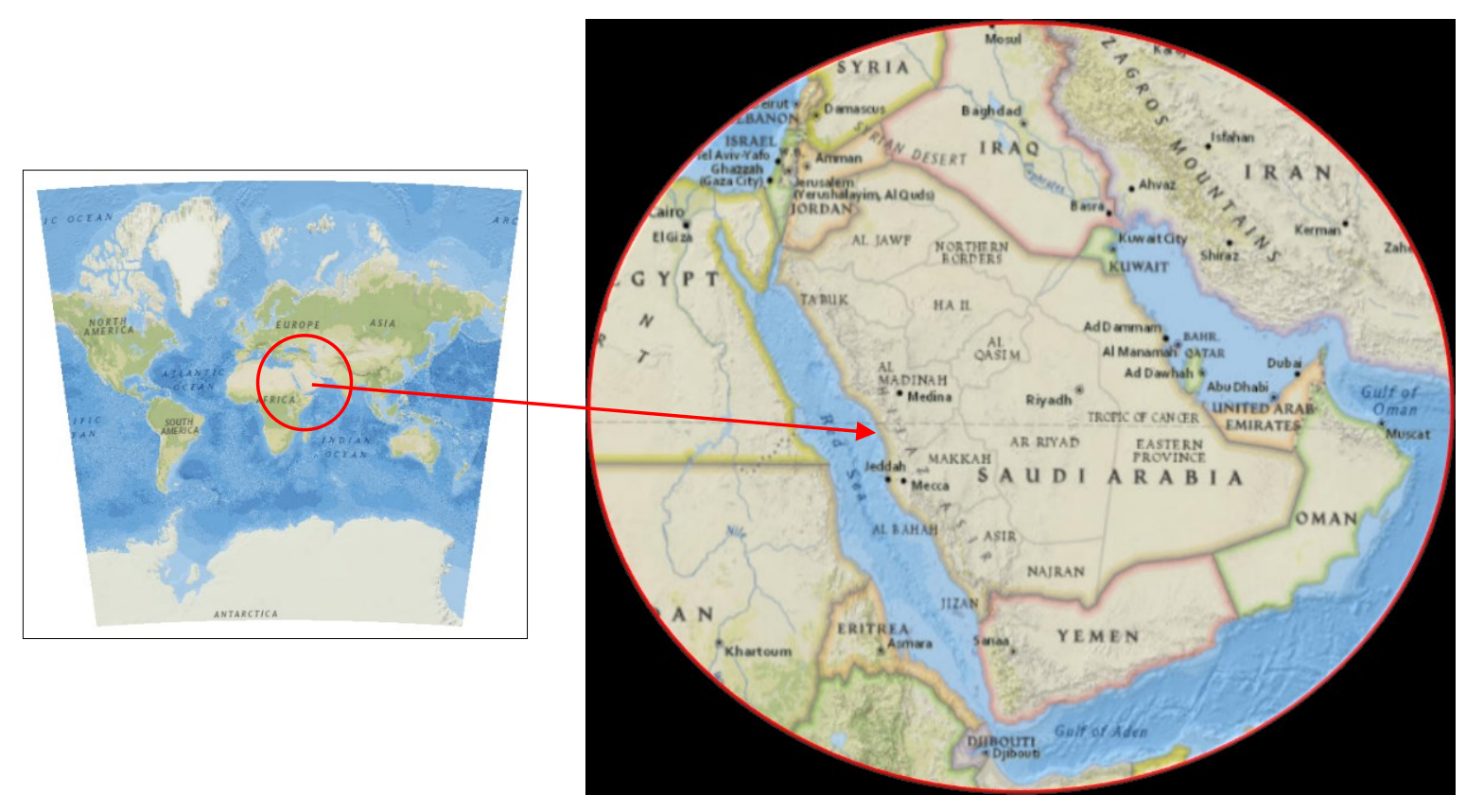

Figure 23 GCC map using Lambert Conformal Conic projection, Esri-2017.

Because the original data were obtained from different sources, they were all in different geographic and projected coordinate systems. Even after converting the coordinate systems to a common geographic and projected system, inconsistencies such as disconnectivity and inaccurate overlay still existed. Several geographic data were used and compared to verify accuracy and make changes to original maps where appropriate. Therefore, rebuilding the network and establishing connectivity was required before moving forward with the model. By using the tools available in ArcGIS in conjunction with Google Earth, Google Maps, and Esri resources, the available road network was manually rectified. Once the relevant routes have been extracted, the issue of 
establishing connectivity, building missing road segments and other issues were addressed.

Unlike road maps, rail lines were created in GIS using raster images to be integrated into the model. However, in order to use that image, geo-referencing and digitizing maps are required. The geo-referencing process involves assigning a coordinate system of a raster image associated with that specific location on the earth. This process will aid in being able to complete an accurate analysis and display (Esri, 2017). Figures 24 and 25 show the geo-referencing process of the future GCC railway projects, while Figures 26 and 27 shows the geo-referencing process of the Saudi rail projects.

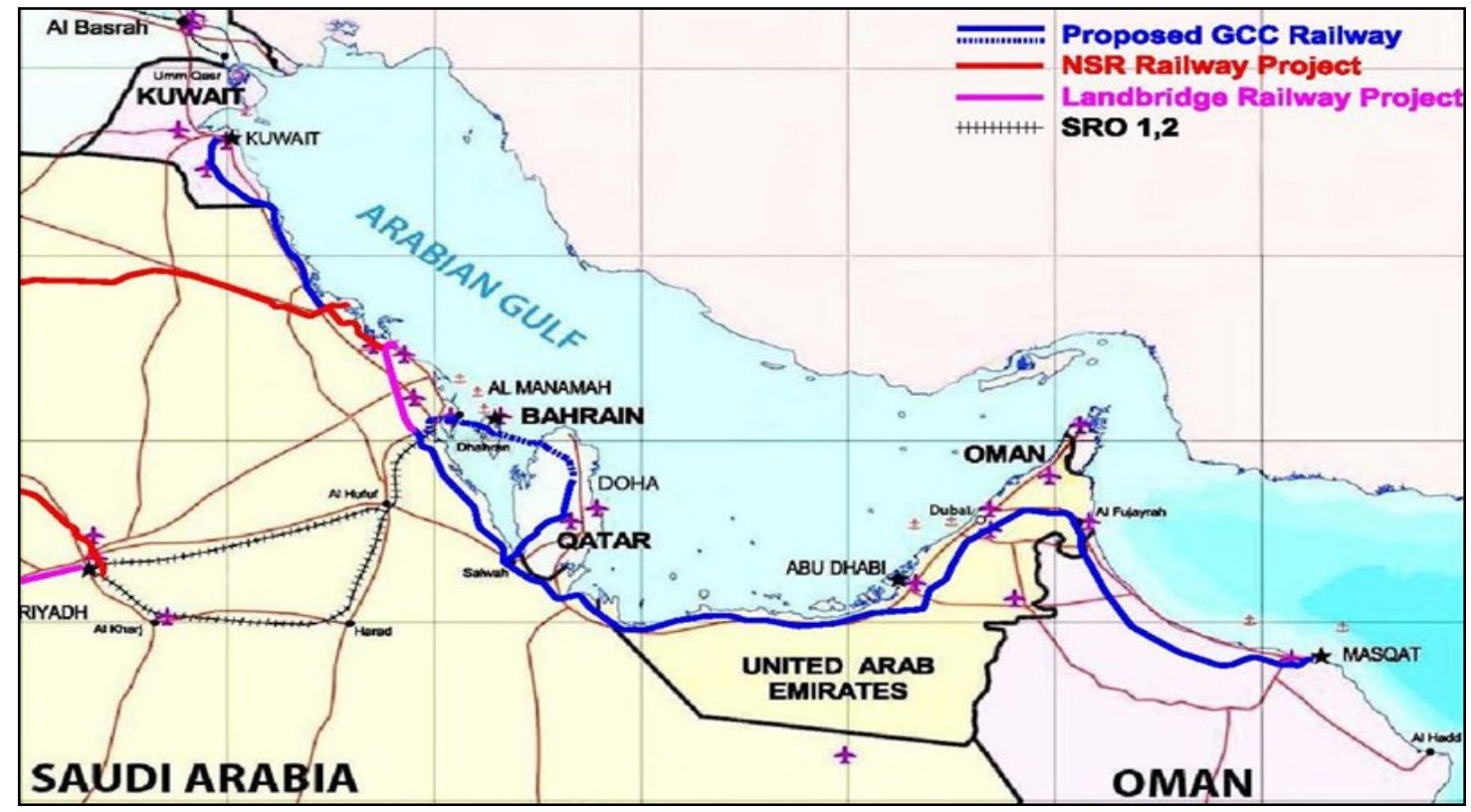

Figure 24 Future GCC rail project raster map, Abu Dhabi Municipality, 2014. 


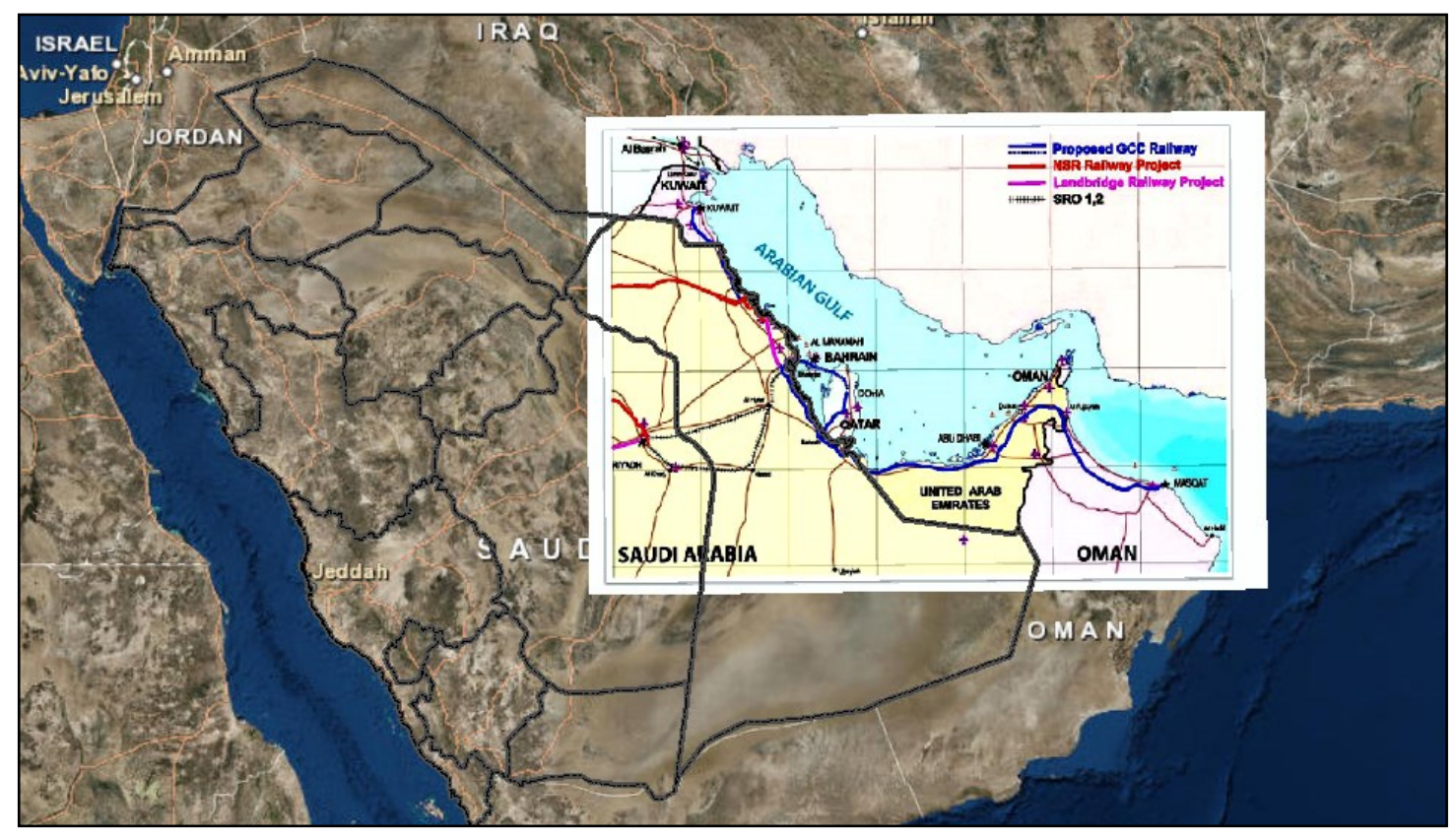

Figure 25 Geo-referencing GCC rail raster map process using ArcGIS.

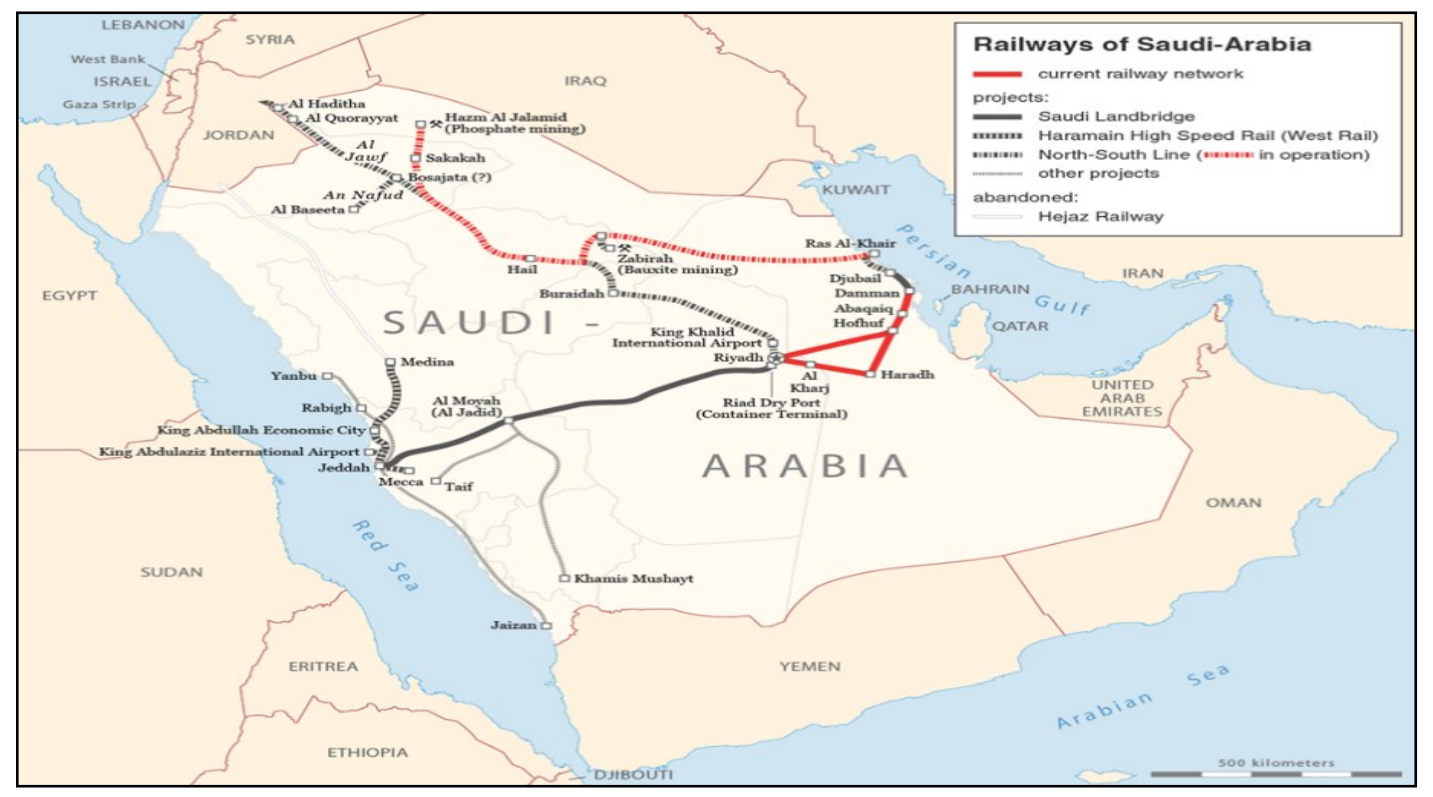

Figure 26 Current and future Saudi rail project's raster map, Saudi Railways Organization, 2018. 


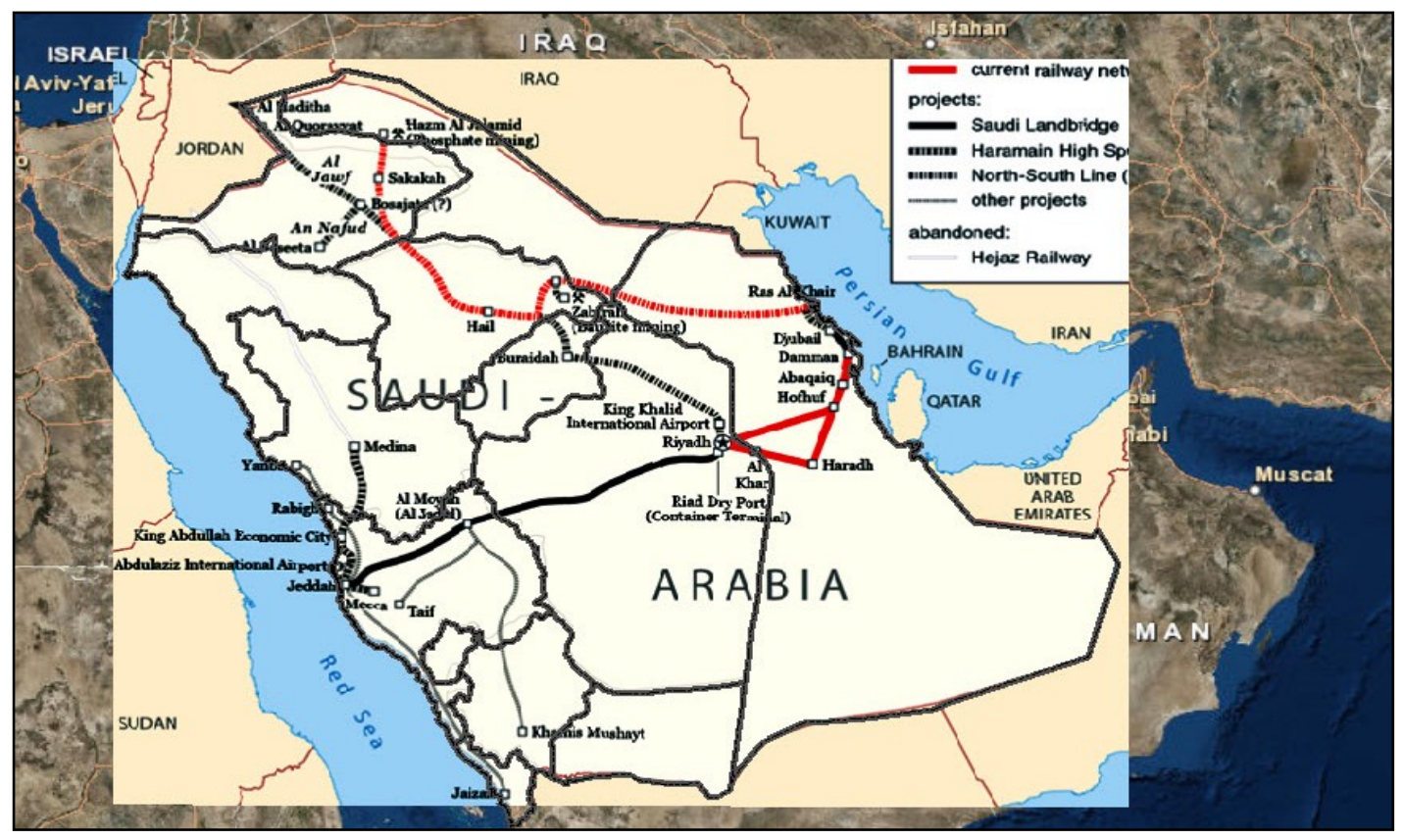

Figure 27 Geo-referencing the Saudi rail raster map process using ArcGIS.

There was a further challenge related to network hierarchy when working with the intermodal transportation model. When selecting a route from one location to another for transportation of freight using the intermodal system, the aim was to use rail whenever possible and highway whenever a railway was not an option while minimizing the travel distance. Ideally, between two points of interest, it was logical to expect a flow of "Highway-Rail-Highway" or "Highway-Rail” or "Rail-Highway", or "Rail-Highway-Rail”. But, because the model builder and network analysis were primarily built with the logic of minimizing travel time or distance, when selecting two points of interest for origin and destination, some generated routes will jump on and off between rail and road networks minimizing travel time or distance but incurring excessive fees and spending additional time loading and unloading. A sample route generated had minimal distance and travel time but had the flow "Highway-Rail-Highway-Rail-Highway", which was not practical and reflective of an optimal flow of logistics. Although the travel time on the network and total distance might be minimized, loading and unloading between the two modes of travel on 
such a frequent basis was impractical. In order to face this challenge, developing factors allowed the model to effectively select priority for railway networks so that excessive jumping on and off between rail and road networks could be minimized. These developed factors allowed the use of a railway whenever possible and highway whenever a railway is not an option while minimizing the travel distance.

Another difficulty was faced when attempting to account for country specific data such as fuel or accident rates to allow for a more accurate analysis. For instance, accident and fuel rates change depending on where a segment is located within the network. As such, while transporting freight within one country was straightforward since factors such as fuel cost remained relatively constant, it was more complicated when routes involved more than one country. When transporting freight between different countries, it was necessary to have the model recognize the crossing of border and change values accordingly. This task could not be achieved directly by inputting the values to the network or model as it was only recognizing and utilizing one constant value for a complete route, whether it crossed country boundaries or not. In order to accomplish the integration of varying and non-constant country specific variables such as accident or fuel rates, Python programming had to be used to write a code that aided ModelBuilder and the network analysis to account for the varying values. The code written assigned each network segment to a specific identifying value.

Finally, it is always required to validate the model before using it and complete all of the processes by joining the model elements and connecting them by tools to the ModelBuilder. Validation is necessary as there can be numerous problems that can occur when the model starts running. These problems are shown as errors when attempts are made to execute the model. The errors can be due to incorrect parameters or missing data that need to be incorporated in the model. 
Errors can also be a result of any improper value variables that are used with specific tools. When a model is validated, it identifies errors and any other problems that may obstruct the model from running successfully. Once all elements in the model and parameters are validated, the elements are sufficiently prepared to run.

In conclusion, this chapter introduces the life cycle cost analysis framework, and the tool that can be used to achieve the thesis. Different types of costs included in the model were illustrated in detail, which touched on direct, indirect and impact costs. The GCC area as a case study was contextualized in terms of its key characteristics, location, freight business, transportation infrastructure, future development and strategic plans. At the end, this chapter provided information about developing the life cycle GIS model, ModelBuilder, as a visual programming language that enables one to create a program without relying much on the actual programming codes. This discussion also offered advantages of ModelBuilder and key considerations before placing a single element into the model, network preparation, as well as difficulties and challenges of developing the network and the modeling process. 


\section{Chapter: Life-Cycle Framework Analysis and Results}

\subsection{Introduction}

As discussed in Chapter 3, there were several difficulties experienced while developing the GIS model that calculated the breakdown and total shipping cost between origin and destination for this thesis. Difficulties ranged anywhere from inconsistencies in the raw network data, the integration of Python programming and socio-economic data to the model, as well as the need to develop factors that combine the practical flow of logistics while selecting optimal routes.

This chapter provides a case study that will show how the framework in the previous chapter and the GIS model can be performed, how it can aid decision-making processes and be used as a valuable tool for developing rules and strategies. Figure 28 shows a pictogram of the LCCA model, workflows, parameters and data that will be created in the GIS model to achieve the research objectives.

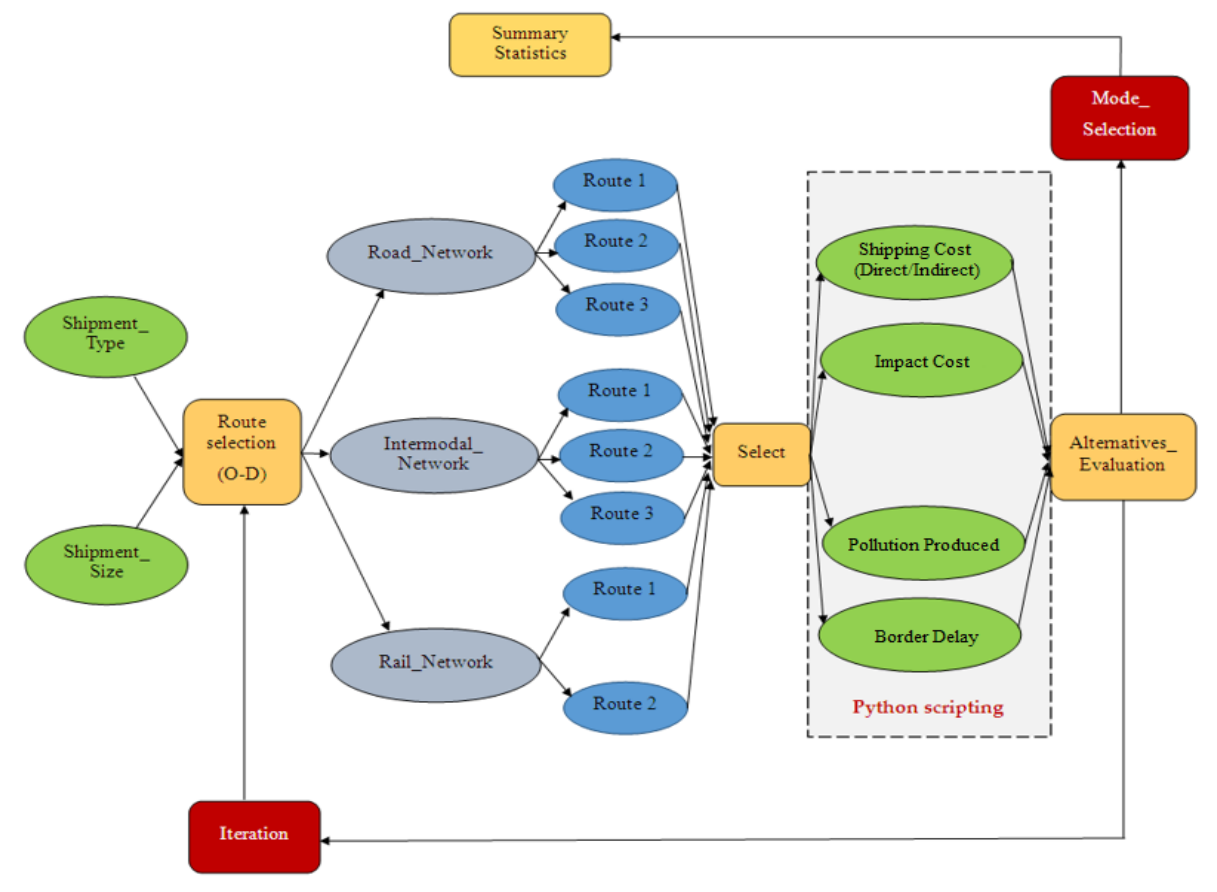

Figure 28 GIS LCCA model flow chart. 
To prepare work and mapping data for the GIS model, several visits to different countries in the GCC area including Saudi Arabia, Kuwait, the United Arab Emirates and Bahrain were undertaken by the researcher. A few of the GCC countries claim that this data is confidential, while others required formal paperwork to process the author's request for information. Accounting for missing or inaccessible data was completed using online resources such as information from the Environmental Systems Research Institute (Esri) and other computer programs like DIVA-GIS for mapping and geographic data analysis. The GIS data that were collected included: road data, countries' administrative boundaries, cities and other secondary data such as natural and shoreline data. Several data such as the cost data were imported to the GIS shape files in order to complete the analysis and aid with achieving the thesis objectives.

As mentioned earlier, several factors will be included in this study, including infrastructure, capital, operation, maintenance, depreciation, noise, pollution, accidents, handling, loading and unloading costs. All factors along with border delay costs were modeled in GIS for road and rail network systems using the data from: the Traffic and highway engineering handbook, (Garber, 2015), Al-Joaan General Transport Operations Department (Dubai, United Arab Emirates, 2016) as well as the UAE and Saudi Arabia's freight transport report data from 2014. ModelBuilder as a visual programming language was used to run multiple geo-processing tools along with their various parameters to develop this GIS model. Moreover, Python scripts were also used to help in finding the model errors, which can be run from outside of ArcGIS. Figure 29 shows a snapshot from the GIS road and rail networks. In the following section, the methodology of analyzing each direct cost type will be discussed in detail based on the rail and the trucking systems freight transport data that is available. 

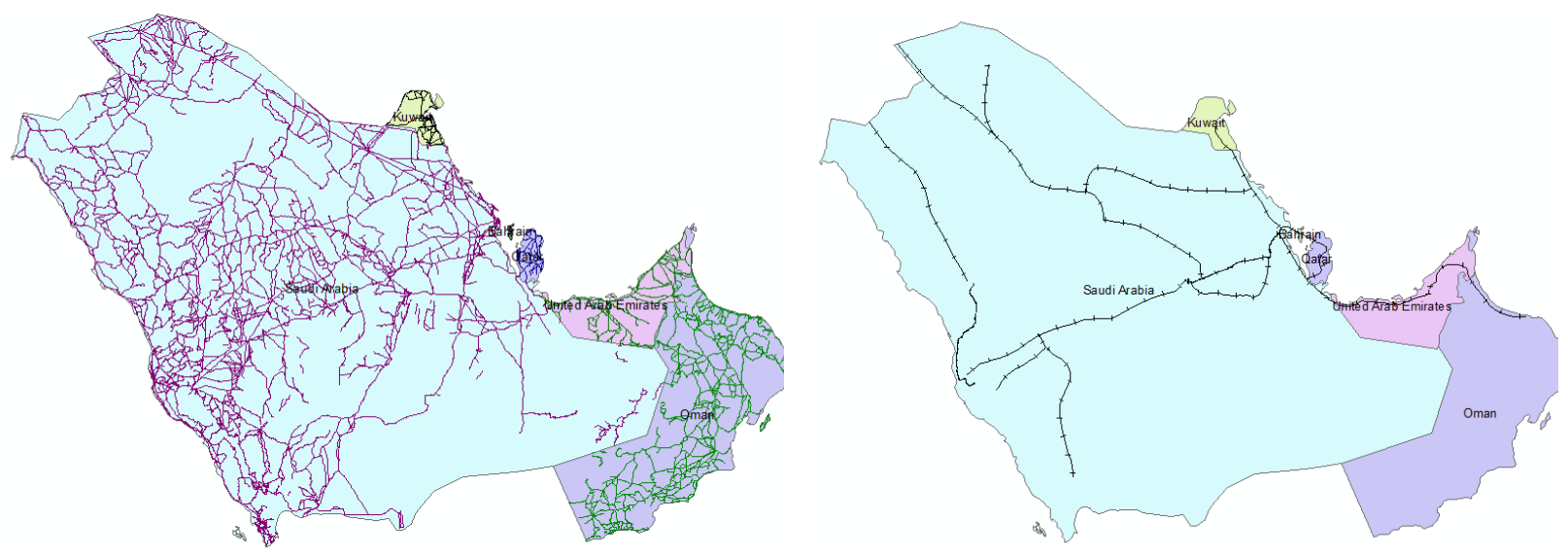

Figure 29 GIS Road/Rail model snapshot.

\subsection{Freight Direct Cost Analysis}

\subsubsection{Infrastructure Cost of the Network}

For trucking and road networks, Table 8 shows the average construction and maintenance cost of the road network in the GCC region.

Table 8 Road infrastructure construction and maintenance cost, Etihad Rail - Abu Dhabi Municipality, 2017.

\begin{tabular}{|c|c|c|}
\hline \multirow{2}{*}{ Construction cost } & \multicolumn{2}{|c|}{$\mathbf{U S \$} / \mathbf{m} 2$} \\
\hline & \multicolumn{2}{|c|}{40.84} \\
\hline \multirow{3}{*}{ Maintenance cost } & \multicolumn{2}{|c|}{$\mathrm{US \$} / \mathbf{m} 2$} \\
\hline & Inlay & Overlay \\
\hline & 1.49 & 2.41 \\
\hline
\end{tabular}

In order to manipulate the infrastructure cost per truck, the following assumptions were used:

- 20402 is the Average Annual Daily Traffic for the network (AADT) 
- Highways have 6 lanes per approach

- There are 250 annual working days

- The percentage of trucks on the roads are $10 \%$

- $\quad 3.6 \mathrm{~m}$ is the lane width

- Design period is 20 years

- $4 \%$ is the annual growth rate in traffic

- 29.78 is the growth factor

Applying the following equations, infrastructure capital and maintenance cost were calculated:

$$
\operatorname{INFR}_{. T}(\text { Capital })=((\text { Avg C.C } * 1000 * 3.6 /(\text { AADT } / 6) * 250 * 0.1 * G . f))
$$

Where;

$I N F R_{\text {.T }}$ (Capital): Infrastucture capital cost of the road network (US\$ $/ \mathrm{km} /$ Truck)

Avg C.C: Average construction cost (US\$/m2)

$A A D T$ : Average Annual Daily Traffic (Vehicle)

G.f: Growth factor

$$
\left.\operatorname{INFR}_{. T} \text { (Maint. }\right)=((\operatorname{Avg} \text { M.C } * 1000 * 3.6 /(A A D T / 6) * 250 * 0.1 * G . f))
$$

Where;

$I N F R_{. T}$ (Maint.): Infrastucture maintenance cost of the road network (US\$/km/ Truck) Avg M.C: Average maintenance cost (US\$/m2)

$A A D T$ : Average Annual Daily Traffic (Vehicle) G.f: Growth factor 
As per the proposed infrastructure maintenance program that includes inlay and overlay processes, infrastructure maintenance cost per truck was calculated.

For railway systems, previous studies focusing on the GCC region in 2010 presented the capital cost of a single-track railway as well as an estimation of the annual maintenance cost for rail infrastructure per kilometer, which was averaged using data provided by the freight division within the Abu Dhabi Municipality. Table 9 shows the average infrastructure cost of the rail track network in the GCC region.

Table 9 Rail infrastructure construction and maintenance cost, Abu Dhabi Municipality, 2014.

\begin{tabular}{|c|c|}
\hline Rail infrastructure & US\$/km \\
\hline Average construction cost & 5494184.0 \\
\hline Average annual maintenance cost & 35687.7 \\
\hline
\end{tabular}

In order to manipulate the average infrastructure cost per wagon, the following assumptions were used:

- There are 250 annual working days

- The rail has 50 wagons

- Design period is 50 years

- Number of rail passes on each section per day is 8

As per the forecasted number of trains per line, the percentage of freight rails were found to be $23 \%$ of the total number of trains that includes passenger and freight trains. Therefore, applying the following equations, infrastructure capital and maintenance cost for a railway system were calculated: 


$$
I_{N F R}(\text { Capital })=(\text { Avg C.C } /(8 * 250 * 50 * 50)) *(23 / 100)
$$

Where;

$I N F R_{. \mathrm{R}}$ (Capital): Infrastucture capital cost of the rail network (US\$ $/ \mathrm{km} /$ wagon)

Avg C.C: Average construction cost (US\$/ km)

$$
I N F R_{. R}(\text { Maint })=(\operatorname{Avg} M . C /(8 * 250 * 50)) *(23 / 100)
$$

Where;

$I N F R_{. \mathrm{R}}$ (Maint): Infrastucture maintenance cost of the rail network (US\$/km/wagon) Avg M.C: Average annual maintenance cost (US\$/ km)

Based on the average construction cost of the rail segments, lifespan of the railway infrastructure, number of passes on the rail track from origin to destination per day, the working days in the year and the number of freight wagons used in the specific rail network being utilized, rail infrastructure cost was estimated.

\subsubsection{Trucking and Rail Systems Capital Cost}

In the case of a 4-axle semi-truck trailer (which is the most common type of truck used for shipping within the GCC region), the payload value is 23 tons, and a capital cost equal to 49,000 US\$. Considering the following assumptions, truck capital cost per kilometer was calculated:

- Average annual mileage is $80,000 \mathrm{~km}$ per year

- Truck life span is 10 years 
- $\quad$ Truck residual value is $20 \%$

Therefore, applying the following equation, truck capital costs were calculated:

$$
\text { Capital }_{. T}=((49000-R . V /(A . m * 10))
$$

Where;

Capital $_{. T}$ :Truck capital cost (US\$/km)

R.v: Truck residual value (US\$)

A. $m$ : Average mileage per year $(\mathrm{km})$

As for rail, locomotive and wagon prices need to be considered when estimating shipping cost, and the price of locomotives also varies based on efficiency and horsepower. Table 10 shows an example of rail rolling stock capital cost and the payload value of each type of wagon.

Table 10 Rail rolling stock capital cost, Abu Dhabi Municipality, 2014.

\begin{tabular}{|c|c|c|}
\hline Item & $\begin{array}{c}\text { Estimated Cost US\$ } \\
\text { (000) }\end{array}$ & $\begin{array}{c}\text { Payload Per Wagon } \\
\text { (tons) }\end{array}$ \\
\hline Locomotive 4400 KW & 3,000 & - \\
\hline Open top hoppers & 85 & 70 \\
\hline Flat deck wagons & 80 & 70 \\
\hline Double stack container flat wagons & 80 & 60 \\
\hline
\end{tabular}

For this thesis, a $4400 \mathrm{AC}$ locomotive and a double stack wagon were selected as the types for analysis. Considering the following assumptions, rail capital cost per kilometer was calculated: 
- Locomotive capital cost is $3,000,000$ US\$

- Wagon capital cost is 80,000 US\$

- Average mileage per year is $240,000 \mathrm{~km}$

- Locomotive and wagon life span is 30 years

- Locomotive and wagon residual value is $20 \%$

Therefore, applying the following equation, truck capital cost was calculated:

$$
\text { Capital }_{. R-\text { Loco }}=((3,000,000-R . V) /(A . m * 30))
$$

Where;

Capital $_{. R-\text { Loco }}:$ Locomotive capital cost (US\$ $\left./ \mathrm{km}\right)$

R.v: Locomotive residual value (US\$)

A. $m$ : Average mileage per year $(\mathrm{km})$

$$
\text { Capital }_{. R-\text { Wagon }}=((80,000-R . V) /(A . m * 30))
$$

Where;

Capital $_{. R-\text { Wagon }}:$ Wagon capital cost $(\mathrm{US} \$ / \mathrm{km})$

R.v: Wagon residual value (US\$)

A. $m$ : Average mileage per year $(\mathrm{km})$

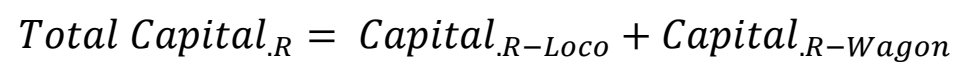

So, based on the above calculations, the capital cost per kilometer for locomotive, wagon and truck equal $0.33 \mathrm{US} \$ / \mathrm{km}, 0.0088 \mathrm{US} \$ / \mathrm{km}$ and $0.049 \mathrm{US} \$ / \mathrm{km}$ respectively.

\subsubsection{Operation and Maintenance Costs}

When selecting between various transportation modes, consideration of operational and maintenance costs is essential. This includes fuel, labor, truck/rolling stock maintenance and repair 
costs. Operation usually depends on the fuel price in each country and average wages as well. For this thesis, operation and maintenance cost for trucks were estimated based on the following assumptions:

- $\quad$ Truck fuel consumption is 0.2613 Liter per $\mathrm{km}$

- Monthly average driver wages are around 950 US\$

- Average mileage per month is $18,000 \mathrm{~km}$

- Repair cost per month is 284.4 US\$

In this thesis, the operational and maintenance costs were estimated based on the data for a 4-axle semi-truck trailer with an average fuel consumption, as well as labor and fuel cost of each GCC country over the whole shipping distances and real data for repair and maintenance. The current diesel price was obtained from the Global Petrol Price index in 2016 as shown in Table 11.

Table 11 Fuel price at the GCC countries US\$/ Liter, Global Petrol Price index, 2016.

\begin{tabular}{|c|c|}
\hline Country & Diesel price / liter \\
\hline UAE & 0.44 \\
\hline Kuwait & 0.36 \\
\hline Qatar & 0.41 \\
\hline Bahrain & 0.32 \\
\hline Oman & 0.41 \\
\hline Saudi Arabia & 0.24 \\
\hline
\end{tabular}

Considering the above assumptions, truck operation and maintenance cost were calculated using the following equations: 


$$
f_{\text {O.T }}(\text { Operation })=\left(\sum(D . p \times F . c \times \text { D.d) }) /(\text { T.S.D })+(M . s) /(\text { A.m })\right.
$$

Where;

$f_{\text {O.T }}($ Operation): Truck operation cost (US\$ $/ \mathrm{km})$

D. p: Diesel price (US\$/Liter)

F.c: Fuel consumption (Liter/km)

D.d: Distance driven on each country $(\mathrm{km})$, and

T.S.D : Total shipping distance $(\mathrm{km})$

M.s : Monthly salary (US\$), and

A. $\mathrm{m}$ : Average mileage per month $(\mathrm{km})$

$$
f_{\text {M.T }}(\text { Maintenance })=(\text { R.cost }) /(A . m)
$$

Where;

$f_{M . T}$ (Maintenance): Truck maintenance cost (US\$/km)

R.c : Repair cost per month (US\$), and

A. $\mathrm{m}$ : Average mileage per month $(\mathrm{km})$

Unlike trucks, rail systems have different components that need to be considered when estimating operational and maintenance costs of a rail shipment, including locomotive, wagon, fuel and labor. Different assumptions were estimated as follows:

- Monthly average driver wages are around 4,000 US\$

- There are 250 working days in the year

- Freight rail speed is $80 \mathrm{~km} / \mathrm{hr}$

- Freight rail has two drivers 
Table 12 shows the operational and maintenance cost of each part of the system based on the Federal Transport Authority in the UAE.

Table 12 Operation and maintenance cost of freight service, Abu Dhabi Municipality, 2014.

\begin{tabular}{|c|c|c|}
\hline Fuel Cost & Unit & Price US\$ \\
\hline Fuel Consumption & Liter/1000ton-km & 3.14 \\
\hline Lubricant Costs & Unit & Price US\$ \\
\hline Locomotives & \$ / unit / year & 20,000 \\
\hline Rolling Stock maintenance materials & Unit & Price US\$ \\
\hline Locomotives & \$ / unit / year & 120,000 \\
\hline Wagons & \$ / unit / year & 20,000 \\
\hline
\end{tabular}

So, considering the above, rail operation and maintenance cost were calculated using the

following equations:

$$
f_{\text {O.R }}(\text { fuel })=\left(\sum(\text { D.p } x \text { F.c } x \text { D.d) }) /(\text { T.S.D })\right.
$$

Where;

$f_{\text {O.R }}($ fuel): Rail fuel cost (US\$/ton-km)

D.p: Diesel price (US\$/Liter)

F.c: Fuel consumption (Liter/ton-km)

D.d: Distance driven on a country $(\mathrm{km})$, and

T.S.D : Total shipping distance $(\mathrm{km})$

$$
f_{O . R}(\text { Driver })=(\text { D.s }) /(\text { R.s })
$$

Where;

$f_{\text {O.R }}($ Driver ): Rail driver cost (US\$/km) 
D.s: Daily salary (US\$), and

R.s: Freight Railway speed $(\mathrm{km} / \mathrm{hr})$

$$
f_{\text {O.R }}(\text { Operation })=f_{\text {O.R }}(\text { Fuel })+\left(2 x f_{\text {O.R }}(\text { Driver })\right)
$$

Where;

$f_{\text {O.R }}($ Operation): Rail operation cost (US\$ $/ \mathrm{km})$

With regards to maintenance, locomotives, wagons and lubrication costs were estimated using the following equations:

$$
\left.f_{M . R}(\text { Loco })=((\text { A.M.C } / A W D) / 24)\right) /(\text { R.s })
$$

Where;

$f_{M . R}($ Loco): Locomotive maintenance cost (US\$/km)

A.M.C: Annual maintenance cost (US\$/ Year)

A.W.D: Annual working days (days), and

R.s: Freight Railway speed $(\mathrm{km} / \mathrm{hr})$

$$
\left.f_{M . R}(\text { Wagon })=((A \cdot M \cdot C / A W D) / 24)\right) /(R . S)
$$

Where;

$f_{M . R}($ Wagon): Wagon maintenance cost (US\$/km)

A.M.C: Annual maintenance cost (US\$/ Year)

A.W.D: Annual working days (days), and

R.s: Freight Railway speed $(\mathrm{km} / \mathrm{hr})$ 


$$
\left.f_{M . R}(\text { Lubrication })=((A . M . C / A W D) / 24)\right) /(R . S)
$$

Where;

$f_{M . R}($ Lubrication): Lubrication maintenance cost $(U S \$ / k m)$

A.M.C: Annual maintenance cost (US\$/ Year)

A.W.D: Annual working days (days), and

R.s: Freight Railway speed $(\mathrm{km} / \mathrm{hr})$

Road distances were configured based on the GIS road map, while the rail for track distances and GCC countries' rail segment lengths were configured based on data provided by the Abu Dhabi Municipality as shown in Figure 30 and Table 13. For the rest of future rail networks, routes have been drawn on a GIS application based on the data available and other published images by the Saudi Railways Organization. 


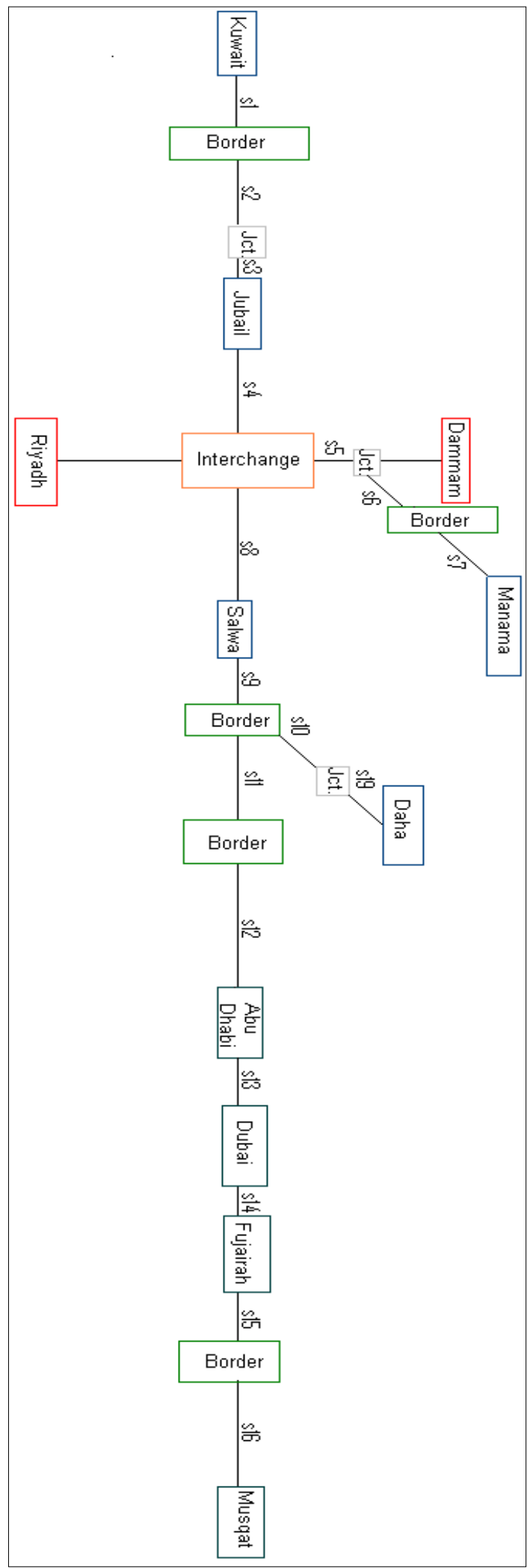

Figure 30 GCC rail connecting segments, Abu Dhabi Municipality, 2014. 
Table 13 GCC Railway segment lengths, Abu Dhabi Municipality, 2014.

\begin{tabular}{|c|c|c|}
\hline \# & Rail Segments & Track Length Km \\
\hline S1 & Kuwait City to Kuwaiti / Saudi border & 111.7 \\
\hline S2 & Kuwaiti / Saudi border to NSR Junction & 144.6 \\
\hline S3 & NSR Junction to SR04 Junction (Jubail) & 75.4 \\
\hline S4 & SRO4 Junction (Jubail) to Interchange Station & 104.6 \\
\hline S5 & Interchange Station to Dammam Junction & 22 \\
\hline S6 & Dammam Junction to Saudi / Bahraini border & 17.9 \\
\hline S7 & Saudi / Bahraini border To Manama & 35 \\
\hline S8 & Interchange Station to As Salwa Station & 191 \\
\hline S9 & As Salwa to Saudi / Qatari border & 26 \\
\hline S10 & Saudi /Qatari border to Doha Junction & 68 \\
\hline S11 & As Salwa to Saudi / Emirati border & 121.8 \\
\hline S12 & Saudi / Emirati border to Abu Dhabi & 368 \\
\hline S13 & Abu Dhabi to Dubai & 69 \\
\hline S14 & Dubai to Fujairah & 137 \\
\hline S15 & Fujairah to Emirati / Omani border & 15.7 \\
\hline S16 & Emirati / Omani border to Muscat & 257.1 \\
\hline S19 & Doha Junction to Doha station & 36.5 \\
\hline
\end{tabular}




\subsection{Freight Indirect Cost Analysis}

In this section, the methodology of analyzing each indirect cost type will be discussed in detail based on rail and the trucking systems freight transport data that are available.

\subsubsection{Shipment Handling, Loading and Unloading Costs}

A key component within the shipment handling process is loading and unloading costs. This is a set of procedures that need to be accounted for in calculating costs. In considering the average labor cost of using forklifts (670 US\$ per month), forklift capital cost (13,600 US\$) and forklift diesel consumption, loading and unloading costs can be calculated. As per the information provided by the Saudi Railways Organization, and the Port of New Orleans - Louisiana, USA, Cargo - Port Facilities Rates \& Tariffs (2012), containers handling loading and unloading costs for a trucking system are about 79.01 US\$ for 5 tons and below, while it is about 104 US\$ for above 5 tons. On the other hand, in using rail and intermodal systems, containers handling loading and unloading costs are about 97.50 US\$, for 5 tons and below, while it is about 122.50 US\$ for above 5 tons or above for a round trip. Based on this information, handling, loading and unloading costs were incorporated into this model.

\subsubsection{Depreciation Cost at the Study Area}

Depreciation costs are another key component that needs to be accounted for. Based on a study undertaken by the Ministry of Economy and Planning of Saudi Arabia (SANTRAPLAN3, 2008) the average depreciation cost was taken for a variety of trucks at the GCC countries and resulted in an average depreciation of 0.14 US\$ per kilometer. Regarding rolling stock depreciation for rail, the annual depreciation for a freight car is 3.6\%, as per the Association of American 
Railroads (A.A.R.). In considering the cost of wagons and locomotives, the annual depreciation of wagons is about 2,880 US\$, and about 108,000 US\$ for locomotives, respectively. Assuming the annual mileage is about $240,000 \mathrm{~km}$, the depreciation rate for locomotives is therefore 0.45 US $\$ / \mathrm{km}$, while the wagon depreciation cost equals 0.012 US $\$ / \mathrm{km}$. Table 14 below summarizes the depreciation costs of rail and trucking systems.

Table 14 Truck and Rolling Stock Depreciation Cost US\$/km, Saudi National Transportation Plan, 2008.

\begin{tabular}{|c|c|c|c|}
\hline \multirow{2}{*}{ Cost } & Trucking system & \multicolumn{2}{|c|}{ Rail System } \\
\hline \multirow{2}{*}{ US\$ per km } & Truck & Locomotive & Wagon \\
\cline { 2 - 4 } & 0.14 & 0.45 & 0.012 \\
\hline
\end{tabular}

\subsubsection{Border Delay Issue}

Unfortunately, roads within the GCC area can be gridlocked due to heavy freight movement. As a result of screening and inspection, the border hours of freight service significantly impact timing and operational abilities for trucks. Figure 31 shows a truck route for crossing the border between the UAE and Saudi Arabia.

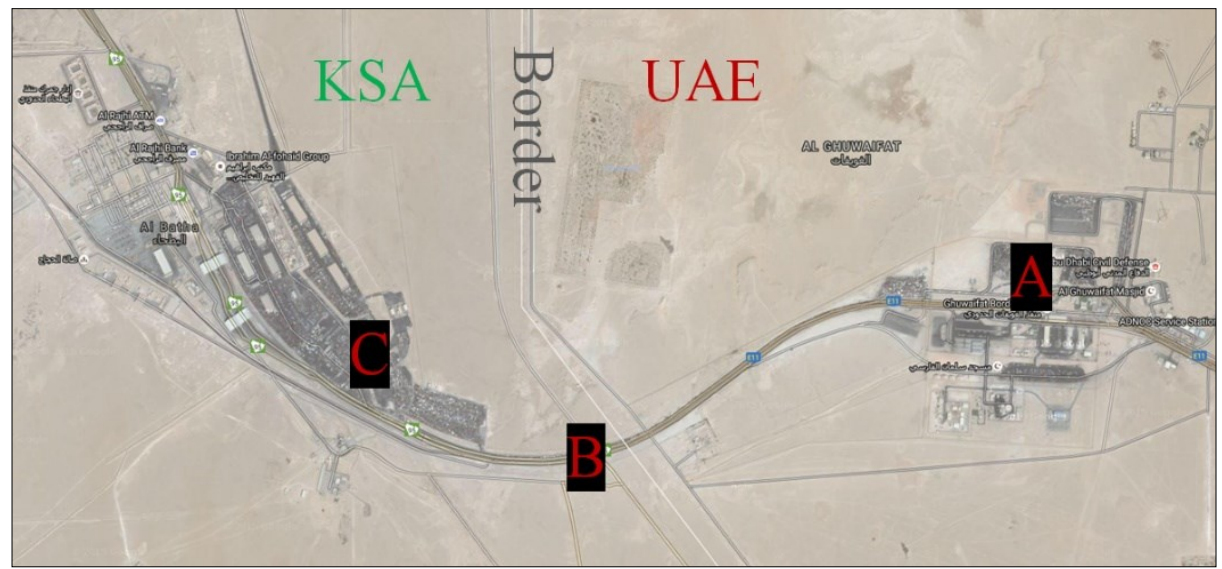

Figure 31 Al-Ghuwaifat border between the UAE and Saudi Arabia, Modified from Google map, 2017. 
As demonstrated in Figures 32 A, B and C, border delays can be a serious issue, and the traffic conditions that trucks can be impacted by when crossing some of the GCC borders are shown below.
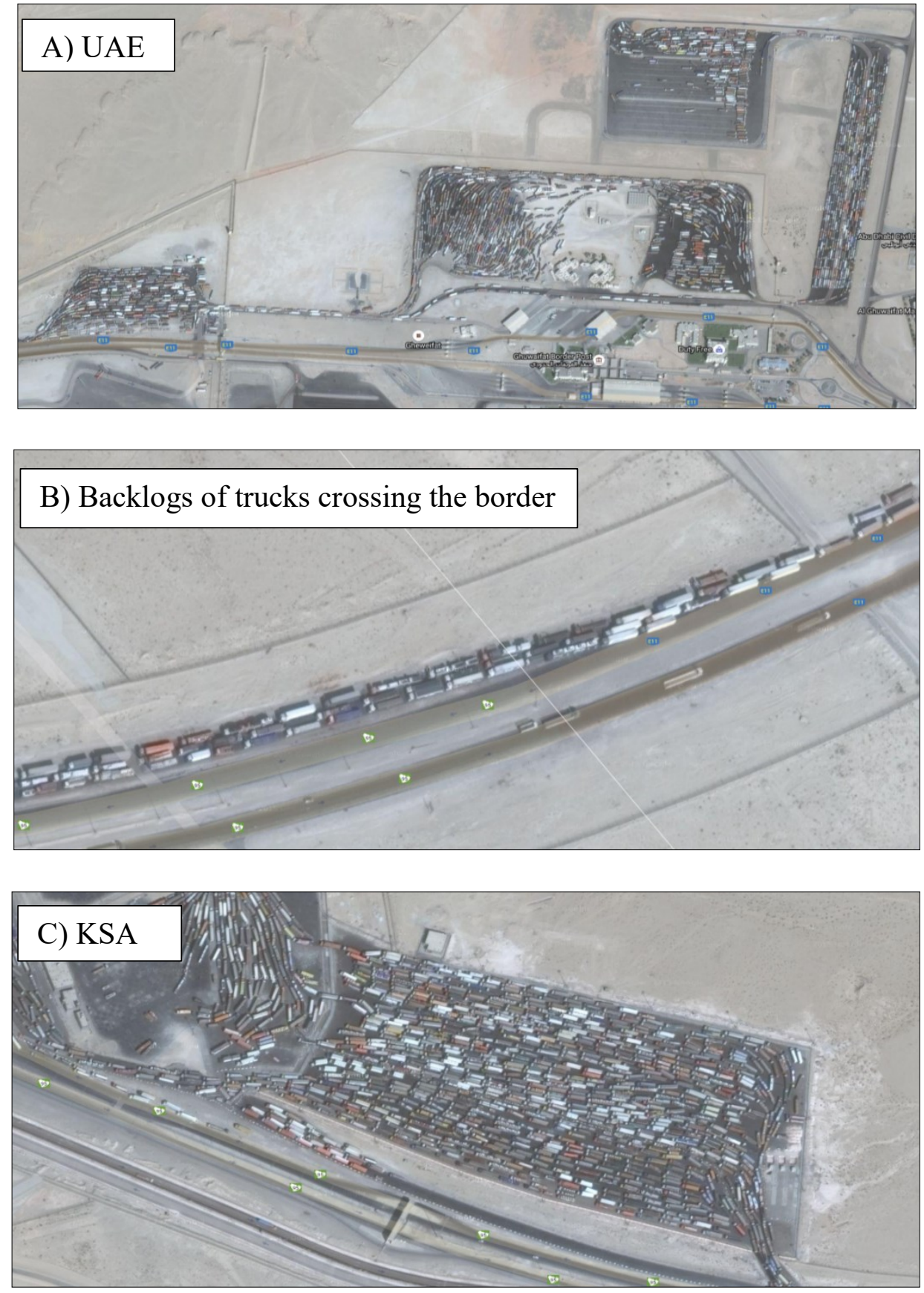

Figure 32 Border delay issues at the border between the UAE and Saudi Arabia, Modified from Google maps, 2017. 
Based on data given by the Al-Joaan private transport company in Dubai, the average border delay for shippers in 2015-2016 on some borders of the GCC countries is shown in Figure 33.

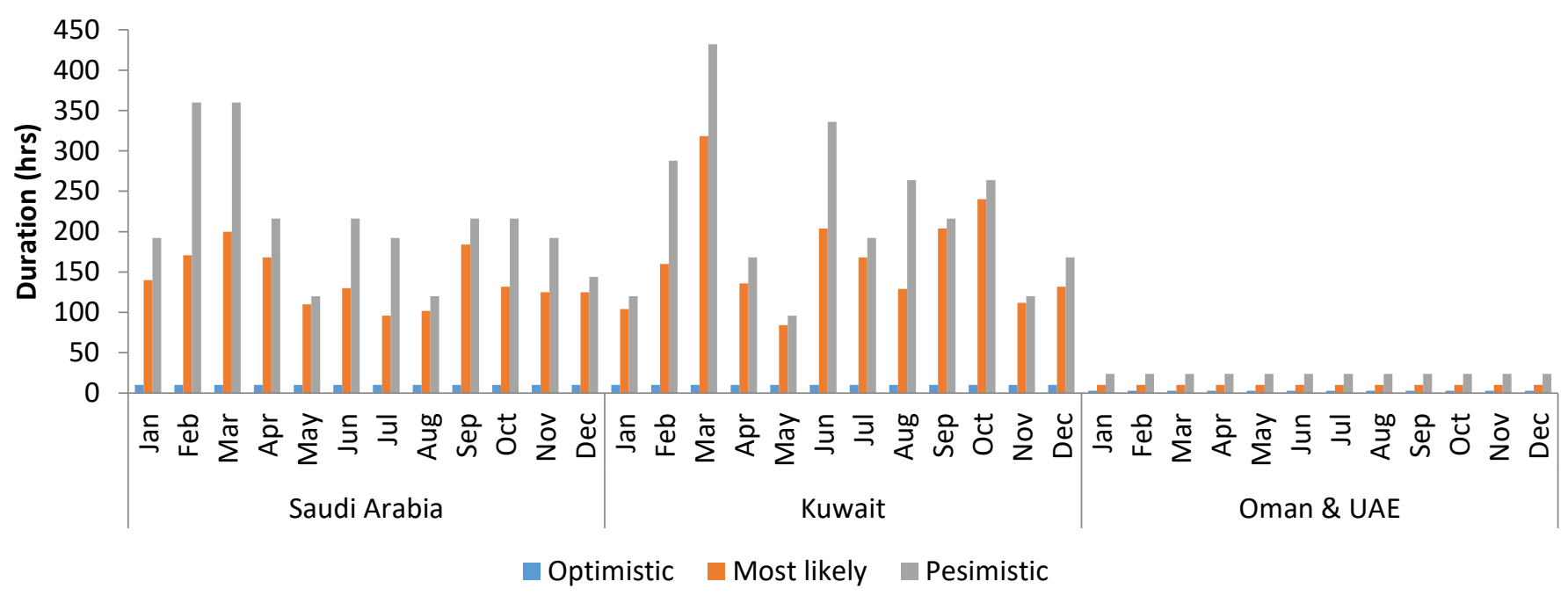

Figure 33 Border delay hours estimate, Al-Joaan General Transport, 2016.

As a result, trucking companies spend about 107 US\$ per day (on a driver's pay, food and fuel) in case there is a delay at the border, and trucking companies usually charge the customer 136 US\$ in case of a delay that is longer than 24 hours at the borders. Delays can be a cost problem in certain scenarios and may affect the mode selection decision, especially when shipping perishable items such as dairy, fruit and vegetables.

Figure 34 shows a truck queue requiring permission to cross the Saudi Arabian and Bahraini border. It is important to note that trucks cannot be delayed more than 6 to 8 hours on the bridge connecting these two countries due to structural issues for this bridge. These structural issues coupled with the delays themselves can result in risky and costly scenarios for shippers to reconcile and resolve when using trucks as the mode choice. 


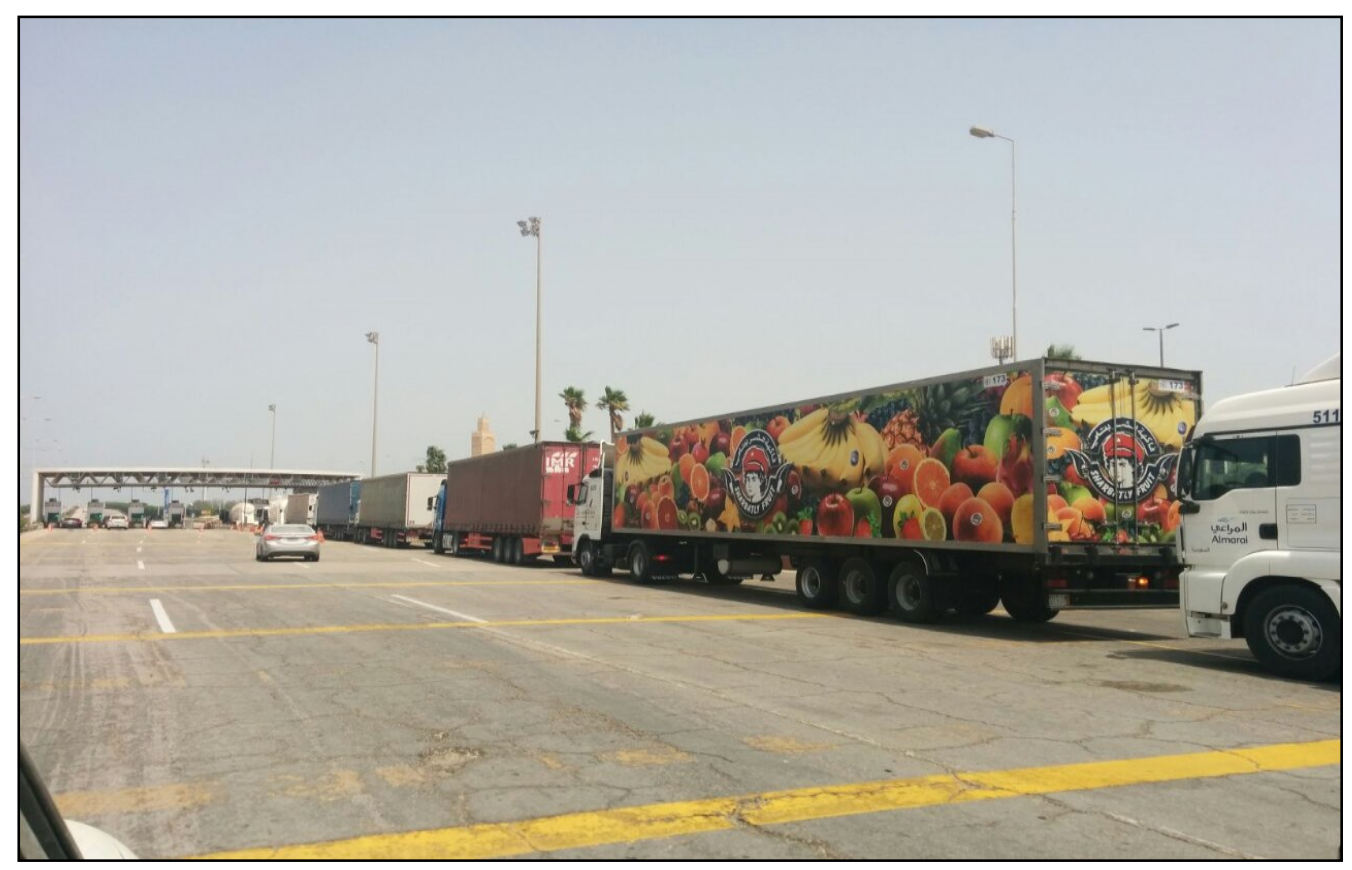

Figure 34 Trucks queue crossing the Saudi Arabian and Bahraini border. Taken by Author.

Each border within the GCC countries has different rules and regulations that have an impact on border crossings. For example, in Kuwait, if a truck shipment enters the country with the intent to pass through to another country, two police cars must follow the shipment out until it crosses the adjacent border. While in Qatar, all shipments must be sealed and truck activity is to be monitored using a GPS system. When entering Saudi Arabia, each truck is to be inspected and screened, and this is to monitor any restrictions on commodities that are not permitted to enter the country. Contraband is not even permitted to pass through the country even when Saudi Arabia is not the final shipment destination. While the above examples of varied regulations serve specific purposes and functions for each GCC country, it is observable how such regulations can result in border delays and subsequently higher operational costs for trucking. 


\subsection{Freight Impact Cost Analysis}

In this section, the methodology of analyzing each impact cost type will be discussed in detail based on the rail and the trucking systems freight transport data that are available.

\subsubsection{Vibration and Noise Costs}

Urban distances have only been considered in calculating noise factors as shown in the equation below (eq.17) and urban distances have been measured using GIS Maps.

$$
f_{T . R}(\text { Noise })=\left(\sum(U . D . D x \text { Average noise cost })\right) /(T . S . D)
$$

Where;

$f_{T . R}($ Noise):Truck /Rail Average noise cost (US\$/ton-km)

U.D.D: Urban distance driven in a country $(\mathrm{km})$

A.N.C: Average noise cost (US\$/ton-km), and

T.S.D : Total shipping distance $(\mathrm{km})$

In designing the GCC freight rail system, significant efforts have been undertaken to reroute the corridors away from residential areas to avoid disturbing neighborhoods, but there are circumstances where corridors cross some residential areas. A recent report in 2016 by Etihad Rail in the UAE shows that rail service is considered to be quieter than the equivalent volume of vehicle 
road traffic. As a more specific example of this, one train carrying 1,000 passengers is quieter than 750 private cars carrying the same number of passengers.

Unfortunately, there were no local factors found to be used within the GCC countries that could estimate these effects, and subsequently, international average factors were used. As per a recent study by UAE Freight Transport in the Abu Dhabi Municipality, the average truck noise cost was estimated to be 0.01605 (USD/ton-km), while the rail noise cost is about $0.0046 \mathrm{US} \$ /$ tonkm (European Commission, 2002).

\subsubsection{Safety and Accident Costs}

To calculate the cost of accidents for rail and trucking systems, different cost factors were applied for each section of the network of each passing country to deliver a given shipment as described in the following equation (eq. 18).

$$
f_{T . R}(\text { Accident })=\left(\sum \text { A.A.C } \times \text { D.d }\right) /(T . S . D)
$$

Where;

$f_{T . R}($ Accident):Truck/Rail Average accident cost (US\$/ton-km)

D.d: Distance driven in a country $(\mathrm{km})$,

A.A.C: Average accident cost (US\$/ton- $\mathrm{km})$, and

T.S.D : Total shipping distance $(\mathrm{km})$

GCC countries are attempting to impose different countermeasures to improve freight safety. Enforced recently in 2016, Saudi Arabian customs prohibits entry of any truck that is not complying with the safety standards as shown in Figure 35, but there are still several road and rail 
accidents causing loss of human life and property damages that can occur despite compliance with safety measures that have been undertaken.

It should be noted that the data that are necessary to calculate accident costs in a useful form are not readily available. As a way to approach this category, a strategy of compiling road accidents, fatalities and injury cost estimates were configured using comparative risk factors (fatalities per capita and per vehicle), that can be used to scale international factors (European Commission, 2002) to GCC levels.

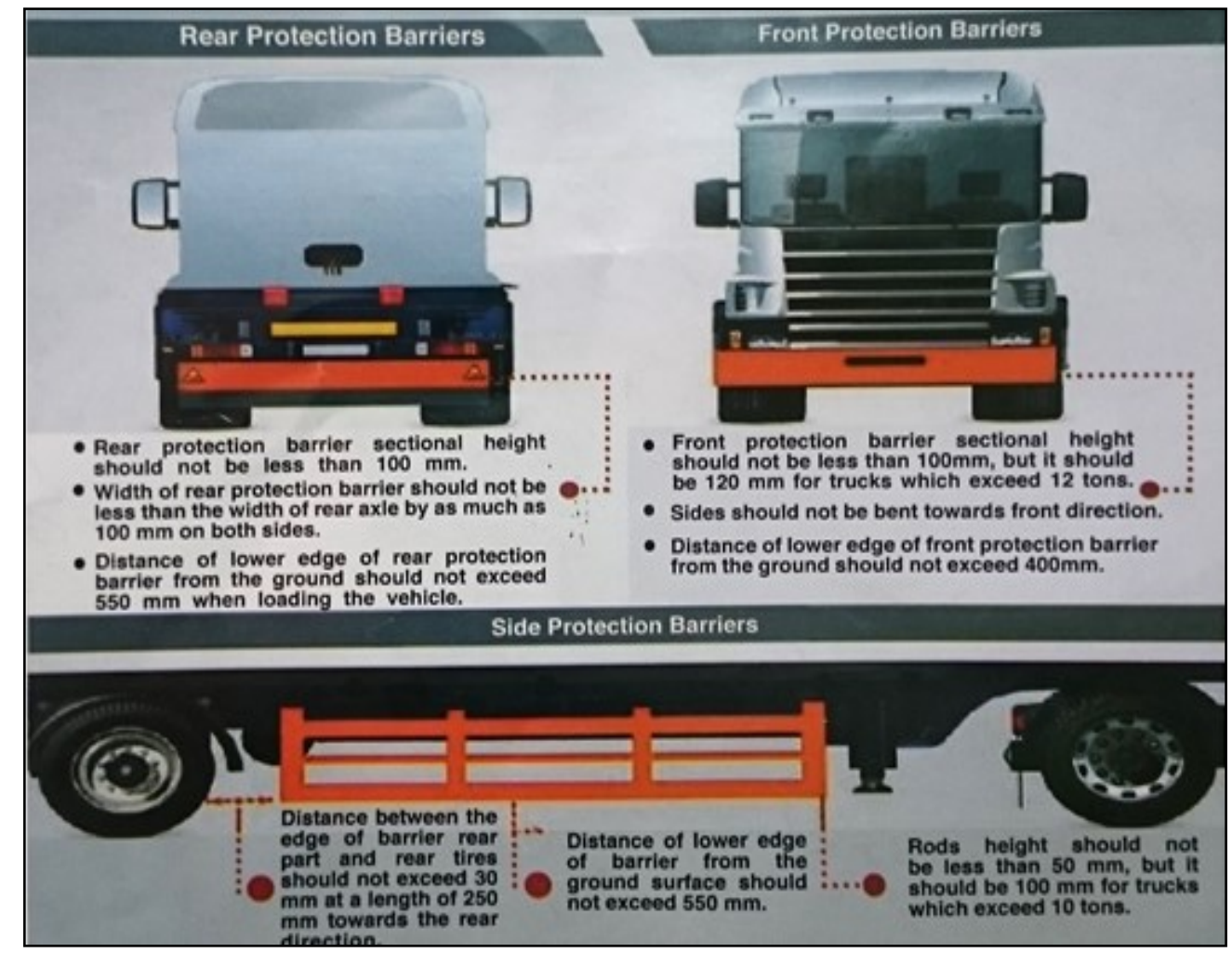

Figure 35 A recent Saudi Arabian Customs safety standard, Saudi Customs, 2016. Taken by Author.

With regards to rail accidents, very limited data was found in Saudi Arabia to complete the comparison of safety and accident factors. In an attempt to provide some insight on these factors, the following table shows the cost of accidents that have been used to scale the countries based on 
a GCC economic study report from 2008. The design of the future GCC Railway includes better crossing protection systems than the current Saudi Arabian Rail System, with the former including fences and camel crossing bridges which can bring the accident rate down. The resulting factors were still used for all six GCC countries in the process of scaling this information.

Table 15 Manipulated Cost-of-accident per 1,000 ton-km for the GCC countries in US\$, Abu Dhabi Municipality, 2014.

\begin{tabular}{|c|c|c|}
\hline Country & Truck & Rail \\
\hline Bahrain & 18.07 & 1.18 \\
\hline Oman & 10.84 & 1.18 \\
\hline Qatar & 31.62 & 1.18 \\
\hline UAE & 9.04 & 1.18 \\
\hline Kuwait & 18.07 & 1.18 \\
\hline Saudi Arabia & 18.07 & \\
\hline
\end{tabular}

The impacts of accidents and their rates are heightened when hazardous materials such as combustible liquids and flammable materials are being moved. Currently, based on information from traffic forecasts, about $1,860,000$ tons of mineral fuel, oils and bituminous products are transported between Saudi Arabia, Qatar, Bahrain and the UAE, which can mean that there is significant risk for further damages and higher accident costs with such high quantities of hazardous materials being transported. Exact numbers on impact costs involving hazardous materials are difficult to estimate, but it should be noted that the accident costs noted in the table above may be subject to some differentiation if the aspect of hazardous materials were included in these figures. 


\subsubsection{Environmental and Pollution Costs}

There are no specific factors that can be used to estimate the environmental impacts of rail and truck freight transportation on the GCC countries. Therefore, international factors have once again been used for estimation, and information has been drawn from resources such as the Strategic Rail Authority (SRA, 2003) and the European Commission (2002) as shown in Table 16. According to the SRA, the average pollution cost for a truck is about 33.28 US\$ per 1,000 ton-km, while rail has lesser value of 7.39 US\$ per 1,000 ton-km as per the European Commission. As was discussed previously, factors that are able to provide details on external impacts (including noise, vibration, safety issues, accident costs and emissions factors) will provide a broader picture of the benefits and disadvantages to modes of transport and subsequently play a significant role in mode selection.

Table 16 Summary of external factor cost items breakdown in US\$ per 1,000 ton-km, (Abu Dhabi Municipality, 2014), (Saudi Railway Organization, 2003), and (European Commission, 2002).

\begin{tabular}{|c|c|c|c|}
\hline Freight Mode & Noise cost & Accident cost & Emission cost \\
\hline Trucking System & 16.05 & 9.04 to 31.62 & 33.28 \\
\hline Railway System & 4.63 & 1.18 & 7.39 \\
\hline
\end{tabular}

Although some of these factors were averaged from different sources in different countries, the closest approximation was used to serve the purpose of this thesis.

\subsection{GIS Model Analysis and Reliability Assessment}

In this thesis, a model using an ArcGIS ModelBuilder was developed to create a series of workflows that will help in achieving the research objectives. Appendix A and B shows the 
implemented complex GIS ModelBuilder of trucking, railway and intermodal systems that uses the data and parameters that were discussed earlier. This developed GIS model will be able to determine the optimum mode choice depending on the studied cases. As shown in Appendix C and D, Python scripting was also incorporated in creating the GIS model to incorporate equations, help in fixing the model errors and finally, to generalize the model analysis process which can be exported and used globally on any transport network considering differences in cost items, border issues and other impact factors.

Several hundred scenarios were created and analyzed to find the most reliable and costeffective results as shown in Appendix E. Figures 36 and 37 show a snapshot of the GIS ModelBuilder results and the route selected between Kuwait to Muscat using trucking and rail systems.

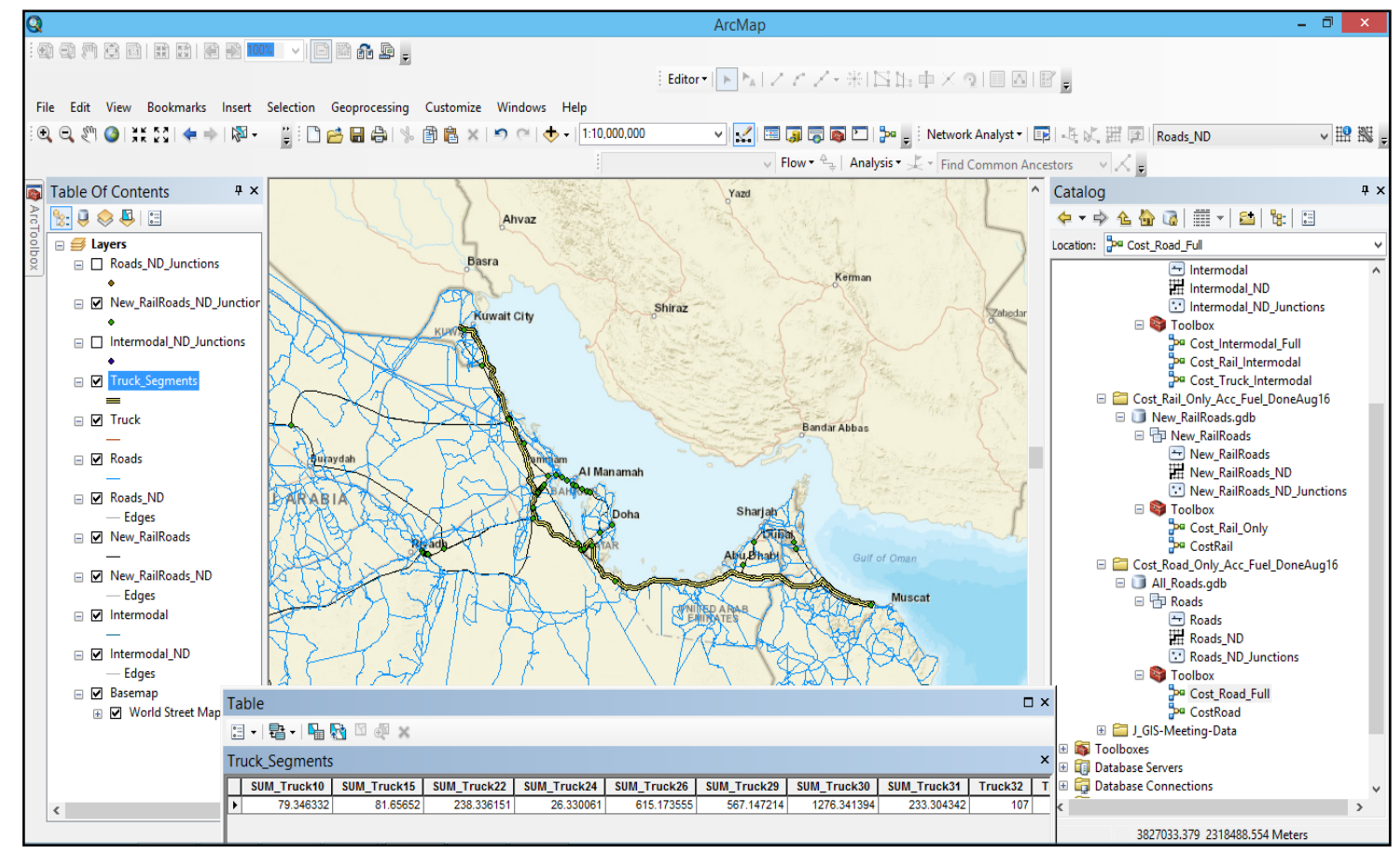

Truck 10: Infrastructure Maintenance Cost per Truck, Truck 15: Truck Capital cost, 22: Truck operation cost, Truck 24: Truck Maintenance Cost, Truck 26: Noise Cost, Truck 29: Accident Cost, Truck 30: Pollution Cost, Truck 31: Avg Depreciation Cost, Truck, Truck 32: Trucking Border Delay Cost per day

Figure 36. GIS ModelBuilder Road selected results snapshot. 


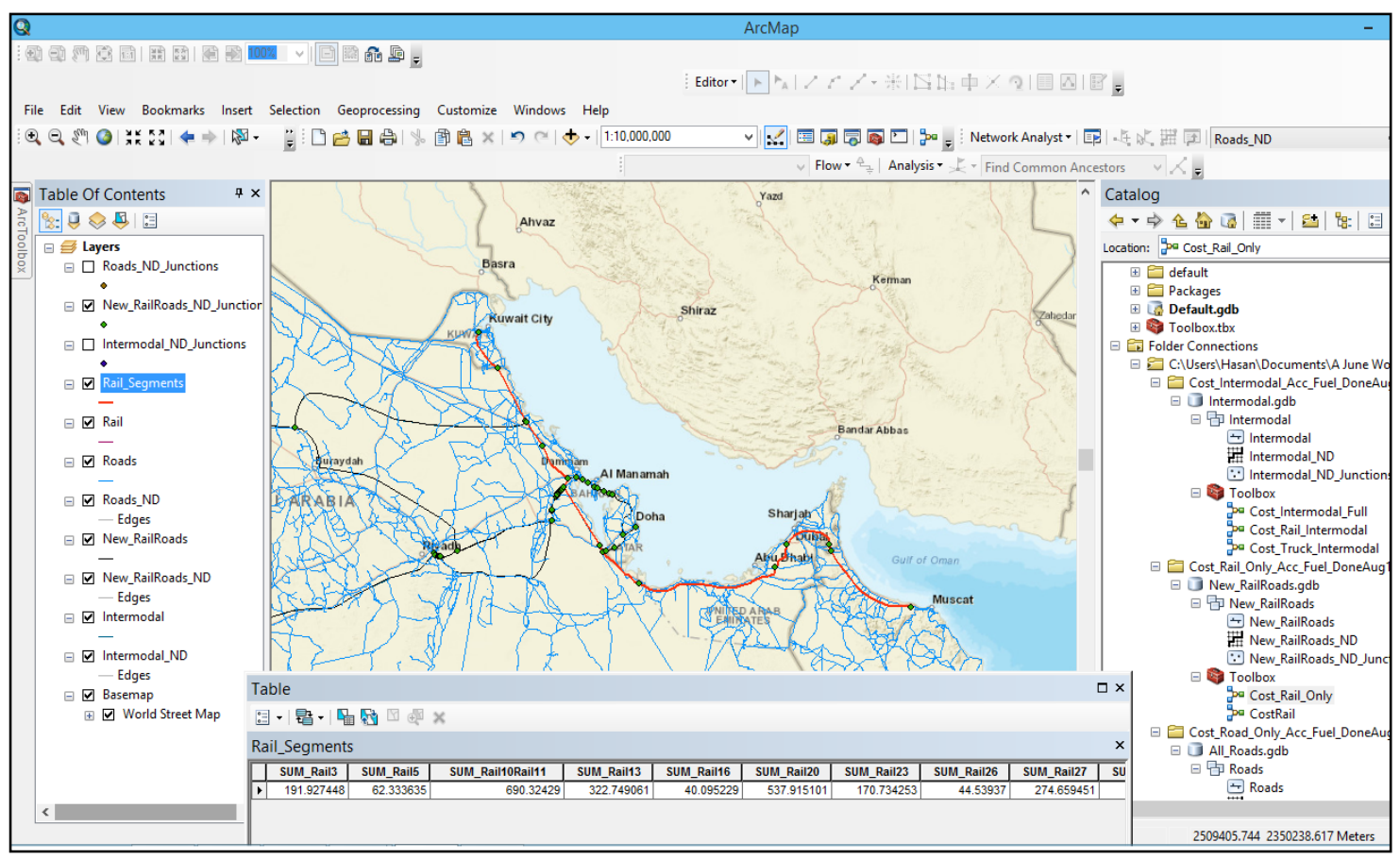

Rail 3: Infrastructure Cost per Wagon, Rail 5: Infrastructure Maintenance Cost per Wagon, Rail 10 + 11: Rail Capital cost (Loco \&Wagon), Rail 13: Rail Operation Cost (Driver), Rail 16: Rail Operation Cost (Fuel), Rail 20: Rail Maintenance Cost, Rail 23: Noise Cost, Rail 26: Accident Cost, Rail 27: Pollution Cost

Figure 37 GIS ModelBuilder Rail selected results snapshot.

Tables 17, 18 and 19 summarize the initial results of the total LCCA model utilizing doorto-door and ramp-to-ramp services for both modes for different shipping distances, with three different origin and destination scenarios being posed in each. 
Table 17 Trucking Life-Cycle Cost Analysis results in US\$.

\begin{tabular}{|c|c|c|c|c|c|c|c|c|c|}
\hline \multirow{5}{*}{ Trucking system } & \multicolumn{9}{|c|}{ US\$ } \\
\hline & \multicolumn{9}{|c|}{$\frac{\text { USS }}{\text { Rivadh to Abu-Dhahi }}$} \\
\hline & \multicolumn{3}{|c|}{ Distance (km) } & \multicolumn{3}{|c|}{ Distance (km) } & \multicolumn{3}{|c|}{ Distance (km) } \\
\hline & \multicolumn{3}{|c|}{399} & \multicolumn{3}{|c|}{980} & \multicolumn{3}{|c|}{1347} \\
\hline & \multicolumn{3}{|c|}{ Tonnage (Tons) } & \multicolumn{3}{|c|}{ Tonnage (Tons) } & \multicolumn{3}{|c|}{ Tonnage (Tons) } \\
\hline Truck & 23 & 46 & 69 & 23 & 46 & 69 & 23 & 46 & 69 \\
\hline Infrastructure Cost & 23.2 & 46.3 & 69.5 & 56.9 & 113.9 & 170.8 & 78.2 & 156.4 & 234.7 \\
\hline Infrastructure Maintenance Cost & 19.0 & 38.0 & 57.0 & 46.7 & 93.4 & 140.1 & 64.1 & 128.3 & 192.4 \\
\hline Truck Capital Cost & 19.6 & 39.1 & 58.7 & 48.0 & 96.1 & 144.1 & 66.0 & 132.0 & 198.0 \\
\hline Truck Maintenance Cost & 6.3 & 12.6 & 18.9 & 15.5 & 31.0 & 46.5 & 21.3 & 42.6 & 63.8 \\
\hline Truck Operation Cost & 49.6 & 99.1 & 148.7 & 130.7 & 261.3 & 392.0 & 187.3 & 374.6 & 562.0 \\
\hline Avg. Depreciation Cost & 55.9 & 111.7 & 167.6 & 137.3 & 274.5 & 411.8 & 188.6 & 377.1 & 565.7 \\
\hline Noise Cost & 73.6 & 147.3 & 220.9 & 181.0 & 361.9 & 542.9 & 348.0 & 696.1 & 1044.1 \\
\hline Accident Cost & 165.8 & 331.7 & 497.5 & 338.9 & 677.7 & 1016.6 & 483.9 & 967.8 & 1451.8 \\
\hline Pollution Cost & 305.6 & 611.2 & 916.8 & 750.9 & 1501.9 & 2252.8 & 1031.6 & 2063.1 & 3094.7 \\
\hline Trucking Border Delay Cost per day & 107.0 & 214.0 & 321.0 & 107.0 & 214.0 & 321.0 & 107.0 & 214.0 & 321.0 \\
\hline Handling, Loading \& Unloading Cost / Container & 104.0 & 208.0 & 312.0 & 104.0 & 208.0 & 312.0 & 104.0 & 208.0 & 312.0 \\
\hline Total Life-Cycle Cost US\$ & 822.5 & 1645.1 & 2467.6 & 1809.9 & 3619.8 & 5429.6 & 2573.0 & 5146.1 & 7719.1 \\
\hline Total Life-Cycle Cost US\$ With 1 day of delay & 929.5 & 1859.1 & 2788.6 & 1916.9 & 3833.8 & 5750.6 & 2680.0 & 5360.1 & 8040.1 \\
\hline Total Life-Cycle Cost US\$ With 3 days of delay & 1143.5 & 2287.1 & 3430.6 & 2130.9 & 4261.8 & 6392.6 & 2894.0 & 5788.1 & 8682.1 \\
\hline
\end{tabular}


Table 18 Railway Life-Cycle Cost Analysis results in US\$.

\begin{tabular}{|c|c|c|c|c|c|c|c|c|c|}
\hline \multirow{5}{*}{ Railway system } & \multicolumn{9}{|c|}{ US\$ } \\
\hline & \multirow{2}{*}{\multicolumn{3}{|c|}{$\begin{array}{c}\text { Kuwait City to Jubail } \\
\text { Distance (km) }\end{array}$}} & \multicolumn{3}{|c|}{ Riyadh to Abu-Dhabi } & \multicolumn{3}{|c|}{ Dubai to Kuwait City } \\
\hline & & & & \multicolumn{3}{|c|}{ Distance (km) } & \multicolumn{3}{|c|}{ Distance (km) } \\
\hline & \multicolumn{3}{|c|}{$\mathbf{3 0 7}$} & \multicolumn{3}{|c|}{1033} & \multicolumn{3}{|c|}{1230} \\
\hline & \multicolumn{3}{|c|}{ Tonnage (Tons) } & \multicolumn{3}{|c|}{ Tonnage (Tons) } & \multicolumn{3}{|c|}{ Tonnage (Tons) } \\
\hline Rail & 23 & 46 & 69 & 23 & 46 & 69 & 23 & 46 & 69 \\
\hline Infrastructure Cost & 36.5 & 36.5 & 36.5 & 122.8 & 122.8 & 122.8 & 146.3 & 146.3 & 146.3 \\
\hline Infrastructure Maintenance Cost & 11.9 & 11.9 & 11.9 & 39.9 & 39.9 & 39.9 & 47.5 & 47.5 & 47.5 \\
\hline Rail Capital cost (Loco \&Wagon) & 131.4 & 131.4 & 131.4 & 441.8 & 441.8 & 441.8 & 526.2 & 526.2 & 526.2 \\
\hline Rail Maintenance Cost & 102.4 & 102.4 & 102.4 & 344.3 & 344.3 & 344.3 & 410.0 & 410.0 & 410.0 \\
\hline Rail Operation Cost & 67.6 & 73.7 & 79.9 & 228.7 & 250.7 & 272.8 & 274.7 & 303.3 & 332.0 \\
\hline Depreciation Cost (Loco \& Wagon) & 141.9 & 141.9 & 141.9 & 477.2 & 477.2 & 477.2 & 568.3 & 568.3 & 568.3 \\
\hline Noise Cost & 16.2 & 65.0 & 54.6 & 54.6 & 109.3 & 163.9 & 91.1 & 182.2 & 273.3 \\
\hline Accident Cost & 8.5 & 17.0 & 25.4 & 28.5 & 57.0 & 85.5 & 34.0 & 418.7 & 628.1 \\
\hline Pollution Cost & 52.3 & 104.5 & 156.8 & 175.8 & 351.6 & 527.4 & 209.4 & 418.7 & 628.1 \\
\hline Handling, Loading \& Unloading Cost & 122.5 & 245.1 & 367.6 & 122.5 & 245.1 & 367.6 & 122.5 & 245.1 & 367.6 \\
\hline Total Life-Cycle Cost US\$ & 691.1 & 929.3 & 1108.4 & 2036.1 & 2439.8 & 2843.3 & 2430.0 & 3266.5 & 3927.5 \\
\hline
\end{tabular}


Table 19 Intermodal Life-Cycle Cost Analysis results in US\$.

\begin{tabular}{|c|c|c|c|c|c|c|c|c|c|}
\hline \multirow{5}{*}{ Railway system } & \multicolumn{9}{|c|}{ US\$ } \\
\hline & \multicolumn{3}{|c|}{ Kuwait City to Jubail } & \multicolumn{3}{|c|}{ Riyadh to Abu-Dhabi } & \multicolumn{3}{|c|}{ Dubai to Kuwait City } \\
\hline & \multicolumn{3}{|c|}{ Distance (km) } & \multicolumn{3}{|c|}{ Distance (km) } & \multicolumn{3}{|c|}{ Distance (km) } \\
\hline & \multicolumn{3}{|c|}{307} & \multicolumn{3}{|c|}{1033} & \multicolumn{3}{|c|}{1230} \\
\hline & \multicolumn{3}{|c|}{ Tonnage (Tons) } & \multicolumn{3}{|c|}{ Tonnage (Tons) } & \multicolumn{3}{|c|}{ Tonnage (Tons) } \\
\hline Rail & 23 & 46 & 69 & 23 & 46 & 69 & 23 & 46 & 69 \\
\hline Infrastructure Cost per Wagon & 36.5 & 36.5 & 36.5 & 122.8 & 122.8 & 122.8 & 146.3 & 146.3 & 146.3 \\
\hline Infrastructure Maintenance Cost per Wagon & 11.9 & 11.9 & 11.9 & 39.9 & 39.9 & 39.9 & 47.5 & 47.5 & 47.5 \\
\hline Rail Capital cost (Loco \&Wagon) & 131.4 & 131.4 & 131.4 & 441.8 & 441.8 & 441.8 & 526.2 & 526.2 & 526.2 \\
\hline Rail Maintenance Cost & 102.4 & 102.4 & 102.4 & 344.3 & 344.3 & 344.3 & 410.0 & 410.0 & 410.0 \\
\hline Rail Operation Cost & 67.6 & 73.7 & 79.9 & 228.7 & 250.7 & 272.8 & 274.7 & 303.3 & 332.0 \\
\hline Depreciation Cost (Loco \&Wagon) & 141.9 & 141.9 & 141.9 & 477.2 & 477.2 & 477.2 & 568.3 & 568.3 & 568.3 \\
\hline Noise Cost & 16.2 & 65.0 & 54.6 & 54.6 & 109.3 & 163.9 & 91.1 & 182.2 & 273.3 \\
\hline Accident Cost & 8.5 & 17.0 & 25.4 & 28.5 & 57.0 & 85.5 & 34.0 & 67.9 & 101.9 \\
\hline Pollution Cost & 52.3 & 104.5 & 156.8 & 175.8 & 351.6 & 527.4 & 209.4 & 418.7 & 628.1 \\
\hline
\end{tabular}


Continue Table 19

\begin{tabular}{|c|c|c|c|c|c|c|c|c|c|}
\hline \multirow{5}{*}{ Trucking system } & \multicolumn{9}{|c|}{ US\$ } \\
\hline & \multirow{2}{*}{\multicolumn{3}{|c|}{$\begin{array}{c}\text { Kuwait City to Jubail } \\
\text { Distance }(\mathrm{km})\end{array}$}} & \multicolumn{3}{|c|}{ Riyadh to Abu-Dhabi } & \multicolumn{3}{|c|}{ Dubai to Kuwait City } \\
\hline & & & & \multicolumn{3}{|c|}{ Distance (km) } & \multicolumn{3}{|c|}{ Distance (km) } \\
\hline & \multicolumn{3}{|c|}{136} & \multicolumn{3}{|c|}{41} & \multicolumn{3}{|c|}{54} \\
\hline & \multicolumn{3}{|c|}{ Tonnage (Tons) } & \multicolumn{3}{|c|}{ Tonnage (Tons) } & \multicolumn{3}{|c|}{ Tonnage (Tons) } \\
\hline Truck & 23 & 46 & 69 & 23 & 46 & 69 & 23 & 46 & 69 \\
\hline Infrastructure Cost & 7.9 & 15.8 & 23.7 & 2.4 & 4.8 & 7.2 & 3.2 & 6.3 & 9.5 \\
\hline Infrastructure Maintenance Cost & 6.5 & 13.0 & 19.5 & 2.0 & 4.0 & 5.9 & 2.6 & 5.2 & 7.8 \\
\hline Truck Capital cost & 6.7 & 13.4 & 20.0 & 2.0 & 4.0 & 6.0 & 2.7 & 5.3 & 8.0 \\
\hline Truck Maintenance Cost & 2.2 & 4.3 & 6.5 & 0.6 & 1.3 & 1.9 & 0.9 & 1.7 & 2.6 \\
\hline Truck Operation Cost & 17.1 & 34.2 & 51.3 & 6.8 & 13.5 & 20.3 & 8.2 & 16.5 & 24.7 \\
\hline Avg. Depreciation Cost & 19.1 & 38.1 & 57.2 & 5.7 & 11.5 & 17.2 & 7.6 & 15.2 & 22.8 \\
\hline Noise Cost & 50.3 & 50.3 & 75.4 & 7.6 & 15.2 & 22.7 & 14.0 & 28.1 & 42.1 \\
\hline Accident Cost & 56.6 & 113.2 & 169.9 & 9.0 & 18.1 & 27.1 & 20.2 & 40.4 & 60.5 \\
\hline Pollution Cost & 104.3 & 208.7 & 313.0 & 31.4 & 62.9 & 94.3 & 41.6 & 83.2 & 124.9 \\
\hline Total Handling, Loading \& Unloading Cost / Container & 330.5 & 661.1 & 991.6 & 330.5 & 661.1 & 991.6 & 330.5 & 661.1 & 991.6 \\
\hline Total Life-Cycle Cost US\$ & 1169.7 & 1836.3 & 2468.8 & 2311.8 & 2991.0 & 3670.0 & 2739.0 & 3533.6 & 4328.1 \\
\hline
\end{tabular}


In focusing on the second scenario (as an example), the cost of truck shipping that can carry 23 tons from Riyadh to Abu-Dhabi is about 1809.90 US\$. However, as the delay increases, the shipping cost increases up to 2130.90 US\$ after a three-day delay at the border. Then, when using a rail system transporting for the same tonnage, the cost will be around 2036.10 US\$, while an intermodal system can also cost about 2311.80 US\$. If, however, the commodities being transported were higher in weight, then rail and intermodal would be favoured over trucking systems, particularly when considering the delay factor as shown in Figure 38.

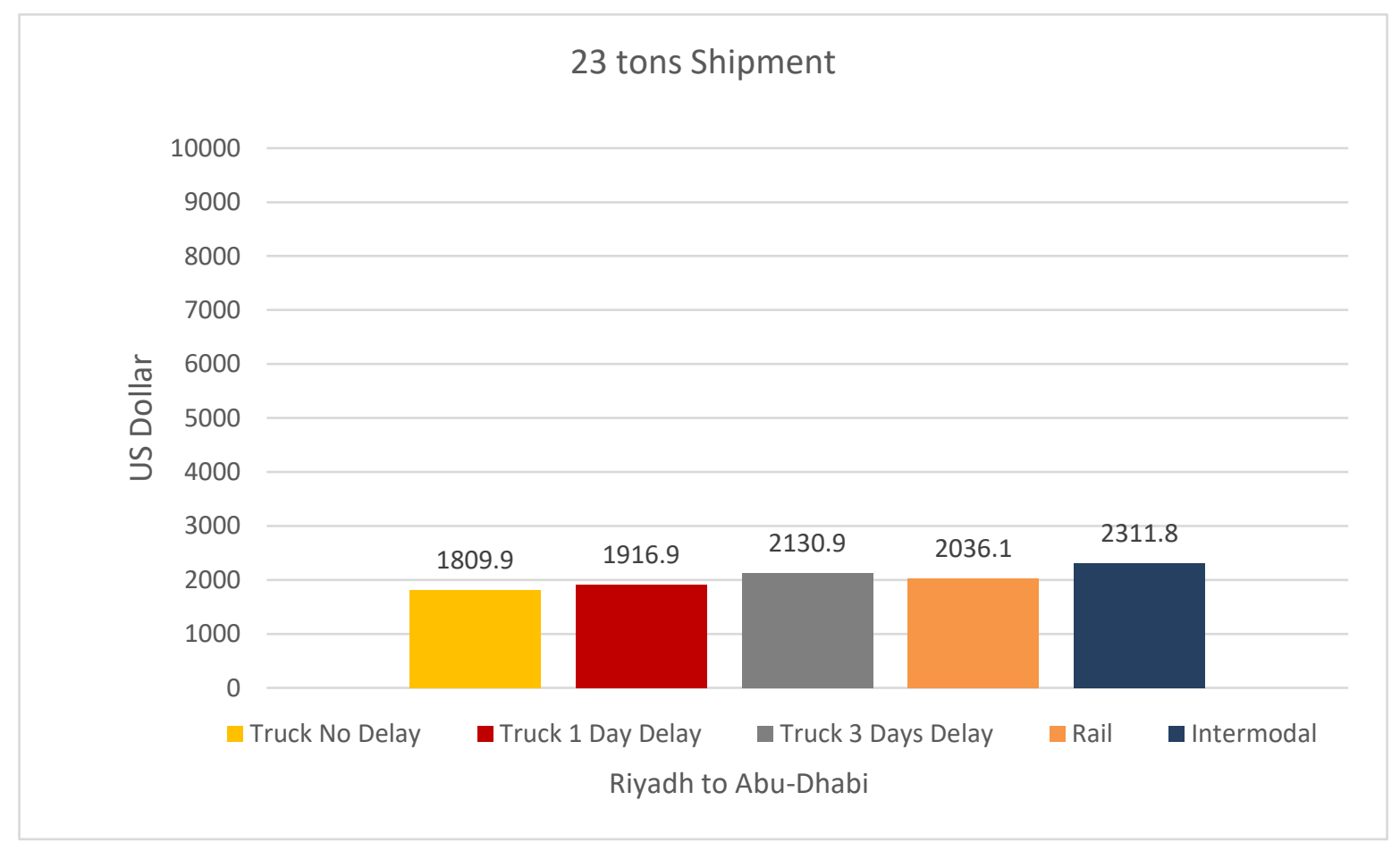

Continue Figure 38 


\section{6 tons Shipment}
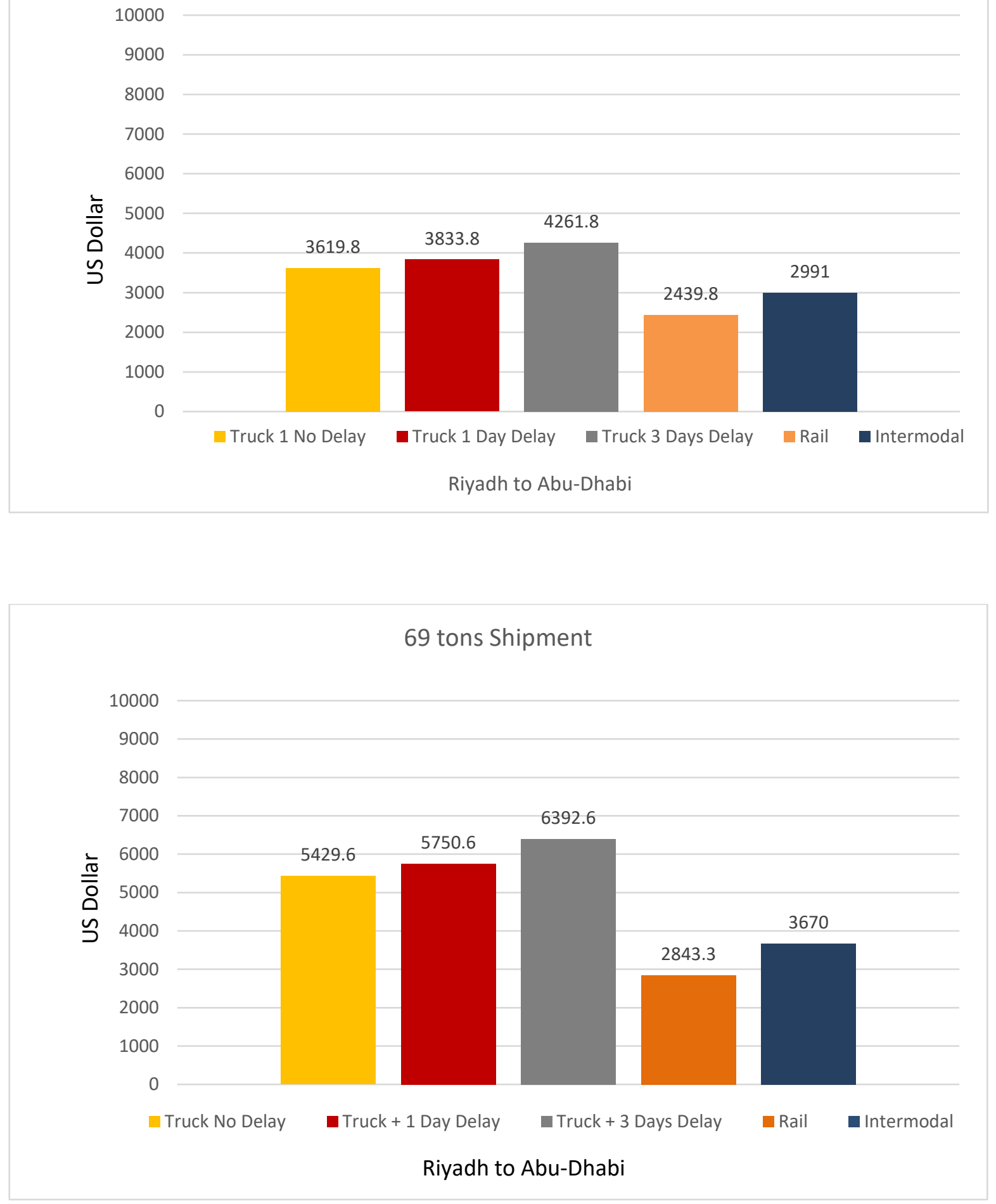

Figure 38 Total shipping cost of various shipment weights from Riyadh to Kuwait using trucking, railway and intermodal systems. 
These scenarios presented above provide key insight about when and where shifts in mode selection are practical and reflective of cost reduction. As a result, substantive statements on what mode works best in which scenario can be made. To expand upon one of these scenarios, using an intermodal system for transporting goods from Riyadh to Kuwait for bulk commodities weighing more than 69 tons is more reliable where delivery supports intermodal service, rather than having a stream of trucks waiting for border clearance. In conclusion, using a trucking system is less expensive between the GCC countries when having tonnages below 23 tons and for short distances. As the tonnage and distance between origins and destinations increase, using an intermodal system will be more reliable due to border delay issues.

\subsubsection{Model Validation Process}

As a first step of validating the developed model and to make sure that this model provides accurate and useful results that represent the real world, a cost tree analysis for trucking and rail systems has been established to make distinctions about responsibilities for particular costs. While there have been several discussions about cost as a broad category, the details of who is ultimately responsible for these costs are important ones. Figure 39 shows the cost tree diagram analysis for trucking systems. 


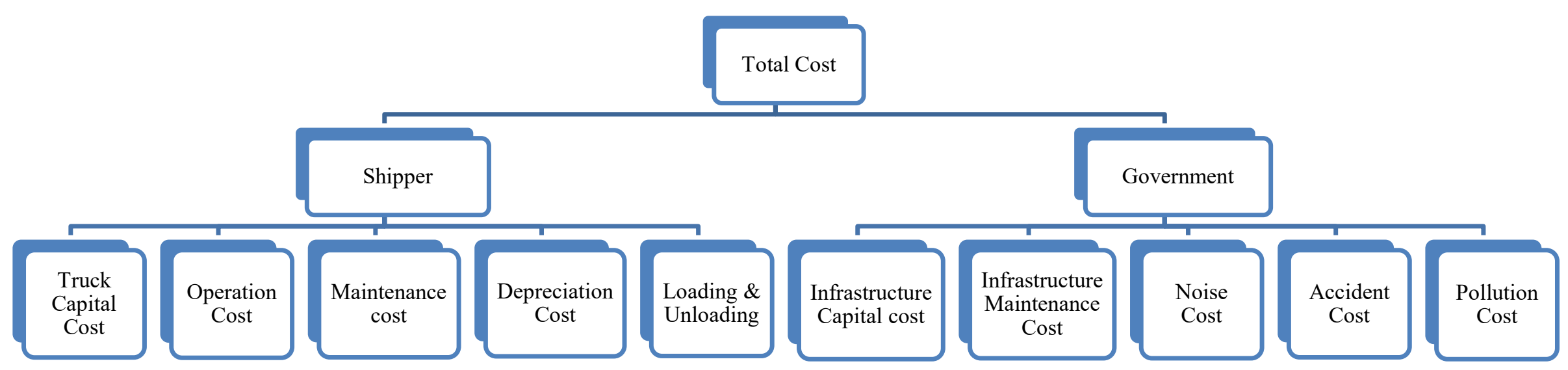

Figure 39 Trucking cost tree diagram. 
Based on data obtained from a shipping logistics group in Saudi Arabia, it has been found that the shipper was only responsible to pay for truck capital, operation, maintenance and depreciation costs. In order to compare the results, only those individual items have been included. Table 20 shows the comparison between the model results and real world truck shipping costs.

Table 20 Trucking real cost vs. the developed model cost.

\begin{tabular}{|c|c|c|c|c|c|}
\hline Origin & Destination & $\mathbf{k m}$ & Market Real & Model & Difference\% \\
\hline Dammam & Dammam & 30 & 120 & 114.55 & 4.65 \\
\hline Dammam & Bahrain & 100 & 150 & 138.44 & 8.02 \\
\hline Dammam & Jubail & 119 & 150 & 144.86 & 3.49 \\
\hline Dammam & Hofuf & 167 & 170 & 161.01 & 5.43 \\
\hline Dammam & Qatar & 399 & 260 & 238.24 & 8.73 \\
\hline Dammam & Riyadh & 405 & 260 & 240.23 & 7.91 \\
\hline Dammam & Kuwait & 471 & 280 & 262.03 & 6.63 \\
\hline Dammam & UAE & 827 & 410 & 378.94 & 7.87 \\
\hline Dammam & Oman & 1395 & 600 & 563.89 & 6.20 \\
\hline Dammam & Jeddah & 1366 & 600 & 554.48 & 7.88 \\
\hline
\end{tabular}

As for rail, Figure 40 shows the cost tree analysis for the railway system. Based on data obtained from the Saudi Railways Organization, operating the lines between Riyadh and Dammam required that the shipper's payment cover the operational and maintenance cost of the rail and wagons. 


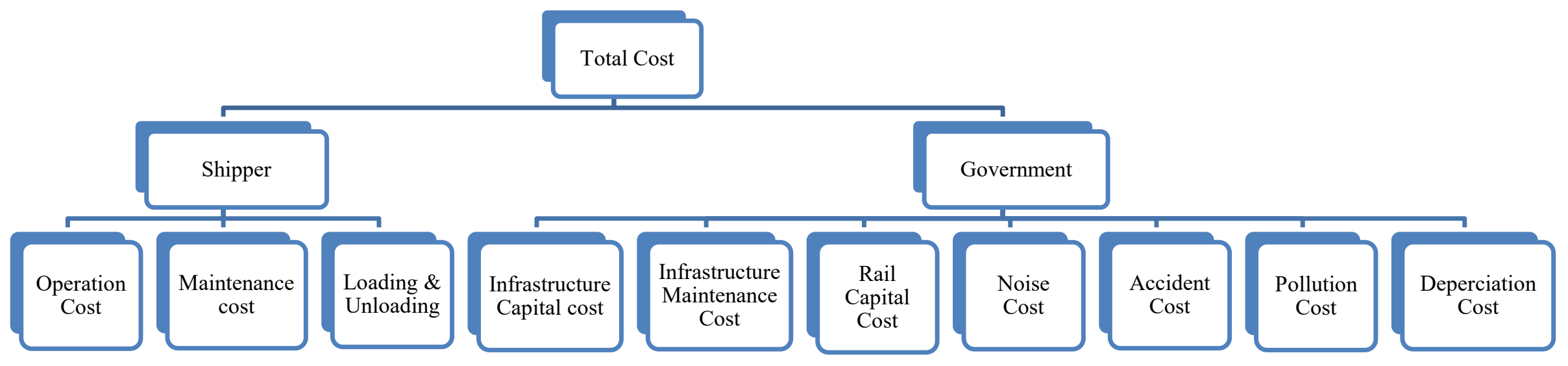

Figure 40 Railway cost tree diagram. 
Due to the limitations of the current rail freight system in operation within the GCC region, the only shipment cost that has been compared with the developed model is a shipment between Riyadh and Dammam. Table 21 shows the comparison between the model results and the real world rail shipping costs between the capital region of Saudi Arabia and the east coast.

Table 21 Railway real cost vs. the developed model cost.

\begin{tabular}{|c|c|c|c|c|c|}
\hline Origin & Destination & km & Market Real & Model & Difference\% \\
\hline Dammam & Riyadh & 459 & 391.1 & 375 & 4.15 \\
\hline
\end{tabular}

So, based on the above results, it has been found that the developed model can predict the total cost of shipping using railway and trucking systems with an average accuracy of $6 \%$.

As the total cost represents the cost incurred by governments and shippers, Figure 41 shows that the government shares a large amount of the total life-cycle cost, particularly for rail systems, and this share increases as the distance and shipment size increases.

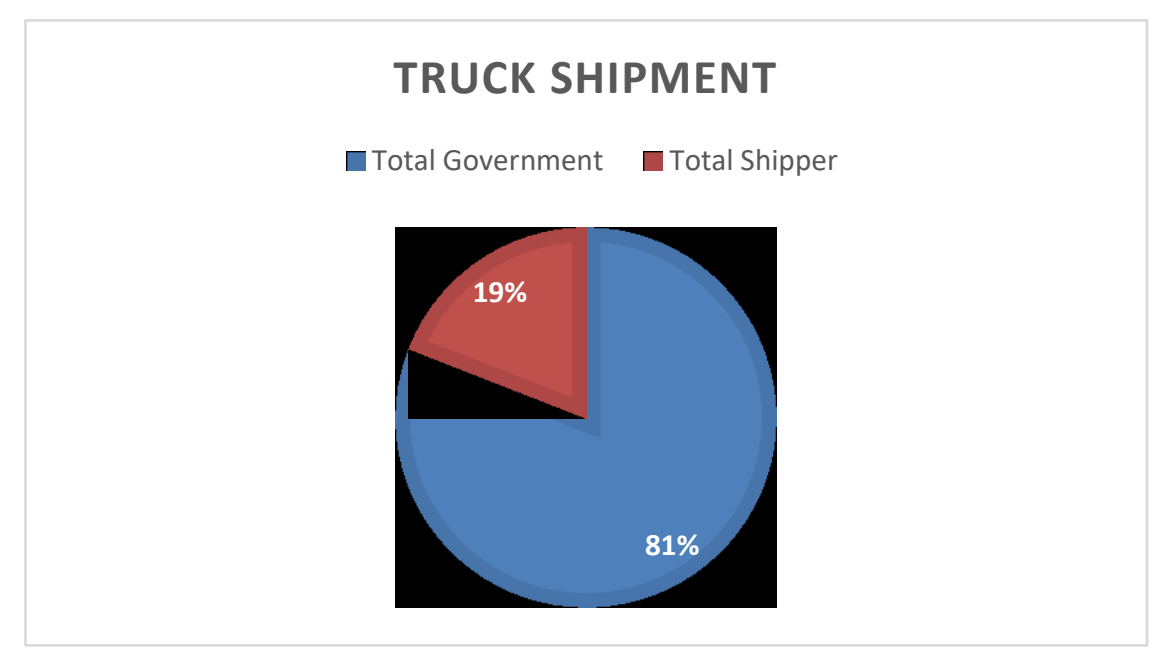

Continue Figure 41 


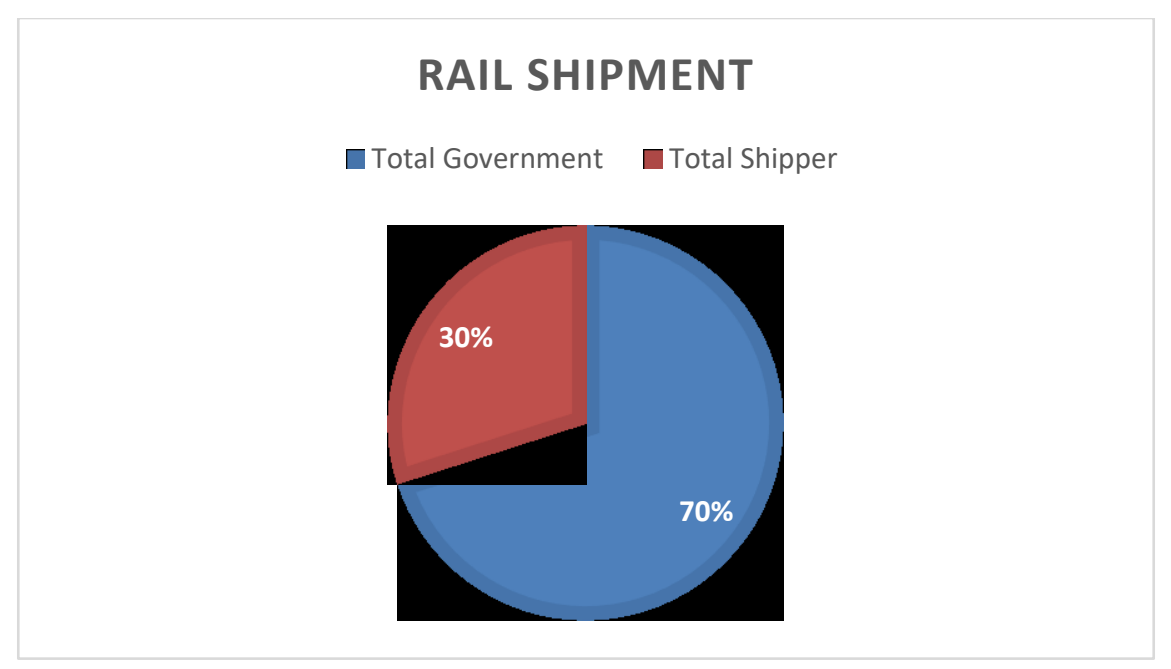

Figure 41 Total life-cycle cost percentages.

Governments within the GCC area should give consideration to ways in which this share can be recovered via taxes, toll fees and other forms of revenue to help in improving road safety, reducing noise, implementing existing ideas to reduce air pollution and finally, providing support for infrastructure construction and maintenance costs.

In addition, a statistical relationship between each type of cost in relation with the total distance of the shipment has been conducted as shown in Figure 42. Applying these statistical relationships can help shippers and governments calculate costs for any specific operation. 

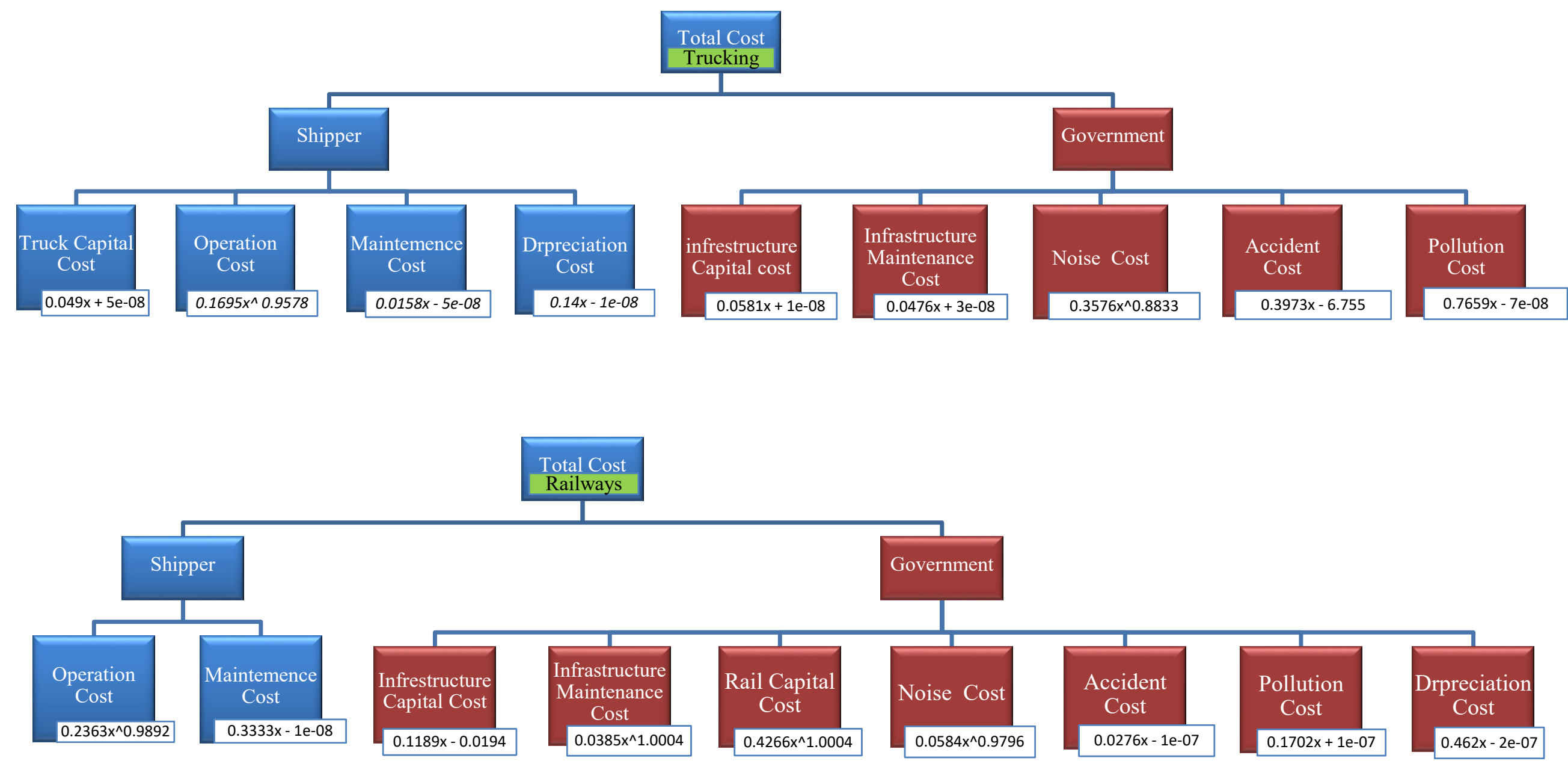

Figure 42 Freight Shipping cost breakdown equations of the GCC region. 
The following statistical equations summarize the total life cycle cost regression analysis results for both trucking and rail systems:

$$
\begin{gathered}
\text { Truck Total Cost }=-6.755+(1.47 * \text { distance })+\left(0.1695 * \text { distance }^{0.9578}\right)+ \\
\left(0.3576 * \text { distanc } e^{0.8833}\right)+(107 \text { delay } / \text { day }+104 \text { loading \& unloading })
\end{gathered}
$$

Truck Total Cost $=\left(2.068 *\right.$ distanc $\left.e^{0.9723}\right)+(107$ delay $/$ day + 104 loading \& unloading)

Based on the equations above, several shipments have been applied and compared with the GIS output. It shows that the equations can predict the total cost with an average around $6 \%$ difference in total cost as shown in Table 22.

Table 22. Sample of the comparison cost results between the statistical equations and GIS model (Trucking system).

\begin{tabular}{|c|c|c|c|c|c|}
\hline $\begin{array}{c}\text { Distance } \\
(\mathbf{k m})\end{array}$ & $\begin{array}{c}\text { GIS } \\
\text { Model }\end{array}$ & Equation 19 & Difference\% & Equation 20 & Difference\% \\
\hline 70.70 & 127.08 & 122.83 & 3.40 & 129.99 & -2.26 \\
\hline 105.70 & 183.87 & 185.67 & -0.97 & 192.17 & -4.42 \\
\hline 207.22 & 371.76 & 366.43 & 1.44 & 369.80 & 0.53 \\
\hline 338.97 & 607.75 & 599.13 & 1.43 & 596.72 & 1.83 \\
\hline 340.12 & 611.99 & 601.15 & 1.79 & 598.69 & 2.20 \\
\hline 430.31 & 715.67 & 759.69 & -5.97 & 752.53 & -5.02 \\
\hline 485.11 & 905.90 & 855.78 & 5.69 & 845.54 & 6.89 \\
\hline 503.80 & 906.49 & 888.53 & 2.00 & 877.21 & 3.28 \\
\hline 549.95 & 967.77 & 969.30 & -0.16 & 955.24 & 1.30 \\
\hline 599.31 & 1110.02 & 1055.61 & 5.03 & 1038.51 & 6.66 \\
\hline
\end{tabular}


Continue Table 22

\begin{tabular}{|c|c|c|c|c|c|}
\hline 773.01 & 1332.87 & 1358.60 & -1.91 & 1330.08 & 0.21 \\
\hline 792.65 & 1368.37 & 1392.81 & -1.77 & 1362.93 & 0.40 \\
\hline 890.41 & 1567.17 & 1562.89 & 0.27 & 1526.10 & 2.66 \\
\hline 893.69 & 1606.44 & 1568.60 & 2.38 & 1531.58 & 4.77 \\
\hline 932.73 & 1642.65 & 1636.45 & 0.38 & 1596.58 & 2.84 \\
\hline 965.87 & 1682.18 & 1694.01 & -0.70 & 1651.71 & 1.83 \\
\hline 998.80 & 1712.45 & 1751.20 & -2.24 & 1706.44 & 0.35 \\
\hline 1020.08 & 1779.42 & 1788.14 & -0.49 & 1741.78 & 2.14 \\
\hline 1028.12 & 1847.37 & 1802.09 & 2.48 & 1755.13 & 5.12 \\
\hline 1058.62 & 1848.71 & 1855.01 & -0.34 & 1805.73 & 2.35 \\
\hline 1109.17 & 1917.17 & 1942.69 & -1.32 & 1889.51 & 1.45 \\
\hline 1113.47 & 1932.27 & 1950.13 & -0.92 & 1896.63 & 1.86 \\
\hline 1132.15 & 1940.30 & 1982.53 & -2.15 & 1927.57 & 0.66 \\
\hline 1160.98 & 2081.11 & 2032.48 & 2.36 & 1975.26 & 5.22 \\
\hline 1203.54 & 2070.98 & 2106.22 & -1.69 & 2045.63 & 1.23 \\
\hline 1247.14 & 2144.34 & 2181.72 & -1.73 & 2117.66 & 1.25 \\
\hline 1339.89 & 2312.90 & 2342.23 & -1.26 & 2270.63 & 1.84 \\
\hline 1355.59 & 2384.71 & 2369.40 & 0.64 & 2296.50 & 3.77 \\
\hline 1443.82 & 2475.28 & 2521.94 & -1.87 & 2441.70 & 1.37 \\
\hline 1473.77 & 2581.50 & 2573.69 & 0.30 & 2490.93 & 3.57 \\
\hline 1480.40 & 2588.16 & 2585.15 & 0.12 & 2501.83 & 3.39 \\
\hline 1501.20 & 2690.87 & 2621.08 & 2.63 & 2536.00 & 5.93 \\
\hline 1541.24 & 2766.99 & 2690.23 & 2.81 & 2601.74 & 6.16 \\
\hline
\end{tabular}

Regarding railway systems, the following statistical equations summarize the total life cycle cost regression analysis results:

Total Cost $(23$ ton $)=-0.01940021+(1.112 *$ distance $)+\left(0.4651 *\right.$ distance $\left.^{1.0004}\right)+$ $\left(0.29 *\right.$ distance $\left.^{0.9892}\right)+(122.54$ loading \& unloading $)$ 
Total Cost $(23$ ton $)=1.8717$ distance $e^{0.9982}+(122.54$ loading \& unloading $)$

Total Cost $(46$ ton $)=-0.0194+(1.31 *$ distance $)+\left(0.4651 *\right.$ distance $\left.e^{1.0004}\right)+$

$\left(0.386^{*}\right.$ distance $\left.e^{0.9806}\right)+(254.08$ loading \& unloading $)$

Total Cost $(46$ ton $)=2.1628 *$ distance $e^{0.9969}+(254.08$ loading \& unloading $)$

Total Cost $(69$ ton $)=-0.0618+(1.51 *$ distance $)+\left(0.46 *\right.$ distance $\left.e^{1.0004}\right)+(0.48 *$ distance $\left.^{0.978}\right)+(367.62$ loading and unloading $)$

Total Cost $(69$ ton $)=2.4471 *$ distance $e^{0.9963}+(367.62$ loading \& unloading $)$

Based on the equations above several shipments have been applied and compared with the GIS output. It shows that the equations predict the total cost with an average of $1 \%$ difference in total cost as shown in Table 23.

Table 23. Sample of the comparison cost results between the statistical equations and GIS model (railway system -23 ton).

\begin{tabular}{|c|c|c|c|c|c|}
\hline $\begin{array}{c}\text { Distance } \\
\mathbf{( k m )}\end{array}$ & GIS Model & Equation 21 & Difference\% & Equation 22 & Difference\% \\
\hline 511.95 & 946.45 & 947.39 & -0.10 & 947.52 & -0.11 \\
\hline 1738.60 & 3177.94 & 3210.57 & -1.02 & 3210.72 & -1.03 \\
\hline 2024.31 & 3748.14 & 3737.20 & 0.29 & 3737.34 & 0.29 \\
\hline 2434.08 & 4459.38 & 4492.28 & -0.73 & 4492.38 & -0.74 \\
\hline 1377.22 & 2516.74 & 2544.25 & -1.09 & 2544.43 & -1.09 \\
\hline 217.90 & 405.28 & 403.84 & 0.36 & 403.92 & 0.34 \\
\hline 816.30 & 1518.01 & 1509.38 & 0.57 & 1509.54 & 0.56 \\
\hline
\end{tabular}


Continue Table 23

\begin{tabular}{|c|c|c|c|c|c|}
\hline 511.18 & 945.97 & 945.96 & 0.00 & 946.09 & -0.01 \\
\hline 729.08 & 1351.25 & 1348.37 & 0.21 & 1348.52 & 0.20 \\
\hline 872.30 & 1618.66 & 1612.74 & 0.37 & 1612.90 & 0.36 \\
\hline 179.50 & 331.92 & 332.78 & -0.26 & 332.85 & -0.28 \\
\hline 803.30 & 1490.13 & 1485.38 & 0.32 & 1485.54 & 0.31 \\
\hline 478.77 & 891.28 & 886.09 & 0.58 & 886.22 & 0.57 \\
\hline 671.40 & 1248.56 & 1241.87 & 0.54 & 1242.01 & 0.53 \\
\hline 272.80 & 507.61 & 505.38 & 0.44 & 505.47 & 0.42 \\
\hline 1340.94 & 2487.85 & 2477.35 & 0.42 & 2477.52 & 0.42 \\
\hline 2161.28 & 4003.28 & 3989.62 & 0.34 & 3989.75 & 0.34 \\
\hline 808.37 & 1503.70 & 1494.74 & 0.60 & 1494.89 & 0.59 \\
\hline 953.27 & 1773.15 & 1762.17 & 0.62 & 1762.34 & 0.61 \\
\hline
\end{tabular}

In conclusion, validating the GIS Model results prove that the developed life cycle cost analysis model for freight shipping using trucking and railway systems is viable and can be representative of real world scenarios. The creation of some equations can provide shippers and government actors with a rough estimate of costs and the impacts associated with shipments and mode selection. Therefore, these models are valuable tools for prediction and implementing rules and regulations to manage the shipping industry and its impacts.

\subsubsection{Effectiveness and Sensitivity Analysis}

In addition to the LCCA, fuel price changes, the amount of pollution produced and weather conditions can also be considered for effectiveness and sensitivity analysis within the context of this study as well as for future work that uses similar approaches laid out in this body of work. The implemented model that was built in this thesis demands annual updates on costs of freight transportation where possible, as the factors at hand are dynamic. In the context of fuel, increasing 
charges are far less of a problem for rail than for trucking due to the fuel-efficient nature of trains. Figure 43 shows the variation of the oil basket price for the last 14 years based on the information published by the Organization of the Petroleum Exporting Countries in 2016 to emphasize the importance of including updates on dynamic factors.

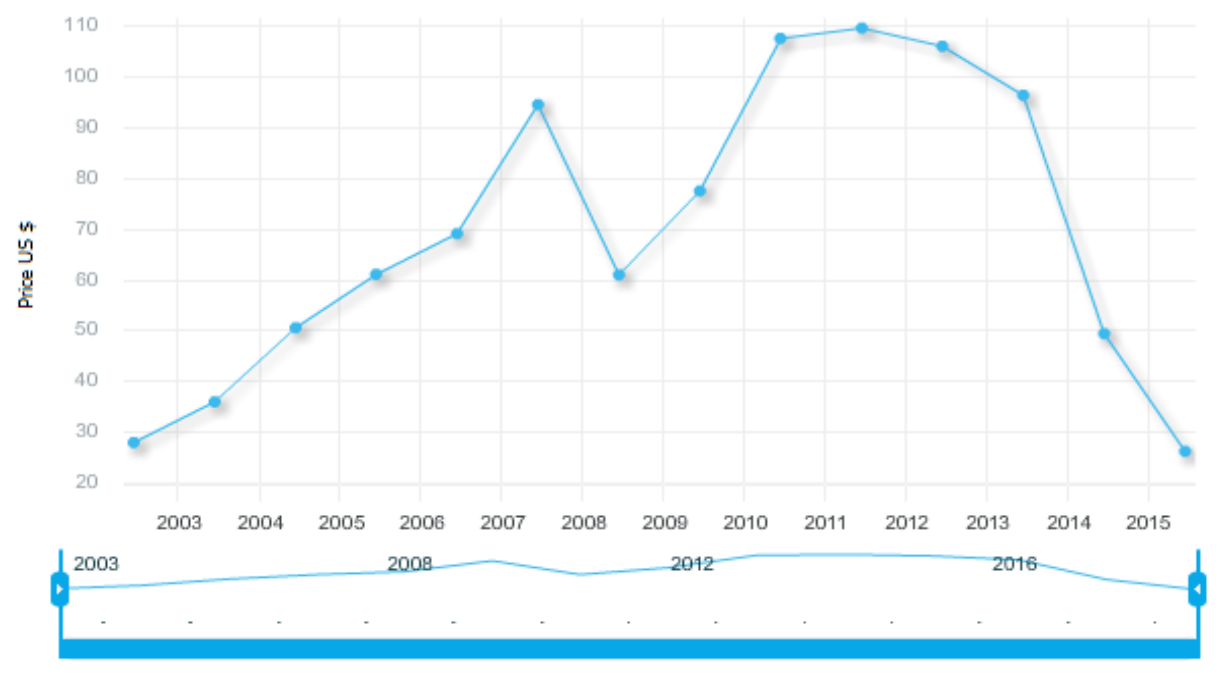

Figure 43 Oil basket price in variation in USD, OPEC, 2016.

Figure 44 shows the shipping cost results between several origins and destinations based on the implemented model before and after an increment of $50 \%, 100 \%, 200 \%$ and $300 \%$ of fuel price within the GCC region. 


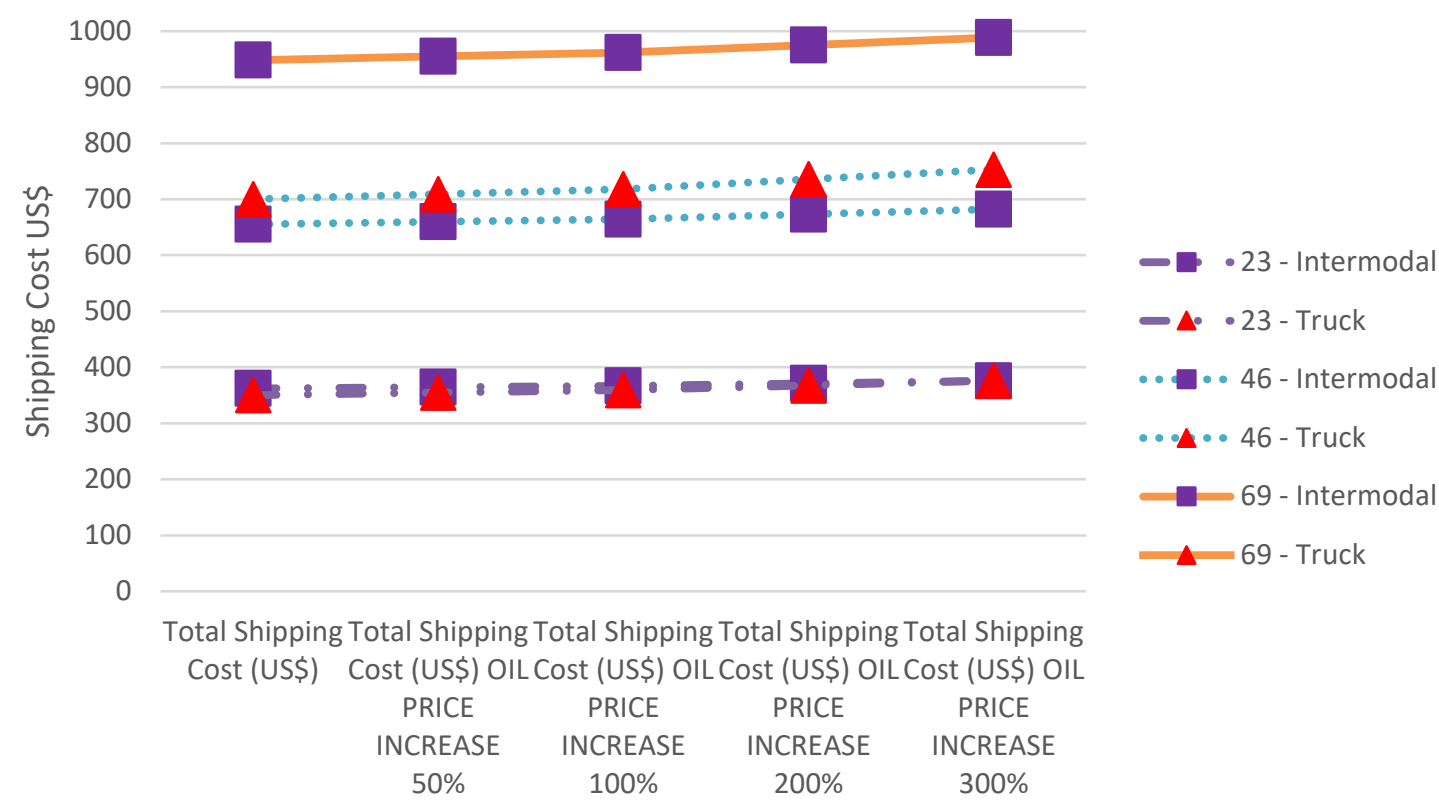

\section{Short Distance}

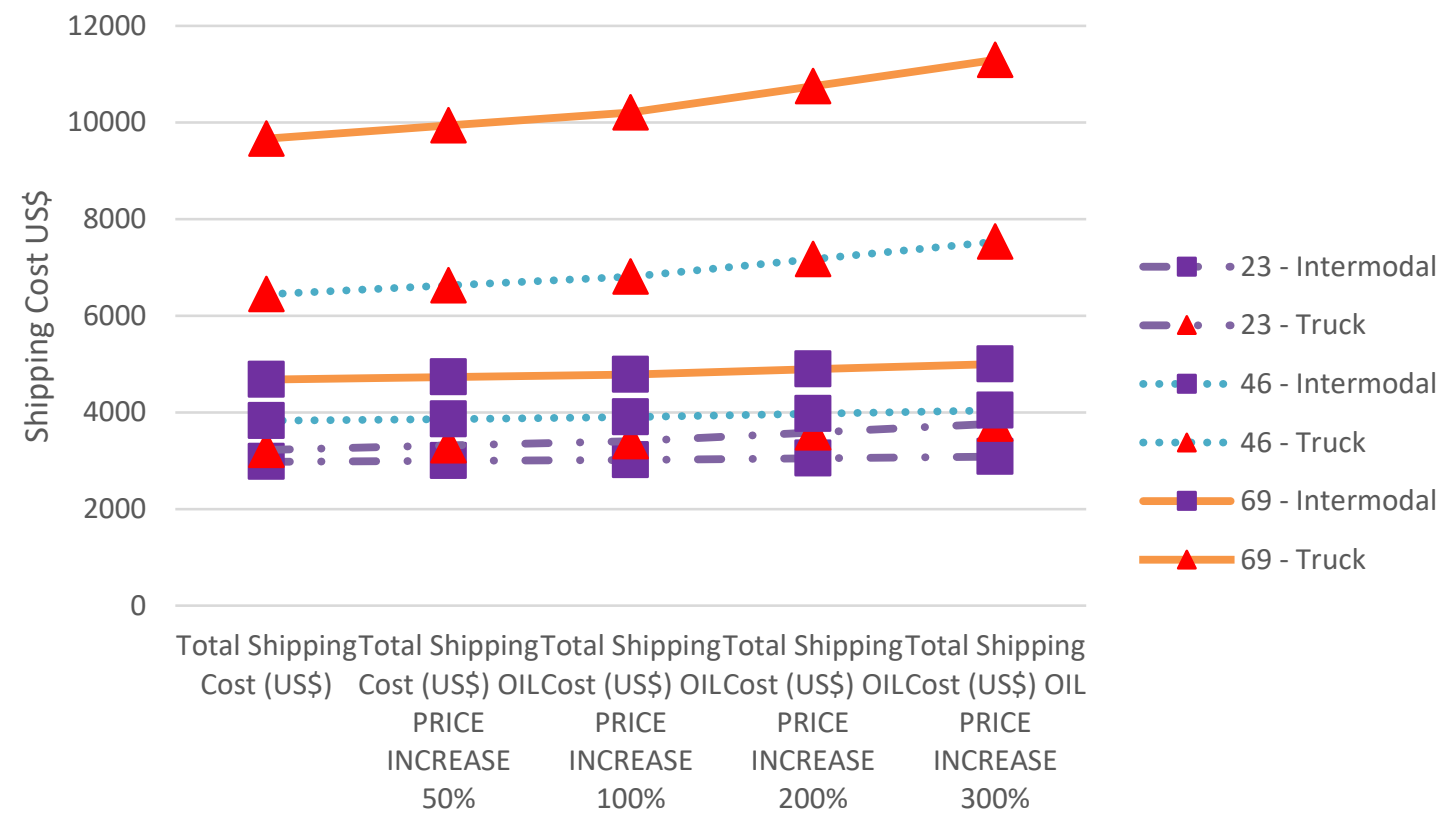

\section{Long Distance}

Figure 44 Impact of fuel price fluctuations on the total shipping cost. 
As shown above, increased fuel prices going up to $300 \%$ will increase the total truck shipping cost from 7 to $20 \%$ as the distance increases, while it will reach to 3 to $5 \%$ for intermodal shipping. An increase in fuel price definitely favours rail and intermodal systems even for small tonnages, particularly when border delays come into play with trucking systems. Based on the above analysis, oil prices can have a direct impact on the shipping cost, mode selection and decision-making processes.

As a method of summarizing the impact cost analysis by accounting for noise, pollution and accident costs, various origins and destinations were randomly selected to examine the model and achieve the thesis objectives. Table 24 summarizes the distance and the impact cost results of shipping a container using different tonnage between two origins and destinations.

Table 24 Shipping distances and the impact cost between the origins and destination.

\begin{tabular}{|c|c|c|c|c|c|c|}
\hline \multirow{3}{*}{ Origins and Destinations } & \multicolumn{6}{|c|}{ Distance } \\
\hline & \multirow{2}{*}{\multicolumn{2}{|c|}{$\begin{array}{c}\text { Trucking sys. } \\
\text { Truck }\end{array}$}} & \multicolumn{4}{|c|}{ Intermodal system } \\
\hline & & & \multicolumn{2}{|c|}{ Rail } & \multicolumn{2}{|c|}{ Truck } \\
\hline Kuwait City to Jubail & \multicolumn{2}{|c|}{399} & \multicolumn{2}{|c|}{307} & \multicolumn{2}{|c|}{136} \\
\hline Riyadh to Abu-Dhabi & \multicolumn{2}{|c|}{980} & \multicolumn{2}{|c|}{1033} & \multicolumn{2}{|c|}{41} \\
\hline Dubai to Kuwait City & \multicolumn{2}{|c|}{1347} & \multicolumn{2}{|c|}{1230} & \multicolumn{2}{|c|}{54} \\
\hline \multirow{3}{*}{ Origins and Destinations } & \multicolumn{6}{|c|}{ Impact Cost - Noise } \\
\hline & \multicolumn{3}{|c|}{ Truck } & \multicolumn{3}{|c|}{ Intermodal } \\
\hline & 23 & 46 & 69 & 23 & 46 & 69 \\
\hline Kuwait City to Jubail & 73.6 & 147.3 & 220.9 & 66.5 & 115.3 & 130.1 \\
\hline Riyadh to Abu-Dhabi & 181.0 & 361.9 & 542.9 & 62.2 & 124.4 & 186.7 \\
\hline Dubai to Kuwait City & 348.0 & 696.1 & 1044.1 & 105.1 & 210.3 & 315.4 \\
\hline \multirow{3}{*}{ Origins and Destinations } & \multicolumn{6}{|c|}{ Impact Cost - Accident } \\
\hline & \multicolumn{3}{|c|}{ Truck } & \multicolumn{3}{|c|}{ Intermodal } \\
\hline & 23 & 46 & 69 & 23 & 46 & 69 \\
\hline Kuwait City to Jubail & 165.8 & 331.7 & 497.5 & 65.1 & 130.2 & 195.3 \\
\hline Riyadh to Abu-Dhabi & 338.9 & 677.7 & 1016.6 & 37.5 & 75.1 & 112.6 \\
\hline Dubai to Kuwait City & 483.9 & 967.8 & 1451.8 & 54.1 & 108.3 & 162.4 \\
\hline
\end{tabular}


Continue Table 24

\begin{tabular}{|c|c|c|c|c|c|c|}
\hline \multirow{2}{*}{ Origins and Destinations } & \multicolumn{5}{|c|}{ Impact Cost- Pollution } \\
\cline { 2 - 7 } & \multicolumn{4}{|c|}{ Truck } & \multicolumn{3}{c|}{ Intermodal } \\
\cline { 2 - 7 } & 23 & 46 & 69 & 23 & 46 & 69 \\
\hline Kuwait City to Jubail & 305.6 & 611.2 & 916.8 & 156.6 & 313.2 & 469.8 \\
\hline Riyadh to Abu-Dhabi & 750.9 & 1501.9 & 2252.8 & 207.2 & 414.5 & 621.7 \\
\hline Dubai to Kuwait City & 1031.6 & 2063.1 & 3094.7 & 251.0 & 502.0 & 753.0 \\
\hline
\end{tabular}

Figure 45 shows a snapshot of the implemented GIS model showing the selected routes between Kuwait City and Jubail. It was expected that using the intermodal system would have less of an impact cost. An analysis like the one above will be beneficial for developing rules and regulations related to land freight transportation systems. This type of analysis is inclusive of dynamic factors (from which decisions and policies can be formulated taking into account the impact cost) and alternative routes. Plans on other origins and destinations are presented below in an effort to both rethink standard procedure and reduce some of the impacts of noise, accidents and pollution.
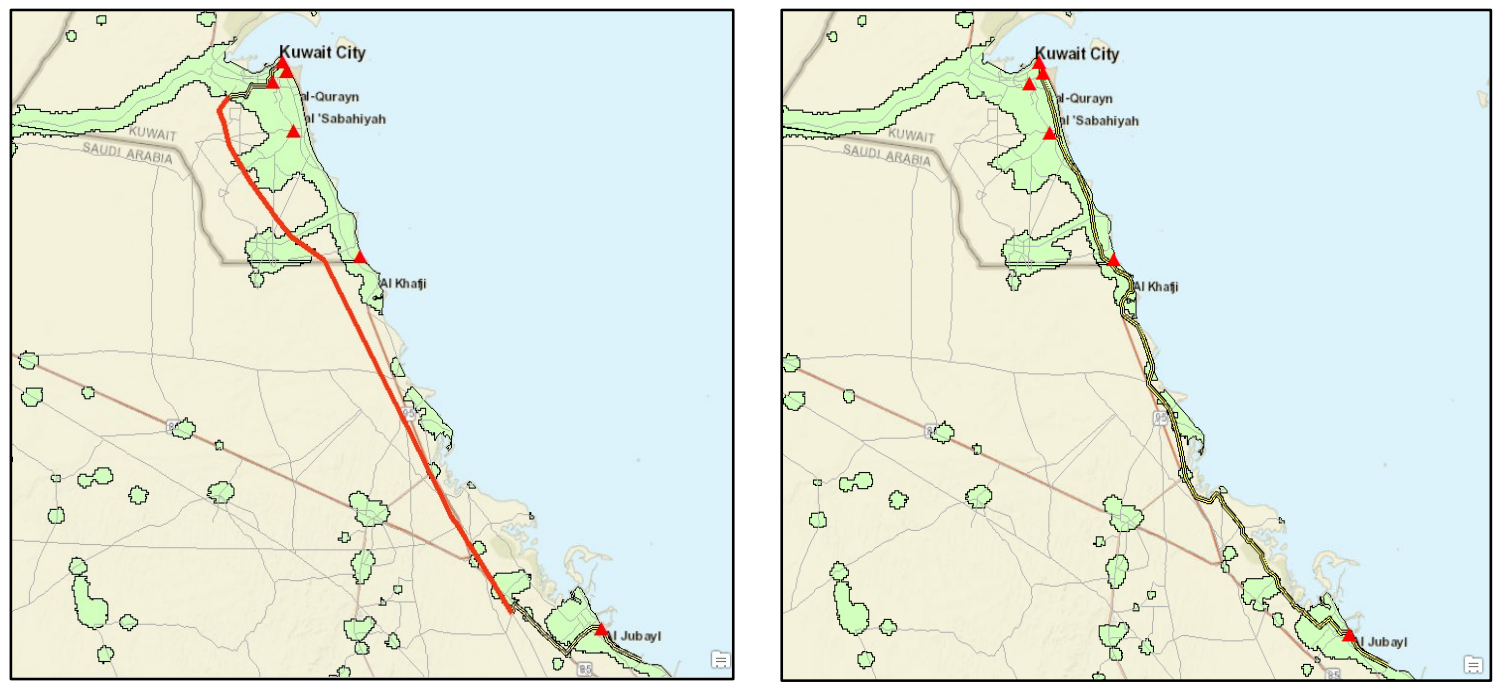

Figure 45 Example of rail and trucking shipping route between Kuwait City and Jubail. 
As mentioned earlier, emissions can have localized and global consequences. In order to decrease the pollution severity level that arises from freight transportation, alternative routes (origins and destinations) have been presented to examine the pollution produced by trucks as shown in Figure 46 and to offer potential viable solutions to help address this issue.

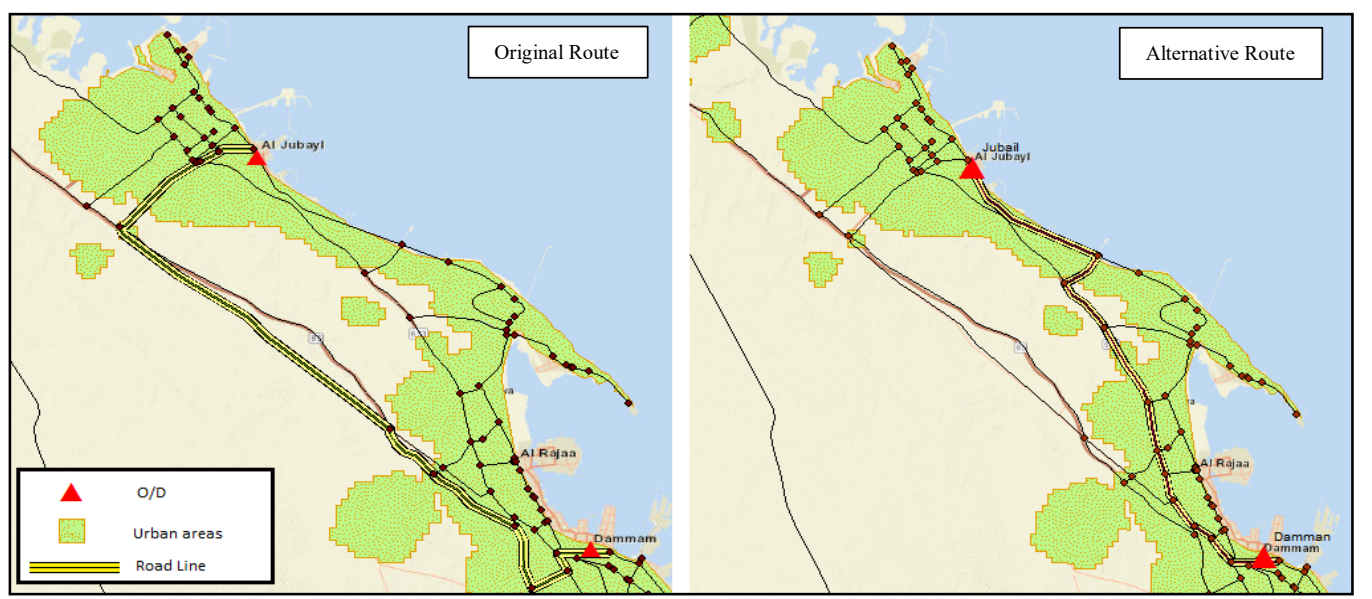

Figure 46 Example of original and alternative shipping routes between Jubail and Dammam city.

Tables 25 and 26 show the amount of $\mathrm{CO}_{2}$ produced by using trucking for the two selected routes. As shown in the below tables, alternative routes produce less $\mathrm{CO}_{2}$ emissions for the same origins and destinations over all distances.

Table $25 \mathrm{CO} 2$ amount produced by using trucking systems on the original routes.

\begin{tabular}{|c|c|c|c|c|}
\hline \multirow{3}{*}{ Distance } & \multirow{3}{*}{$\begin{array}{c}\text { Origins and Destinations } \\
\text { O/D } \\
\text { Original route }\end{array}$} & \multicolumn{3}{|c|}{ Pollution produced $\left(\mathrm{CO}_{2} \mathrm{Kg}\right)$} \\
\hline & & \multicolumn{3}{|c|}{ Truck } \\
\hline & & 23 & 46 & 69 \\
\hline Short & Jubail / Dammam & 211.6 & 423.3 & 634.9 \\
\hline Medium & Abu Dhabi / Muscat & 1014.2 & 2028.6 & 3042.8 \\
\hline Long & Riyadh / Madinah & 1735.7 & 3471.5 & 5207.2 \\
\hline
\end{tabular}


Table $26 \mathrm{CO} 2$ amount produced by trucking systems using the alternative routes.

\begin{tabular}{|c|c|c|c|c|}
\hline \multirow{2}{*}{ Distance } & \multirow{2}{*}{$\begin{array}{c}\text { Origins and Destinations } \\
\text { O/D }\end{array}$} & \multicolumn{3}{|c|}{ Pollution produced (CO) Kg) } \\
\cline { 3 - 5 } & Alternative Route & $\mathbf{2 3}$ & $\mathbf{4 6}$ & $\mathbf{6 9}$ \\
\cline { 3 - 5 } & Jubail / Dammam & 163.3 & 326.6 & 489.9 \\
\hline Short & Abu Dhabi / Muscat & 850.2 & 1679.3 & 2518.9 \\
\hline Medium & Riyadh / Madinah & 1582.6 & 3170.7 & 4720.8 \\
\hline
\end{tabular}

Figure 47 illustrates the amount of $\mathrm{CO}_{2}$ produced using the two selected routes for various origins and destinations.

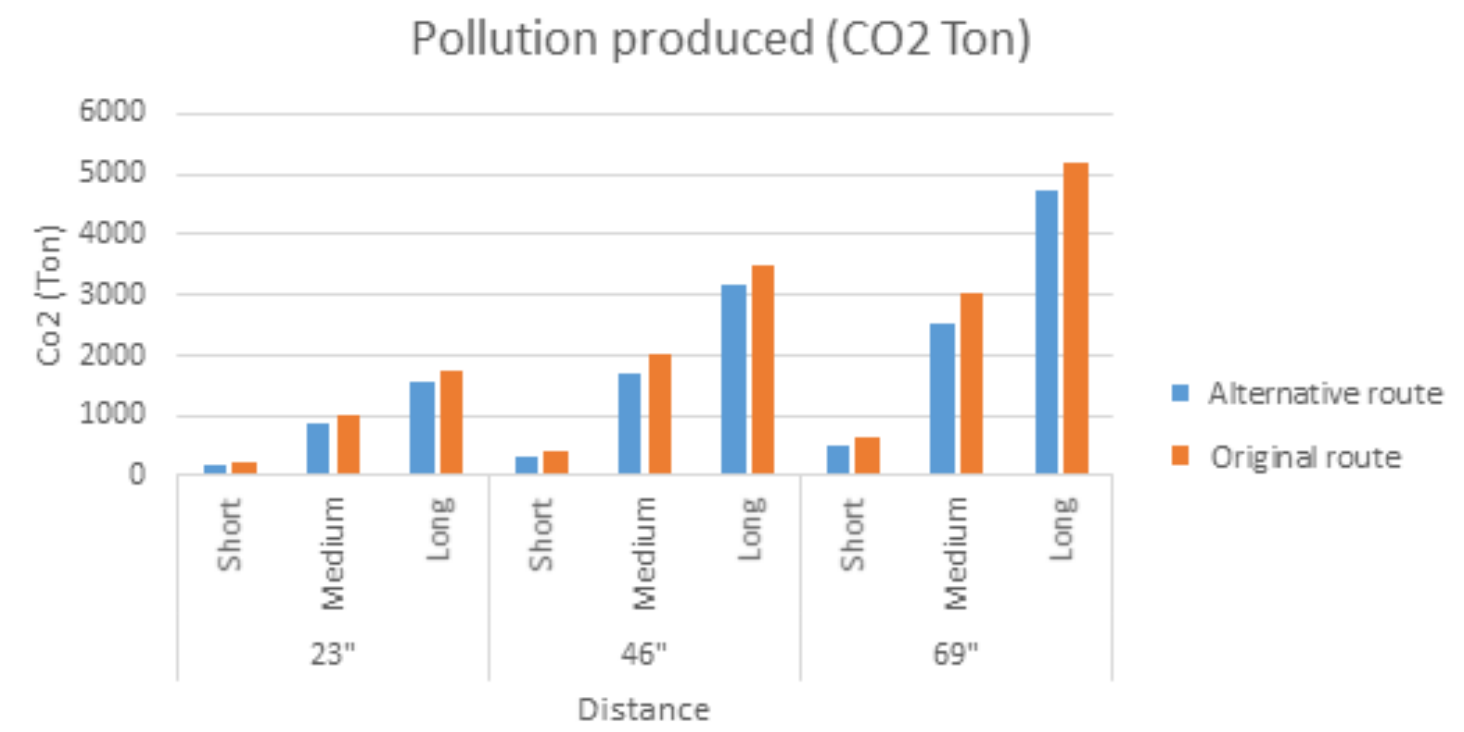

Figure 47 Original and alternative routes $\mathrm{CO} 2$ impact produced.

To complete the comparison between the two selected routes, Table 27 shows the total shipping cost for both alternative and original shipping scenarios. 
Table 27 Total shipping cost for original and alternative shipping routes.

\begin{tabular}{|c|c|c|c|c|c|c|c|}
\hline \multirow{2}{*}{ Distance } & \multirow{2}{*}{$\begin{array}{c}\text { Origins and Destinations } \\
\text { O/D }\end{array}$} & \multicolumn{4}{|c|}{ Total Shipping Cost - Trucking system } \\
\cline { 3 - 8 } & & \multicolumn{3}{|c|}{ Original route } & \multicolumn{3}{|c|}{ Alternative route } \\
\cline { 3 - 8 } & & 23 & 46 & 69 & 23 & 46 & 69 \\
\hline \multirow{2}{*}{ Short } & Jubail / Dammam & 454.8 & 909.7 & 1364.5 & 413.7 & 827.4 & 1241.1 \\
\hline Medium & Abu Dhabi / Muscat & 1282.1 & 2564.2 & 3846.3 & 1183.6 & 2342.9 & 3514.4 \\
\hline Long & Riyadh / Madinah & 2075.3 & 4150.7 & 6225.9 & 1963.8 & 3933.6 & 5861.3 \\
\hline
\end{tabular}

By drawing on the model results, it is clear that while trucking can be less expensive in terms of dollar value, the cost is heightened by the amount of $\mathrm{CO}_{2}$ and noise produced that affects surrounding communities. Subsequently, rail is then the more reliable option due to lower percentages of $\mathrm{CO}_{2}$ and other impacts. An intermodal system shares some of the same benefits as rail but has some of the added advantages of using trucks that support door-to-door shipments. There are trends toward creating rules and regulations that are environmentally conscious and using rail and intermodal systems supports these types of shifts.

Finally, although most of the route segments are located at undeveloped areas, environmental and weather conditions can be a serious issue that affects freight mode selection. The GCC area is arid, so the temperature is usually high and rainfall is rare. Based on the meteorological information from the Presidency of Meteorology and Environment in Saudi Arabia, the minimum and maximum temperatures are illustrated in Figures 48 and 49. 


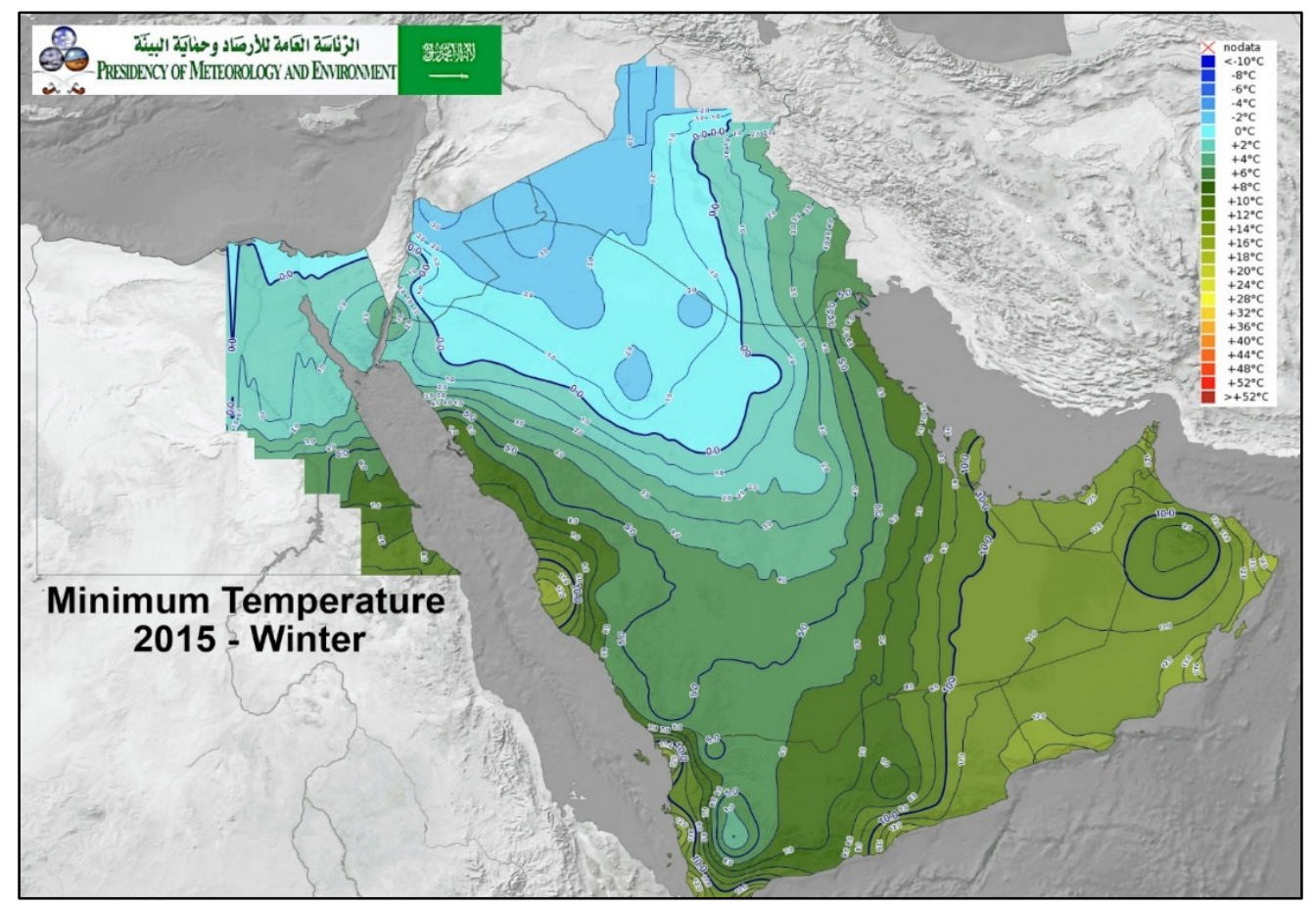

Figure 48 Minimum temperature around the GCC Region, Presidency of Meteorology and Environment,

2016.

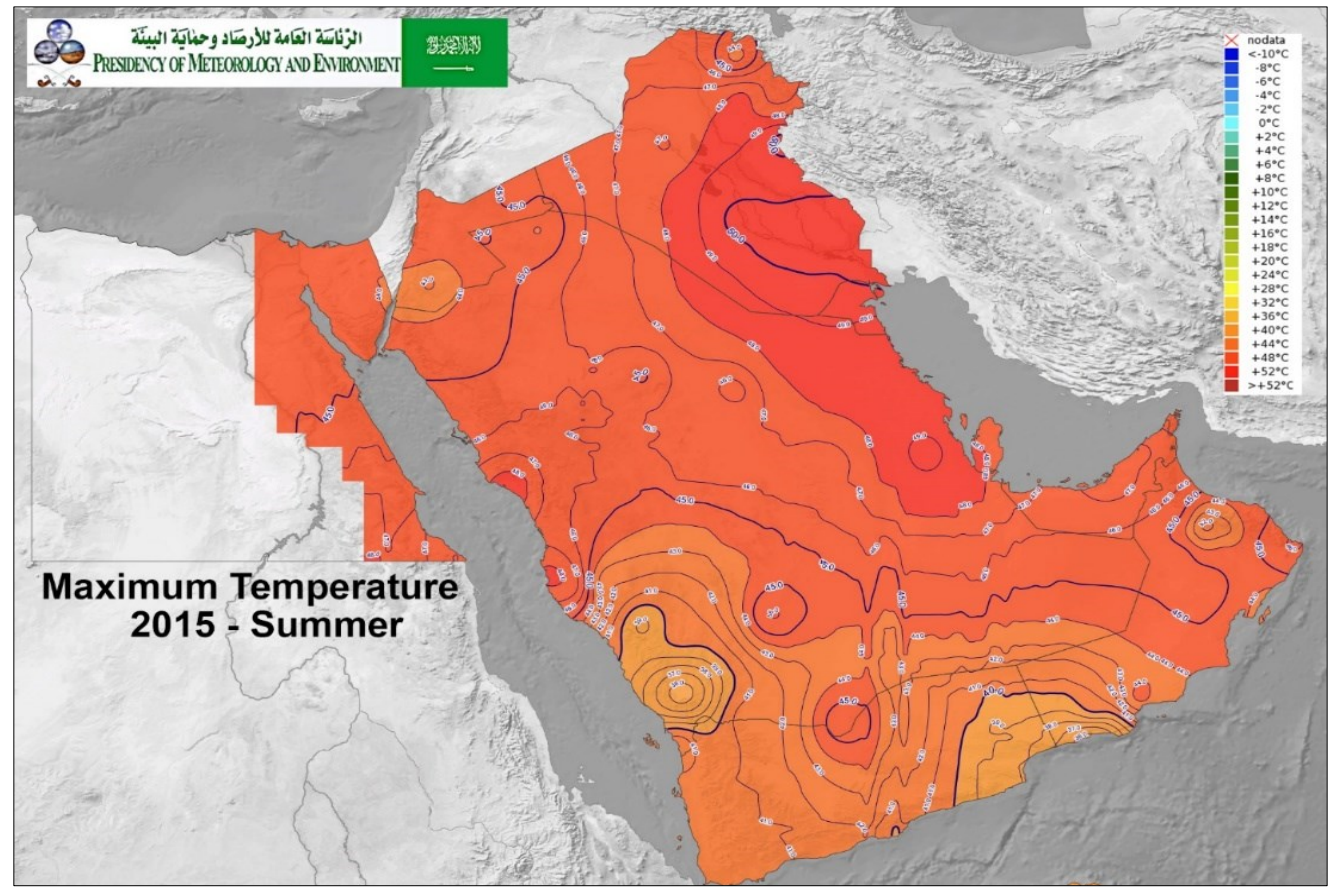

Figure 49 Maximum temperature around the GCC Region, Presidency of Meteorology and Environment, 2016. 
Climate change effects sometimes result in severe changes to the annual forecast as shown in Figure 50. Roads can be paralyzed due to hail and snow, which affects shipment delivery and the overall cost of selecting trucking as the mode of transport. The exact effects of weather can be unpredictable in terms of road conditions, potential damages to trucks in extreme conditions or accidents, as well as potential impacts to perishable goods as a of result transit delays.
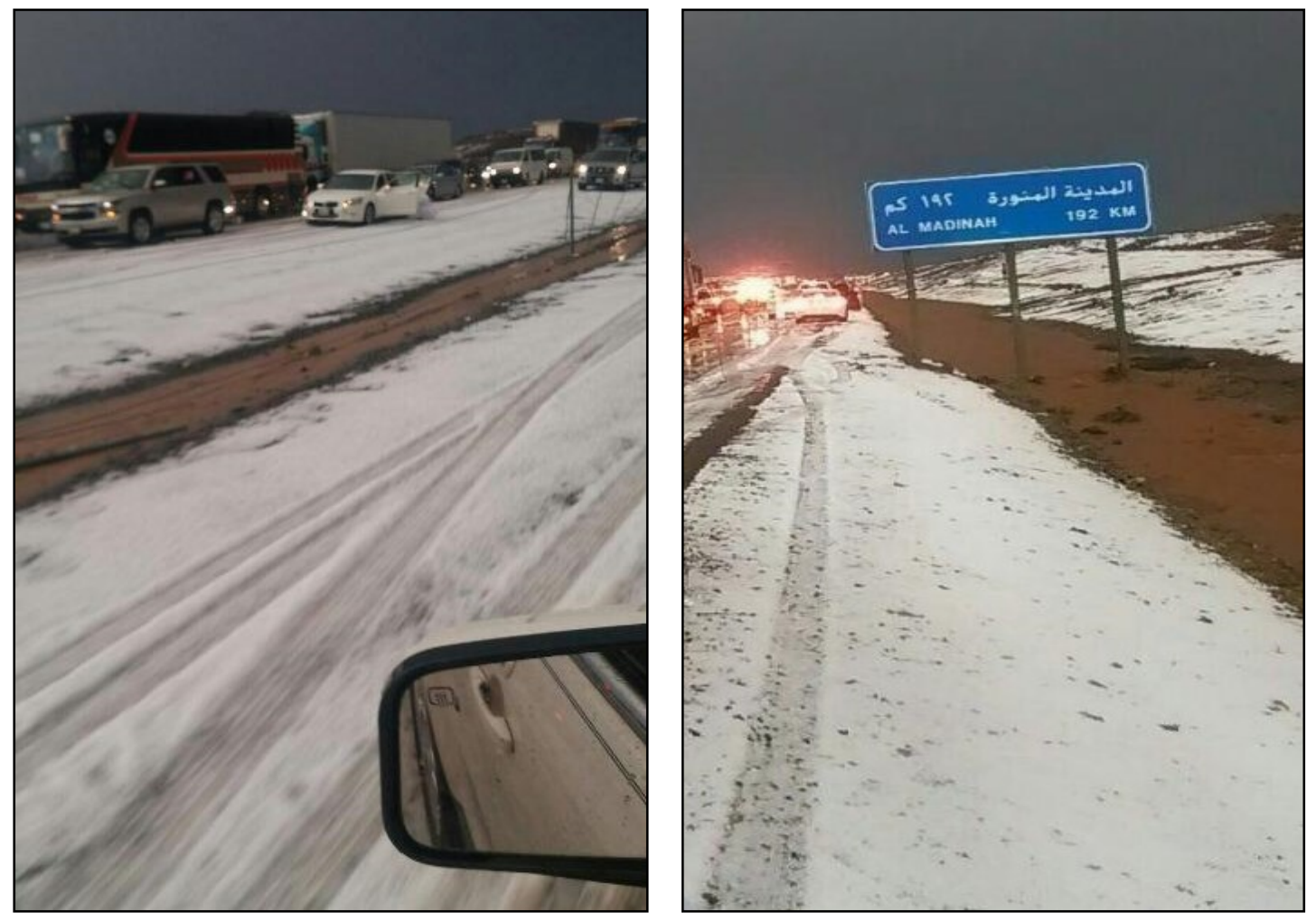

Figure 50 The effect of hail and snow on the shipment delivery, Presidency of Meteorology and Environment, 2016.

In conclusion, this chapter introduces the developed framework analysis and results that includes direct, indirect and impact costs that are present in road and rail as modes of transportation. In order to test the developed model, a case study has been conducted on various origins and destinations in the Gulf Cooperation Council (GCC) region. Moreover, the life cycle 
cost breakdown, assumptions, and the manipulated equations have been illustrated in detail in order to get the unit rate of moving goods using trucking and rail systems. Following this, the GIS Model-Builder preliminary results have been discussed. Model verification and calibration processes were then conducted to represent the current shipping market price. Finally, effectiveness and sensitivity analysis were discussed in the context of fuel price increases, climate change and the amount of pollution produced that might affect the mode selection process of using either rail or trucking systems. What can be seen as a result of these discussions and calculations is that such considerations in the implemented model can help to facilitate well-informed decisionmaking processes for both shippers and government actors. In addition, the contents of this chapter present what can define more viable and reliable modes of transportation based on a detailed cost analysis. 


\section{Chapter: Logistic Application of Proposed Framework}

\subsection{Introduction}

Logistics has three important objectives, which are cost, service level and profit. Transport systems comprise the most important logistics systems, where cost comes as a direct component. It is an objective to make available the right quantity of the right quality of products to consumers at minimal cost. In addition, the products must be available at the right place and in the right condition. The role of customers is vital for any activity, as planning and execution of business and service should be reflective of customers' requirements. Thus, how to offer best service to consumers is one of the most important objectives of logistics. Finally, for maximizing profits, the third main objective is to reduce the cost of operations and to maintain transparency.

The Middle East in terms of logistics can be recognized as the world's major hub in distributing oil and gas. In recent years, the area has become an emerging market due to an increase in its population and noticeable economic growth. This area has grown extensively in providing facilities of oil and gas storage, tourism, airlines, ports, manufacturing and oil field maintenance. The implemented GIS model not only can be used for selecting the optimum and alternative routes among all modes, but it also has another application that facilitates logistics management processes and services. The following sections illustrate how the implemented GIS model can be beneficial for logistics applications dealing with warehouse locations, intermodal yard locations, risk assessment and multiple destination shipments.

\subsection{Freight Logistics Warehouse Application}

There are several factors that need to be considered when opening a new warehouse facility 
such as market demand, cost of shipping and proximity to airports, railway stations and ports. In this thesis, two warehouse location scenarios were selected as examples and evaluated for different shipment sizes to different origins and destinations as shown in Figure 51. Each scenario has been analyzed based on the implemented GIS Model.

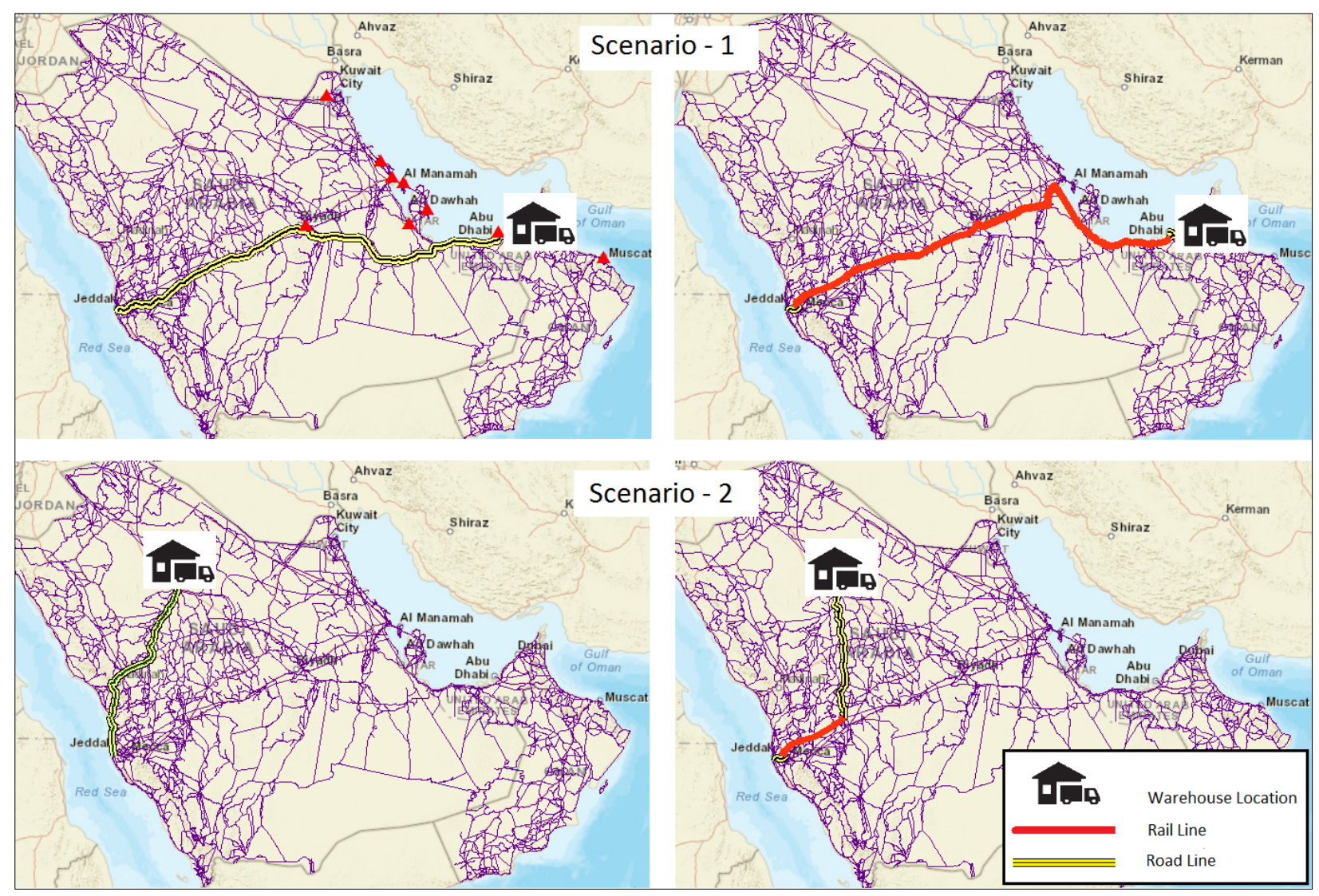

Figure 51 Snapshot of the warehouse location scenario and the model LCCA.

Table 28 summarizes the total cost of shipping a container from the warehouse locations to different destinations including Jeddah, Kuwait City and Dubai. 
Table 28 Warehouse location scenarios cost analysis.

\begin{tabular}{|c|c|c|c|c|c|c|c|c|c|c|c|}
\hline \multirow{4}{*}{\multicolumn{2}{|c|}{ Warehouse Location 1_scenario }} & \multicolumn{4}{|c|}{ Distance $(\mathrm{km})$} & \multicolumn{6}{|c|}{ Cost (US\$) } \\
\hline & & \multirow{4}{*}{ Destination } & Trucking & \multicolumn{2}{|c|}{ Intermodal } & & & & & \multirow{2}{*}{\multicolumn{2}{|c|}{ Intermodal }} \\
\hline & & & \multirow{3}{*}{ Truck } & \multirow{3}{*}{ Truck } & \multirow{3}{*}{ Rail } & \multicolumn{3}{|c|}{ Truck } & & & \\
\hline & & & & & & \multicolumn{6}{|c|}{ Shipment size (tons) } \\
\hline \multirow{4}{*}{ Origin } & \multirow{4}{*}{$\begin{array}{c}\text { ABC Factory } \\
\text { (Abu Dhabi, UAE) }\end{array}$} & & & & & 23 & 46 & 69 & 23 & 46 & 69 \\
\hline & & Jeddah & 1891.4 & 123.6 & 1899.6 & 3477.7 & 6955.4 & 10433.1 & 3922.7 & 4653.1 & 5478.3 \\
\hline & & Kuwait City & 1204.8 & 59.6 & 1069.1 & 2468.9 & 4937.9 & 7406.9 & 2311.1 & 2932.4 & 3553.8 \\
\hline & & Dubai & 180.6 & 20.6 & 161.1 & 610.9 & 1221.9 & 1832.8 & 568.7 & 889.2 & 1169.4 \\
\hline \multirow{3}{*}{\multicolumn{2}{|c|}{ Warehouse Location 2_scenario }} & \multicolumn{4}{|c|}{ Distance $(\mathrm{km})$} & \multicolumn{6}{|c|}{ Cost (US\$) } \\
\hline & & \multirow{3}{*}{ Destination } & \multirow{3}{*}{ Truck } & \multirow{3}{*}{ Truck } & \multirow{3}{*}{ Rail } & \multicolumn{3}{|c|}{ Truck } & \multicolumn{3}{|c|}{ Intermodal } \\
\hline & & & & & & \multicolumn{6}{|c|}{ Shipment size (tons) } \\
\hline \multirow{4}{*}{ Origin } & \multirow{4}{*}{ ABC Factory (Hail, KSA) } & & & & & 23 & 46 & 69 & 23 & 46 & 69 \\
\hline & & Jeddah & 887.1 & 658.3 & 316.6 & 1731.1 & 3462.1 & 5193.1 & 1803.4 & 3096.5 & 4394.5 \\
\hline & & Kuwait City & 897.4 & 46.7 & 1091.5 & 1866.9 & 3733.9 & 5600.9 & 2310.4 & 2895.4 & 3480.5 \\
\hline & & Dubai & 1806.6 & 19.7 & 1811.4 & 3523.3 & 7046.6 & 10569.9 & 3636.1 & 4408.8 & 5181.6 \\
\hline
\end{tabular}


It is clear from the table above that as the destination closeness of proximity to the warehouse location increases, the price goes down, and the inverse applies if the destination is further away. However, warehouse locations should be analyzed based on the quantity that are available and multiple destinations of the goods being carried. So, assuming different shipment sizes to be carried, the probability distribution has been established in order to help in making a decision on warehouse selection to facilitate good planning and effective decisions that maximize services and reduce the total shipping costs. Table 29 shows the warehouse probability distribution of the analysis results.

Table 29 Warehouse scenario distribution analysis.

\begin{tabular}{|c|c|c|c|c|c|c|}
\hline \multirow{6}{*}{$\begin{array}{l}\text { Shipping distribution } \\
\text { probability - A }\end{array}$} & \multirow{2}{*}{ Destination } & \multirow{2}{*}{ Tonnage } & \multicolumn{2}{|c|}{$\begin{array}{l}\text { Warehouse Location } 1_{-} \\
\text {scenario }\end{array}$} & \multicolumn{2}{|c|}{$\begin{array}{l}\text { Warehouse Location } 2 \text { - } \\
\text { scenario }\end{array}$} \\
\hline & & & Trucking & Intermodal & Trucking & Intermodal \\
\hline & Jeddah & 23 & 3477.7 & 3922.7 & 1731.1 & 1803.4 \\
\hline & Kuwait & 23 & 2468.9 & 2311.1 & 1866.9 & 2310.4 \\
\hline & Dubai & 46 & 1221.9 & 889.2 & 7046.6 & 4408.8 \\
\hline & \multicolumn{2}{|c|}{ Total Cost } & 7168.5 & 7123 & 10644.6 & 8522.6 \\
\hline \multirow{6}{*}{$\begin{array}{l}\text { Shipping distribution } \\
\text { probability - B }\end{array}$} & \multirow{2}{*}{ Destination } & \multirow{2}{*}{ Tonnage } & \multicolumn{2}{|c|}{$\begin{array}{l}\text { Warehouse Location 1_ } \\
\text { scenario }\end{array}$} & \multicolumn{2}{|c|}{$\begin{array}{l}\text { Warehouse Location } 2_{-} \\
\text {scenario }\end{array}$} \\
\hline & & & Trucking & Intermodal & Trucking & Intermodal \\
\hline & Jeddah & 46 & 10433.1 & 4653.1 & 5193.1 & 4394.5 \\
\hline & Kuwait & 46 & 4937.9 & 2932.4 & 3733.9 & 2895.4 \\
\hline & Dubai & 23 & 610.9 & 568.7 & 3523.3 & 3636.1 \\
\hline & \multicolumn{2}{|c|}{ Total Cost } & 15981.92 & 8154.2 & 12450.3 & 10926 \\
\hline
\end{tabular}

Based on Table 29, the total shipping cost of different scenarios depends on what mode the shipper is using and the quantity of tonnage being moved. Having a shipping distribution-A 
favours the warehouse location in Abu Dhabi (Location 1) for trucking systems, while the second scenario distribution favours the location on Hail (Location 2). As a result, using this GIS model with a different distribution to a different destination will help in selecting the most effective and reliable location for warehouses.

\subsection{Intermodal Yard Location Application}

Intermodal yards are the interface between trucking and railway transport services. There are several freight activities that can be completed in intermodal yards to facilitate logistics services including marshalling, loading/unloading and interchange with other lines within the network. Since the model developed a future network for this thesis, several marshalling, interchange and intermodal yards were assigned to form and dispatch freight trains. Figure 52 shows how the intermodal yard locations can change the route and the mode used for shipping a container within the GCC transportation network. 


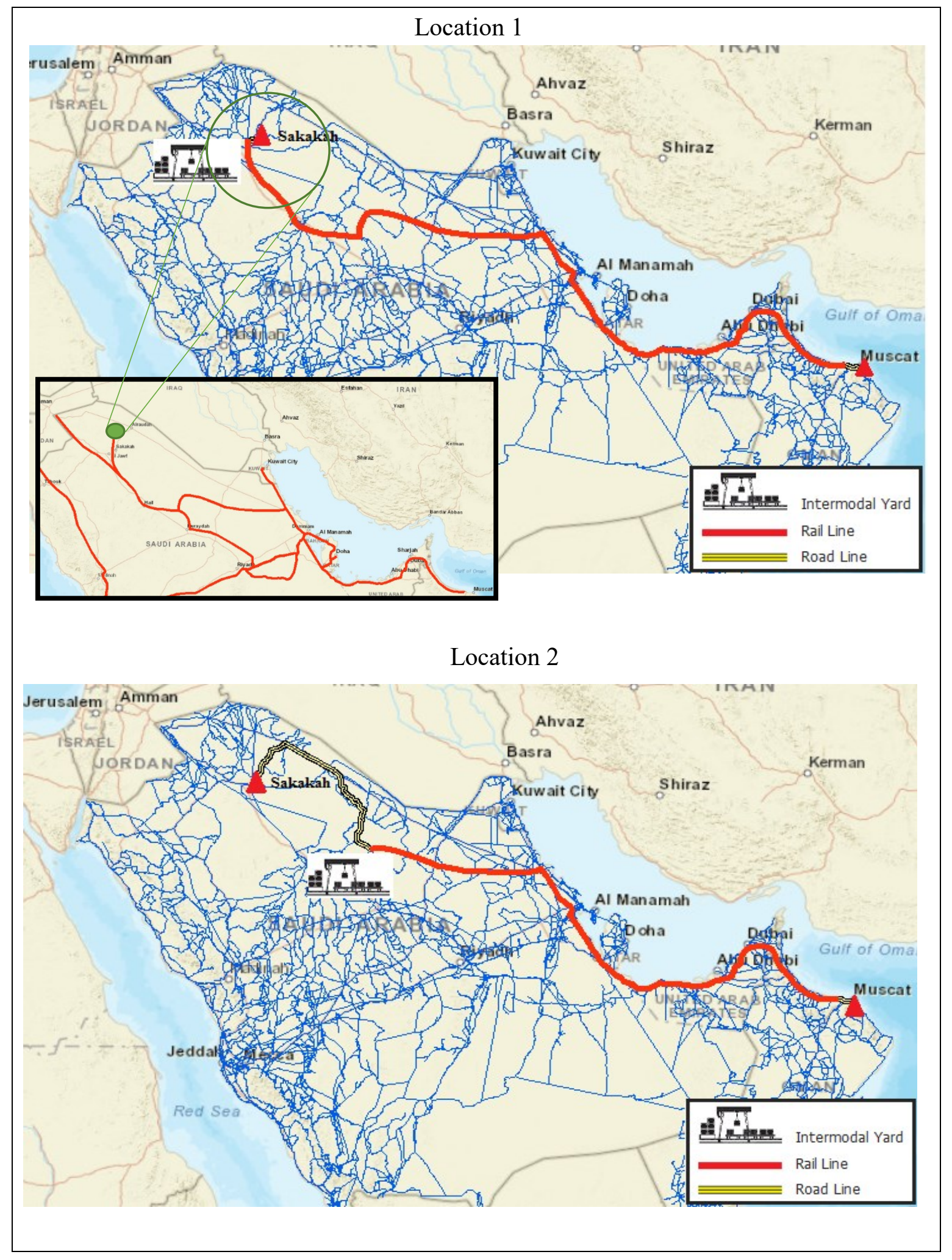

Figure 52 Intermodal yard location effect on mode selection within the GCC network. 
The location of the intermodal yard will also have an effect on the total shipping cost and therefore the shipping mode selection. Having an intermodal yard close to an origin or a destination will shorten the use of trucking systems, and even sometimes eliminate the use of them completely resulting in potential reduction of impact costs. While rare, eliminating the use of trucking systems can be an outcome if the company warehouse is located side by side to the intermodal yard. Table 30 shows an example of how changing the intermodal yard location will affect the total shipping cost and decision-making processes using the implemented GIS LCCA model.

Table 30 Intermodal yard location impact on shipping cost and mode selection.

\begin{tabular}{|c|c|c|c|c|c|c|c|c|c|c|}
\hline \multirow{4}{*}{$\begin{array}{c}\text { Origin/ } \\
\text { Destination }\end{array}$} & \multicolumn{4}{|c|}{ Distance $(\mathrm{Km})$} & \multicolumn{6}{|c|}{ Total Shipping Cost (US\$) } \\
\hline & \multirow{2}{*}{\multicolumn{2}{|c|}{$\begin{array}{l}\text { Intermodal } \\
\text { Location } 1\end{array}$}} & \multirow{2}{*}{\multicolumn{2}{|c|}{$\begin{array}{l}\text { Intermodal } \\
\text { Location } 2\end{array}$}} & \multicolumn{3}{|c|}{ Intermodal - Location 1} & \multicolumn{3}{|c|}{ Intermodal - Location 2} \\
\hline & & & & & \multicolumn{6}{|c|}{ Tonnage (Tons) } \\
\hline & Rail & Truck & Rail & Truck & 23 & 46 & 69 & 23 & 46 & 69 \\
\hline $\begin{array}{l}\text { Al- Ain to } \\
\text { Muscat }\end{array}$ & 198.7 & 145.7 & 94.6 & 255.5 & 899.7 & $1,485.3$ & $2,070.8$ & 934.2 & $1,693.1$ & $2,465.12$ \\
\hline $\begin{array}{l}\text { Hail to Al- } \\
\text { Manama }\end{array}$ & 1076.7 & 21.3 & 808.7 & 294.3 & $2,319.4$ & $2,937.2$ & $3,554.8$ & $2,381.2$ & $3,484.0$ & $4,586.91$ \\
\hline $\begin{array}{l}\text { Muscat to } \\
\text { Sakakah }\end{array}$ & 2550.0 & 74.1 & 1923.8 & 758.6 & $5,238.22$ & $6,445.6$ & $7,653.0$ & $5,579.7$ & $7,918.4$ & $10,357.2$ \\
\hline
\end{tabular}

As shown in Table 30 changing the intermodal yard location will increase the total shipping cost of that shipment. However, different criteria have to be considered when deciding on the suitable location for intermodal yards, which includes full awareness of the freight distribution within the region, accessibility, level of safety and the possibility for future expansion. All of these criteria need to be analyzed by all stockholders including planners, decision makers and private shipping companies to build more reliable logistics services. 


\subsection{Vehicle Routing Problem Application}

As mentioned earlier, the Vehicle Routing Problem is one of the most important issues concerning supply chain logistics management. Minimizing the shipping cost and fleet size while delivering material on time are very challenging when performing logistics management. The implemented GIS model touches on this issue by finding the most reliable mode of shipping and the optimum route to deliver shipments within the GCC area. Figure 53 shows a snapshot of selected routes to circulate a shipment starting from Tabouk and passing by Riyadh, Jizan and reaching Jeddah as a final destination using different transportation modes.

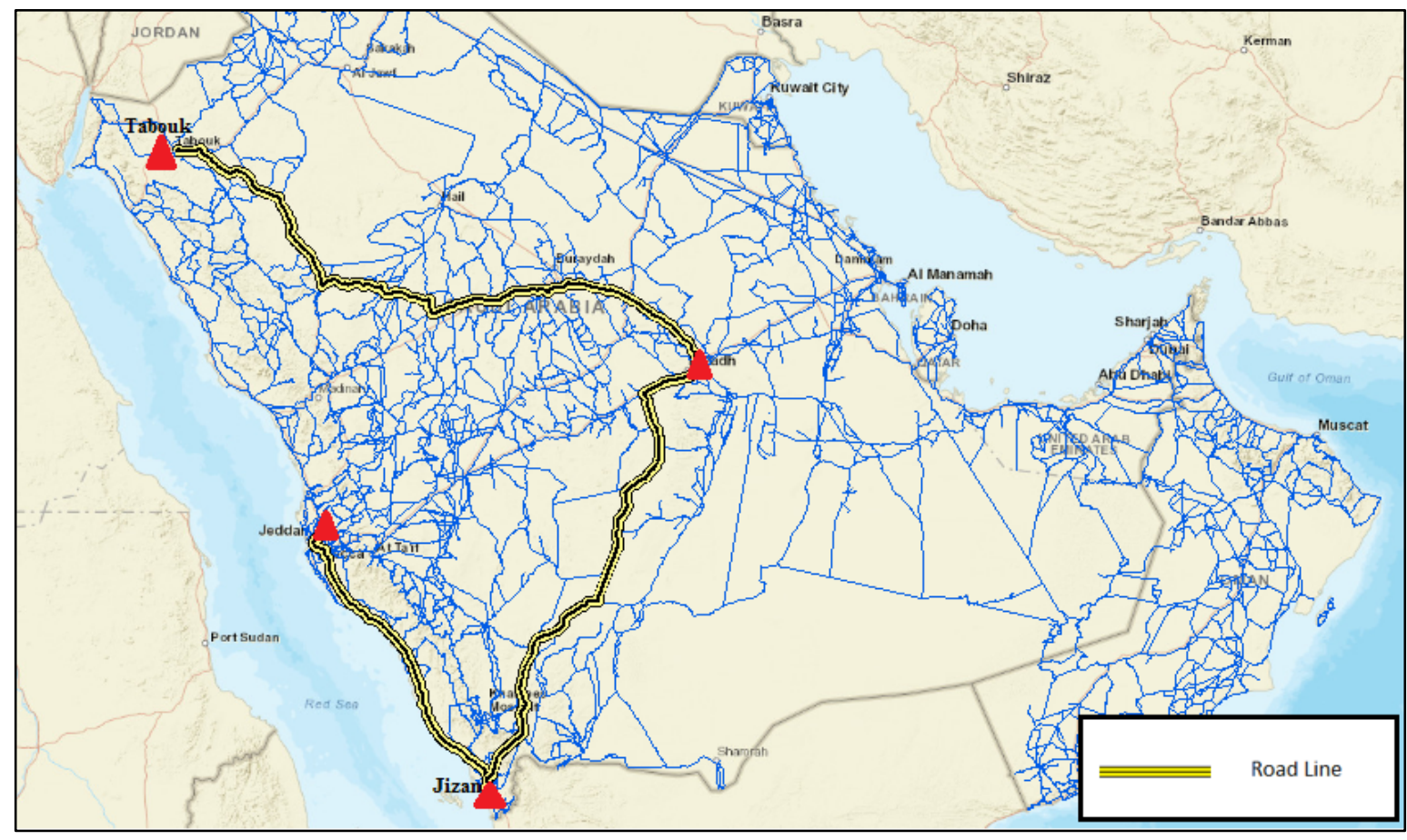

Continue Figure 53 


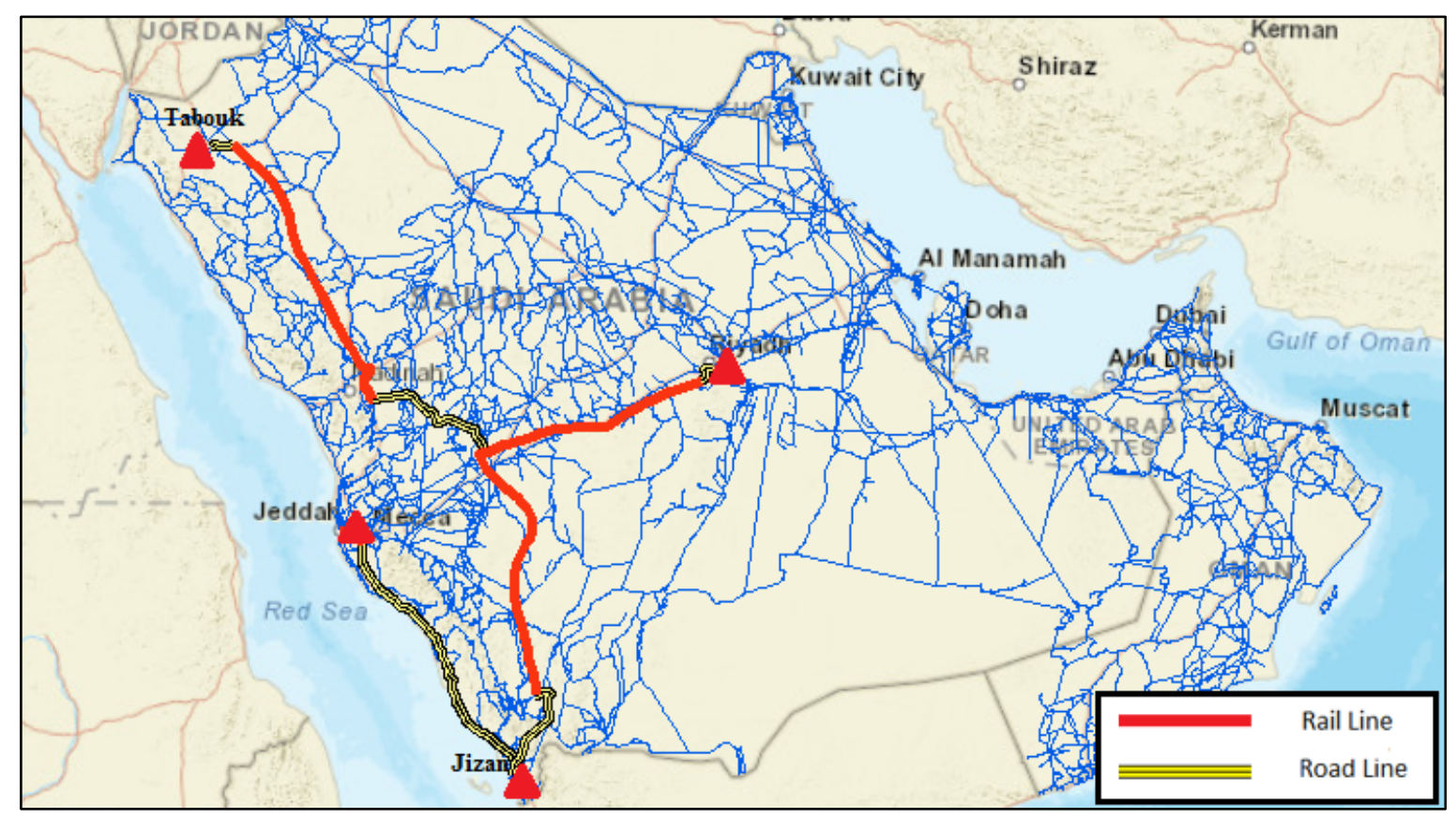

Figure 53 Snapshot of a selected shipment route using different transportation modes.

To analyze the shipping cost of those routes, Table 31 shows the cost of delivering the shipments to and from different origins and destinations using different transportation modes.

Table 31 Total shipping cost of delivering shipments between different origins and destinations using different routes and different transportation modes.

\begin{tabular}{|c|c|c|c|c|c|c|c|c|c|}
\hline \multirow{2}{*}{ Origin/Destination } & \multicolumn{3}{|c|}{ Distance (Km) } & \multicolumn{5}{c|}{ Total Shipping Cost (US\$) } \\
\cline { 2 - 11 } & Trucking & \multicolumn{2}{c|}{ Intermodal } & \multicolumn{5}{c|}{ Truck } & \multicolumn{3}{c|}{ Intermodal } \\
\cline { 3 - 11 } & Truck & Rail & Truck & 23 & 46 & 69 & 23 & 46 & 69 \\
\cline { 2 - 11 } & & & \multicolumn{5}{c|}{ Tonnage (Tons) } \\
\hline $\begin{array}{c}\text { Tabouk / Riyadh / } \\
\text { Jeddah / Jizan }\end{array}$ & 3026.78 & 1910.43 & 795.4 & 5412.1 & 10824.2 & 16236.3 & 5946.4 & 8913.0 & 11839.6 \\
\hline $\begin{array}{c}\text { Tabouk / Jeddah } \\
\text { /Jizan / Riyadh }\end{array}$ & 2763.3 & 1599.3 & 1392.1 & 4960.7 & 9921.4 & 14882.2 & 6614.8 & 10635.4 & 14780.9 \\
\hline $\begin{array}{c}\text { Tabouk / Riyadh / } \\
\text { Jizan / Jeddah }\end{array}$ & 3206.9 & 1600.12 & 1373.4 & 5750.4 & 11500.8 & 17251.1 & 6480.7 & 10453.6 & 14311.4 \\
\hline
\end{tabular}


The analysis shows that using this model can help in solving the VRP, which can ultimately affect decision-making processes and improve logistics management. On the other hand, further analysis can also be completed, where decision makers may examine the size of fleet required while considering the time required to deliver shipments.

\subsection{Risk and Impact Assessment Application}

A risk assessment is an analysis of any danger to the activities of an organization or structure from external or internal sources and identifying the areas that can be vulnerable to such threats and further implementing procedures to reduce or control such risks. Assessments ought to utilize some kind of hazard scaling, but need not be mind-boggling. In this thesis, a numerical ranking arrangement of 1-5 was implemented and this ranking system turned out to be quite useful. For organizations with few differences within districts of operations, a predetermined number of supply chains and an unfaltering plan of action, a basic high/medium/low framework might be more fitting. The main objective of keeping ranked records is that it provides immediate solutions for a company in reducing and managing risks by putting time, energy and its resources to more vulnerable areas.

For highway transporters, a supply network can be confronted by many stages. It starts from the manufacturing division and depot and then passes through the export and import representatives before the merchandise is transported to the final distributing warehouse or its last goal. Every stage has issues to be reviewed. For instance, ensuring physical security around trucks and trailers, limiting access to stacking docks, securing overnight stockpiling, following and observing trucks, and directly administrating oversight if something does go wrong are all examples of processes. Nonetheless, once a new risk is identified, the territorial risk assessment 
can be connected against these phases to figure out where shortcomings and vulnerabilities exist. The history of highway carriers has demonstrated the issues below as being repetitive contributors to security breaches. Therefore, each stage in a carrier's supply chain should be analyzed for weaknesses. Once these vulnerabilities are identified, an action plan to address such issues can be implemented. The implemented model for this thesis can help in finding solutions and alternative routes based on the risk assessment results. As a first step to apply this exercise, risk categories were identified.

Examples of risks that can occur might include crashes, theft of inventory, natural disasters, or bombing and explosions while shipping hazardous materials. Each category needs to be assessed in terms of likelihoods and impact to establish an initial risk rating. Table 32 summarizes the risk score rating combining the impact and likelihood rating.

Table 32 Shipping Risk Analysis Matrix, PMI, 2013.

\begin{tabular}{|c|c|c|c|c|c|c|}
\hline $\begin{array}{l}\text { Risk } \\
\text { Matrix }\end{array}$ & \multicolumn{6}{|c|}{ Risk Severity } \\
\hline \multirow{6}{*}{ 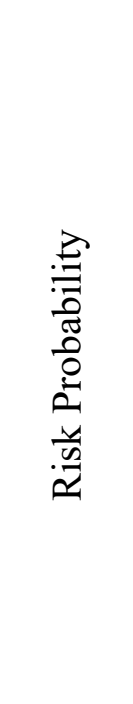 } & & $\begin{array}{l}\text { Negligible } \\
\text { (1) }\end{array}$ & $\begin{array}{l}\text { Minor } \\
(2)\end{array}$ & $\begin{array}{c}\text { Moderate } \\
\text { (3) }\end{array}$ & $\begin{array}{l}\text { Major } \\
(4)\end{array}$ & $\begin{array}{c}\text { Extreme } \\
\text { (5) }\end{array}$ \\
\hline & $\begin{array}{c}\text { Almost certain } \\
\text { (5) }\end{array}$ & 5 & 10 & 15 & 20 & 25 \\
\hline & Likely (4) & 4 & 8 & 12 & 16 & 20 \\
\hline & Possible (3) & 3 & 6 & 9 & 12 & 15 \\
\hline & Unlikely (2) & 2 & 4 & 6 & 8 & 10 \\
\hline & Rare (1) & 1 & 2 & 3 & 4 & 5 \\
\hline
\end{tabular}


- Score between 1-5 is low risk

- Score between 6-12 is medium risk

- Score between 15-25 is high risk

After assigning a score to each category, the process of evaluating the risks will come into play, and appropriate actions are then taken. For example, based on historical data and expertise, rain flooding is one of the most serious threats to shipping industries when shipping within Saudi Arabia. Floods are considered to be high risk, as these can paralyze all roads and rail lines around the affected area(s). Therefore, assessing such impact with the help of the GIS model allows for selecting the most reliable alternative routes to deliver the shipment to customers on time as promised.

Figures 54 and 55 show a snapshot of GIS hazards scenarios that might occur on the network and how the implemented model can select the most other appropriate routes to avoid hazards and deliver the shipment using different modes of transportation. 

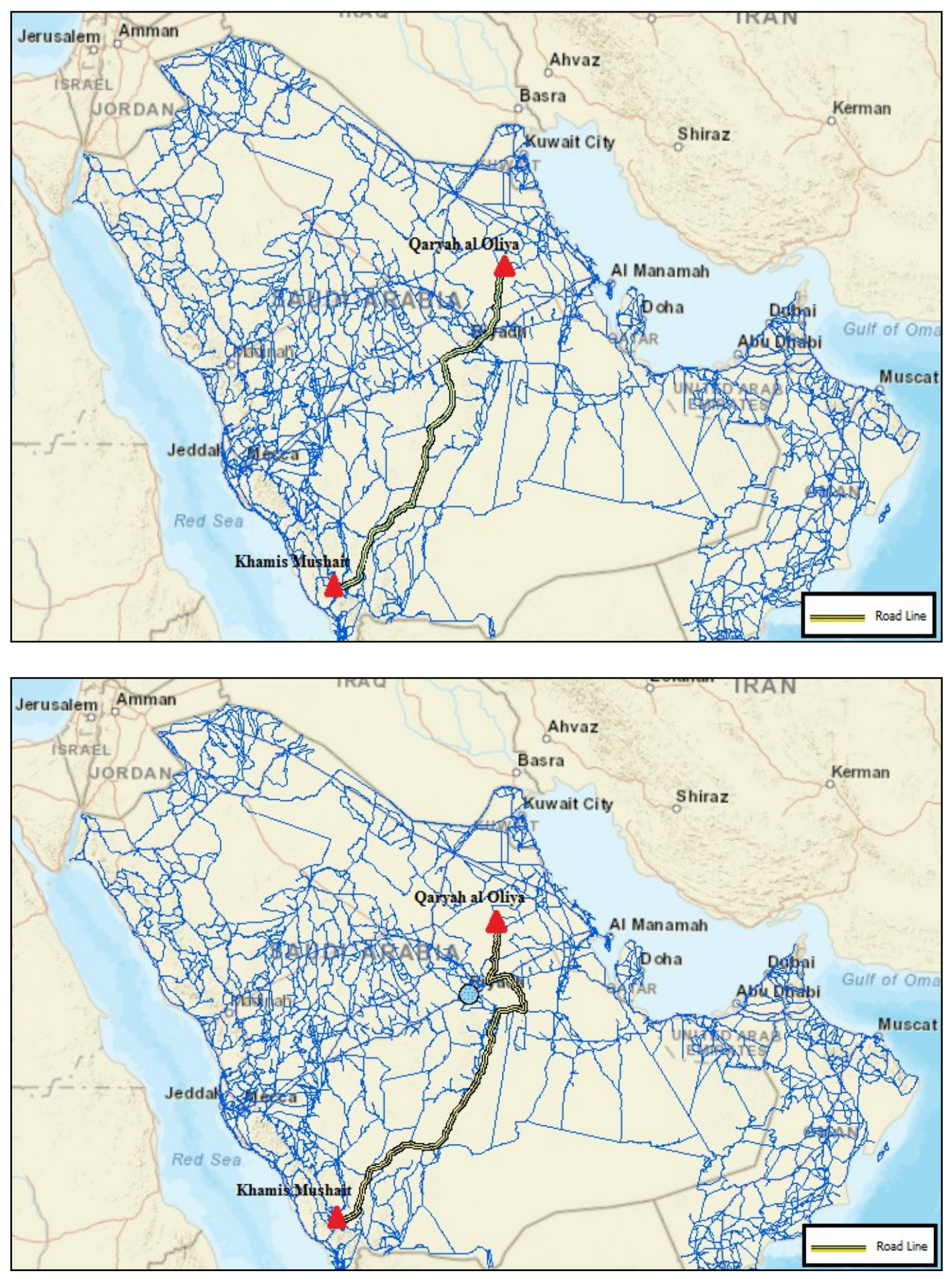

Figure 54 Snapshot of flood scenario when shipping a container using trucking transportation system. 

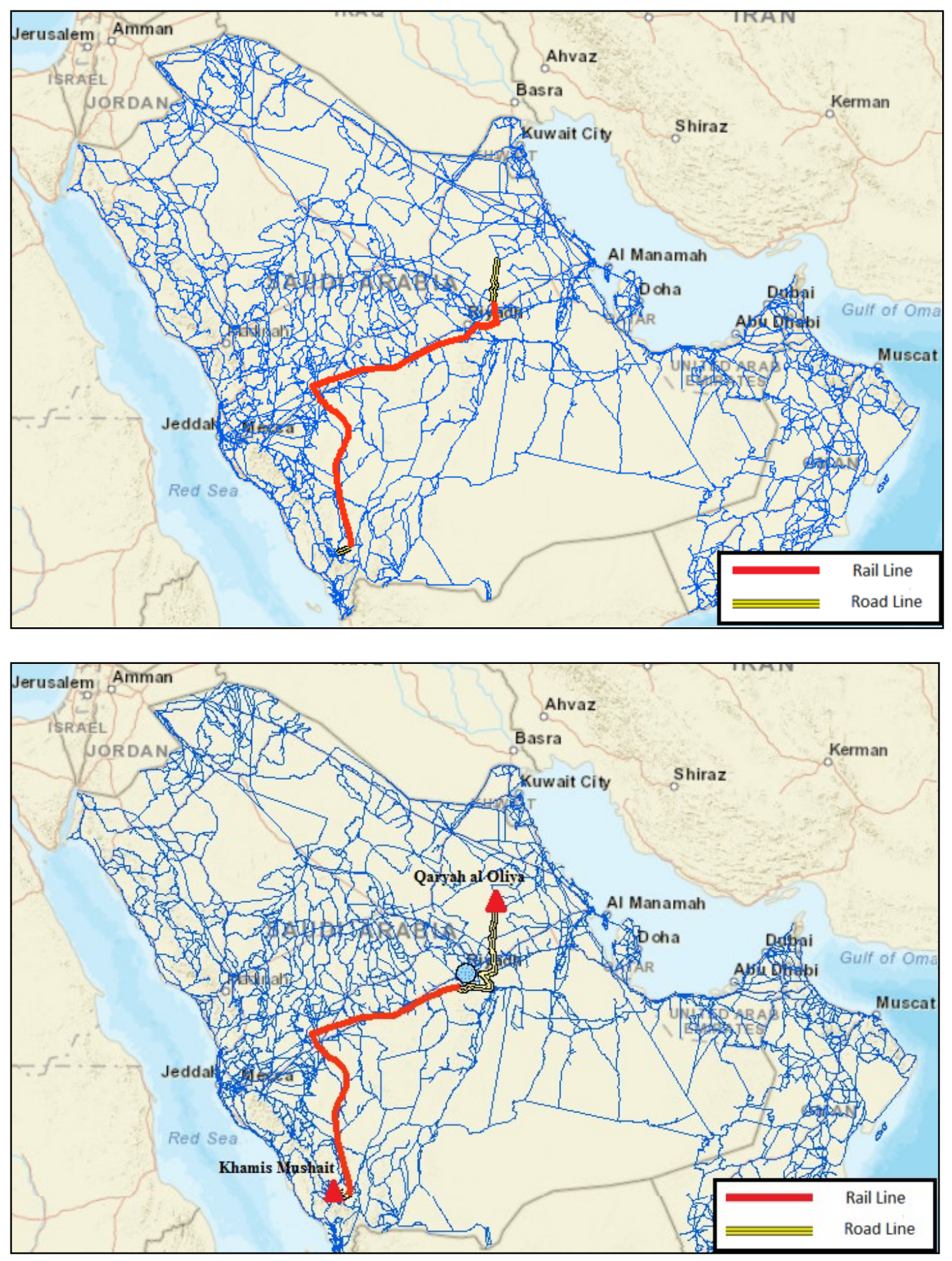

Figure 55 Snapshot of flood scenario when shipping a container using an intermodal transportation system. 
As shown in Figures 54 and 55, the scenario shows a flood around the city of Riyadh in Saudi Arabia. In order to avoid this kind of risk, alternative routes proposed by the implemented model will be used to deliver this shipment. Tables 33 and 34 show the total cost of using the original and the alternative routes affected by floods.

Table 33 Shipping cost in normal conditions using different modes between origins and destinations.

\begin{tabular}{|c|c|c|c|c|c|c|c|c|c|}
\hline \multirow{4}{*}{ Origin/Destination } & \multicolumn{3}{|c|}{ Distance $(\mathrm{Km})$} & \multicolumn{6}{|c|}{ Total Shipping Cost (US\$) } \\
\hline & \multirow{3}{*}{ Truck } & \multirow{2}{*}{\multicolumn{2}{|c|}{ Intermodal }} & \multicolumn{3}{|c|}{ Truck } & \multicolumn{3}{|c|}{ Intermodal } \\
\hline & & & & \multicolumn{6}{|c|}{ Tonnage (Tons) } \\
\hline & & Rail & Truck & 23 & 46 & 69 & 23 & 46 & 69 \\
\hline Dharma to Al-Kharj & 150.9 & 101.4 & 67.8 & 390.91 & 781.82 & 1172.73 & 541.30 & 942.24 & 1323.19 \\
\hline Al Dawadmy to Harad & 611.8 & 503.5 & 119.9 & 1205.27 & 2410.54 & 3615.81 & 1424.90 & 2005.85 & 2512.81 \\
\hline $\begin{array}{c}\text { Khamis Mushait to } \\
\text { Qaryah al Oliya }\end{array}$ & 1249.8 & 1246.3 & 193.6 & 2320.80 & 4641.60 & 6962.40 & 2980.36 & 3950.80 & 4690.50 \\
\hline
\end{tabular}

Table 34 Shipping cost during hazardous conditions using different modes between origins and destinations.

\begin{tabular}{|c|c|c|c|c|c|c|c|c|c|}
\hline \multirow{4}{*}{ Origin/Destination } & \multicolumn{3}{|c|}{ Distance $(\mathrm{Km})$} & \multicolumn{6}{|c|}{ Total Shipping Cost (US\$) } \\
\hline & \multirow{3}{*}{ Truck } & \multirow{2}{*}{\multicolumn{2}{|c|}{ Intermodal }} & \multicolumn{3}{|c|}{ Truck } & \multicolumn{3}{|c|}{ Intermodal } \\
\hline & & & & \multicolumn{6}{|c|}{ Tonnage (Tons) } \\
\hline & & Rail & Truck & 23 & 46 & 69 & 23 & 46 & 69 \\
\hline Dharma to Al-Kharj & 334.7 & 67.9 & 272.7 & 710.80 & 1421.60 & 2132.40 & 906.20 & 1735.03 & 2533.86 \\
\hline Al Dawadmy to Harad & 657.9 & 369.3 & 256.4 & 1270.60 & 2541.20 & 3811.80 & 1435.22 & 2316.74 & 3190.26 \\
\hline $\begin{array}{l}\text { Khamis Mushait to } \\
\text { Qaryah al Oliya }\end{array}$ & 1402.6 & 1207.9 & 330.2 & 2700.39 & 5400.78 & 8101.17 & 3004.04 & 4440.80 & 5623.55 \\
\hline
\end{tabular}

As shown in the above tables, changing the routes due to the risk will absolutely affect the total shipping cost to deliver those shipments. During certain times of the year when hazardous weather is more likely, shippers do need to consider how risk is incorporated into total cost. The developed model can help in identifying the hazard of each segment on the rail or road network, 
so, after studying the consequences and the likelihoods of each risk category, freight mode and route alternatives can be selected.

In conclusion, this chapter discusses freight logistics as an application to the developed LCCA model. It shows that the warehouse location to deliver shipments can have a huge effect on the mode selection and therefore the shipping cost using trucking, rail, and intermodal systems. The developed model showed that the intermodal yard location where loading and unloading processes take place can also affect decision-making processes, where there may be opportunities for substantial cost savings. Moreover, the developed model proves to be beneficial when delivering shipments to multiple origins and destinations using the optimum routes, which can improve logistics management. Finally, in the case of risk, the implemented model was very reliable in selecting other appropriate routes and scenarios to avoid hazards and deliver shipments using different modes of transportation. Given the level of detail that the model and analysis can provide, the above applications can serve as important tools and strategies for planners and decision makers to build more reliable logistics services as part of viable transportation processes. 


\section{Chapter: Discussion, Conclusions and Recommendations}

\subsection{Discussion and Conclusion}

Research shows that there is a need to fully understand the costs associated with shipping and freight transportation. Within this, there is also an established need to understand what gives shape to governing the relationships that achieve optimum conditions of costs, time and network constraints, while simultaneously supporting decision-making processes, future planning and development in a given region. Due to lack of data, researchers often find it difficult to accurately estimate the total life-cycle cost of shipping using railway and trucking systems. Knowing the cost of each item can serve to motivate researchers to develop new ideas to aid in reducing shipping costs, minimizing freight transportation impacts, as well as assisting governmental efforts by developing models that facilitate future transport network planning decisions and implementing rules and regulations that help to recover the impact cost while at the same time supporting sustainable transportation initiatives.

Contributions of this thesis to the broader literature include: (1) Development of a Life Cycle Cost Analysis (LCCA) model that includes all of the direct costs, indirect costs and pollution produced by using rail and trucking freight transportation systems; (2) Determination of effects of the issue of border delays, which is one of the main constraints when shipping takes place between different countries that have border inspection stations; (3) Planning a future rail transportation network that passes through different countries using ArcGIS; (4) Application of the reliability and sensitivity analysis using the implemented model; (5) Development of logistics applications using different scenarios that can help evaluate intermodal yard locations, alternative route selection, risk and warehouse facility locations; and (6) Establishment of guidelines for sustainable 
and environmentally friendly freight transportation systems. Data from different countries, different municipalities and various companies within the GCC region were used to build the model and conduct the analysis.

The thesis first explored the traditional factors that are most often included to calculate and evaluate the shipping life-cycle cost of using rail and trucking transportation systems. Next, all life-cycle cost factors were obtained to establish a framework for assessing and evaluating the shipping cost and mode selection criteria. GIS ModelBuilder was developed based on the unit rate per ton per distance of using rail and trucking systems. Then, results have been validated and verified with the current freight shipping costs to have more accurate and reliable results. Based on the model results, different logistics concepts and applications have been evaluated and discussed. Based on the final model analysis results, the selected system modes and the specific origins and destinations, this thesis supports the following conclusions:

- Shipping life-cycle cost and shipping mode selection depends on different factors such as infrastructure cost, operation and maintenance cost, external costs, depreciation, potential delays and other environmental issues.

- The distance of transport can favour road to rail depending on how long or how short the shipping distance is. Using a trucking system can be less expensive for small shipping weights, although it might be not reliable in terms of distance, potential delays and pollution.

- Crossing borders can cause delays, which might be extended up to multiple days in the context of the GCC case study, and will ultimately affect the total freight cost between those countries.

- In case of delays, intermodal systems cost less than shipping with trucking systems 
for bulk commodities. As a result, intermodal systems can be considered more reliable as they also produce lower percentages of $\mathrm{CO}_{2}$.

- If destinations are closer in proximity to warehouse locations, the price goes down, and vice versa. However, as shown in this thesis, warehouse locations should be analyzed based on the quantity and multiple destinations of the goods being carried to have an effective decision that maximizes service benefits and reduces the total shipping costs.

- The location of the intermodal yard might have an effect on the total shipping cost and therefore the shipping mode selection. Different criteria have to be considered when deciding on suitable locations for intermodal yards, which includes full awareness of the freight distribution within the region, accessibility, level of safety and the possibility for future expansion. All of these criteria need to be analyzed by decision makers to build more reliable logistics services.

- Using the implemented model can help in solving the vehicle routing problem by identifying the cost of shipping using alternative routes and fleet required to deliver shipments on time, which can impact decision-making processes and improve logistics management.

- Using a risk assessment analysis will help in finding alternative routes based on the risk assessment results. After assigning risk, the process of evaluating the risks will come into play, whether this is to accept it, avoid it, transfer it or control the risk. Applying the implemented model will help to select the most reliable alternative plans to deliver shipments to customers on time.

- Taxation can be a viable way to generate revenues that cover freight impacts. For 
example, in France and Switzerland, vehicles pay tax based on the vehicle's travelled distance, weight and emission level in addition to the freight licence. There are no parallel examples of combined taxation and freight licence fees in the GCC area, so this may be a key consideration for future regulations and policy changes.

- Tolls can also be used as a charge to aid in recovering from impacts and can also simultaneously generate revenue to address externalities. Examples of the use of tolls are taking place in the U.K. and other EU countries, where tolls have been introduced that cover external costs and some of costs associated with air pollution. Coverage of costs linked to noise and vibration will depend on the class of the vehicle. The Council of the European Union suggests that funds generated through tolls can also be used in making transport more sustainable as well as using these funds to support research and development into cleaner technologies. The UAE has begun applying some of these same principles to generate revenue, as well as to address congestion problems. More widespread use of tolls in other GCC countries could result in a more cohesive set of processes when opportunities for transport linkages are assessed.

- Implementing restrictions on the quantity of drivers' working hours could be a good regulation to aid in reducing accident rates and impact costs. Drivers may overload their trucks in scenarios where working hour regulations are not as stringent in order to deliver more shipments in a constrained time period, and the probability of accidents can increase when a truck weight exceeds maximum weights and when drivers are under pressure to over-deliver. 
- Incentivizing shifts from truck to rail or to intermodal systems is key for shippers' participation in reducing environmental and societal impacts. Encouraging shippers to change their mode selection can relieve congestion and lower accident rates.

The main strength of this thesis lies in developing a comprehensive model that can estimate in detail the life-cycle cost of shipping containers between origins and destinations. The developed model is general and can be applied to analyze the shipping cost and transport of goods between any origins and destinations worldwide, by adjusting the factors related to the study area. Further to this, application of this model can aid governments, shippers and designers, provide an important step forward toward cost optimization, evaluate risks and impacts, facilitate rules and regulations, as well as provide directions that help the supply chain to enhance logistics management for sustainable freight transportation systems using the implemented freight model. Finally, having a user-friendly graphical interface will help to operate the model and produces the desired results.

\subsection{Recommendations for Future Work}

Shipping using land transport modes has several positive and negative impacts. Land transport can contribute positively to national economies and can also assist in the growth of industrial sectors. Using rail can be faster when moving goods in bulk quantities and will ultimately affect market conditions. Therefore, rail has the potential to increase the business base in the GCC region. On the other hand, people living and working around shipping corridors can be affected with either rail or trucking as a shipping mode. There are, however, different methods of improving 
road freight governance to maximize the benefits and minimize negative impacts such as education, regulations, incentives and subsidy programs. Regulations related to compliance with safety and operations standards such as weight enforcement contribute to a reduction of overloading. Shifting to another mode of transport will secure road users and at the same time contribute growth to market conditions by using other transport modes. Such freight governance will improve market conditions and at the same time maximize users' benefits.

This thesis addressed some of the limitations that were identified through a literature review, which is linking between modeling freight transportation systems, life-cycle cost as well as introducing logistics applications that help and support decision-making processes. In this section, further recommendations for future work are suggested as follows:

- This thesis was based on the GCC cost data of the years between 2008 and 2014. Going forward, it is important to consider: new rail and trucking technologies, data for each segment in the network, incremental increases in wages and other types of costs that will produce more accurate life-cycle cost estimates.

- Additional types of trucks/wagons and selecting different shipping materials and different tonnages need to be investigated to have more coverage for each type of shipment when running the model, which includes reefer shipping and less than truck load shipping (dry and reefer freight options).

- Investigating the effects of rules and regulations is key. Areas to examine effects could include areas such as taxes, tolls, weight restrictions, break point for shifting and safety measures of governments, the environment and communities. Investigating impacts on these items and others will validate the effectiveness of those rules and provides an idea of what to modify to have more reliable and 
sustainable freight transportation systems.

- Additional variables that can also influence decision-making processes need to be investigated such as shipping duration time and rail departure schedules. Delivering goods on time is one of the critical parts of freight transportation and logistics management.

- Due to data availability, not all types of roads were involved in the model such as local roads, and having the data of each segment in the network that includes the average annual daily traffic, speed limits and traffic direction will produce more accurate cost estimations supporting door-to-door shipping services.

- It is worth studying the effect of using alternative vehicles, such as autonomous trucks or electric vehicles, and to investigate their effects on design processes. From one perspective, it might save operational costs to use alternative vehicles, but at the same time, it can be very expensive to get an entire fleet of these.

- Studying the shipping routes, all freight modes, cost and impact in detail will build a huge database for governments to use in future. After that, they can take advantage of having government/national shipping companies that are certified and qualified for shipping and handling materials, which will generate new employment, add additional economic benefits for the region as well as manage shipping activities.

- More work on environmentally sustainable models and designs need to be implemented to mitigate impacts and to ensure that the environment and quality of life can be preserved. Over long periods of time, environmental, safety and noise pollution can have significant impacts on humans, structures surrounding 
transportation hubs, agriculture and proliferation of eco-systems. Therefore, shifting to rail systems will minimize the impacts caused by thousands of trucks and will also generate substantial environmental and social benefits by reducing emissions, accidents and noise levels.

- Building an integrated freight life-cycle cost model that covers all modes of freight transport which includes air, ocean and land systems will provide more alternatives, minimize shipping costs, reduce freight impacts as well as transform any region into a logistics hub.

- Analyzing delivering cargos using the implemented model to other locales than the GCC countries (such as Iraq and Jordan) can be valuable for shippers to expand their business and evaluate their logistics plans and alternatives.

- As the scale of global trade expands, studying future factors that might affect the freight transportation industry will definitely help in setting contingency plans and facilitate decision-making processes. For example, future supersized cargo ships affecting container shipping industry since small ports getting bypassed.

- Applying the developed model using Q-GIS as an open source software can be a good option for shipping beginners to conduct their analysis and positively influence decision-making processes. 


\section{Appendices}

Appendix A ModelBuilder Road Life-Cycle Analysis model

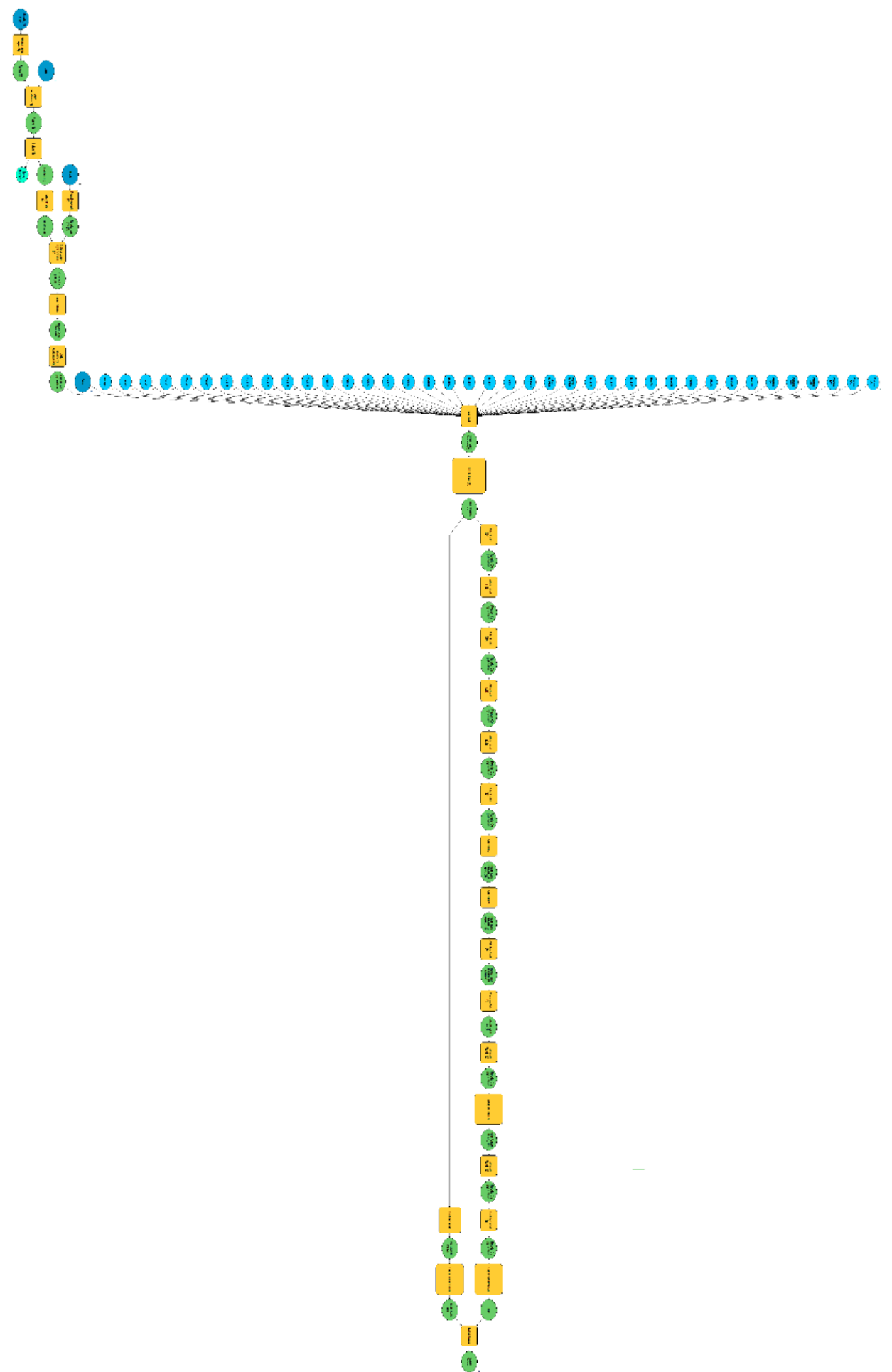




\section{Appendix B ModelBuilder Intermodal Life-Cycle Analysis model}

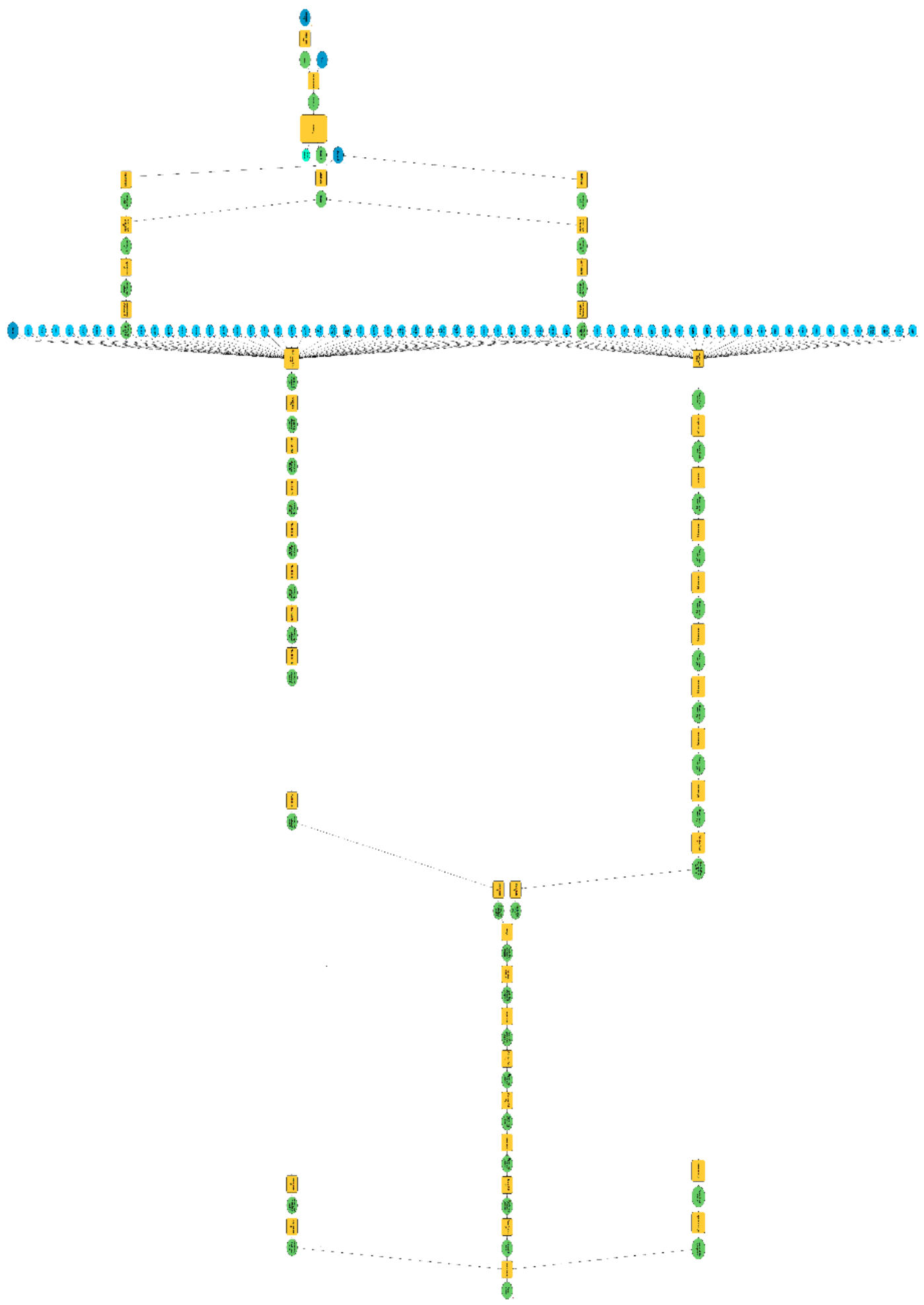




\section{Appendix C Trucking Life-Cycle Script}

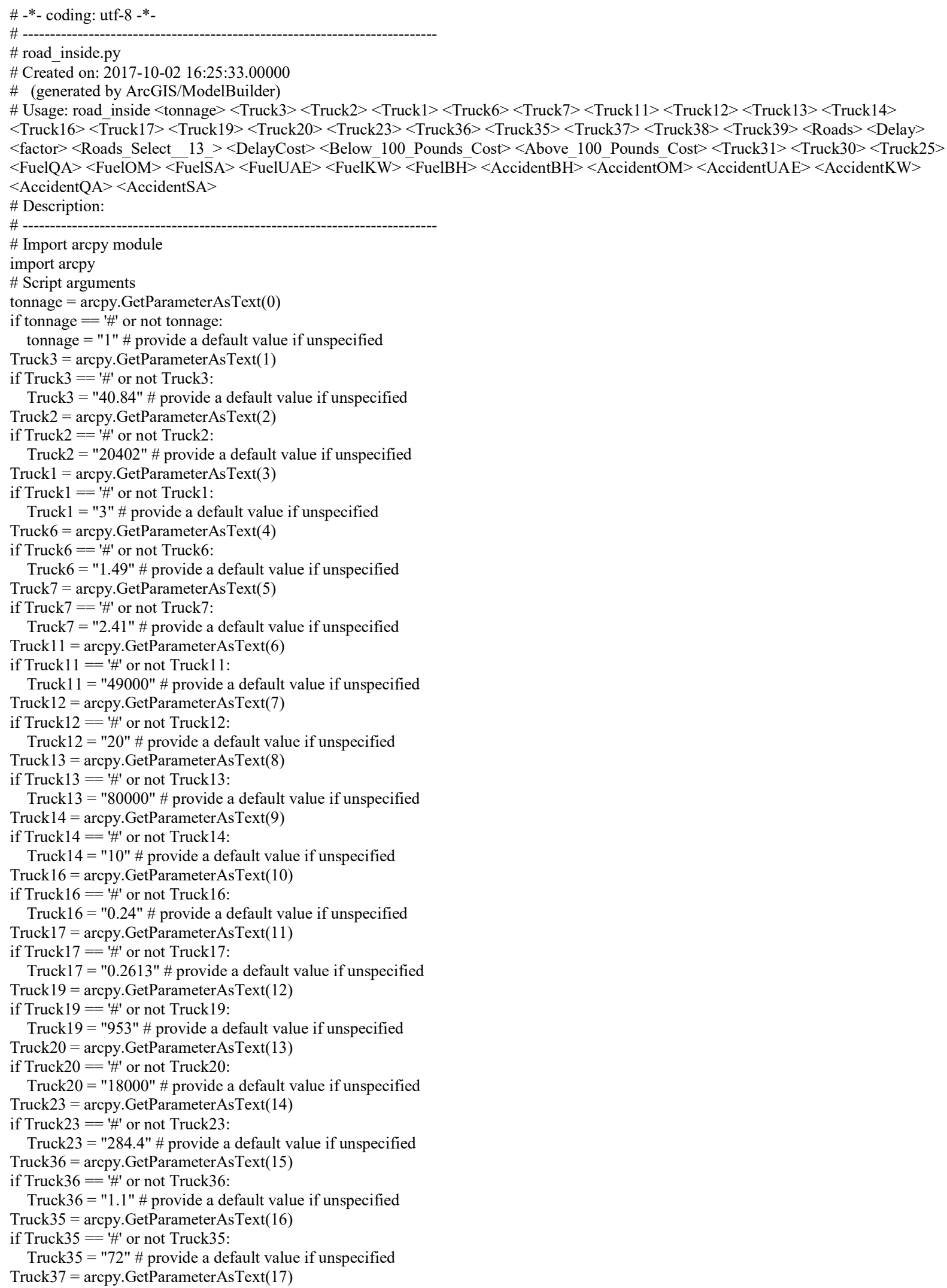


if Truck37 == '\#' or not Truck37:

Truck37 = "1.5" \# provide a default value if unspecified

Truck38 = arcpy.GetParameterAsText(18)

if Truck38 = '\#' or not Truck38:

Truck38 = "0.1" \# provide a default value if unspecified

Truck39 = arcpy.GetParameterAsText(19)

if Truck39 == '\#' or not Truck39:

Truck39 = "0.15" \# provide a default value if unspecified

Roads $=$ arcpy.GetParameterAsText(20)

if Roads == '\#' or not Roads:

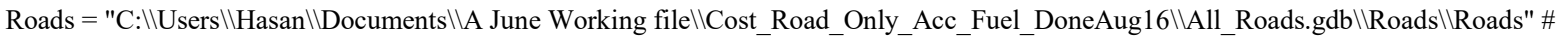
provide a default value if unspecified

Delay $=$ arcpy.GetParameterAsText(21)

if Delay $==$ '\#' or not Delay:

Delay = "1" \# provide a default value if unspecified

factor $=$ arcpy.GetParameterAsText $(22)$

if factor $==$ '\#' or not factor:

factor $=$ "1" \# provide a default value if unspecified

Roads_Select_13_=arcpy.GetParameterAsText(23)

if Roads Select $\overline{13}==$ '\#' or not Roads Select 13 :

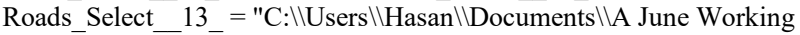

file $\backslash \backslash$ Cost_Road_Only_Acc_Fuel_DoneAug16 $\backslash \backslash$ All_Roads.gdb $\backslash \backslash$ Roads $\backslash \backslash$ Roads" \# provide a default value if unspecified

DelayCost $=$ arcpy.GetParameterAsText(24)

if DelayCost $==$ '\#' or not DelayCost:

DelayCost $=$ "107" \# provide a default value if unspecified

Below_100_Pounds_Cost $=$ arcpy.GetParameterAsText(25)

if Below_100_Pounds_Cost $==$ '\#' or not Below_100_Pounds_Cost:

Below_100_Pounds_Cost $=$ "79.01" \# provide a default value if unspecified

Above_100_Pounds_Cost $=$ arcpy.GetParameterAsText(26)

if Above_100_Pounds_Cost $==$ '\#' or not Above_100_Pounds_Cost:

Above_100_Pounds_Cost $=$ "104" \# provide a default value if unspecified

Truck31 = arcpy.GetParameterAsText(27)

if Truck31 =='\#' or not Truck31:

Truck31 = "0.14" \# provide a default value if unspecified

Truck30 $=$ arcpy.GetParameterAsText(28)

if Truck30 == '\#' or not Truck30:

Truck30 = "0.0333" \# provide a default value if unspecified

Truck25 = arcpy.GetParameterAsText(29)

if Truck25 == '\#' or not Truck25:

Truck25 = "0.01605" \# provide a default value if unspecified

FuelQA = arcpy.GetParameterAsText(30)

if FuelQA == '\#' or not FuelQA:

FuelQA = "0.41" \# provide a default value if unspecified

FuelOM = arcpy.GetParameterAsText(31)

if FuelOM == '\#' or not FuelOM:

FuelOM = "0.41" \# provide a default value if unspecified

FuelSA = arcpy.GetParameterAsText(32)

if FuelSA == '\#' or not FuelSA:

FuelSA $=$ "0.24" \# provide a default value if unspecified

FuelUAE = arcpy.GetParameterAsText(33)

if FuelUAE $==$ '\#' or not FuelUAE:

FuelUAE $=$ "0.44" \# provide a default value if unspecified

FuelKW = arcpy.GetParameterAsText(34)

if FuelKW == '\#' or not FuelKW:

FuelKW = "0.36" \# provide a default value if unspecified

FuelBH $=$ arcpy.GetParameterAsText(35)

if FuelBH == '\#' or not FuelBH:

FuelBH $=$ "0.32" \# provide a default value if unspecified

AccidentBH = arcpy.GetParameterAsText(36)

if AccidentBH == '\#' or not AccidentBH:

AccidentBH $=$ "0.01807" \# provide a default value if unspecified

AccidentOM = arcpy.GetParameterAsText(37)

if AccidentOM = '\#' or not AccidentOM:

AccidentOM $=$ "0.01084" \# provide a default value if unspecified

AccidentUAE $=$ arcpy.GetParameterAsText(38)

if AccidentUAE $==$ '\#' or not AccidentUAE:

AccidentUAE $=$ "0.00904" \# provide a default value if unspecified

AccidentKW = arcpy.GetParameterAsText(39)

if AccidentKW == '\#' or not AccidentKW:

AccidentKW $=$ "0.01807" \# provide a default value if unspecified 
AccidentQA $=$ arcpy.GetParameterAsText(40)

if AccidentQA == '\#' or not AccidentQA:

AccidentQA $=$ "0.03162" \# provide a default value if unspecified

AccidentSA $=$ arcpy.GetParameterAsText(41)

if AccidentSA $==$ ' $\#$ ' or not AccidentSA:

AccidentSA = "0.01807" \# provide a default value if unspecified

\# Local variables:

Routes 2 = Roads

Roads_Select_3_= Routes_2

Routes 3_= Roads_Select 3

Roads_Select_34_= Routes 3

Routes $5=$ Roads Select 34

Roads_Select_35_= Routes_5

Routes 4 = Roads_Select_35

Roads_Select_4_= Routes_4_

Routes $6=$ Roads Select 4

Roads_Select_36_= Routes_ 6

Routes_7_= Roads_Select_36_

Roads_Select_2_= Routes_7

Routes_8_= Roads_Select_2

Roads_Select_37_= Routes_ 8

Routes_9_= Roads_Select_37

Roads_Select_5_= Routes_9

Routes $10 \_=$Roads_Select $\overline{5}$

Roads_Select 6 - Routes 10

Routes_11_ $=$ Roads_Select_6

Roads Select $38=$ Routes 11

Routes_12_= Roads_Select_38-

Roads Select $39=$ Routes 12

Routes_13_= Roads_Select_39

Roads Select $40=$ Routes 13

Routes_14_= Roads_Select_40

Roads Select $41=$ Routes 14

Routes $15=$ Roads Select 41

Roads_Select_ $7 \_=$Routes 15

Routes 16_ $=$ Roads_Select 7

Roads_Select $42_{-}=$Routes $1 \overline{6}$

Routes_17_= Roads_Select_42

Roads_Select_43_ $=$ Routes _ 17

Routes_18_= Roads_Select_43

Roads_Select_8_ $=$ Routes 18

Routes 19_ = Roads_Select 8

Roads_Select_44_ $=$ Routes_ 19

Routes 20 = Roads Select 44

Roads_Select $45=$ Routes 20

Routes 21_= Roads_Select 45

Roads_Select_9_= Routes_ 21

Routes 23 = Roads_Select 9

Roads_Select_46_ $=$ Routes -23

Routes $24=$ Roads Select 46

Roads_Select_11_ $=$ Routes_24

Routes $26=$ Roads Select 11

Roads_Select_26_ $=$ Routes_26_-

Roads $3=\overline{\text { Roads Select } 26}$

Roads_Select_17_= Roads_3

Roads_Select_18 $=$ Roads Select 17

Roads_Select_23_= Roads_Select_18

Roads_Select_25_= Roads_Select_23

Roads_Select_21_= Roads_Select_25_

Routes $29=$ Roads Select 21

Routes_25_= Routes_29

Roads 2 = Routes $\overline{25}$

Routes_36 = Roads_2

Roads 4 _ $=$ Routes 36

Roads_Select_29_= Roads 4

Routes 30 = Roads_Select 29

Roads_Select 30 = Routes _30

Routes_31_= Roads_Select_30_

Roads Select $31=$ Routes 31

Routes_32_= Roads_Select_31_ 
Roads Select $32=$ Routes 32

Routes_33_= Roads_Select_32

Roads Select $33=$ Routes 33

Routes_35_= Roads_Select_33

Roads_Select_15_= Routes_35

Routes_34_= Roads_Select_15

Roads_Select $48+=$ Routes_ 34

Output_Feature_Class_12= Roads_Select_48

Output_Feature_Class_11_ $=$ Output_Feature_Class_12

Output_Feature_Class_10_= Output_Feature_Class_11

Output_Feature_Class_ $9{ }_{-}=$Output_Feature_Class_ ${ }_{1}{ }_{-}$

Output Feature Class $8=$ Output Feature Class 9

Output_Feature_Class_7 ${ }_{-}^{-}=$Output_Feature_Class_8

Output_Feature Class $=$ Output Feature Class 7

Output_Feature_Class_2_= Output_Feature_Class

Output Feature Class $6=$ Output Feature Class 2

Output_Feature_Class_5_=Output_Feature_Class_6

Output_Feature_Class_4_- Output_Feature_Class_5

Output_Feature_Class_3_-Output_Feature_Class_4_

Routes_28_= Output_Feature_Class_ 3 _

Roads_Select_14_ $=$ Routes_28

Output_Feature_Class_13_= Roads_Select 14

Routes_55_= Output_Feature_Class_13

Roads_Select $60=$ Routes 55

Routes $45=$ Roads Select 60

Roads_Select_20_= Routes_45

Routes $57=$ Roads Select 20

Roads_Select_62_= Routes_57-

Routes $62=$ Roads Select 62

Roads_Select 67 = Routes $62-$

Routes $58=$ Roads Select 67

Roads_Select_63_= Routes_58

Routes 60_ = Roads_Select 63

Roads_Select_65_= Routes_60

Routes 44 = Roads_Select 65

Roads_Select $19=$ Routes 44

Routes $56=$ Roads Select 19

Roads_Select_61_= Routes_56_

Routes $43=$ Roads Select 61

Roads_Select_16_ $=$ Routes_43

Routes 61 = Roads Select 16

Roads_Select_66_ $=$ Routes_61

Routes_59_= Roads_Select_66

Roads_Select_64_ $=$ Routes_59

Routes_63_= Roads_Select_64

Roads_Select 68 - Routes _63

Roads_Select_22_- Roads_Select 68

Routes_22_= Roads_Select_22

Roads_Select $10 \_=$Routes 22

Roads $5=\overline{\text { Roads Select } 10}$

Routes_ $27_{-}=$Roads 5 -

\# Process: Add Truck 4

arcpy.AddField_management(Roads, "Truck4", "DOUBLE", "', "', "', "', "NULLABLE", "NON_REQUIRED", "')

\# Process: CalculateTruck 4

arcpy.CalculateField_management(Routes_2_, "Truck4", "mult(\%Truck3\%)", "PYTHON_9.3", "def mult(x): \\n x= float (x * 3600)\n return $\left.x^{\prime \prime}\right)$

\# Process: Add Truck2

arcpy.AddField_management(Roads_Select 3 , "Truck2", "DOUBLE", "', "', "', "', "NULLABLE", "NON_REQUIRED", "')

\# Process: Calculate Truck2

arcpy.CalculateField_management(Routes_3_, "Truck2", "calctruck(\%Truck2\%)", "PYTHON", "def calctruck( x ): \nn r = x\\n return r") \# Process: Add Truck1

arcpy.AddField_management(Roads_Select_34_, "Truck1", "DOUBLE", "', "', "', "'", "NULLABLE", "NON_REQUIRED", "')

\# Process: Calculate Truck1

arcpy.CalculateField_management(Routes_5_, "Truck1", "calctruck(\%Truck1\%)", "PYTHON", "def calctruck( x ): \\n r = x\\n return r")

\# Process: Add Truck 5

arcpy.AddField_management(Roads_Select_35_, "Truck5", "DOUBLE", "', "', "', "', "NULLABLE", "NON_REQUIRED", "')

\# Process: Calculate Truck 5

arcpy.CalculateField management(Routes 4, "Truck5", "calctruck(!Truck4! , !Truck2! , !Truck1!)", "PYTHON", "def calctruck( x , y , $\mathrm{z}): \backslash \ln \mathrm{r}=$ float $(\mathrm{x} /((\mathrm{y} /(2.0 * \mathrm{z})) * 250 * 0.1 * 29.78)) \backslash \mathrm{n}$ return $\mathrm{r} ")$ 
\# Process: Add Truck6

arcpy.AddField_management(Roads_Select_4_, "Truck6", "DOUBLE", "", "', "', "', "NULLABLE", "NON_REQUIRED", "') \# Process: Calculate Truck6

arcpy.CalculateField_management(Routes_6_, "Truck6", "calctruck(\%Truck6\%)", "PYTHON", "def calctruck( x ): $\backslash \backslash n$ r = x \\n return r") \# Process: Add Truck 8

arcpy.AddField_management(Roads_Select_36_, "Truck8", "DOUBLE", "', "', "', "'", "NULLABLE", "NON_REQUIRED", "') \# Process: Calculate Truck 8

arcpy.CalculateField_management(Routes_7,, "Truck8", "calctruck( \%Truck6\% ,\%Truck2\%, \%Truck1\% )", "PYTHON", "def calctruck( x , y, z $): \backslash n \mathrm{r}=((\mathrm{x} * 3 . \overline{6} * 1000) /(\mathrm{y} /(2 * \mathrm{z}) * 2 \overline{50} * 0.1 * 29.78)) \backslash$ n return $\mathrm{r} ")$

\# Process: Add Truck7

arcpy.AddField_management(Roads_Select_2_, "Truck7", "DOUBLE", "', "', "'", "', "NULLABLE", "NON_REQUIRED", "')

\# Process: Calculate Truck7

arcpy.CalculateField_management(Routes_8_, "Truck7", "calctruck(\%Truck7\%)", "PYTHON", "def calctruck( x ): \\n r=x $\backslash \backslash$ n return r")

\# Process: Add Truck9

arcpy.AddField_management(Roads_Select_37_, "Truck9", "DOUBLE", "', "', "', "', "NULLABLE", "NON_REQUIRED", "')

\# Process: Calculate Truck9

arcpy.CalculateField_management(Routes_9_, "Truck9", "calctruck(!Truck7! , !Truck2! , !Truck1! )", "PYTHON", "def calctruck( x , y , $\mathrm{z}): \backslash \backslash \mathrm{n} \mathrm{r}=$ float $((\mathrm{x} * \overline{3.6} * 1000.0) /(\mathrm{y} /(2.0 * \overline{\mathrm{z}}) * 250.0 * 0.1 * 29.78)) \backslash \backslash \mathrm{n}$ return $\mathrm{r} ")$

\# Process: Add Truck10

arcpy.AddField management(Roads Select 5, "Truck10", "DOUBLE", "', "'", "', "', "NULLABLE", "NON REQUIRED", "')

\# Process: Calculate Truck10

arcpy.CalculateField_management(Routes_10_, "Truck10", "calctruck( !Truck8! , !Truck9! )", "PYTHON", "def calctruck( x , y ): \n r

$=(16 * \mathrm{x})+(4 * \mathrm{y}) \backslash \mathrm{n}$ return $\left.\mathrm{r}^{\prime \prime}\right)$

\# Process: Add Truck11

arcpy.AddField_management(Roads_Select_6_, "Truck11", "DOUBLE", "', "', "'", "', "NULLABLE", "NON_REQUIRED", "')

\# Process: Calculate Truck11

arcpy.CalculateField_management(Routes_11_, "Truck11", "calctruck(\%Truck11\%)", "PYTHON", "def calctruck( x ): \n r = x \n return r") \# Process: Add Truck 12

arcpy.AddField_management(Roads_Select_38_, "Truck12", "DOUBLE", "', "', "', "', "NULLABLE", "NON_REQUIRED", "')

\# Process: Calculate Truck12

arcpy.CalculateField_management(Routes_12_, "Truck12", "calctruck(\%Truck12\%)", "PYTHON", "def calctruck( x ): \\n r x $\backslash \backslash n$ return r") \# Process: Add Truck-13

arcpy.AddField management(Roads Select 39, "Truck13", "DOUBLE", "', "', "', "', "NULLABLE", "NON REQUIRED", "')

\# Process: Calculate Truck13

arcpy.CalculateField_management(Routes_13,, "Truck13", "calctruck(\% Truck13\%)", "PYTHON", "def calctruck( x ): \n r= x\\n return r")

\# Process: Add Truck 14

arcpy.AddField_management(Roads_Select_40_, "Truck14", "DOUBLE", "', "', "', "'", "NULLABLE", "NON_REQUIRED", "')

\# Process: Calculate Truck14

arcpy.CalculateField management(Routes 14 , "Truck14", "calctruck(\%Truck14\%)", "PYTHON", "def calctruck( x ): \n r = x \n return r")

\# Process: Add Truck-15

arcpy.AddField_management(Roads_Select_41_, "Truck15", "DOUBLE", "', "', "', "'", "NULLABLE", "NON_REQUIRED", "')

\# Process: Calculate Truck15

arcpy.CalculateField_management(Routes_15_, "Truck15", "calctruck( !Truck11! , !Truck12!,!Truck13! , !Truck14! )", "PYTHON", "def calctruck $(\mathrm{x}, \mathrm{y}, \mathrm{z}, \mathrm{p}): \backslash \mathrm{n} \mathrm{r}=\left(\mathrm{x}-\left((\mathrm{y} / 100)^{*} \mathrm{x}\right)\right) /(\mathrm{z} * \mathrm{p}) \backslash \backslash \mathrm{n}$ return $\left.\mathrm{r}^{\prime \prime}\right)$

\# Process: Add Truck16

arcpy.AddField_management(Roads_Select_7_, "Truck16", "DOUBLE", "', "', "'", "', "NULLABLE", "NON_REQUIRED", "")

\# Process: Calculate Truck16

arcpy.CalculateField_management(Routes_16_, "Truck16", "calctruck(\%Truck16\%)", "PYTHON", "def calctruck( x ): \n r= x\\n return r") \# Process: Add Truck 17

arcpy.AddField_management(Roads_Select_42_, "Truck17", "DOUBLE", "', "', "', "', "NULLABLE", "NON_REQUIRED", "')

\# Process: Calculate Truck17

arcpy.CalculateField management(Routes 17, "Truck17", "calctruck(\%Truck17\%)", "PYTHON", "def calctruck( x ): \n r= x \n return r") \# Process: Add Truck 18

arcpy.AddField_management(Roads_Select_43_, "Truck18", "DOUBLE", "', "', "', "', "NULLABLE", "NON_REQUIRED", "')

\# Process: Calculate Truck 18

arcpy.CalculateField_management(Routes_18_, "Truck18", "calctruck( !Truck16! , !Truck17!)", "PYTHON", "def calctruck( x , y ): \n r =

float $(\mathrm{x} * \mathrm{y}) \backslash$ n return $\left.\mathrm{r}^{\prime \prime}\right)$

\# Process: Add Truck19

arcpy.AddField_management(Roads_Select_8_, "Truck19", "DOUBLE", "", "', "'", "", "NULLABLE", "NON_REQUIRED", "')

\# Process: Calculate Truck19

arcpy.CalculateField_management(Routes_19_, "Truck19", "calctruck(\%Truck19\%)", "PYTHON", "def calctruck( x ): \n r=x \\n return r") \# Process: Add Truck20

arcpy.AddField_management(Roads_Select_44_, "Truck20", "DOUBLE", "', "', "', "', "NULLABLE", "NON_REQUIRED", "')

\# Process: Calculate Truck20

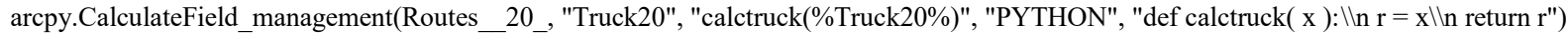
\# Process: Add Truck̄21

arcpy.AddField_management(Roads_Select_45_, "Truck21", "DOUBLE", "', "', "', "', "NULLABLE", "NON_REQUIRED", "')

\# Process: Calculate Truck 21

arcpy.CalculateField_management(Routes_21_, "Truck21", "calctruck( !Truck19! , !Truck20! )", "PYTHON", "def calctruck( x , y ): \n r = $\mathrm{x} / \mathrm{y} \backslash \backslash \mathrm{n}$ return $\left.\mathrm{r}^{\prime \prime}\right)$ 
\# Process: Add Truck23

arcpy.AddField_management(Roads_Select_9_, "Truck23", "DOUBLE", "', "', "', "', "NULLABLE", "NON_REQUIRED", "') \# Process: Calculate Truck23

arcpy.CalculateField_management(Routes_23_, "Truck23", "calctruck(\%Truck23\%)", "PYTHON", "def calctruck( x ): $\backslash \backslash n \mathrm{r}=\mathrm{x} \backslash \backslash n$ return r") \# Process: Add Truck 24

arcpy.AddField_management(Roads_Select_46_, "Truck24", "DOUBLE", "', "', "', "', "NULLABLE", "NON_REQUIRED", "')

\# Process: Calculate Truck 24

arcpy.CalculateField_management(Routes_24_, "Truck24", "calctruck( !Truck23!, !Truck20! )", "PYTHON", "def calctruck( x , y ):\\n r = float(x / y) \n return $\left.\overline{\mathrm{r}^{\prime \prime}}\right)$

\# Process: Add Truck26

arcpy.AddField_management(Roads_Select_11_, "Truck26", "DOUBLE", "', "', "', "', "NULLABLE", "NON_REQUIRED", "')

\# Process: Truck 26 by $\mathrm{km}$ by ton

arcpy.CalculateField_management(Routes_26_, "Truck26", "calctruck( \%Truck25\%,\%factor\% , \%tonnage\% , !SHAPE_Length! )",

"PYTHON_9.3", "def calctruck( w, x , y, z ): \\n return float(w* $\left.\left.x^{*} y^{*} \mathrm{z} / 1000.0\right) "\right)$

\# Process: Add Field

arcpy.AddField_management(Roads_Select_26_, "TrucksNeeded", "LONG", "', "', "', "TrucksNeeded", "NULLABLE",

"NON_REQUIRED", "')

\# Process: Calculate Trucks Needed

arcpy.CalculateField_management(Roads_3_, "TrucksNeeded", "TonnageToTruck(\%tonnage\%)", "PYTHON_9.3", "def

TonnageToTruck(x): $\backslash$ n $\mathrm{x}=$ math.ceil( float $(\mathrm{x}) / 23$ ) $\backslash \mathrm{n}$ return $\mathrm{x} ")$

\# Process: Truck 5 by $\mathrm{km}$ by count

arcpy.CalculateField_management(Roads_Select_17_, "Truck5", "calctruck( !Truck5!, !SHAPE_Length!, !TrucksNeeded! )", "PYTHON",

"def calctruck $(\mathrm{x}, \mathrm{y}, \mathrm{z}): \backslash \ln \mathrm{r}=\mathrm{x} * \mathrm{y} * \mathrm{z} / 1000 \backslash \mathrm{n}$ return $\mathrm{r} ")$

\# Process: truck15 by km

arcpy.CalculateField_management(Roads_Select_18_, "Truck15", "calctruck(!Truck15!,!SHAPE_Length!, !TrucksNeeded! )",

"PYTHON", "def calctruck $(\mathrm{x}, \mathrm{y}, \mathrm{z}): \backslash \mathrm{n} \mathrm{r}=\mathrm{x} * \mathrm{y} \overline{\mathrm{z}} / 1000 \backslash \mathrm{n}$ return $\mathrm{r}$ ")

\# Process: truck24 by km

arcpy.CalculateField_management(Roads_Select_23_, "Truck24", "calctruck(!Truck24!,!SHAPE_Length!, !TrucksNeeded! )",

"PYTHON", "def calctruck $(\mathrm{x}, \mathrm{y}, \mathrm{z}): \backslash \mathrm{n} \mathrm{r}=\mathrm{x} * \mathrm{y}^{*} \mathrm{z} / 1000 \backslash \mathrm{n}$ return $\mathrm{r}$ ")

\# Process: Truck10 by km by count

arcpy.CalculateField management(Roads Select 25 , "Truck10", "calctruck(!Truck10!,!SHAPE Length!, !TrucksNeeded! )",

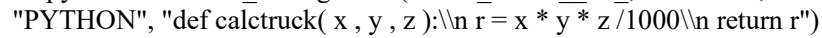

\# Process: Add Truck35

arcpy.AddField_management(Roads_Select_21_, "Truck35", "DOUBLE", "', "', "', "Truck35", "NULLABLE", "NON_REQUIRED", "') \# Process: Add Truck30 (2)

arcpy.AddField_management(Routes_29_, "Truck30", "DOUBLE", "', "', "', "Truck30", "NULLABLE", "NON_REQUIRED", "')

\# Process: Calculate Truck 30 by ton $\mathrm{km}$

arcpy.CalculateField_management(Routes_25_, "Truck30", "calctruck( \%Truck30\%, \%tonnage\% , !SHAPE_Length! )", "PYTHON_9.3", "def calctruck(x,y,z): $\backslash \backslash$ n return float $((\mathrm{x} * \mathrm{y} * \overline{\mathrm{z}}) / 1000) ")$

\# Process: Add Truck35 (3)

arcpy.AddField_management(Roads_2, "Truck31", "DOUBLE", "', "', "', "Truck31", "NULLABLE", "NON_REQUIRED", "')

\# Process: Calculate Truck 31 by ton km

arcpy.CalculateField_management(Routes_36, "Truck31", "calctruck( \%Truck31\%, !TrucksNeeded! , !SHAPE_Length! )",

"PYTHON_9.3", "def calctruck( $\mathrm{x}, \mathrm{y}, \mathrm{z}): \backslash \overline{\mathrm{nn}} \operatorname{return}$ float $\left.\left(\left(\mathrm{x}^{*} \mathrm{y}^{*} \mathrm{z}\right) / 1000\right) "\right)$

\# Process: $\overline{\mathrm{T}} 35 \mathrm{G}$ per km per ton

arcpy.CalculateField_management(Roads_4_, "Truck35", "calctruck(\%Truck35\%,!SHAPE_Length!, \%tonnage\% )", "PYTHON_9.3",

"def calctruck $(\mathrm{x}, \mathrm{y}, \mathrm{z}): \backslash \ln \mathrm{r}=\mathrm{x} * \mathrm{y} * \mathrm{z} / \overline{1000} \backslash \backslash \mathrm{n}$ return $\mathrm{r} ")$

\# Process: Add Truck36

arcpy.AddField_management(Roads_Select_29_, "Truck36", "DOUBLE", "', "'", "', "Truck36", "NULLABLE", "NON_REQUIRED", "') \# Process: T36 G per km per ton

arcpy.CalculateField_management(Routes_30_, "Truck36", "calctruck( \%Truck36\%,!SHAPE_Length!, \%tonnage\% )", "PYTHON_9.3", "def calctruck $(\mathrm{x}, \mathrm{y}, \mathrm{z}): \backslash \backslash \mathrm{n} \mathrm{r}=\mathrm{x} * \mathrm{y} * \mathrm{z} / 1000 \backslash \backslash \mathrm{n}$ return $\mathrm{r} ")$

\# Process: Add Truck37

arcpy.AddField_management(Roads_Select_30_, "Truck37", "DOUBLE", "', "', "', "Truck37", "NULLABLE", "NON_REQUIRED", "') \# Process: T37 G per km per ton

arcpy.CalculateField_management(Routes_31_, "Truck37", "calctruck( \%Truck37\%,!SHAPE_Length!, \%tonnage\% )", "PYTHON_9.3", "def calctruck $(\mathrm{x}, \mathrm{y}, \mathrm{z}): \backslash \ln \mathrm{r}=\mathrm{x} * \mathrm{y} * \mathrm{z} / 1000 \backslash \backslash \mathrm{n}$ return $\mathrm{r} ")$

\# Process: Add Truck38

arcpy.AddField_management(Roads_Select_31_, "Truck38", "DOUBLE", "', "', "', "Truck38", "NULLABLE", "NON_REQUIRED", "') \# Process: T38 G per km per ton

arcpy.CalculateField_management(Routes_32_, "Truck38", "calctruck( \%Truck38\%,!SHAPE_Length!, \%tonnage\% )", "PYTHON_9.3", "def calctruck $(\mathrm{x}, \mathrm{y}, \mathrm{z}): \backslash \ln \mathrm{r}=\mathrm{x} * \mathrm{y} * \mathrm{z} / 1000 \backslash \backslash$ n return $\mathrm{r} ")$

\# Process: Add Truck39

arcpy.AddField_management(Roads_Select_32_, "Truck39", "DOUBLE", "', "', "', "Truck39", "NULLABLE", "NON_REQUIRED", "') \# Process: T39 G per km per ton

arcpy.CalculateField_management(Routes_33_, "Truck39", "calctruck(\%Truck39\%,!SHAPE_Length!, \%tonnage\% )", "PYTHON_9.3", "def calctruck $(\mathrm{x}, \mathrm{y}, \mathrm{z}): \backslash \ln \mathrm{r}=\mathrm{x} * \mathrm{y} * \mathrm{z} / 1000 \backslash \backslash \mathrm{n}$ return $\mathrm{r}$ ")

\# Process: Add Truck33

arcpy.AddField management(Roads Select 33 , "Truck33", "DOUBLE", "', "', "', "Truck33", "NULLABLE", "NON REQUIRED", "') \# Process: Calc truck33 
arcpy.CalculateField_management(Routes_35, "Truck33", "calctruck(\%Above_100_Pounds_Cost\%,\%Below_100_Pounds_Cost\%,

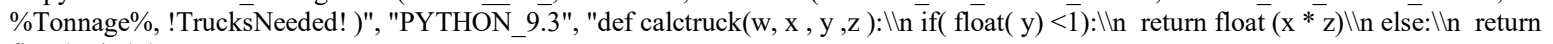
float $(\mathrm{w} * \mathrm{z}) ")$

\# Process: Add Truck32

arcpy.AddField_management(Roads_Select_15_, "Truck32", "DOUBLE", "', "', "', "Truck32", "NULLABLE", "NON_REQUIRED", "') \# Process: T32 cost per day

arcpy.CalculateField_management(Routes_34_, "Truck32", "calctruck(\%DelayCost\%,\%Delay\%, !TrucksNeeded!)", "PYTHON_9.3", "def calctruck $(\mathrm{x}, \mathrm{y}, \mathrm{z}): \backslash \mathrm{n} \mathrm{r}=\mathrm{x} * \mathrm{y}^{*} \mathrm{z} \backslash \mathrm{n}$ return $\left.\mathrm{r}^{\prime \prime}\right)$

\# Process: Add Field Truck29BH

arcpy.AddField_management(Roads_Select_48_, "Truck29BH", "DOUBLE", "', "', "', "', "NULLABLE", "NON_REQUIRED", "')

\# Process: Calculate Field Truck29BH

arcpy.CalculateField_management(Output_Feature_Class_12,, "Truck29BH", "calctruck(\%AccidentBH\%, !Code! )", "PYTHON_9.3",

"def calctruck(w, $\mathrm{x}): \bar{\backslash} \backslash \mathrm{n}$ if( float $(\mathrm{x})==2): \backslash \overline{\mathrm{n}} \operatorname{return}$ float $(\bar{w}) \backslash \backslash \mathrm{n}$ else: $\backslash \mathrm{n}$ return $0 ")$

\# Process: Add Field Truck29OM

arcpy.AddField_management(Output_Feature_Class_11_, "Truck29OM", "DOUBLE", "', "', "', "', "NULLABLE", "NON_REQUIRED", "')

\# Process: Calculate Field Truck29OM

arcpy.CalculateField_management(Output_Feature_Class_10_, "Truck29OM", "calctruck(\%AccidentOM\%, !Code! )", "PYTHON_9.3",

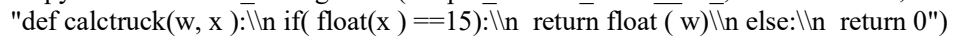

\# Process: Add Field Truck29SA

arcpy.AddField_management(Output_Feature_Class_9_, "Truck29SA", "DOUBLE", "', "', "', "', "NULLABLE", "NON_REQUIRED", "')

\# Process: Calculate Field Truck29SA

arcpy.CalculateField_management(Output_Feature_Class_8_, "Truck29SA", "calctruck(\%AccidentSA\%, !Code! )", "PYTHON_9.3", "def calctruck(w, $\mathrm{x}): \backslash \mathrm{n}$ if( float $(\mathrm{x})==19): \backslash \backslash \mathrm{n}$ return float $(\mathrm{w}) \overline{\backslash n}$ else: $\backslash \backslash n$ return $0 ")$

\# Process: Add Field Truck29QA

arcpy.AddField_management(Output_Feature_Class_7_, "Truck29QA", "DOUBLE", "', "', "', "', "NULLABLE", "NON_REQUIRED", "'")

\# Process: Calculate Field Truck29QA

arcpy.CalculateField_management(Output_Feature_Class, "Truck29QA", "calctruck(\%AccidentQA\%, !Code! )", "PYTHON_9.3", "def calctruck(w, $\mathrm{x}): \backslash \ln$ if( float $(\mathrm{x})==17): \backslash \mathrm{n}$ return float $(\mathrm{w}) \backslash \backslash \mathrm{n}$ else: $\backslash \mathrm{n}$ return $0 ")$

\# Process: Add Field Truck29KW

arcpy.AddField_management(Output_Feature_Class___, "Truck29KW", "DOUBLE", "', "', "', "', "NULLABLE", "NON_REQUIRED", "')

\# Process: Calculate Field Truck29KW

arcpy.CalculateField_management(Output_Feature_Class_6_, "Truck29KW", "calctruck(\%AccidentKW\%, !Code! )", "PYTHON_9.3",

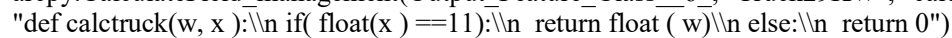

\# Process: Add Field Truck29UAE

arcpy.AddField_management(Output_Feature_Class_5_, "Truck29UAE", "DOUBLE", "', "', "', "', "NULLABLE", "NON_REQUIRED", "')

\# Process: Calculate Field Truck29UAE

arcpy.CalculateField_management(Output_Feature_Class_4_, "Truck29UAE", "calctruck(\%AccidentUAE\%, !Code!)", "PYTHON_9.3",

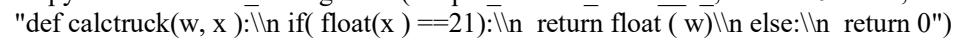

\# Process: Add Truck29

arcpy.AddField_management(Output_Feature_Class_3_, "Truck29", "DOUBLE", "', "', "', "Truck29", "NULLABLE",

"NON_REQUIRED", "')

\# Process: Calculate Truck29

arcpy.CalculateField_management(Routes_28_, "Truck29", "calctruck( !Truck29BH!, !Truck29OM!, !Truck29SA!, !Truck29QA!,

!Truck29KW!, !Truck29UAE! )", "PYTHON", "def calctruck( a, b,c,d,e,f ): \n return float (a+b+c+d+e+f)")

\# Process: Calculate Truck29 by ton $\mathrm{km}$

arcpy.CalculateField_management(Roads_Select_14_, "Truck29", "calctruck( !Truck29! , !SHAPE_Length! , \%tonnage\% )",

"PYTHON 9.3", "def calctruck(a,b,c): \n $\mathrm{r}=$ float $(\mathrm{a} * \mathrm{~b} * \mathrm{c} / 1000) \backslash \mathrm{n}$ return $\mathrm{r} \backslash \backslash \mathrm{n}$ ")

\# Process: Add Truck18OM

arcpy.AddField_management(Output_Feature_Class_13_, "Truck18OM", "DOUBLE", "', "', "', "', "NULLABLE", "NON_REQUIRED", "')

\# Process: Calculate Truck18OM

arcpy.CalculateField_management(Routes_55_, "Truck18OM", "calctruck( \%FuelOM\% , !Truck17!, !Code! )", "PYTHON", "def calctruck $(\mathrm{w}, \mathrm{x}, \mathrm{y}): \backslash \overline{\mathrm{n}}$ if $($ float $(\mathrm{y})==15): \backslash \overline{\mathrm{n}}$ return float $(\mathrm{x} * \mathrm{w}) \backslash \mathrm{n}$ else: $\backslash \mathrm{nn}$ return $0 \backslash \backslash \mathrm{n} ")$

\# Process: Add Truck22OM

arcpy.AddField_management(Roads_Select_60_, "Truck22OM", "DOUBLE", "', "', "', "'", "NULLABLE", "NON_REQUIRED", "')

\# Process: Calculate Truck22OM

arcpy.CalculateField_management(Routes_45_, "Truck22OM", "calctruck(!Truck18OM! , !Truck21!, !Code! )", "PYTHON", "def

calctruck $(\mathrm{x}, \mathrm{y}, \mathrm{z}): \backslash \overline{\mathrm{n}}$ if ( float $(\mathrm{z})==15): \backslash \overline{\mathrm{n}} \operatorname{return}$ float $(\mathrm{x}+\mathrm{y}) \backslash \mathrm{n}$ else: $\backslash \mathrm{n}$ return $0 \backslash \backslash \mathrm{n} ")$

\# Process: Add Truck18KW

arcpy.AddField_management(Roads_Select_20_, "Truck18KW", "DOUBLE", "', "', "', "', "NULLABLE", "NON_REQUIRED", "')

\# Process: Calculate Truck18KW

arcpy.CalculateField_management(Routes_57_, "Truck18KW", "calctruck( \%FuelKW\%, !Truck17!, !Code! )", "PYTHON", "def 
calctruck(w, x , y ): \n if( float $(\mathrm{y})==11): \backslash$ n return float $(\mathrm{x} * \mathrm{w}) \backslash$ n else: $\backslash$ n return $0 \backslash \backslash \mathrm{n} ")$

\# Process: Add Truck22KW

arcpy.AddField_management(Roads_Select_62_, "Truck22KW", "DOUBLE", "', "', "'", "', "NULLABLE", "NON_REQUIRED", "') \# Process: Calculate Truck22KW

arcpy.CalculateField_management(Routes_62_, "Truck22KW", "calctruck(!Truck18KW! , !Truck21!, !Code! )", "PYTHON", "def

calctruck $(x, y, z): \backslash \bar{n}$ if( float $(z)==11): \backslash \backslash n$ return float $(x+y) \backslash$ n else: $\backslash n$ return $0 \backslash \backslash n ")$

\# Process: Add Truck18SA

arcpy.AddField_management(Roads_Select_67_, "Truck18SA", "DOUBLE", "', "', "', "', "NULLABLE", "NON_REQUIRED", "')

\# Process: Calculate Truck18SA

arcpy.CalculateField_management(Routes_58_, "Truck18SA", "calctruck( \%FuelSA\%, !Truck17!, !Code! )", "PYTHON", "def

calctruck $(\mathrm{w}, \mathrm{x}, \mathrm{y}): \backslash \backslash \overline{\mathrm{n}}$ if $($ float $(\mathrm{y})==19): \backslash \backslash \overline{\mathrm{n}}$ return float $(\mathrm{x} * \mathrm{w}) \backslash \backslash \mathrm{n}$ else: $\backslash \backslash \mathrm{n}$ return $0 \backslash \backslash \mathrm{n} ")$

\# Process: Add Truck22SA

arcpy.AddField_management(Roads_Select_63_, "Truck22SA", "DOUBLE", "', "'", "', "', "NULLABLE", "NON_REQUIRED", "') \# Process: Calculate Truck22SA

arcpy.CalculateField_management(Routes_60_, "Truck22SA", "calctruck( !Truck18SA! , !Truck21!, !Code! )", "PYTHON", "def calctruck(x , y, z ): \n if( float $\mathrm{z})==19): \backslash \overline{\mathrm{n}}$ return float $(\mathrm{x}+\mathrm{y}) \backslash \backslash \mathrm{n}$ else: $\backslash \backslash \mathrm{n}$ return $0 \backslash \backslash \mathrm{n} ")$

\# Process: Add Truck18UAE

arcpy.AddField_management(Roads_Select_65_, "Truck18UAE", "DOUBLE", "", "', "'", "', "NULLABLE", "NON REQUIRED", "')

\# Process: Calculate Truck18UAE

arcpy.CalculateField management(Routes 44, "Truck18UAE", "calctruck( \%FuelUAE\% , !Truck17!, !Code! )", "PYTHON", "def

calctruck $(\mathrm{w}, \mathrm{x}, \mathrm{y}): \backslash \backslash \mathrm{n}$ if $($ float $(\mathrm{y})==21): \backslash \backslash \mathrm{n}$ return float $(\mathrm{x} * \mathrm{w}) \backslash \backslash \mathrm{n}$ else $: \backslash \mathrm{n}$ return $0 \backslash \backslash \mathrm{n} ")$

\# Process: Add Truck22UAE

arcpy.AddField_management(Roads_Select_19_, "Truck22UAE", "DOUBLE", "", "', "', "", "NULLABLE", "NON_REQUIRED", "") \# Process: Calculate Truck22UAE

arcpy.CalculateField_management(Routes_56_, "Truck22UAE", "calctruck( !Truck18UAE! , !Truck21!, !Code! )", "PYTHON", "def calctruck(x, y, z ): \n if( float $(z)==21): \backslash \backslash n$ return float $(x+y) \backslash \backslash n$ else: $\backslash n$ return $0 \backslash \backslash n ")$

\# Process: Add Truck18BH

arcpy.AddField_management(Roads_Select_61_, "Truck18BH", "DOUBLE", "', "', "', "', "NULLABLE", "NON_REQUIRED", "') \# Process: Calculate Truck18BH

arcpy.CalculateField_management(Routes_43_, "Truck18BH", "calctruck( \%FuelBH\%, !Truck17!, !Code! )", "PYTHON", "def calctruck(w, x , y ): \n if( float $(y)==2):\lfloor n$ return float $(x * w) \backslash n$ else: $\backslash n$ return $0 \backslash \backslash n ")$

\# Process: Add Truck22BH

arcpy.AddField_management(Roads_Select_16_, "Truck22BH", "DOUBLE", "", "', "', "', "NULLABLE", "NON_REQUIRED", "')

\# Process: Calculate Truck22BH

arcpy.CalculateField_management(Routes_61_, "Truck22BH", "calctruck( !Truck18BH! , !Truck21!, !Code! )", "PYTHON", "def

calctruck $(\mathrm{x}, \mathrm{y}, \mathrm{z}): \backslash \overline{\mathrm{n}}$ if $($ float $(\mathrm{z})==2): \backslash \mathrm{n}$ return float $(\mathrm{x}+\mathrm{y}) \backslash \mathrm{n}$ else: $\backslash \mathrm{n}$ return $0 \backslash \backslash \mathrm{n} ")$

\# Process: Add Truck18QA

arcpy.AddField_management(Roads_Select_66_, "Truck18QA", "DOUBLE", "', "', "', "', "NULLABLE", "NON_REQUIRED", "') \# Process: Calculate Truck18QA

arcpy.CalculateField_management(Routes_59_, "Truck18QA", "calctruck( \%FuelQA\%, !Truck17!, !Code! )", "PYTHON", "def

calctruck $(\mathrm{w}, \mathrm{x}, \mathrm{y}): \backslash \backslash \overline{\mathrm{n}}$ if $($ float $(\mathrm{y})==17): \backslash \backslash \mathrm{n}$ return float $(\mathrm{x} * \mathrm{w}) \backslash \backslash \mathrm{n}$ else: $\backslash \backslash \mathrm{n}$ return $0 \backslash \backslash \mathrm{n} ")$

\# Process: Add Truck22QA

arcpy.AddField_management(Roads_Select_64_, "Truck22QA", "DOUBLE", "', "'", "', "'", "NULLABLE", "NON_REQUIRED", "')

\# Process: Calculate Truck22QA

arcpy.CalculateField_management(Routes_63_, "Truck22QA", "calctruck( !Truck18QA! , !Truck21!, !Code! )", "PYTHON", "def

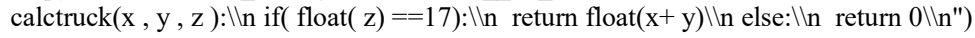

\# Process: truck21 by $\mathrm{km}$

arcpy.CalculateField_management(Roads_Select_68_, "Truck21", "calctruck( !Truck21!,!SHAPE_Length! )", "PYTHON", "def calctruck(

$\mathrm{x}, \mathrm{y}): \backslash \mathrm{n} \mathrm{r}=\mathrm{x} * \mathrm{y} / 1000 \backslash \mathrm{n}$ return $\left.\mathrm{r}^{\prime \prime}\right)$

\# Process: Add Truck22

arcpy.AddField_management(Roads_Select_22_, "Truck22", "DOUBLE", "', "', "', "'", "NULLABLE", "NON_REQUIRED", "')

\# Process: Calculate Truck22

arcpy.CalculateField_management(Routes_22_, "Truck22", "calctruck( !Truck22OM!, !Truck22KW!, !Truck22SA!, !Truck22UAE!,

!Truck22BH!, !Truck22QA! )", "PYTHON", "def calctruck(a,b,c,d,e,f): $\backslash \backslash n \mathrm{r}=$ float(a+b+c+d+e+f) $\backslash$ n return r $\backslash \backslash n$ ")

\# Process: Calculate Truck22 by KM

arcpy.CalculateField_management(Roads_Select_10_, "Truck22", "calctruck( !Truck22!, !SHAPE_Length! , !TrucksNeeded! )",

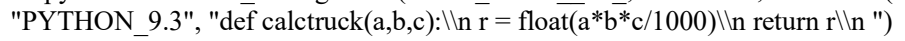

\# Process: Add Truck Total

arcpy.AddField_management(Roads_5_, "Total", "DOUBLE", "', "", "', "Total", "NULLABLE", "NON_REQUIRED", "')

\# Process: Calculate Total

arcpy.CalculateField_management(Routes_27_, "Total", "calctruck( !Truck5!, !Truck10!, !Truck15!, !Truck24!, !Truck22!, !Truck31!,

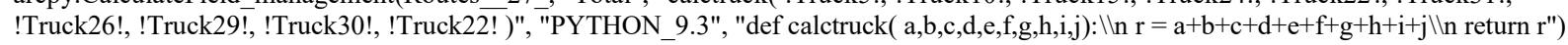




\section{Appendix D Rail Life-Cycle Script}

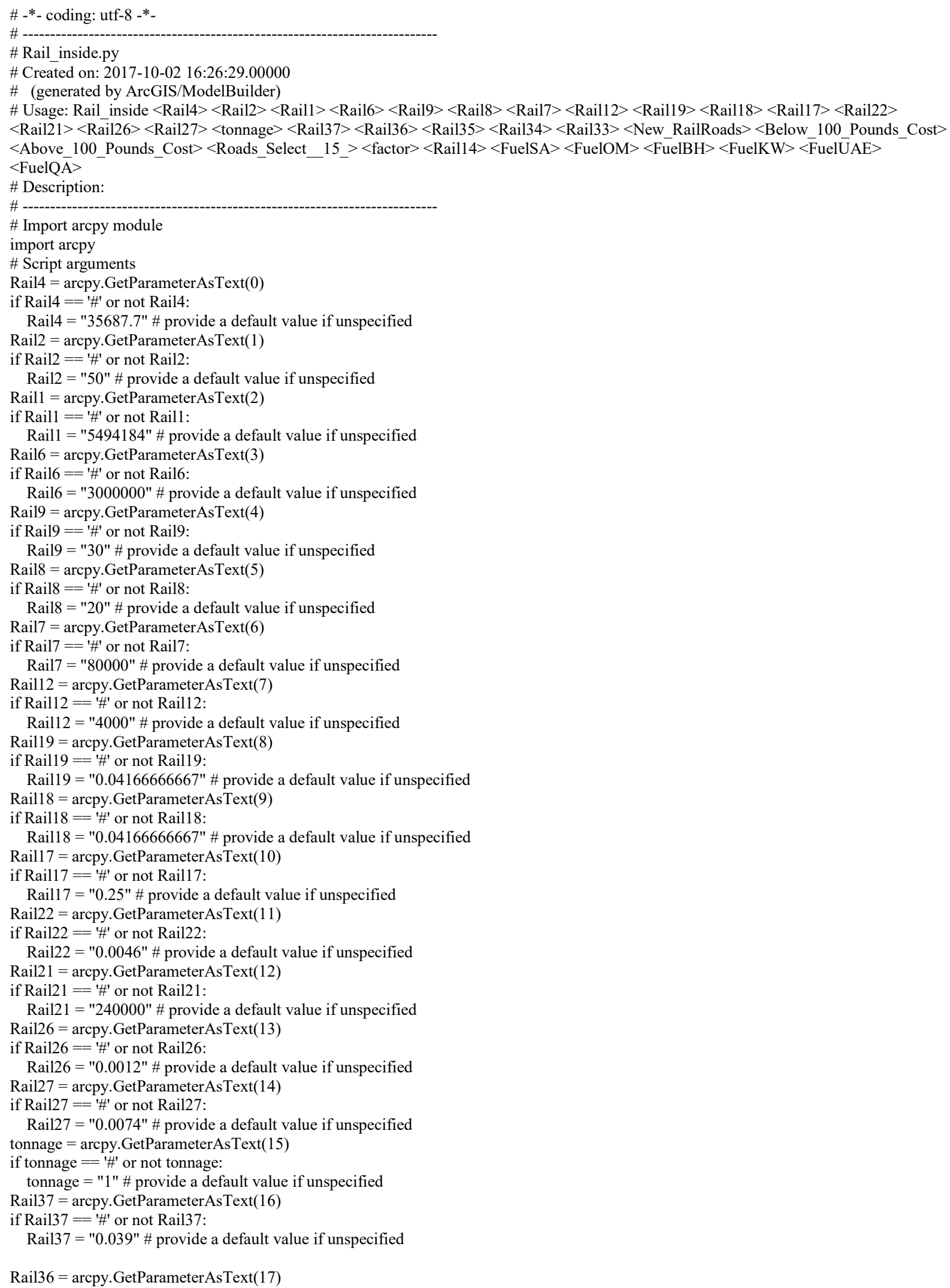


if Rail36 == '\#' or not Rail36:

Rail36 = "0.018" \# provide a default value if unspecified

Rail35 = arcpy.GetParameterAsText(18)

if Rail35 == '\#' or not Rail35:

Rail35 = "0.148" \# provide a default value if unspecified

Rail34 = arcpy.GetParameterAsText(19)

if Rail34 == '\#' or not Rail34:

Rail34 = "0.834" \# provide a default value if unspecified

Rail33 = arcpy.GetParameterAsText(20)

if Rail33 == '\#' or not Rail33:

Rail33 = "38.296" \# provide a default value if unspecified

New_RailRoads $=$ arcpy.GetParameterAsText(21)

if New_RailRoads == '\#' or not New_RailRoads:

New RailRoads $=$ "C: $\backslash \backslash$ Users $\backslash \backslash$ Hasan $\backslash \backslash$ Documents $\backslash \backslash$ J June Working

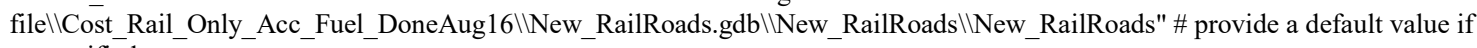
unspecified

Below_100_Pounds_Cost = arcpy.GetParameterAsText(22)

if Below 100 Pounds Cost $==$ '\#' or not Below 100 Pounds Cost:

Below_100_Pounds_Cost $=$ "97.55" \# provide a default value if unspecified

Above_100_Pounds_Cost $=$ arcpy.GetParameterAsText(23)

if Above_100_Pounds_Cost $==$ '\#' or not Above_100_Pounds_Cost:

Above_100_Pounds_Cost $=$ "122.54" \# provide a default value if unspecified

Roads_Select_15_= arcpy.GetParameterAsText(24)

if Roads_Select $\overline{15}==$ '\#' or not Roads_Select_15_:

Roads_Select $15_{-}^{-}=$"C: $\backslash \backslash$ Users $\backslash \backslash$ Hasan $\backslash \backslash$ Documents $\backslash \backslash A$ June Working

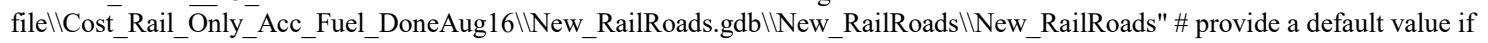
unspecified

factor $=$ arcpy.GetParameterAsText(25)

if factor $==$ '\#' or not factor:

factor $=" 1 " \#$ provide a default value if unspecified

Rail14 = arcpy.GetParameterAsText(26)

if Rail14 == '\#' or not Rail14:

Rail14 = "0.0031" \# provide a default value if unspecified

FuelSA = arcpy.GetParameterAsText(27)

if FuelSA $==$ '\#' or not FuelSA:

FuelSA $=$ "0.24" \# provide a default value if unspecified

FuelOM = arcpy.GetParameterAsText(28)

if FuelOM == '\#' or not FuelOM:

FuelOM = "0.41" \# provide a default value if unspecified

FuelBH = arcpy.GetParameterAsText(29)

if FuelBH == '\#' or not FuelBH:

FuelBH $=$ "0.32" \# provide a default value if unspecified

FuelKW = arcpy.GetParameterAsText(30)

if FuelKW == '\#' or not FuelKW:

FuelKW = "0.36" \# provide a default value if unspecified

FuelUAE = arcpy.GetParameterAsText(31)

if FuelUAE $==$ '\#' or not FuelUAE:

FuelUAE $=$ "0.44" \# provide a default value if unspecified

FuelQA = arcpy.GetParameterAsText(32)

if FuelQA == '\#' or not FuelQA:

FuelQA = "0.41" \# provide a default value if unspecified

\# Local variables:

Routes_5_=New_RailRoads

Roads Select $35=$ Routes 5

Routes 3 _ $=\overline{\text { Roads_Select } 35}$

Roads Select $34=$ Routes 3

Routes 2 _ Roads_Select 34

Roads Select $3=$ Routes 2

Routes $4=$ Roads Select 3

Roads_Select_4_ $=$ Routes _ 4

Routes 6 = Roads_Select 4

Roads_Select 36_ = Routes_ 6

Routes $35=$ Roads Select $3 \overline{6}$

Roads_Select 49 _ $=$ Routes_35

Routes $37=$ Roads Select 49

Roads_Select $\quad 51=\overline{\text { Routes }} 37$

Routes $38=$ Roàds Select 51

Roads_Select 52 _

Routes_8_= Roads_Select_52_

Roads_Select_26 $=$ Routes_ ${ }_{8}$. 
Routes $9=$ Roads Select 26

Roads_Select_38_= Routes_9

Routes 41 = Roads Select 38

Roads_Select_56_= Routes_41

Routes_42_= Roads_Select 56

Roads_Select_55_= Routes_42

Routes $43=$ Roads Select 55

Roads_Select $57_{-}=$Routes 43

Roads_Select_5_ $=$ Roads_Select_57_

Roads Select $7=$ Roads Select 5

Roads_Select_6 $61_{-}=$Roads_Select_ $\overline{7}$

Roads Select $59=$ Roads Select 61

Roads_Select_2 $=$ Roads_Select_59_

Roads Select $23=$ Roads Select 2

Roads_Select_6_ $=$ Roads_Select_23

Roads_Select $20=$ Roads_Select 6

Output_Feature_Class_11_= Roads_Select_20

Output Feature Class $12=$ Output Feature Class 11

Output_Feature_Class_9_= Output_Feature_Class_12_

Output Feature Class $1 \overline{0}=$ Output Feature Class 9

Output_Feature_Class_7_ $=$ Output_Feature_Class_ ${ }_{-} 0_{-}$

Output_Feature_Class_8_ $=$ Output_Feature_Class _ 7

Output_Feature_Class $=$ Output_Feature_Class_8

Output Feature Class $2=$ Output Feature $\overline{\text { Class }}$

Output_Feature_Class_5_=Output_Feature_Class_ 2

Output_Feature_Class_6_-Output_Feature_Class ${ }_{-}{ }_{-}^{-}$

Output_Feature_Class_3_=Output_Feature_Class 6

Output_Feature_Class_4_- Output_Feature_Class_3

New RailRoads $2=$ Output_Feature_Class 4

New_RailRoads_5_- New_RailRoads_2

Roads Select $\overline{13}=$ New RailRoads 5

Roads_Select_14_ $=$ Roads_Select_ $\overline{13}_{-}$

Roads Select $19^{-}=$Roads Select $14^{-}$

Roads_Select_37_= Roads_Select_19-

Roads_Select 333_= Roads_Select_ 37-

Roads_Select_21_= Roads_Select_33_

Roads_Select_29_= Roads_Select_21

Roads_Select_22_= Roads_Select_29-

Roads_Select_28_= Roads_Select_22-

Roads_Select_24_=Roads_Select_28

Roads_Select_30_ $=$ Roads_Select_24_

Roads_Select_25_= Roads_Select_30

Roads_Select_31_- Roads_Select_25

Roads_Select_27_= Roads_Select_31_

Roads_Select_32_= Roads_Select_27_

Routes_27_= Roads_Select_32_

\# Process: Add Raill

arcpy.AddField_management(New_RailRoads, "Rail1", "DOUBLE", "', "', "', "', "NULLABLE", "NON_REQUIRED", "')

\# Process: Calculate Rail 1

arcpy.CalculateField_management(Routes_5,, "Rail1", "calctruck(\%Rail1\%)", "PYTHON", "def calctruck( x ): $\backslash \backslash n$ r = x \\n return r")

\# Process: Add Rail2

arcpy.AddField_management(Roads_Select_35_, "Rail2", "DOUBLE", "', "', "', "', "NULLABLE", "NON_REQUIRED", "')

\# Process: Calculate Rail2

arcpy.CalculateField_management(Routes_3, "Rail2", "calctruck(\%Rail2\%)", "PYTHON", "def calctruck( x ): \\n r = x \nn return r")

\# Process: Add Rail $\overline{3}$

arcpy.AddField_management(Roads_Select_34_, "Rail3", "DOUBLE", "', "', "', "', "NULLABLE", "NON_REQUIRED", "')

\# Process: Calculate Rail 3

arcpy.CalculateField management(Routes 2, "Rail3", "mult(!Rail1!)", "PYTHON 9.3", "def mult(x): \\n x=(x / (17.0* $250.0 * 50.0 *$

$50.0)) * 23.0 / 100.0 \backslash \backslash n$ return $\mathrm{x} ")$

\# Process: Add Rail 5

arcpy.AddField_management(Roads_Select_3_, "Rail5", "DOUBLE", "', "', "', "', "NULLABLE", "NON_REQUIRED", "')

\# Process: Calculate Rail 5

arcpy.CalculateField_management(Routes_4_, "Rail5", "mult(\%Rail4\%)", "PYTHON_9.3", "def mult(x): $\backslash \ln$ x= (x / ( $17.0 * 250.0 * 50.0))$

* 23.0 / $100.0 \backslash$ \n return $\mathrm{x} ")$

\# Process: Add Rail 10

arcpy.AddField_management(Roads_Select_4_, "Rail10Rail11", "DOUBLE", "', "', "', "', "NULLABLE", "NON_REQUIRED", "')

\# Process: Calculate Rail $10+11$

arcpy.CalculateField_management(Routes_6_, "Rail10Rail11", "mult(\%Rail6\%,\%Rail8\%,\%Rai19\%,\%Rail7\% )", "PYTHON_9.3", "def mult(x,y,z,w): \n x = float( $\mathrm{x}-(\mathrm{y} / 100.0)) /(240000.0 * \mathrm{z})+$ float $(\mathrm{w}-(\mathrm{y} / 100.0)) /(240000.0 * \mathrm{z}) \backslash \mathrm{n}$ return $\mathrm{x} ")$

\# Process: Add Rail 13 
arcpy.AddField_management(Roads_Select_36_, "Rail13", "DOUBLE", "", "", "', "', "NULLABLE", "NON_REQUIRED", "') \# Process: Calculate Rail 13

arcpy.CalculateField_management(Routes_35_, "Rail13", "mult(\%Rail12\% )", "PYTHON_9.3", "def mult(x ): \n x= float(((((x * 12.0 )/ 250.0 )/ 24.0 ) $\left./ 80.0)^{*} * 2.0\right) \backslash$ ) return $\left.x^{\prime \prime}\right)$

\# Process: Add Rail 20

arcpy.AddField_management(Roads_Select_49_, "Rail20", "DOUBLE", "", "", "", "", "NULLABLE", "NON_REQUIRED", "')

\# Process: Calculate Rail 20

arcpy.CalculateField_management(Routes_37_, "Rail20", "mult(\%Rail17\%,\%Rail18\%,\%Rail19\%)", "PYTHON_9.3", "def mult(x,y,z): \n

$\mathrm{x}=$ float $(\mathrm{x}+\mathrm{y}+\mathrm{z}) \backslash \backslash \overline{\mathrm{n}}$ return $\left.\mathrm{x}^{\prime \prime}\right)$

\# Process: Add Rail 23

arcpy.AddField_management(Roads_Select_51_, "Rail23", "DOUBLE", "", "", "', "', "NULLABLE", "NON_REQUIRED", "')

\# Process: Calculate Rail 23 ( 28,29,30)

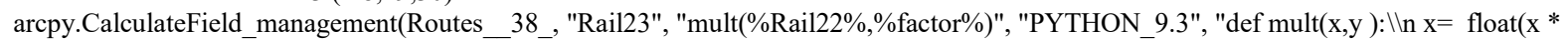
y) \n return $\left.x^{\prime \prime}\right)$

\# Process: Add Rail 26

arcpy.AddField management(Roads Select 52 , "Rail26", "DOUBLE", "', "', "', "', "NULLABLE", "NON REQUIRED", "')

\# Process: Rail $\overline{2} 6$ by km by ton

arcpy.CalculateField_management(Routes_8_, "Rail26", "calctruck( \%Rail26\%, !SHAPE_Length!, , \%tonnage\% )", "PYTHON_9.3", "def

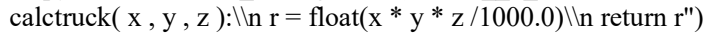

\# Process: Add Rail 27

arcpy.AddField_management(Roads_Select_26, "Rail27", "DOUBLE", "", "', "', "', "NULLABLE", "NON_REQUIRED", "')

\# Process: Rail $\overline{2} 7$ by km by ton

arcpy.CalculateField_management(Routes__9, "Rail27", "calctruck( \%Rail27\%,!SHAPE_Length!, \%tonnage\% )", "PYTHON_9.3", "def

calctruck $(\mathrm{x}, \mathrm{y}, \mathrm{z}): \backslash \backslash \mathrm{n} \mathrm{r}=$ float $(\mathrm{x} * \mathrm{y} * \mathrm{z} / \overline{1000.0)} \backslash \backslash \mathrm{n}$ return $\mathrm{r} ")$

\# Process: Add Rail 28

arcpy.AddField_management(Roads_Select_38_, "Rail28", "DOUBLE", "", "', "', "', "NULLABLE", "NON_REQUIRED", "")

\# Process: Calculate Rail 28

arcpy.CalculateField_management(Routes_41_, "Rail28", "mult(\%Rail6\%,\%Rail21\%)", "PYTHON_9.3", "def mult(x,y ): \n x=float(( x * ( 3.6 / 100.0)) / y) \\n return $\left.x^{\prime \prime}\right)$

\# Process: Add Rail 29

arcpy.AddField_management(Roads_Select_56_, "Rail29", "DOUBLE", "", "", "', "', "NULLABLE", "NON_REQUIRED", "')

\# Process: Calculate Rail 29

arcpy.CalculateField management(Routes 42, "Rail29", "mult(\%Rail7\%,\%Rail21\%)", "PYTHON 9.3", "def mult(x,y ): \n x=float(( x * (

$3.6 / 100.0)) / y) \backslash \backslash$ n return $\left.x^{\prime \prime}\right)$

\# Process: Add Rail 30

arcpy.AddField_management(Roads_Select_55_, "Rail30", "DOUBLE", "", "", "', "', "NULLABLE", "NON_REQUIRED", "')

\# Process: Calculate Rail 30

arcpy.CalculateField_management(Routes_43_, "Rail30", "mult(!Rail28!,!Rail29!)", "PYTHON_9.3", "def mult(x,y ): \n x= x + y \!n return $\left.\mathrm{x}^{\prime \prime}\right)$

\# Process: Add Trucks Needed (2)

arcpy.AddField_management(Roads_Select_57,, "TrucksNeeded", "LONG", "', "', "', "WagonsNeeded", "NULLABLE",

"NON_REQUIRED", "")

\# Process: Calculate Truck Needed (2)

arcpy.CalculateField_management(Roads_Select_5_, "TrucksNeeded", "TonnageToTrucks(\%tonnage\%)", "PYTHON_9.3", "def

TonnageToTrucks(x): $\backslash \backslash n \mathrm{x}=$ math.ceil( float $(\mathrm{x}) / \overline{23}) \backslash \overline{\mathrm{n}}$ return $\mathrm{x} "$ )

\# Process: Add WagonsNeeded

arcpy.AddField_management(Roads_Select_7_, "WagonsNeeded", "LONG", "', "', "', "WagonsNeeded", "NULLABLE",

"NON REQUIRED", "")

\# Process: Calculate Wagons Needed (3)

arcpy.CalculateField_management(Roads_Select_61_, "WagonsNeeded", "TonnageToWagon(\%tonnage\%)", "PYTHON_9.3", "def

TonnageToWagon(x): $\backslash \backslash n \mathrm{x}=$ math.ceil( float $(\mathrm{x}) / \overline{70}) \backslash \overline{\mathrm{n}}$ return $\mathrm{x} ")$

\# Process: Rail5 by km by wagon count

arcpy.CalculateField_management(Roads_Select_59_, "Rail5", "calctruck( !Rail5!,!SHAPE_Length!, !WagonsNeeded! )", "PYTHON",

"def calctruck $(\mathrm{x}, \mathrm{y}, \mathrm{z}): \backslash \mathrm{n} \mathrm{r}=\mathrm{x} * \mathrm{y} * \mathrm{z} / \overline{1000} \backslash \backslash \mathrm{n}$ return $\mathrm{r} ")$

\# Process: Rail 10 by $\mathrm{km}$

arcpy.CalculateField management(Roads Select 2, "Rail10Rail11", "calctruck( !Rail10Rail11!,!SHAPE Length! )", "PYTHON", "def calctruck $(\mathrm{x}, \mathrm{y}): \backslash \mathrm{n} \overline{\mathrm{r}}=\mathrm{x} * \mathrm{y} / 1000 \backslash \mathrm{n}$ return $\mathrm{r} ")$

\# Process: Rail 13 by km

arcpy.CalculateField_management(Roads_Select_23_, "Rail13", "calctruck( !Rail13!,!SHAPE_Length! )", "PYTHON", "def calctruck( x , $\mathrm{y}): \backslash \ln \mathrm{r}=$ float $(\mathrm{x} * \overline{\mathrm{y}} / 1000.0) \backslash \backslash \mathrm{n}$ return $\left.\mathrm{r}^{-}\right)$

\# Process: Rail 3 by km by wagon count

arcpy.CalculateField_management(Roads_Select_6_, "Rail3", "calctruck( !Rail3!,!SHAPE_Length!, !WagonsNeeded! )", "PYTHON",

"def calctruck $(\mathrm{x}, \mathrm{y}, \mathrm{z}): \backslash \backslash \mathrm{n} \mathrm{r}=\mathrm{x} * \mathrm{y} * \mathrm{z} / \overline{1000} \backslash \mathrm{n}$ return $\left.\mathrm{r}^{\prime \prime}\right)$

\# Process: Add Rail160M

arcpy.AddField_management(Roads_Select_20_, "Rail16OM", "DOUBLE", "', "', "', "', "NULLABLE", "NON_REQUIRED", "') \# Process: Calculate Rail16OM

arcpy.CalculateField_management(Output_Feature_Class_11_, "Rail16OM", "calcrail( \%FuelOM\%,\%Rail14\%, !Code!)", "PYTHON", "def calcrail(w, x , y ): $\backslash \backslash n$ if( float $(y)==15): \backslash n$ return float $\left(x^{*} w\right) \backslash \backslash n$ else: $\backslash n$ return $\left.0 \backslash \backslash n "\right)$

\# Process: Add Rail16UAE 
arcpy.AddField_management(Output_Feature_Class_12_, "Rail16UAE", "DOUBLE", "', "'", "', "', "NULLABLE", "NON_REQUIRED", "")

\# Process: Calculate Rail16UAE

arcpy.CalculateField_management(Output_Feature_Class_9_, "Rail16UAE", "calcrail( \%FuelUAE\%,\%Rail14\%, !Code!)", "PYTHON",

"def calcrail $(\mathrm{w}, \mathrm{x}, \mathrm{y}): \backslash \backslash \mathrm{n}$ if( float $(\mathrm{y})==21): \backslash \backslash \mathrm{n}$ return float $\left(\mathrm{x}^{*} \mathrm{w}\right) \backslash \backslash \mathrm{n}$ else: $\backslash \backslash \mathrm{n}$ return $\left.0 "\right)$

\# Process: Add Rail16SA

arcpy.AddField_management(Output_Feature_Class_10_, "Rail16SA", "DOUBLE", "', "', "', "', "NULLABLE", "NON_REQUIRED", "') \# Process: Calculate Rail16SA

arcpy.CalculateField_management(Output_Feature_Class_7_, "Rail16SA", "calcrail( \%FuelSA\%,\%Rail14\%, !Code!)", "PYTHON_9.3",

"def calcrail $(\mathrm{w}, \mathrm{x}, \mathrm{y}): \backslash \backslash \mathrm{n}$ if $($ float $(\mathrm{y})==19): \backslash \backslash \mathrm{n}$ return float $(\mathrm{x} * \mathrm{w}) \backslash \backslash \mathrm{n}$ else: $\backslash \backslash \mathrm{n}$ return $0 ")$

\# Process: Add Rail16QA

arcpy.AddField_management(Output_Feature_Class_8_, "Rail16QA", "DOUBLE", "", "", "", "', "NULLABLE", "NON_REQUIRED", "")

\# Process: Calculate Rail16QA

arcpy.CalculateField_management(Output_Feature_Class, "Rail16QA", "calcrail( \%FuelQA\%,\%Rail14\%, !Code!)", "PYTHON_9.3", "def

calcrail $(\mathrm{w}, \mathrm{x}, \mathrm{y}): \backslash \mathrm{n}$ if ( float $(\mathrm{y})==17): \backslash \mathrm{n}$ return float $(\mathrm{x} * \mathrm{w}) \backslash \mathrm{n}$ else $: \backslash \mathrm{n}$ return $0 ")$

\# Process: Add Rail16KW

arcpy.AddField_management(Output_Feature_Class_2_, "Rail16KW", "DOUBLE", "', "', "', "', "NULLABLE", "NON_REQUIRED", "') \# Process: Calculate Rail16KW

arcpy.CalculateField_management(Output_Feature_Class_5_, "Rail16KW", "calcrail(\%FuelKW\%,\%Rail14\%, !Code!)", "PYTHON_9.3", "def calcrail $(\mathrm{w}, \mathrm{x}, \mathrm{y}): \backslash \backslash \mathrm{n}$ if $($ float $(\mathrm{y})==1 \overline{1}): \backslash \backslash \mathrm{n}$ return float $(\mathrm{x} * \mathrm{w}) \backslash \backslash \mathrm{n}$ else: $\backslash \backslash \mathrm{n}$ return $0 ")$

\# Process: Add Rail16BH

arcpy.AddField_management(Output_Feature_Class_6_, "Rail16BH", "DOUBLE", "', "', "'", "', "NULLABLE", "NON_REQUIRED", "') \# Process: Calculate Rail16BH

arcpy.CalculateField_management(Output_Feature_Class_3_, "Rail16BH", "calcrail( \%FuelBH\%,\%Rail14\%, !Code!)", "PYTHON_9.3",

"def calcrail $(\mathrm{w}, \mathrm{x}, \mathrm{y}): \backslash \backslash \mathrm{n}$ if( float $(\mathrm{y})==2): \backslash$ n return float $(\mathrm{x} * \mathrm{w}) \backslash \mathrm{n}$ else: $\backslash \mathrm{n}$ return $0 ")$

\# Process: Add Rail 16

arcpy.AddField_management(Output_Feature_Class_4_, "Rail16", "DOUBLE", "", "', "', "', "NULLABLE", "NON_REQUIRED", "')

\# Process: Calculate Rail16 by ton $\mathrm{km}$

arcpy.CalculateField_management(New_RailRoads_2_, "Rail16", "calcrail( !Rail16OM!, !Rail16UAE!, !Rail16SA!, !Rail16QA!,

!Rail16KW!, !Rail16BH!, !SHAPE_Length!,\%tonnage\% )", "PYTHON_9.3", "def calcrail(a,b,c,d,e,f,g,h ): \n x=

float $((\mathrm{a}+\mathrm{b}+\mathrm{c}+\mathrm{d}+\mathrm{e}+\mathrm{f}) * \mathrm{~g} * \mathrm{~h} / 1000) \backslash \mathrm{n}$ return $\mathrm{x} ")$

\# Process: Rail20 by km

arcpy.CalculateField_management(New_RailRoads_5_, "Rail20", "calctruck( !Rail20!,!SHAPE_Length! )", "PYTHON", "def calctruck( x , $\mathrm{y}): \backslash \mathrm{n} \mathrm{r}=\mathrm{x} * \mathrm{y} / 1000.0 \backslash \backslash \mathrm{n}$ return $\mathrm{r} ")$

\# Process: Rail 23 by km by ton

arcpy.CalculateField_management(Roads_Select_13, "Rail23", "calctruck( !Rail23!,!SHAPE_Length!, \%tonnage\% )", "PYTHON_9.3",

"def calctruck $(x, y, z): \backslash n \mathrm{r}=\mathrm{x} * \mathrm{y} * \mathrm{z} / 1000.0 \backslash \backslash \mathrm{n}$ return $\mathrm{r}$ ")

\# Process: Rail 30 by km

arcpy.CalculateField_management(Roads_Select_14_, "Rail30", "calctruck( !Rail30!,!SHAPE_Length! )", "PYTHON", "def calctruck(x , $\mathrm{y}): \backslash \operatorname{n} \mathrm{r}=\mathrm{x} * \mathrm{y} / 1000.0 \backslash \mathrm{n}$ return $\left.\mathrm{r}^{\prime \prime}\right)$

\# Process: Add Rail31

arcpy.AddField_management(Roads_Select_19_, "Rail31", "DOUBLE", "", "", "', "Rail31", "NULLABLE", "NON_REQUIRED", "')

\# Process: Calc Rail 31

arcpy.CalculateField_management(Roads_Select_37, "Rail31", "calctruck(\%Above_100_Pounds_Cost $\%$,\%Below_100_Pounds_Cost $\%$,

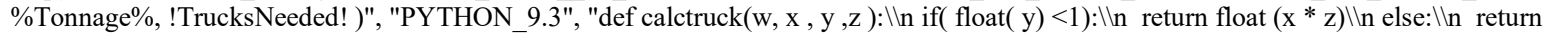

float $(\mathrm{w} * \mathrm{z}) ")$

\# Process: Add Rail33

arcpy.AddField_management(Roads_Select_33_, "Rail33", "DOUBLE", "', "', "', "Rail33", "NULLABLE", "NON_REQUIRED", "')

\# Process: Rail $33 \mathrm{G}$ per km per ton

arcpy.CalculateField_management(Roads_Select_21_, "Rail33", "calctruck( \%Rail33\%,!SHAPE_Length!, \%tonnage\% )",

"PYTHON_9.3", "def calctruck( $\mathrm{x}, \mathrm{y}, \mathrm{z}): \backslash \backslash \mathrm{n} \mathrm{r}=\overline{\mathrm{x}} * \mathrm{y} * \mathrm{z} / 1000.0 \backslash \backslash \mathrm{n}$ return $\mathrm{r}$ ")

\# Process: Add Rail34

arcpy.AddField_management(Roads_Select_29_, "Rail34", "DOUBLE", "', "', "', "', "NULLABLE", "NON_REQUIRED", "')

\# Process: Rail $\overline{3} 4 \mathrm{G}$ per km per ton

arcpy.CalculateField_management(Roads_Select_22,, "Rail34", "calctruck( \%Rail34\%,!SHAPE_Length!, \%tonnage\% )",

"PYTHON_9.3", "def calctruck( $\mathrm{x}, \mathrm{y}, \mathrm{z}) \overline{:} \backslash \backslash \mathrm{n} \mathrm{r}=\overline{\mathrm{x}} * \mathrm{y} * \mathrm{z} / 1000.0 \backslash \mathrm{n}$ return $\mathrm{r}$ ")

\# Process: Add Rail35

arcpy.AddField_management(Roads_Select_28_, "Rail35", "DOUBLE", "", "', "', "', "NULLABLE", "NON_REQUIRED", "')

\# Process: Rail $35 \mathrm{G}$ per km per ton

arcpy.CalculateField_management(Roads_Select_24_, "Rail35", "calctruck( \%Rail35\%,!SHAPE_Length!, \%tonnage\% )",

"PYTHON_9.3", "def calctruck( $\mathrm{x}, \mathrm{y}, \mathrm{z}): \backslash \backslash \mathrm{n} \mathrm{r}=\overline{\mathrm{x}} * \mathrm{y} * \mathrm{z} / 1000.0 \backslash \backslash \mathrm{n}$ return $\mathrm{r}$ ")

\# Process: Add Rail36

arcpy.AddField_management(Roads_Select_30_, "Rail36", "DOUBLE", "", "", "', "'", "NULLABLE", "NON_REQUIRED", "")

\# Process: Rail $36 \mathrm{G}$ per km per ton

arcpy.CalculateField_management(Roads_Select_25_, "Rail36", "calctruck( \%Rail36\%,!SHAPE_Length!, \%tonnage\% )",

"PYTHON_9.3", "def calctruck( $\mathrm{x}, \mathrm{y}, \mathrm{z}): \backslash \backslash \mathrm{n} \mathrm{r}=\overline{\mathrm{x}} * \mathrm{y} * \mathrm{z} / 1000.0 \backslash \backslash \mathrm{n}$ return $\mathrm{r}$ ")

\# Process: Add Rail37

arcpy.AddField management(Roads_Select 31 , "Rail37", "DOUBLE", "", "", "', "Rail19", "NULLABLE", "NON REQUIRED", "')

\# Process: Rail $37 \mathrm{G}$ per km per ton 
arcpy.CalculateField_management(Roads_Select_27_, "Rail37", "calctruck( \%Rail37\%,!SHAPE_Length!!, \%tonnage\% )", "PYTHON_9.3", "def calctruck( $\mathrm{x}, \mathrm{y}, \mathrm{z}): \backslash \ln \mathrm{r}=\mathrm{x} * \mathrm{y} * \mathrm{z} / 1000.0 \backslash \backslash \mathrm{n}$ return $\mathrm{r}$ ")

\# Process: Âdd Rail Total

arcpy.AddField_management(Roads_Select_32_, "Total", "DOUBLE", "', "', "', "Total", "NULLABLE", "NON_REQUIRED", "')

\# Process: Calculate Total

arcpy.CalculateField_management(Routes_27, "Total", "calctruck( !Rail3! , !Rail5! , !Rail10Rail11! , !Rail13! , !Rail20! , !Rail23!,

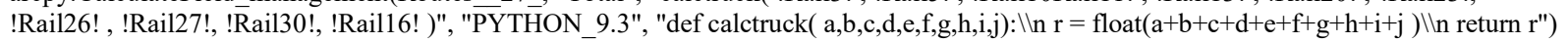




\section{Appendix E LCCA Model Results}

\section{$\underline{\text { Trucking }}$}

\begin{tabular}{|c|c|c|c|c|c|c|c|c|c|c|}
\hline Distance & $\begin{array}{c}\text { Infrastructure } \\
\text { Capital cost }\end{array}$ & $\begin{array}{c}\text { Infrastructure } \\
\text { Maintenance } \\
\text { Cost }\end{array}$ & $\begin{array}{l}\text { Noise } \\
\text { Cost }\end{array}$ & $\begin{array}{l}\text { Accident } \\
\text { Cost }\end{array}$ & $\begin{array}{l}\text { Pollution } \\
\text { Cost }\end{array}$ & $\begin{array}{c}\text { Capital } \\
\text { Cost }\end{array}$ & $\begin{array}{c}\text { Operation } \\
\text { Cost }\end{array}$ & $\begin{array}{l}\text { Maintenance } \\
\text { Cost per }\end{array}$ & $\begin{array}{l}\text { Avg. } \\
\text { Depreciation } \\
\text { Cost }\end{array}$ & $\begin{array}{l}\text { Total } \\
\text { Cost }\end{array}$ \\
\hline 951.82 & 55.28 & 45.32 & 175.68 & 395.58 & 729.00 & 46.64 & 110.08 & 15.04 & 133.25 & 1705.88 \\
\hline 339.48 & 19.72 & 16.16 & 62.66 & 141.09 & 260.01 & 16.63 & 39.26 & 5.36 & 47.53 & 608.42 \\
\hline 150.61 & 8.75 & 7.17 & 27.80 & 62.59 & 115.35 & 7.38 & 17.42 & 2.38 & 21.08 & 269.92 \\
\hline 1101.55 & 63.97 & 52.45 & 203.32 & 457.81 & 843.68 & 53.98 & 127.40 & 17.40 & 154.22 & 1974.23 \\
\hline 509.91 & 29.61 & 24.28 & 94.12 & 211.92 & 390.54 & 24.99 & 58.97 & 8.06 & 71.39 & 913.88 \\
\hline 349.75 & 20.31 & 16.65 & 64.56 & 145.36 & 267.88 & 17.14 & 40.45 & 5.53 & 48.97 & 626.84 \\
\hline 76.51 & 4.44 & 3.64 & 14.12 & 31.80 & 58.60 & 3.75 & 8.85 & 1.21 & 10.71 & 137.12 \\
\hline 641.58 & 37.26 & 30.55 & 118.42 & 266.65 & 491.39 & 31.44 & 74.20 & 10.14 & 89.82 & 1149.87 \\
\hline 52.78 & 3.07 & 2.51 & 13.64 & 21.94 & 40.42 & 2.59 & 6.10 & 0.83 & 7.39 & 98.49 \\
\hline 985.19 & 57.22 & 46.91 & 109.11 & 409.46 & 754.56 & 48.27 & 113.94 & 15.57 & 137.93 & 1692.95 \\
\hline 1281.00 & 74.40 & 60.99 & 236.44 & 532.40 & 981.12 & 62.77 & 148.16 & 20.24 & 179.34 & 2295.85 \\
\hline 518.01 & 30.08 & 24.66 & 95.61 & 215.29 & 396.75 & 25.38 & 59.91 & 8.18 & 72.52 & 928.40 \\
\hline 758.78 & 44.07 & 36.13 & 140.05 & 315.35 & 581.15 & 37.18 & 87.76 & 11.99 & 106.23 & 1359.90 \\
\hline 996.11 & 57.85 & 47.43 & 147.09 & 413.99 & 762.92 & 48.81 & 115.21 & 15.74 & 139.46 & 1748.49 \\
\hline 418.82 & 24.32 & 19.94 & 77.30 & 174.07 & 320.78 & 20.52 & 48.44 & 6.62 & 58.64 & 750.63 \\
\hline 1372.47 & 79.71 & 65.35 & 151.99 & 570.41 & 1051.17 & 67.25 & 158.73 & 21.68 & 192.15 & 2358.45 \\
\hline 1789.36 & 103.92 & 85.20 & 198.16 & 743.67 & 1370.47 & 87.68 & 206.95 & 28.27 & 250.51 & 3074.83 \\
\hline 106.13 & 6.16 & 5.05 & 19.59 & 44.11 & 81.28 & 5.20 & 12.27 & 1.68 & 14.86 & 190.20 \\
\hline 29.01 & 1.68 & 1.38 & 5.35 & 12.06 & 22.22 & 1.42 & 3.35 & 0.46 & 4.06 & 51.99 \\
\hline 196.51 & 11.41 & 9.36 & 36.27 & 81.67 & 150.50 & 9.63 & 22.73 & 3.10 & 27.51 & 352.19 \\
\hline
\end{tabular}




\begin{tabular}{|c|c|c|c|c|c|c|c|c|c|c|}
\hline Distance & $\begin{array}{l}\text { Infrastructure } \\
\text { Capital cost }\end{array}$ & $\begin{array}{c}\text { Infrastructure } \\
\text { Maintenance } \\
\text { Cost }\end{array}$ & $\begin{array}{l}\text { Noise } \\
\text { Cost }\end{array}$ & $\begin{array}{l}\text { Accident } \\
\text { Cost }\end{array}$ & $\begin{array}{l}\text { Pollution } \\
\text { Cost }\end{array}$ & $\begin{array}{c}\text { Capital } \\
\text { Cost }\end{array}$ & $\begin{array}{c}\text { Operation } \\
\text { Cost }\end{array}$ & $\begin{array}{l}\text { Maintenance } \\
\text { Cost per }\end{array}$ & $\begin{array}{l}\text { Avg. } \\
\text { Depreciation } \\
\text { Cost }\end{array}$ & $\begin{array}{l}\text { Total } \\
\text { Cost }\end{array}$ \\
\hline 154.41 & 8.97 & 7.35 & 28.50 & 32.10 & 118.26 & 7.57 & 25.93 & 2.44 & 21.62 & 252.73 \\
\hline 19.13 & 1.11 & 0.91 & 3.53 & 3.98 & 14.65 & 0.94 & 3.21 & 0.30 & 2.68 & 31.32 \\
\hline 167.07 & 9.70 & 7.95 & 30.84 & 34.74 & 127.96 & 8.19 & 28.05 & 2.64 & 23.39 & 273.46 \\
\hline 278.56 & 16.18 & 13.26 & 51.41 & 57.92 & 213.35 & 13.65 & 46.77 & 4.40 & 39.00 & 455.94 \\
\hline 247.79 & 14.39 & 11.80 & 45.74 & 51.52 & 189.78 & 12.14 & 41.61 & 3.92 & 34.69 & 405.58 \\
\hline 113.93 & 6.62 & 5.42 & 21.03 & 23.69 & 87.26 & 5.58 & 19.13 & 1.80 & 15.95 & 186.47 \\
\hline 129.30 & 7.51 & 6.16 & 23.87 & 26.88 & 99.03 & 6.34 & 21.71 & 2.04 & 18.10 & 211.64 \\
\hline 111.78 & 6.49 & 5.32 & 20.63 & 23.24 & 85.61 & 5.48 & 18.77 & 1.77 & 15.65 & 182.96 \\
\hline 98.54 & 5.72 & 4.69 & 18.19 & 20.49 & 75.47 & 4.83 & 16.55 & 1.56 & 13.79 & 161.28 \\
\hline 84.38 & 4.90 & 4.02 & 15.57 & 17.54 & 64.62 & 4.13 & 14.17 & 1.33 & 11.81 & 138.11 \\
\hline 18.06 & 1.05 & 0.86 & 4.67 & 7.51 & 13.83 & 0.88 & 2.47 & 0.29 & 2.53 & 34.08 \\
\hline 36.44 & 2.12 & 1.74 & 9.42 & 15.15 & 27.91 & 1.79 & 4.98 & 0.58 & 5.10 & 68.76 \\
\hline 27.30 & 1.59 & 1.30 & 7.05 & 11.35 & 20.91 & 1.34 & 3.73 & 0.43 & 3.82 & 51.52 \\
\hline 124.62 & 7.24 & 5.93 & 23.00 & 51.79 & 95.45 & 6.11 & 18.32 & 1.97 & 17.45 & 227.25 \\
\hline 40.76 & 2.37 & 1.94 & 10.53 & 16.94 & 31.22 & 2.00 & 5.99 & 0.64 & 5.71 & 77.34 \\
\hline 72.65 & 4.22 & 3.46 & 13.41 & 30.19 & 55.64 & 3.56 & 10.63 & 1.15 & 10.17 & 132.43 \\
\hline 94.13 & 5.47 & 4.48 & 17.37 & 39.12 & 72.10 & 4.61 & 13.84 & 1.49 & 13.18 & 171.66 \\
\hline 33.06 & 1.92 & 1.57 & 6.10 & 13.74 & 25.32 & 1.62 & 4.86 & 0.52 & 4.63 & 60.29 \\
\hline 160.23 & 9.31 & 7.63 & 59.15 & 39.95 & 122.72 & 7.85 & 25.65 & 2.53 & 22.43 & 297.22 \\
\hline 221.42 & 12.86 & 10.54 & 81.74 & 55.20 & 169.58 & 10.85 & 35.44 & 3.50 & 31.00 & 410.71 \\
\hline 1022.01 & 59.35 & 48.66 & 188.64 & 254.81 & 782.75 & 50.08 & 163.60 & 16.15 & 143.08 & 1707.12 \\
\hline 969.53 & 56.31 & 46.16 & 178.95 & 241.72 & 742.56 & 47.51 & 155.20 & 15.32 & 135.73 & 1619.46 \\
\hline 2051.27 & 119.13 & 97.67 & 378.61 & 758.02 & 1571.07 & 100.51 & 261.02 & 32.41 & 287.18 & 3605.63 \\
\hline 430.31 & 24.99 & 20.49 & 79.42 & 103.46 & 329.58 & 21.09 & 69.61 & 6.80 & 60.24 & 715.67 \\
\hline 1339.89 & 77.82 & 63.80 & 247.31 & 425.01 & 1026.22 & 65.65 & 198.34 & 21.17 & 187.58 & 2312.90 \\
\hline 1020.08 & 59.24 & 48.57 & 188.28 & 346.16 & 781.28 & 49.98 & 146.98 & 16.12 & 142.81 & 1779.42 \\
\hline
\end{tabular}




\begin{tabular}{|c|c|c|c|c|c|c|c|c|c|c|}
\hline Distance & $\begin{array}{l}\text { Infrastructure } \\
\text { Capital cost }\end{array}$ & $\begin{array}{l}\text { Infrastructure } \\
\text { Maintenance } \\
\text { Cost }\end{array}$ & $\begin{array}{l}\text { Noise } \\
\text { Cost }\end{array}$ & $\begin{array}{l}\text { Accident } \\
\text { Cost }\end{array}$ & $\begin{array}{l}\text { Pollution } \\
\text { Cost }\end{array}$ & $\begin{array}{c}\text { Capital } \\
\text { Cost }\end{array}$ & $\begin{array}{l}\text { Operation } \\
\text { Cost }\end{array}$ & $\begin{array}{l}\text { Maintenance } \\
\text { Cost per }\end{array}$ & $\begin{array}{c}\text { Avg. } \\
\text { Depreciation } \\
\text { Cost }\end{array}$ & $\begin{array}{l}\text { Total } \\
\text { Cost }\end{array}$ \\
\hline 965.87 & 56.09 & 45.99 & 178.28 & 324.02 & 739.76 & 47.33 & 140.24 & 15.26 & 135.22 & 1682.18 \\
\hline 1058.62 & 61.48 & 50.40 & 195.39 & 362.96 & 810.80 & 51.87 & 150.87 & 16.73 & 148.21 & 1848.71 \\
\hline 932.73 & 54.17 & 44.41 & 172.16 & 336.78 & 714.38 & 45.70 & 129.73 & 14.74 & 130.58 & 1642.65 \\
\hline 549.95 & 31.94 & 26.19 & 101.51 & 187.45 & 421.21 & 26.95 & 86.85 & 8.69 & 76.99 & 967.77 \\
\hline 1355.59 & 78.73 & 64.54 & 250.21 & 486.67 & 1038.25 & 66.42 & 188.69 & 21.42 & 189.78 & 2384.71 \\
\hline 1480.40 & 85.98 & 70.49 & 273.24 & 511.68 & 1133.84 & 72.54 & 209.74 & 23.39 & 207.26 & 2588.16 \\
\hline 1109.17 & 64.42 & 52.81 & 204.73 & 366.48 & 849.51 & 54.35 & 152.06 & 17.52 & 155.28 & 1917.17 \\
\hline 599.31 & 34.81 & 28.54 & 110.62 & 280.51 & 459.01 & 29.37 & 73.79 & 9.47 & 83.90 & 1110.02 \\
\hline 489.29 & 28.42 & 23.30 & 90.31 & 203.35 & 374.75 & 23.98 & 56.96 & 7.73 & 68.50 & 877.29 \\
\hline 1443.82 & 83.85 & 68.75 & 266.49 & 448.83 & 1105.82 & 70.75 & 205.84 & 22.81 & 202.14 & 2475.28 \\
\hline 2527.55 & 146.79 & 120.35 & 466.52 & 955.97 & 1935.85 & 123.85 & 316.11 & 39.94 & 353.86 & 4459.23 \\
\hline 1513.26 & 87.89 & 72.05 & 279.31 & 628.93 & 1159.01 & 74.15 & 178.95 & 23.91 & 211.86 & 2716.05 \\
\hline 1501.20 & 87.18 & 71.48 & 277.08 & 623.91 & 1149.77 & 73.56 & 173.99 & 23.72 & 210.17 & 2690.87 \\
\hline 1028.12 & 59.71 & 48.95 & 189.77 & 427.30 & 787.44 & 50.38 & 123.65 & 16.24 & 143.94 & 1847.37 \\
\hline 338.97 & 19.69 & 16.14 & 62.56 & 140.88 & 259.62 & 16.61 & 39.45 & 5.36 & 47.46 & 607.75 \\
\hline 503.80 & 29.26 & 23.99 & 92.99 & 209.38 & 385.86 & 24.69 & 61.83 & 7.96 & 70.53 & 906.49 \\
\hline 1247.14 & 72.43 & 59.38 & 230.19 & 396.96 & 955.18 & 61.11 & 174.78 & 19.70 & 174.60 & 2144.34 \\
\hline 803.77 & 46.68 & 38.27 & 148.36 & 240.23 & 615.61 & 39.38 & 129.47 & 12.70 & 112.53 & 1383.23 \\
\hline 773.01 & 44.89 & 36.81 & 142.68 & 233.83 & 592.05 & 37.88 & 124.30 & 12.21 & 108.22 & 1332.87 \\
\hline 1113.47 & 64.67 & 53.02 & 205.52 & 365.57 & 852.80 & 54.56 & 162.66 & 17.59 & 155.89 & 1932.27 \\
\hline 1203.54 & 69.90 & 57.30 & 222.14 & 385.23 & 921.79 & 58.97 & 168.13 & 19.02 & 168.50 & 2070.98 \\
\hline 773.01 & 44.89 & 36.81 & 142.68 & 233.83 & 592.05 & 37.88 & 124.30 & 12.21 & 108.22 & 1332.87 \\
\hline 70.70 & 4.11 & 3.37 & 13.05 & 29.38 & 54.15 & 3.46 & 8.55 & 1.12 & 9.90 & 127.08 \\
\hline 207.22 & 12.03 & 9.87 & 38.25 & 86.12 & 158.71 & 10.15 & 24.34 & 3.27 & 29.01 & 371.76 \\
\hline 1132.15 & 65.75 & 53.91 & 208.97 & 338.78 & 867.12 & 55.48 & 173.91 & 17.89 & 158.50 & 1940.30 \\
\hline 998.80 & 58.01 & 47.56 & 184.35 & 293.12 & 764.98 & 48.94 & 159.88 & 15.78 & 139.83 & 1712.45 \\
\hline
\end{tabular}




\begin{tabular}{|c|c|c|c|c|c|c|c|c|c|c|}
\hline Distance & $\begin{array}{c}\text { Infrastructure } \\
\text { Capital cost }\end{array}$ & $\begin{array}{l}\text { Infrastructure } \\
\text { Maintenance } \\
\text { Cost }\end{array}$ & $\begin{array}{l}\text { Noise } \\
\text { Cost }\end{array}$ & $\begin{array}{l}\text { Accident } \\
\text { Cost }\end{array}$ & $\begin{array}{l}\text { Pollution } \\
\text { Cost }\end{array}$ & $\begin{array}{c}\text { Truck } \\
\text { Capital } \\
\text { Cost }\end{array}$ & $\begin{array}{c}\text { Truck } \\
\text { Operation } \\
\text { Cost }\end{array}$ & $\begin{array}{l}\text { Maintenance } \\
\text { Cost per }\end{array}$ & $\begin{array}{l}\text { Avg. } \\
\text { Depreciation } \\
\text { Cost }\end{array}$ & $\begin{array}{l}\text { Total } \\
\text { Cost }\end{array}$ \\
\hline 2371.30 & 137.72 & 112.91 & 437.68 & 836.01 & 1816.18 & 116.19 & 312.65 & 37.47 & 331.98 & 4138.78 \\
\hline 792.65 & 46.03 & 37.74 & 146.30 & 242.05 & 607.09 & 38.84 & 126.82 & 12.52 & 110.97 & 1368.37 \\
\hline 105.70 & 6.14 & 5.03 & 27.31 & 25.75 & 80.95 & 5.18 & 17.03 & 1.67 & 14.80 & 183.87 \\
\hline 1473.77 & 85.59 & 70.17 & 272.02 & 515.37 & 1128.76 & 72.21 & 207.75 & 23.29 & 206.33 & 2581.50 \\
\hline 405.96 & 23.58 & 19.33 & 74.93 & 168.72 & 310.92 & 19.89 & 49.29 & 6.41 & 56.83 & 729.91 \\
\hline 340.12 & 19.75 & 16.19 & 62.78 & 141.36 & 260.50 & 16.67 & 41.76 & 5.37 & 47.62 & 611.99 \\
\hline 1547.20 & 89.86 & 73.67 & 285.57 & 643.03 & 1185.00 & 75.81 & 181.19 & 24.45 & 216.61 & 2775.18 \\
\hline 893.69 & 51.90 & 42.55 & 164.95 & 371.43 & 684.48 & 43.79 & 108.10 & 14.12 & 125.12 & 1606.44 \\
\hline 1160.98 & 67.43 & 55.28 & 214.29 & 482.51 & 889.19 & 56.89 & 134.64 & 18.34 & 162.54 & 2081.11 \\
\hline 890.41 & 51.71 & 42.40 & 164.35 & 319.19 & 681.96 & 43.63 & 125.20 & 14.07 & 124.66 & 1567.17 \\
\hline 1541.80 & 89.54 & 73.41 & 284.58 & 672.22 & 1180.87 & 75.55 & 182.80 & 24.36 & 215.85 & 2799.18 \\
\hline 1541.24 & 89.51 & 73.38 & 284.47 & 640.55 & 1180.43 & 75.52 & 182.99 & 24.35 & 215.77 & 2766.99 \\
\hline 2171.51 & 126.11 & 103.39 & 400.81 & 787.59 & 1663.16 & 106.40 & 280.32 & 34.31 & 304.01 & 3806.11 \\
\hline 2180.57 & 126.64 & 103.83 & 402.48 & 784.91 & 1670.10 & 106.85 & 282.73 & 34.45 & 305.28 & 3817.27 \\
\hline 485.11 & 28.17 & 23.10 & 89.54 & 233.05 & 371.54 & 23.77 & 61.15 & 7.66 & 67.91 & 905.90 \\
\hline
\end{tabular}




\section{$\underline{\text { Rail } 23}$}

\begin{tabular}{|c|c|c|c|c|c|c|c|c|c|c|}
\hline Distance & $\begin{array}{l}\text { Infrastructure } \\
\text { Capital cost }\end{array}$ & $\begin{array}{c}\text { Infrastructure } \\
\text { Maintenance Cost }\end{array}$ & $\begin{array}{c}\text { Capital } \\
\text { Cost }\end{array}$ & $\begin{array}{c}\text { Operation } \\
\text { Cost }\end{array}$ & $\begin{array}{c}\text { Maintenance } \\
\text { Cost per }\end{array}$ & $\begin{array}{l}\text { Noise } \\
\text { Cost }\end{array}$ & $\begin{array}{c}\text { Accident } \\
\text { Cost }\end{array}$ & $\begin{array}{c}\text { Pollution } \\
\text { Cost }\end{array}$ & $\begin{array}{c}\text { Avg. } \\
\text { Depreciation } \\
\text { Cost }\end{array}$ & $\begin{array}{l}\text { Total } \\
\text { Cost }\end{array}$ \\
\hline 1016.16 & 120.86 & 39.25 & 434.69 & 220.62 & 338.72 & 53.75 & 28.05 & 172.95 & 469.47 & 1878.36 \\
\hline 1282.43 & 152.52 & 49.54 & 548.59 & 278.43 & 427.48 & 67.84 & 35.40 & 218.27 & 592.48 & 2370.55 \\
\hline 865.49 & 102.94 & 33.43 & 370.24 & 187.91 & 288.50 & 45.78 & 23.89 & 147.31 & 399.86 & 1599.84 \\
\hline 1111.78 & 132.23 & 42.94 & 475.60 & 241.38 & 370.59 & 58.81 & 30.69 & 189.23 & 513.64 & 2055.11 \\
\hline 459.05 & 54.60 & 17.73 & 196.37 & 99.67 & 153.02 & 24.28 & 12.67 & 78.13 & 212.08 & 848.55 \\
\hline 139.95 & 16.64 & 5.41 & 59.87 & 30.38 & 46.65 & 7.40 & 3.86 & 23.82 & 64.66 & 258.69 \\
\hline 1324.94 & 157.58 & 51.18 & 566.78 & 287.66 & 441.65 & 70.09 & 36.57 & 225.51 & 612.12 & 2449.14 \\
\hline 126.60 & 15.06 & 4.89 & 54.16 & 27.49 & 42.20 & 6.70 & 3.49 & 21.55 & 58.49 & 234.02 \\
\hline 223.81 & 26.62 & 8.64 & 95.74 & 48.59 & 74.60 & 11.84 & 6.18 & 38.09 & 103.40 & 413.70 \\
\hline 1183.11 & 140.71 & 45.70 & 506.11 & 256.87 & 394.37 & 62.59 & 32.65 & 201.37 & 546.60 & 2186.97 \\
\hline 69.00 & 8.21 & 2.67 & 29.52 & 15.96 & 23.00 & 3.65 & 1.90 & 11.74 & 31.88 & 128.53 \\
\hline 136.97 & 16.29 & 5.29 & 58.59 & 31.69 & 45.66 & 7.25 & 3.78 & 23.31 & 63.28 & 255.14 \\
\hline
\end{tabular}




\begin{tabular}{|c|c|c|c|c|c|c|c|c|c|c|}
\hline Distance & $\begin{array}{c}\text { Infrastructure } \\
\text { Capital cost }\end{array}$ & $\begin{array}{c}\text { Infrastructure } \\
\text { Maintenance Cost }\end{array}$ & $\begin{array}{c}\text { Capital } \\
\text { Cost }\end{array}$ & $\begin{array}{c}\text { Operation } \\
\text { Cost }\end{array}$ & $\begin{array}{c}\text { Maintenance } \\
\text { Cost per }\end{array}$ & $\begin{array}{l}\text { Noise } \\
\text { Cost }\end{array}$ & $\begin{array}{c}\text { Accident } \\
\text { Cost }\end{array}$ & $\begin{array}{c}\text { Pollution } \\
\text { Cost }\end{array}$ & $\begin{array}{c}\text { Avg. } \\
\text { Depreciation } \\
\text { Cost }\end{array}$ & $\begin{array}{l}\text { Total } \\
\text { Cost }\end{array}$ \\
\hline 205.97 & 24.50 & 7.96 & 88.11 & 47.66 & 68.66 & 10.90 & 5.68 & 35.06 & 95.16 & 383.67 \\
\hline 111.70 & 13.28 & 4.31 & 47.78 & 25.21 & 37.23 & 5.91 & 3.08 & 19.01 & 51.61 & 207.43 \\
\hline 82.75 & 9.84 & 3.20 & 35.40 & 18.97 & 27.58 & 4.38 & 2.28 & 14.08 & 38.23 & 153.96 \\
\hline 192.85 & 22.94 & 7.45 & 82.50 & 41.99 & 64.28 & 10.20 & 5.32 & 32.82 & 89.10 & 356.60 \\
\hline 1157.84 & 137.70 & 44.72 & 495.30 & 257.61 & 385.95 & 36.75 & 31.96 & 197.06 & 534.92 & 2121.97 \\
\hline 873.33 & 103.87 & 33.73 & 373.59 & 190.57 & 291.11 & 46.20 & 24.10 & 148.64 & 403.48 & 1615.29 \\
\hline 1568.81 & 186.58 & 60.60 & 671.10 & 352.13 & 522.94 & 82.99 & 43.30 & 267.01 & 724.79 & 2911.45 \\
\hline 1090.04 & 129.64 & 42.10 & 466.30 & 241.91 & 363.35 & 57.66 & 30.09 & 185.53 & 503.60 & 2020.17 \\
\hline 1296.01 & 154.14 & 50.06 & 554.41 & 289.56 & 432.00 & 68.56 & 35.77 & 220.58 & 598.76 & 2403.84 \\
\hline 511.95 & 60.89 & 19.78 & 219.00 & 111.27 & 170.65 & 27.08 & 14.13 & 87.13 & 236.52 & 946.45 \\
\hline 1738.60 & 206.78 & 67.16 & 743.73 & 378.43 & 579.53 & 55.18 & 47.99 & 295.91 & 803.23 & 3177.94 \\
\hline 2024.31 & 240.76 & 78.19 & 865.96 & 445.73 & 674.77 & 107.09 & 55.87 & 344.54 & 935.23 & 3748.14 \\
\hline 2434.08 & 289.49 & 94.02 & 1041.25 & 539.99 & 811.36 & 77.26 & 67.18 & 414.28 & 1124.55 & 4459.38 \\
\hline 1377.22 & 163.80 & 53.20 & 589.14 & 299.13 & 459.07 & 43.71 & 38.01 & 234.40 & 636.28 & 2516.74 \\
\hline 217.90 & 25.92 & 8.42 & 93.21 & 49.79 & 72.63 & 11.53 & 6.01 & 37.09 & 100.67 & 405.28 \\
\hline 816.30 & 97.08 & 31.53 & 349.19 & 186.33 & 272.10 & 43.18 & 22.53 & 138.93 & 377.13 & 1518.01 \\
\hline
\end{tabular}




\begin{tabular}{|c|c|c|c|c|c|c|c|c|c|c|}
\hline Distance & $\begin{array}{l}\text { Infrastructure } \\
\text { Capital cost }\end{array}$ & $\begin{array}{c}\text { Infrastructure } \\
\text { Maintenance Cost }\end{array}$ & $\begin{array}{c}\text { Capital } \\
\text { Cost }\end{array}$ & $\begin{array}{c}\text { Operation } \\
\text { Cost }\end{array}$ & $\begin{array}{c}\text { Maintenance } \\
\text { Cost per }\end{array}$ & $\begin{array}{l}\text { Noise } \\
\text { Cost }\end{array}$ & $\begin{array}{c}\text { Accident } \\
\text { Cost }\end{array}$ & $\begin{array}{c}\text { Pollution } \\
\text { Cost }\end{array}$ & $\begin{array}{c}\text { Avg. } \\
\text { Depreciation } \\
\text { Cost }\end{array}$ & $\begin{array}{l}\text { Total } \\
\text { Cost }\end{array}$ \\
\hline 511.18 & 60.80 & 19.75 & 218.67 & 112.05 & 170.39 & 27.04 & 14.11 & 87.00 & 236.16 & 945.97 \\
\hline 729.08 & 86.71 & 28.16 & 311.88 & 161.85 & 243.03 & 38.57 & 20.12 & 124.09 & 336.83 & 1351.25 \\
\hline 872.30 & 103.74 & 33.69 & 373.15 & 195.62 & 290.77 & 46.14 & 24.08 & 148.47 & 403.00 & 1618.66 \\
\hline 179.50 & 21.35 & 6.93 & 76.79 & 39.09 & 59.83 & 9.50 & 4.95 & 30.55 & 82.93 & 331.92 \\
\hline 803.30 & 95.54 & 31.03 & 343.63 & 179.65 & 267.77 & 42.49 & 22.17 & 136.72 & 371.12 & 1490.13 \\
\hline 478.77 & 56.94 & 18.49 & 204.81 & 110.22 & 159.59 & 25.33 & 13.21 & 81.49 & 221.19 & 891.28 \\
\hline 671.40 & 79.85 & 25.93 & 287.21 & 153.27 & 223.80 & 35.52 & 18.53 & 114.27 & 310.18 & 1248.56 \\
\hline 272.80 & 32.44 & 10.54 & 116.70 & 62.57 & 90.93 & 14.43 & 7.53 & 46.43 & 126.03 & 507.61 \\
\hline 1340.94 & 159.48 & 51.80 & 573.63 & 300.28 & 446.98 & 70.94 & 37.01 & 228.23 & 619.52 & 2487.85 \\
\hline 2161.28 & 257.05 & 83.48 & 924.55 & 477.43 & 720.43 & 114.33 & 59.65 & 367.85 & 998.51 & 4003.28 \\
\hline 808.37 & 96.14 & 31.22 & 345.80 & 184.96 & 269.46 & 42.76 & 22.31 & 137.58 & 373.47 & 1503.70 \\
\hline 953.27 & 113.38 & 36.82 & 407.79 & 218.02 & 317.76 & 50.43 & 26.31 & 162.25 & 440.41 & 1773.15 \\
\hline
\end{tabular}




\section{Rail 46}

\begin{tabular}{|c|c|c|c|c|c|c|c|c|c|c|}
\hline Distance & $\begin{array}{l}\text { Infrastructure } \\
\text { Capital cost }\end{array}$ & $\begin{array}{c}\text { Infrastructure } \\
\text { Maintenance Cost }\end{array}$ & $\begin{array}{c}\text { Capital } \\
\text { Cost }\end{array}$ & $\begin{array}{c}\text { Operation } \\
\text { Cost }\end{array}$ & $\begin{array}{c}\text { Maintenance } \\
\text { Cost per }\end{array}$ & $\begin{array}{l}\text { Noise } \\
\text { Cost }\end{array}$ & $\begin{array}{l}\text { Accident } \\
\text { Cost }\end{array}$ & $\begin{array}{c}\text { Pollution } \\
\text { Cost }\end{array}$ & $\begin{array}{c}\text { Avg. } \\
\text { Depreciation } \\
\text { Cost }\end{array}$ & $\begin{array}{l}\text { Total } \\
\text { Cost }\end{array}$ \\
\hline 1016.16 & 120.86 & 39.25 & 434.69 & 238.01 & 338.72 & 107.51 & 56.09 & 345.90 & 469.47 & 2150.50 \\
\hline 1282.43 & 152.52 & 49.54 & 548.59 & 300.38 & 427.48 & 135.68 & 70.79 & 436.54 & 592.48 & 2714.00 \\
\hline 865.69 & 102.96 & 33.44 & 370.32 & 202.77 & 288.56 & 91.59 & 47.79 & 294.68 & 399.95 & 1832.06 \\
\hline 1111.78 & 132.23 & 42.94 & 475.60 & 260.41 & 370.59 & 117.63 & 61.37 & 378.45 & 513.64 & 2352.86 \\
\hline 459.05 & 54.60 & 17.73 & 196.37 & 107.52 & 153.02 & 48.57 & 25.34 & 156.26 & 212.08 & 971.49 \\
\hline 141.21 & 16.79 & 5.45 & 60.41 & 33.07 & 47.07 & 14.94 & 7.79 & 48.07 & 65.24 & 298.84 \\
\hline 1324.32 & 157.51 & 51.15 & 566.52 & 310.19 & 441.44 & 140.11 & 73.10 & 450.80 & 611.84 & 2802.65 \\
\hline 126.60 & 15.06 & 4.89 & 54.16 & 29.65 & 42.20 & 13.39 & 6.99 & 43.09 & 58.49 & 267.92 \\
\hline 222.55 & 26.47 & 8.60 & 95.20 & 52.13 & 74.18 & 23.55 & 12.28 & 75.76 & 102.82 & 470.98 \\
\hline 1185.54 & 141.00 & 45.79 & 507.15 & 277.68 & 395.18 & 125.43 & 65.44 & 403.56 & 547.72 & 2508.95 \\
\hline 69.00 & 8.21 & 2.67 & 29.52 & 18.13 & 23.00 & 7.30 & 3.81 & 23.49 & 31.88 & 147.99 \\
\hline 136.97 & 16.29 & 5.29 & 58.59 & 35.99 & 45.66 & 14.49 & 7.56 & 46.62 & 63.28 & 293.78 \\
\hline
\end{tabular}




\begin{tabular}{|c|c|c|c|c|c|c|c|c|c|c|}
\hline Distance & $\begin{array}{c}\text { Infrastructure } \\
\text { Capital cost }\end{array}$ & $\begin{array}{c}\text { Infrastructure } \\
\text { Maintenance Cost }\end{array}$ & $\begin{array}{c}\text { Capital } \\
\text { Cost }\end{array}$ & $\begin{array}{c}\text { Operation } \\
\text { Cost }\end{array}$ & $\begin{array}{c}\text { Maintenance } \\
\text { Cost per }\end{array}$ & $\begin{array}{l}\text { Noise } \\
\text { Cost }\end{array}$ & $\begin{array}{c}\text { Accident } \\
\text { Cost }\end{array}$ & $\begin{array}{c}\text { Pollution } \\
\text { Cost }\end{array}$ & $\begin{array}{c}\text { Avg. } \\
\text { Depreciation } \\
\text { Cost }\end{array}$ & $\begin{array}{l}\text { Total } \\
\text { Cost }\end{array}$ \\
\hline 205.97 & 24.50 & 7.96 & 88.11 & 54.12 & 68.66 & 21.79 & 11.37 & 70.11 & 95.16 & 441.77 \\
\hline 111.70 & 13.28 & 4.31 & 47.78 & 28.07 & 37.23 & 11.82 & 6.17 & 38.02 & 51.61 & 238.30 \\
\hline 82.75 & 9.84 & 3.20 & 35.40 & 21.39 & 27.58 & 8.75 & 4.57 & 28.17 & 38.23 & 177.12 \\
\hline 192.85 & 22.94 & 7.45 & 82.50 & 45.40 & 64.28 & 20.40 & 10.65 & 65.65 & 89.10 & 408.36 \\
\hline 1159.04 & 137.85 & 44.77 & 495.81 & 283.94 & 386.35 & 73.58 & 63.98 & 394.54 & 535.48 & 2416.29 \\
\hline 873.33 & 103.87 & 33.73 & 373.59 & 206.47 & 291.11 & 92.40 & 48.21 & 297.28 & 403.48 & 1850.13 \\
\hline 1568.81 & 186.58 & 60.60 & 671.10 & 390.50 & 522.94 & 165.98 & 86.60 & 534.02 & 724.79 & 3343.12 \\
\hline 1090.04 & 129.64 & 42.10 & 466.30 & 265.81 & 363.35 & 115.33 & 60.17 & 371.05 & 503.60 & 2317.35 \\
\hline 1296.01 & 154.14 & 50.06 & 554.41 & 319.93 & 432.00 & 137.12 & 71.54 & 441.16 & 598.76 & 2759.11 \\
\hline 511.95 & 60.89 & 19.78 & 219.00 & 120.14 & 170.65 & 54.16 & 28.26 & 174.27 & 236.52 & 1083.67 \\
\hline 1738.60 & 206.78 & 67.16 & 743.73 & 409.13 & 579.53 & 110.37 & 95.97 & 591.82 & 803.23 & 3607.72 \\
\hline 2024.31 & 240.76 & 78.19 & 865.96 & 486.61 & 674.77 & 214.17 & 111.74 & 689.08 & 935.23 & 4296.50 \\
\hline 2434.08 & 289.49 & 94.02 & 1041.25 & 593.17 & 811.36 & 154.52 & 134.36 & 828.56 & 1124.55 & 5071.28 \\
\hline 1377.22 & 163.80 & 53.20 & 589.14 & 322.81 & 459.07 & 87.43 & 76.02 & 468.81 & 636.28 & 2856.56 \\
\hline 217.90 & 25.92 & 8.42 & 93.21 & 56.01 & 72.63 & 23.05 & 12.03 & 74.17 & 100.67 & 466.12 \\
\hline 816.30 & 97.08 & 31.53 & 349.19 & 209.39 & 272.10 & 86.36 & 45.06 & 277.87 & 377.13 & 1745.73 \\
\hline
\end{tabular}




\begin{tabular}{|c|c|c|c|c|c|c|c|c|c|c|}
\hline Distance & $\begin{array}{l}\text { Infrastructure } \\
\text { Capital cost }\end{array}$ & $\begin{array}{c}\text { Infrastructure } \\
\text { Maintenance Cost }\end{array}$ & $\begin{array}{c}\text { Capital } \\
\text { Cost }\end{array}$ & $\begin{array}{c}\text { Operation } \\
\text { Cost }\end{array}$ & $\begin{array}{c}\text { Maintenance } \\
\text { Cost per }\end{array}$ & $\begin{array}{l}\text { Noise } \\
\text { Cost }\end{array}$ & $\begin{array}{c}\text { Accident } \\
\text { Cost }\end{array}$ & $\begin{array}{c}\text { Pollution } \\
\text { Cost }\end{array}$ & $\begin{array}{c}\text { Avg. } \\
\text { Depreciation } \\
\text { Cost }\end{array}$ & $\begin{array}{l}\text { Total } \\
\text { Cost }\end{array}$ \\
\hline 511.18 & 60.80 & 19.75 & 218.67 & 121.87 & 170.39 & 54.08 & 28.22 & 174.00 & 236.16 & 1083.94 \\
\hline 729.08 & 86.71 & 28.16 & 311.88 & 177.88 & 243.03 & 77.14 & 40.25 & 248.18 & 336.83 & 1550.06 \\
\hline 872.30 & 103.74 & 33.69 & 373.15 & 216.78 & 290.77 & 92.29 & 48.15 & 296.93 & 403.00 & 1858.50 \\
\hline 179.50 & 21.35 & 6.93 & 76.79 & 42.28 & 59.83 & 18.99 & 9.91 & 61.10 & 82.93 & 380.11 \\
\hline 803.30 & 95.54 & 31.03 & 343.63 & 198.65 & 267.77 & 84.99 & 44.34 & 273.44 & 371.12 & 1710.51 \\
\hline 478.77 & 56.94 & 18.49 & 204.81 & 124.69 & 159.59 & 50.65 & 26.43 & 162.97 & 221.19 & 1025.78 \\
\hline 671.40 & 79.85 & 25.93 & 287.21 & 172.25 & 223.80 & 71.03 & 37.06 & 228.54 & 310.18 & 1435.87 \\
\hline 272.80 & 32.44 & 10.54 & 116.70 & 70.58 & 90.93 & 28.86 & 15.06 & 92.86 & 126.03 & 584.01 \\
\hline 1340.94 & 159.48 & 51.80 & 573.63 & 332.36 & 446.98 & 141.87 & 74.02 & 456.46 & 619.52 & 2856.11 \\
\hline 2161.28 & 257.05 & 83.48 & 924.55 & 522.59 & 720.43 & 228.66 & 119.30 & 735.70 & 998.51 & 4590.28 \\
\hline 808.37 & 96.14 & 31.22 & 345.80 & 208.24 & 269.46 & 85.53 & 44.62 & 275.17 & 373.47 & 1729.64 \\
\hline 953.27 & 113.38 & 36.82 & 407.79 & 245.38 & 317.76 & 100.86 & 52.62 & 324.49 & 440.41 & 2039.50 \\
\hline
\end{tabular}




\section{$\underline{R A I L ~} 69$}

\begin{tabular}{|c|c|c|c|c|c|c|c|c|c|c|}
\hline Distance & $\begin{array}{l}\text { Infrastructure } \\
\text { Capital cost }\end{array}$ & $\begin{array}{c}\text { Infrastructure } \\
\text { Maintenance Cost }\end{array}$ & $\begin{array}{c}\text { Capital } \\
\text { Cost }\end{array}$ & $\begin{array}{c}\text { Operation } \\
\text { Cost }\end{array}$ & $\begin{array}{c}\text { Maintenance } \\
\text { Cost per }\end{array}$ & $\begin{array}{l}\text { Noise } \\
\text { Cost }\end{array}$ & $\begin{array}{c}\text { Accident } \\
\text { Cost }\end{array}$ & $\begin{array}{c}\text { Pollution } \\
\text { Cost }\end{array}$ & $\begin{array}{c}\text { Avg. } \\
\text { Depreciation } \\
\text { Cost }\end{array}$ & $\begin{array}{l}\text { Total } \\
\text { Cost }\end{array}$ \\
\hline 1016.16 & 120.86 & 39.25 & 434.69 & 255.40 & 338.72 & 161.26 & 84.14 & 518.85 & 469.47 & 2422.64 \\
\hline 1282.43 & 152.52 & 49.54 & 548.59 & 322.32 & 427.48 & 203.52 & 106.19 & 654.81 & 592.48 & 3057.45 \\
\hline 865.69 & 102.91 & 33.42 & 370.14 & 217.47 & 288.42 & 137.32 & 71.64 & 441.81 & 399.75 & 2062.89 \\
\hline 1111.78 & 132.23 & 42.94 & 475.60 & 279.43 & 370.59 & 176.44 & 92.06 & 567.68 & 513.64 & 2650.61 \\
\hline 459.05 & 54.60 & 17.73 & 196.37 & 115.38 & 153.02 & 72.85 & 38.01 & 234.39 & 212.08 & 1094.43 \\
\hline 141.21 & 16.64 & 5.41 & 59.87 & 35.17 & 46.65 & 22.21 & 11.59 & 71.46 & 64.66 & 333.65 \\
\hline 1324.32 & 157.57 & 51.17 & 566.74 & 332.98 & 441.62 & 210.25 & 109.70 & 676.47 & 612.08 & 3158.57 \\
\hline 126.60 & 15.06 & 4.89 & 54.16 & 31.82 & 42.20 & 20.09 & 10.48 & 64.64 & 58.49 & 301.83 \\
\hline 222.55 & 26.47 & 8.60 & 95.20 & 55.93 & 74.18 & 35.32 & 18.43 & 113.63 & 102.82 & 530.58 \\
\hline 1185.54 & 140.92 & 45.77 & 506.85 & 297.80 & 394.95 & 188.04 & 98.11 & 604.98 & 547.40 & 2824.81 \\
\hline 69.00 & 8.21 & 2.67 & 29.52 & 20.29 & 23.00 & 10.95 & 5.71 & 35.23 & 31.88 & 167.46 \\
\hline 136.97 & 16.29 & 5.29 & 58.59 & 40.29 & 45.66 & 21.74 & 11.34 & 69.94 & 63.28 & 332.41 \\
\hline
\end{tabular}




\begin{tabular}{|c|c|c|c|c|c|c|c|c|c|c|}
\hline Distance & $\begin{array}{c}\text { Infrastructure } \\
\text { Capital cost }\end{array}$ & $\begin{array}{c}\text { Infrastructure } \\
\text { Maintenance Cost }\end{array}$ & $\begin{array}{c}\text { Capital } \\
\text { Cost }\end{array}$ & $\begin{array}{c}\text { Operation } \\
\text { Cost }\end{array}$ & $\begin{array}{c}\text { Maintenance } \\
\text { Cost per }\end{array}$ & $\begin{array}{l}\text { Noise } \\
\text { Cost }\end{array}$ & $\begin{array}{c}\text { Accident } \\
\text { Cost }\end{array}$ & $\begin{array}{c}\text { Pollution } \\
\text { Cost }\end{array}$ & $\begin{array}{c}\text { Avg. } \\
\text { Depreciation } \\
\text { Cost }\end{array}$ & $\begin{array}{l}\text { Total } \\
\text { Cost }\end{array}$ \\
\hline 205.97 & 24.50 & 7.96 & 88.11 & 60.58 & 68.66 & 32.69 & 17.05 & 105.17 & 95.16 & 499.87 \\
\hline 111.70 & 13.28 & 4.31 & 47.78 & 30.94 & 37.23 & 17.73 & 9.25 & 57.03 & 51.61 & 269.17 \\
\hline 82.75 & 9.84 & 3.20 & 35.40 & 23.81 & 27.58 & 13.13 & 6.85 & 42.25 & 38.23 & 200.28 \\
\hline 192.85 & 22.94 & 7.45 & 82.50 & 48.82 & 64.28 & 30.61 & 15.97 & 98.47 & 89.10 & 460.12 \\
\hline 1159.04 & 137.85 & 44.77 & 495.81 & 310.00 & 386.35 & 110.36 & 95.97 & 591.81 & 535.48 & 2708.40 \\
\hline 873.33 & 103.87 & 33.73 & 373.59 & 222.37 & 291.11 & 138.60 & 72.31 & 445.92 & 403.48 & 2084.98 \\
\hline 1568.81 & 186.58 & 60.60 & 671.10 & 428.87 & 522.94 & 248.97 & 129.90 & 801.04 & 724.79 & 3774.79 \\
\hline 1090.04 & 129.64 & 42.10 & 466.30 & 289.71 & 363.35 & 172.99 & 90.26 & 556.58 & 503.60 & 2614.52 \\
\hline 1296.01 & 154.14 & 50.06 & 554.41 & 350.29 & 432.00 & 205.68 & 107.31 & 661.74 & 598.76 & 3114.39 \\
\hline 511.95 & 60.89 & 19.78 & 219.00 & 129.02 & 170.65 & 81.25 & 42.39 & 261.40 & 236.52 & 1220.90 \\
\hline 1738.60 & 206.78 & 67.16 & 743.73 & 439.84 & 579.53 & 165.55 & 143.96 & 887.73 & 803.23 & 4037.50 \\
\hline 2024.31 & 240.76 & 78.19 & 865.96 & 527.48 & 674.77 & 321.26 & 167.61 & 1033.61 & 935.23 & 4844.87 \\
\hline 2434.08 & 289.49 & 94.02 & 1041.25 & 646.35 & 811.36 & 231.77 & 201.54 & 1242.84 & 1124.55 & 5683.17 \\
\hline 1377.22 & 163.80 & 53.20 & 589.14 & 346.49 & 459.07 & 131.14 & 114.03 & 703.21 & 636.28 & 3196.37 \\
\hline 217.90 & 25.92 & 8.42 & 93.21 & 62.22 & 72.63 & 34.58 & 18.04 & 111.26 & 100.67 & 526.96 \\
\hline 816.30 & 97.08 & 31.53 & 349.19 & 232.46 & 272.10 & 129.55 & 67.59 & 416.80 & 377.13 & 1973.44 \\
\hline
\end{tabular}




\begin{tabular}{|c|c|c|c|c|c|c|c|c|c|c|}
\hline Distance & $\begin{array}{l}\text { Infrastructure } \\
\text { Capital cost }\end{array}$ & $\begin{array}{c}\text { Infrastructure } \\
\text { Maintenance Cost }\end{array}$ & $\begin{array}{c}\text { Capital } \\
\text { Cost }\end{array}$ & $\begin{array}{c}\text { Operation } \\
\text { Cost }\end{array}$ & $\begin{array}{c}\text { Maintenance } \\
\text { Cost per }\end{array}$ & $\begin{array}{l}\text { Noise } \\
\text { Cost }\end{array}$ & $\begin{array}{c}\text { Accident } \\
\text { Cost }\end{array}$ & $\begin{array}{c}\text { Pollution } \\
\text { Cost }\end{array}$ & $\begin{array}{c}\text { Avg. } \\
\text { Depreciation } \\
\text { Cost }\end{array}$ & $\begin{array}{l}\text { Total } \\
\text { Cost }\end{array}$ \\
\hline 511.18 & 60.80 & 19.75 & 218.67 & 131.69 & 170.39 & 81.12 & 42.33 & 261.01 & 236.16 & 1221.92 \\
\hline 729.08 & 86.71 & 28.16 & 311.88 & 193.91 & 243.03 & 115.70 & 60.37 & 372.27 & 336.83 & 1748.87 \\
\hline 872.30 & 103.74 & 33.69 & 373.15 & 237.94 & 290.77 & 138.43 & 72.23 & 445.40 & 403.00 & 2098.35 \\
\hline 179.50 & 21.35 & 6.93 & 76.79 & 45.46 & 59.83 & 28.49 & 14.86 & 91.65 & 82.93 & 428.30 \\
\hline 803.30 & 95.54 & 31.03 & 343.63 & 217.64 & 267.77 & 127.48 & 66.51 & 410.16 & 371.12 & 1930.89 \\
\hline 478.77 & 56.94 & 18.49 & 204.81 & 139.16 & 159.59 & 75.98 & 39.64 & 244.46 & 221.19 & 1160.27 \\
\hline 671.40 & 79.85 & 25.93 & 287.21 & 191.24 & 223.80 & 106.55 & 55.59 & 342.81 & 310.18 & 1623.18 \\
\hline 272.80 & 32.44 & 10.54 & 116.70 & 78.59 & 90.93 & 43.29 & 22.59 & 139.29 & 126.03 & 660.41 \\
\hline 1340.94 & 159.48 & 51.80 & 573.63 & 364.45 & 446.98 & 212.81 & 111.03 & 684.69 & 619.52 & 3224.38 \\
\hline 2161.28 & 257.05 & 83.48 & 924.55 & 567.76 & 720.43 & 343.00 & 178.95 & 1103.55 & 998.51 & 5177.28 \\
\hline 808.37 & 96.14 & 31.22 & 345.80 & 231.53 & 269.46 & 128.29 & 66.93 & 412.75 & 373.47 & 1955.59 \\
\hline 953.27 & 113.38 & 36.82 & 407.79 & 272.75 & 317.76 & 151.28 & 78.93 & 486.74 & 440.41 & 2305.85 \\
\hline
\end{tabular}




\section{References}

- ABN AMRO(2015). Companies in Transport and Logistics need to manage risks, [online] ABN AMRO. Available at:

https://www.abnamro.com/en/newsroom/newsarticles/ companies -in-transport-andlogistics-need-to-managerisks.html [Accessed on 15 June 2015].

○ Abu-Taleb A., \& Easa S. (1996). Disaggregate Mode Choice Models: Review and Application to Freight Transportation in Egypt. Transportation Specialty Conference, Edmonton, Alberta, CA.

- Abdelwahab, W. M. (1998). Elasticities of mode choice probabilities and market elasticities of demand: evidence from a simultaneous mode choice/shipment-size freight transport model. Transportation Research Part E: Logistics and Transportation Review, 34(4), 257-266.

○ Abu Dhabi Municipality (2008-2014). GCC Railway Freight Traffic Forecast Study, UAE.

- Allen, B. Hamilton Inc. (1999). California Life Cycle Benefit/Cost Analysis Model. California Department of Transportation. Sacramento, CA.

○ Allen, D. W. (2011). Getting to Know ArcGIS ModelBuilder. Esri Press.

O Anderson, W. P. (2012). Trucking Across the Border: The Relative Cost of Cross-border and Domestic Trucking, 2004 to 2009.Statistics Canada. 
- Angel Ibeasa, J. L. (2012). Antonio Comi, Urban freight transport demand: transferability of survey results analysis and models, Procedia. Social and Behavioral Sciences, $1068-$ 1079.

- Ashfaq A. (2010). Truck drivers get familiar with toll gate rules, Gulf News Transport.

○ Belella, P. (2005). Measures - A Systematic Approach to Evaluating ITS for Freight Applications. Delcon, Inc. Los Angeles, CA.

○ Beuthe, M., Degrandsart, F., Geerts, J. F., \& Jourquin, B. (2002). External costs of the Belgian interurban freight traffic: a network analysis of their internalization. Transportation Research Part D: Transport and Environment, 7(4), 285-301.

- Beuthe, M, Jourquin, B. and et al. (2001), Freight Transportation demand elasticities: a geographic multimodal transportation network analysis, Transportation Research part E $37,253-266$.

- Brenchley, R. (2000). Project report to understand how trade compliance risk should be identified, assessed and managed in increasingly dis-integrated global supply networks at Hewlett Packard. Part Time Executive MBA, University of Bath.

○ Brogan, J.J. et al. (2001), Application of a Statewide Intermodal freight planning methodology, report, Virginia transportation research council, Charlottesville, VA 22903, $1-66$.

○ Bryan J., Weisbrod G., \& Martland C.D. (2008). Rail Freight as a Means of Reducing Roadway Congestion. Transportation Research Record: Journal of the Transportation Research Board, Washington, D.C., 2007, pp. 75-83. 
○ Builders, L. S. (2005). Operating costs of trucks in Canada 2005.Prepared for the Economic Analysis Directorate Transport Canada.

○ Caputo, A. C., Pelagagge, P. M., \& Salini, P. (2011). Impact of accidents risk on hydrogen road transportation cost. International Journal of Energy Sector Management, 5(2), 215-241.

- Cenek, P. D. (2012). Freight transport efficiency: A comparative study of coastal shipping, rail and road modes.

○ CER-UIC-UNIFE (2014). Megatrucks versus rail freight' [Brochure]. Europe: CER-UICUNIFE.

○ Chan, A, P, C., and Chan, A, P, L. (2004). Key performance indicators for measuring construction success. Benchmarking: an international journal, 11, pp. 203-221.

○ Chopra, S., and Sodhi., M. S. (2004). Managing risk to avoid supply chain breakdown. MIT Sloan Management Review, 46(1), pp. 52 - 61

- Crainic, T. G. (1986). Multicommodity, multimode freight transportation: A general modeling and algorithmic framework for the service network design problem. . Transportation Research Part B: Methodological, 225-242.

○ C. R. (2008). Feasibility of Diverting Truck Freight to Rail in the Columbia River Corridor. Oregon Department of Transportation.

○ Crainic T.G. \& Laporte G., (1997). Planning models for freight transportation, 97, pp. European Journal of Operational Research, 409-438.

- Crainic, T. G. (2004). Advanced freight transportation systems for congested urban areas.. Transportation Research Part C: Emerging Technologies, 119-137. 
○ Crevier, B., Cordeau, J. F., \& Savard, G. (2012). Integrated operations planning and revenue management for rail freight transportation. Transportation Research Part B: Methodological, 46(1), 100-119.

○ Deflorio, F. P., Gonzalez-Feliu, J., Perboli, G., \& Tadei, R. (2013). Transportation cost estimation in freight distribution services with time windows: application to an Italian urban area. In The Sixth International Conference on City Logistics (pp. 555-568).

○ Environmental Systems Research Institute (ESRI) (2016). 10.3.1 Arc GIS Desktop help.

- Environment and Climate Change Canada (2017). National Inventory Report 1990-2015: Greenhouse Gas Sources and Sinks in Canada.

- Ellis, J. et al. (1996).A GIS and Transportation Optimization model approach to determining highway and rural road commodity flows, EWITS working paper Number 3, Washington State University, Pullman, WA,1-19.

- Etihad Rail Freight Transport (2014). Pricing, Regulation and Economic Impact, UAE.

- European Commission (2002). INFRAS (2004), The External Costs of Transport: Update Study.

○ European Commission (2011). Road Charging Heavy Lorries to Pay of Air and Noise Pollution.

○ European Commission (2014). Joint Research Centre, Emissions Database for Global Atmospheric Research (EDGAR).

○ Fabrycky, W. J. (1991). Life cycle cost and economic analysis. Prentice Hall.

- Falzarano et al. (2007). Development of an intermodal network for freight transportation analysis, ESRI, user conference paper 1488, 1-14.

○ Fender, K. J. (2012). An Analysis of the Operational Costs of Trucking: A 2012 Update. 
○ Forkenbrock, D. J. (1999). External costs of intercity truck freight transportation. Transportation Research Part A: Policy and Practice, 505-526.

○ Forkenbrock, D. J. (2001). Comparison of external costs of rail and truck freight transportation. Transportation Research Part A: Policy and Practice, 321-337.

○ Gaines, L. (1998). Lifecycle-analysis for heavy vehicles. Argonne National Lab., IL (United States). Funding organization: US Department of Energy (United States). United States.

- Gaudenzi, B., and Borghesi, A. (2006). Managing risks in the supply chain using the AHP method. The International Journal of Logistics Management, (17)1, pp. 114 - 136.

- GCC Statistical Center (GCC-STAT) (2013). Muscat, Sultanate of Oman.

- Google Maps (2016). Retrieved from https://www.google.ca/maps/@24.3079057,45.4241817,6z.

○ Gasoline and diesel prices by country (2016), GlobalPetrolPrices.com. Retrieved September 15, 2016, from http://www.globalpetrolprices.com/

○ Ghiani, G., Laporte, G., \& Musmanno, R. (2013). Introduction to logistics systems management. John Wiley \& Sons.

○ Goh, M., Lim, J,Y,S., and Meng, F.(2007). A stochastic model for risk management in global supply chain networks. European Journal of Operation Research, 182, pp. 164-173

○ Grossardt, T. (2015). Integrated freight network model: A GIS-Based platform for transportation Analysis, Research Report, Multimodal Transportation Infrastructure Consortium, University of Kentucky transportation centre, 1-32. 
○ Hall J. (2010). Saving Fuel, Saving Money: An Assessment of Fleet Cost Savings from High Efficiency Trucks. Report by CALSTART Inc. Pasadena CA 91106 626/744-5600, pp. 1-30.

○ Ham, H., Kim, T. J., \& Boyce, D. (2005). Implementation and estimation of a combined model of interregional, multimodal commodity shipments and transportation network flows. Transportation Research Part B: Methodological, 39(1), 65-79.

○ Hamel, G., and Prahalad, C, K. (1994). Competing for the future, Harvard Business School Publishing.

○ Holguín-Veras, J. (2013). Freight Data Cost Elements (Vol. 22). Transportation Research Board.

- Institute, V. T. (2013). Transportation cost and benefit analysis.

○ Holguín-Veras, J., Sánchez-Díaz, I., \& Browne, M. (2016). Sustainable urban freight systems and freight demand management. Transportation Research Procedia, 12, 40-52.

○ Javanovic, M. N., Barreto, M., \& Strelow, H. (2004). Glossary for Transport Statistics.

○ Jenkins, J., Ahem, J., Lewis, R., Nield, L., MacKenzie, K., and Pink, J. (2010). A Guide to Supply Chain Risk Management for the Pharmaceutical and Medical Device Industries and their Suppliers.

○ Karttunen, K., Lättilä, L., Korpinen, O. J., \& Ranta, T. (2013). Cost-efficiency of intermodal container supply chain for forest chips. Silva Fennica, 47(4), 24.

- Kim, N. S. (2009). Assessment of $\mathrm{CO}_{2}$ emissions for truck-only and rail-based intermodal freight systems in Europe. . Transportation planning and technology, 313-333.

○ Komor, P. (1995). Reducing energy use in US freight transport. Transport Policy. 
- Kulpa, T. (2014). Freight Truck Trip Generation Modeling at Regional Level. . ProcediaSocial and Behavioral Sciences, 192-202.

○ Kusmantini, T., Guritno, A. D., \& Rustamaji, H. C. (2015). Mapping of Supply Chain Risk in Industrial Furniture Base on House of Risk Framework.

○ Lam, J. S. L., \& Gu, Y. (2016). A market-oriented approach for intermodal network optimisation meeting cost, time and environmental requirements. International Journal of Production Economics, 171(2), 266-274.

○ Le Maître, H. (2015). Noise costs of road traffic. In Transportation Research Board 94th Annual Meeting (No. 15-0888).

○ Le, T. (1997). The competitive dynamics of the freight container manufacturing industry. Maritime Policy \& Management, 24(1), 55-71.

○ Liangrokapart, J.(2012). Supply Chain Impact Analysis: A Case Study of Hospital Supply Chain Disruptions in Thailand. Managing the Future Supply Chain: Current Concepts and Solutions for Reliability and Robustness, Kersten, W. Blecker, T, and Ringle C.M. (Eds) Lohmar-Koln: Josef Eul Verlag GmbH, p 389-405.

- Ma, Q. (1997). Condition-based maintenance applied to rail freight car components: the case of rail car trucks (Doctoral dissertation, Massachusetts Institute of Technology).

○ Mahmudi H. \& Flvnn P. C. (2006). Rail vs Truck Transport of Biomass.Rail vs Truck Transport of Biomass.., 129-132.

○ Mahoney, J. H. (1985). Intermodal freight transportation.

○ Manners-Bell, J. (2016). Introduction to Global Logistics: Delivering the Goods. Kogan Page Publishers. 
- Major Vulnerabilities to Railway Security (2015). Major Vulnerabilities to Railway Security. Personal.psu.edu. Retrieved 18 June 2015, from http://www.personal.psu.edu/staff/r/p/rpt117/sra211/vulnerabilities.htm

○ Miller, T., etal. (1991). The cost of highway crashes. Report No. FHWA-RD-91-055, US Department of Transportation, Federal Highway Administration, Washington, DC.

- Morton, B. S. (2006). A life cycle cost analysis of the Gauteng to Durban freight corridor: Introduction to study. In Proceedings of the 25th Southern African Transport Conference, (p. 13).

○ Norton, H. S. (1971). Modern transportation economics. (Columbus, OH: Charles E. Merrill Publishing company).

- Organization of the Petroleum Exporting Countries (OPEC) (2016). Vienna, Austria.

- Osterhaudt, M. (2002). Analysis of accident cost and comparison with available research.

○ Pedersen, E, L., and Grey, R. (1998). The transport selection criteria of Norwegian exporters. International Journal of Physical Distribution \& Logistics Management, (28)2, pp. $108-120$.

○ Plant, J., Young, R., \& Krepp, D. (2013). Protecting Critical Railroad Infrastructure. The Pennsylvania State University, 1(1), 1-11. Retrieved October 19, 2014.

○ Penner, P. S. (1978). Energy and labor requirements of intercity motor freight transportation. Resources and Energy, 375-395.

○ Piecyk, M. \&. (2007). Internalising the external costs of road freight transport in the U.K. Logistics Research Centre: Edinburgh: Heriot-Watt University.

○ Project Management Institute. (2013). A guide to the project management body of knowledge (PMBOK guide). 
○ Pujawan, I. N., and Geraldin, L.H. (2015). House of risk: a model for proactive supply chain risk management. Business Process Management Journal, (15)6, pp. 953- 967.

○ Railway Reform (2011). Toolkit for Improving Rail Sector Performance. Washington, DC, the World Bank.

○ Radvanovsky, R., \& Brodsky, J. (2016). Handbook of SCADA/control systems security. CRC Press.

○ Presidency of Meteorology and Environment (PME) (2016), Jeddah, Saudi Arabia.

- Rwakarehe, E. E. (2014). Development of a Freight Demand Model for the Province of Alberta Using Public Sources of Data. Procedia-Social and Behavioral Sciences, 695705.

- Saat, M., \& Barkan, C. (2005). Release Risk and Optimization of Railroad Tank Car Safety Design. Transportation Research Record: Journal of the Transportation Research Board, 1916, 78-87. doi:10.3141/1916-11

○ Sage, J., Casavant, K., Goodchild, A., McCormack, E., Wang, Z., McMullen, B. S., \& Holder, D. (2013). Development of a Freight Benefit/Cost Methodology for Project Planning.

- Saudi Arabian National Transportation Plan (SANTRAPLAN3) (2008). Ministry of Economy and Planning.

○ Saudi Customs (2016). Front, Side and Rear Protection Barriers of Truck and Trailers, KSA.

○ Saudi Railways Organization (SRO) (2016). General Operation Department, Dammam Riyadh, Saudi Arabia. 
○ Schroeder, M., and Gomes, R, B. (2014). Supply Chain Risk Management in International Trade Operations Between Germany and Brazil. [online] HICL, Available at https://hicl.org/sites/hicl.org/files/books/2014/schroeder-2014-supply-chainriskmanagement-international-trade-operations-between-germany-and.pdf [Accessed on 19 May 2015]

- Significance, V. U. (2012). Values of time and reliability in passenger and freight transport in the Netherlands. Ministry of Infrastructure and the Environment.

○ Southworth, F. \& Peterson B.E. (2000). Intermodal and international freight network modeling, Transportation Research Part C 8, 147-166.

○ Southworth, F. (2003). Freight transportation planning: models and methods. Transportation systems planning: methods and applications, 4-1.

- Spraggins, H. B. (2010). The case for rail transportation of hazardous materials. . Journal of Management and Marketing Research.

- Standifer, G. and Walton, C.M. (2000). Development of GIS Model for Intermodal Freight, Research Report, Centre for transportation research, University of Texas at Austin,Texas,1-138.

- Statista, Inc. (2017), Number of passenger cars and commercial vehicles in use worldwide from 2006 to 2015 in (1,000 units), NY, United States. Systematics, C. (2006). Guide to Quantifying the Economic Impacts of Federal Investments in LargeScale Freight transportation Projects. Washington D.C: U.S. Department of Transportation. 
o Southworth, F. (2003). Freight transportation planning: models and methods.

Transportation systems planning: methods and applications, 4-1.

○ Storchmann, K. (2004). On the depreciation of automobiles: An international comparison. Transportation, 31(4), 371-408.

○ Tang, O., Musa, S.N. (2011). Identifying risk issues and research advancements in supply chain risk management. International journal of production economics, 133(25), 25-34.

○ Transport Research Laboratory (TRL) (2001). Methodology for calculating transport emissions and energy consumption, United Kingdom.

○ Tavasszy, L. A., Smeenk, B., \&Ruijgrok, C. J. (1998). A DSS for modeling logistic chains in freight transport policy analysis. International Transactions in Operational Research, 5(6), 447-459.

- The Center for Urban Transportation Research (CURT) (2001). Analysis of Freight Movement Mode Choice Factors, The University of South Florida, Florida Department of Transportation Rail Planning and Safety.

○ Tummala, R., \& Schoenherr, T. (2011). Assessing and managing risks using the supply chain risk management process (SCRMP). Supply Chain Management: An International Journal, 16(6), 474-483.

- Ubeda, S. F. (2006). Assessment of environmental costs in road freight transport in Spain. In Logistics Research Network 2006 Conference Proceedings. (pp. (2006). 462467). Newcastle: University of Newcastle.

○ Upton, J. (2008). Best practice in freight transport operations. Christchurch [N.Z.: Environment Canterbury. 
○ United States Environmental Protection Agency (EPA) (2013). U.S Greenhouse Gas Emission in 2013, Washington, D.C.

- Vantuono, W. C. (2010). Will intermodal lead the recovery? Railway Age, 211(9).

- Victoria Transport Policy Institute (2013). Transportation cost and benefit analysis. Transport Policy Institute (www.vtpi.org).

○ Visser, JGSN. and Maat, K. (1996). A simulation model for urban freight transport with GIS, Proceedings of seminar J held at the PTRC European transport forum, Brunel University, England, 1-12.

○ Wang, M. Q. (1996). GREET 1.0--Transportation fuel cycles model: Methodology and use (No. ANL/ESD--33). Argonne National Lab., IL (United States).

○ Wang, Y. D. (2013). An Analysis of Interstate Freight Mode Choice between Truck and Rail.A Case Study of Maryland, United States. Procedia-Social and Behavioral Sciences, 1239-1249.

○ Wessam Z, Joaan General Transport (2016). Operation Department, Dubai, United Arab Emirates.

○ Wilson et al. (2011). 'Benefit-Cost and Economic Impact Analyses'. Rural Freight Rail Transportation Project. Texas Department of Transportation.

○ Winebrake, J. J., Corbett, J. J., Falzarano, A., Hawker, J. S., Korfmacher, K., Ketha, S., \& Zilora, S. (2008). Assessing energy, environmental, and economic tradeoffs in intermodal freight transportation. Journal of the Air \& Waste Management Association, 58(8), 10041013. 
○ Wood, M., \& Welch, C. (2010). Are 'qualitative' and 'quantitative' useful terms for describing research?. Methodological Innovations Online, 5(1), 56-71.

○ Zhu, L., Yu, F. R., Member, S., Ning, B., \& Tang, T. (2012). Handoff Performance Improvements in Train Control Systems, 13(2), 582-593. 